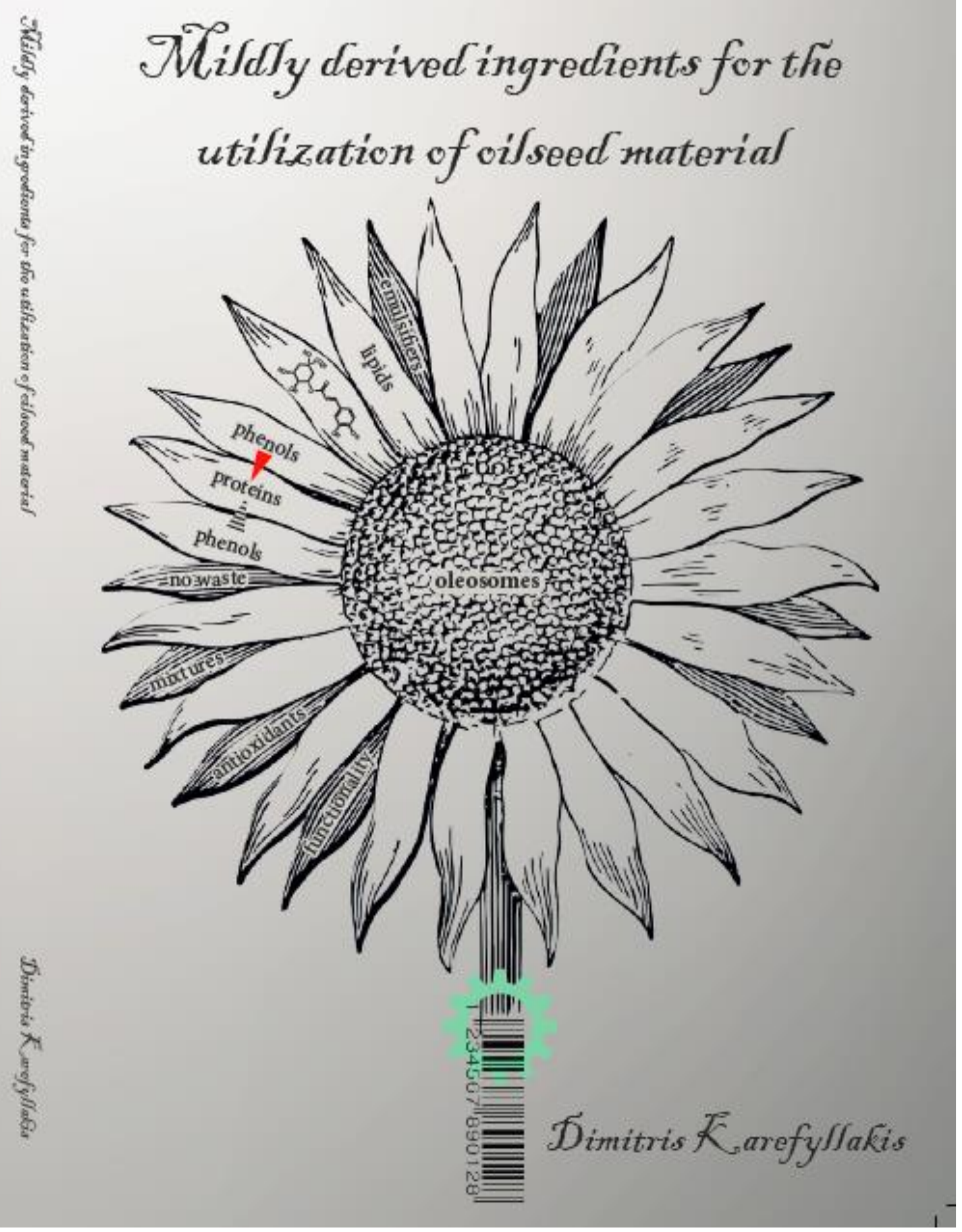




\section{Propositions}

1. Processing of oilseed ingredients often rushes towards purity overlooking the opportunities hidden in native complexity.

(this thesis)

2. The positive cooperativity of proteins and phenols indicates that removal of phenols during the extraction of sunflower proteins is not a necessity.

(this thesis)

3. Efforts towards bridging fundamental with applied research may dissatisfy the entire scientific community.

4. The impact factor should be a factor with less impact.

5. A sustainable future will only be guaranteed if food researchers will commit to actual and long-term environmental practises despite the presence or absence of corporate interest towards that direction.

6. Aiming away from perpetual economic growth and fossil fuel consumption is a more effective route to control climate change than urging people into personal actions, such as adopting a vegan diet.

Propositions belonging to the thesis entitled:

Mildly derived ingredients for the utilization of oilseed material

Dimitris Karefyllakis

Wageningen, 17 May 2019 
Mildly derived ingredients for the utilization of oilseed material 


\section{Thesis committee}

\section{Promotor}

Prof. Dr AJ van der Goot

Professor of Food Process Engineering

Wageningen University \& Research

\section{Co-promotor}

Dr K. Nikiforidis

Assistant professor, Biobased chemistry and technology

Wageningen University \& Research

\section{Other members}

Prof. Dr V. Fogliano, Wageningen University \& Research

Prof. Dr H.J. Heeres, University of Groningen

Dr L. Pouvreau, Cargill, Vilvoorde, Belgium

Dr D. Gray, University of Nottingham, United Kingdom

This research was conducted under the auspices of the Graduate School for Nutrition, Food Technology, Agrobiotechnology and Health Science (VLAG) 


\title{
Mildly derived ingredients for the utilization of oilseed material
}

\author{
Dimitris Karefyllakis
}

\section{Thesis}

submitted in fulfilment of the requirements for the degree of doctor at Wageningen University

by the authority of the Rector Magnificus,

Prof. Dr A.P.J. Mol,

in the presence of the

Thesis Committee appointed by the Academic Board

to be defended in public

on Friday 17 May 2019

at 11 a.m. in the Aula. 
Dimitris Karefyllakis

Mildly derived ingredients for the utilization of oilseed material 130 pages.

$\mathrm{PhD}$ thesis, Wageningen University, Wageningen, the Netherlands (2019)

With references, with summary in English

ISBN 978-94-6343-937-4

DOI https://doi.org/10.18174/475040 
To the memory of my father and to the friend that made all this possible 


\section{Table of contents}

Chapter 1 General introduction

Chapter 2 Physical bonding between sunflower proteins and phenols : Impact on interfacial properties

Chapter 3 Covalent bonding of Chlorogenic Acid induces structural modifications on sunflower proteins

Chapter 4 The emulsifying performance of mildly derived mixtures from sunflower seeds

Chapter 5 The behaviour of sunflower oil bodies at the interfaces

Chapter 6 Enhancing the utilization potential of oilseed ingredients : Multicomponent emulsifiers from sunflower seeds 

Chapter 1

General introduction

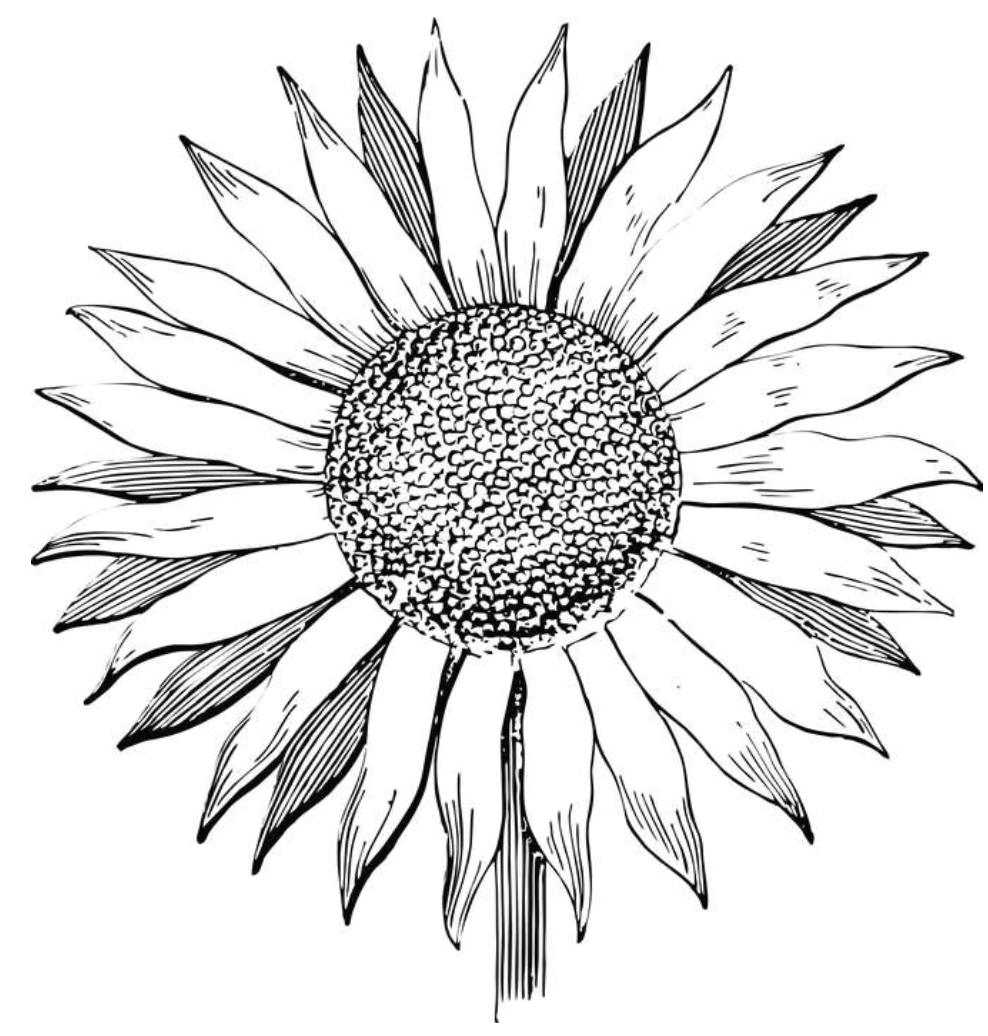




\subsection{Plant ingredients: sustainable but not without challenges}

Global demand for food escalates and since the land for cultivation and pasture is finite, the need for more efficient production of food ingredients rises. Various aspects of food production can be fine-tuned, from the selection of the raw material source and the holistic valorisation of the material (Boye \& Arcand, 2013). Animal sources of ingredients, though extensively exploited, are considered less environmental friendly compared with ingredients derived from plants (Aiking, 2011). However, plant-based biomass is not always directly suitable for human consumption and hence requires certain processing (Campbell, et al., 2011). One route is to fractionate plant materials into its constituents, but this route is far from trivial. Breakdown can be difficult due to sturdy cell walls and in addition, the presence of a plethora of compounds, from polysaccharide to phenols, often results in complexation or interactions that hinder molecular separation (Boland, et al., 2013). For these reasons downstream processing of plant ingredients often involves intensive physicochemical and thermal steps, which can lead to alteration of their functional properties (Moure, Sineiro, Domínguez, \& Parajó, 2006). The challenges associated with the fractionation processes of plant material explain why the availability and applicability of certain plant ingredients is still limited.

Proteins from oilseeds are the primary ingredient of interest when the utilisation of these materials is pursued. As the extraction of proteins is usually prioritised over the rest of the ingredients, the chemicals and conditions applied during processing are meant to solubilise and extract the proteins exclusively, as shown in Fig.1.1 (Sharif, et al., 2018). As a result, non-protein ingredients are neglected and discarded with the solid residues or the liquid streams. For example, the most extensively utilised oilseed proteins, soy proteins, are isolated after their solubilisation in alkaline solutions ( $\mathrm{pH}$ 7.5-9), a process which results in significant losses of material and compounds (Meyer, 2016). Although the alkaline conditions have no negative impact on soy proteins, the same does not hold true for proteins from other sources. For example, the solubilisation of sunflower proteins at alkaline $\mathrm{pH}$ is accompanied by complications, namely covalent protein-phenol complexation, which yield dark-coloured products with decreased functionality (Fig.1.1) (González-Pérez \& Vereijken, 2007; Wildermuth, Young, \& Were, 2016). This obstacle is particularly relevant in case of byproducts with high phenolic content like sunflower and rapeseed cake (Lomascolo, UzanBoukhris, Sigoillot, \& Fine, 2012). Sunflower cake contains a rather large amount of phenols, up to $3 \% \mathrm{w} / \mathrm{w}$ (Weisz, Kammerer, \& Carle, 2009). These complications have hindered the industrial application of sunflower proteins (Weisz, Schneider, Schweiggert, Kammerer, \& Carle, 2010) and point towards the need of a different overall approach to find potential uses for these ingredients in particular and for the whole material in general. Milder and simpler processes should be developed in order to avoid use of chemicals and conditions that either disregard useful ingredients or hinder the utilisation of proteins altogether. 


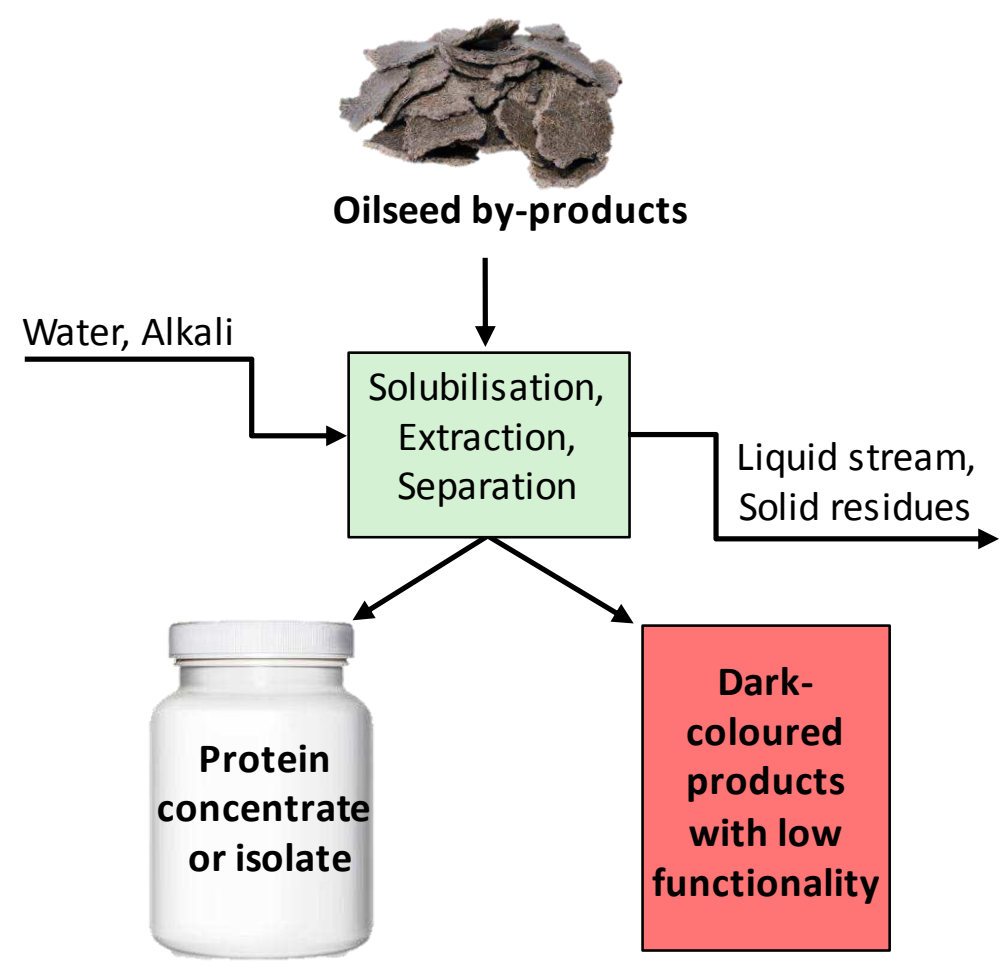

Figure 1.1: Conventional processing of oilseed by-products is meant to produce protein concentrates and isolates. However, in the case of oilseeds with high phenolic content (e.g. sunflower, rapeseed) the use of alkali induces undesirable changes and a big amount of ingredients is wasted throughout protein isolation.

\subsection{Oilseed processing and residues}

The current production of food, feed and biofuels is still associated with production of large quantities of agro-food by products. A better use of those by-products is recognized as a route to mitigate the increasing food demand, the deficiencies in the feed supply and the global bioenergy demands (Balan, et al., 2009; Rodrigues, Coelho, \& Carvalho, 2012). Cakes or meals are by-products obtained after oil removal from different oilseeds used in the edible oil industry. These residues give a disposal problem for the industry and great amounts of those by-products are currently underutilized as low-value animal feed (Geneau-Sbartaï, Leyris, Silvestre, \& Rigal, 2008), despite the fact that they are promising sources of compounds with technological and nutritional interest (Sarkis, et al., 2014). A characteristic example is sunflower cake, which contains $25-55 \%$ w/w proteins (Pickardt, Eisner, Kammerer, \& Carle, 2015), and up to $3 \% \mathrm{w} / \mathrm{w}$ phenols, up to $3 \% \mathrm{w} / \mathrm{w}$ (Weisz, et al., 2009). This interesting composition explains the increased number of investigations on possible applications for these residues (Kammerer, Kammerer, Valet, \& Carle, 2014; Matthäus, 2002).

Currently, the most commonly used method of industrial processing of oilseeds is the prepress solvent extraction (Salunkhe, 1992). Screw-pressing is applied until the majority of the oil is extracted from the seeds. Subsequently the obtained residue is subjected to solvent extraction for the minimization of its oil content (Lomascolo, et al., 2012). During the latter, 
oil is usually extracted with toxic, flammable and harmful for the environment organic solvents (the most prevalent being hexane). Beyond that, desolventizing (the removal and recovery of solvent adhering to the residual solids) is an economic necessity for the application of these volatile organic solvents; however, at the same time it is the step where the major portion of ingredient degradation occurs (Williams, 2005). In addition, the use of organic solvents ranks rather low in consumer acceptance (Dunn, Wells, \& Williams, 2010). It is therefore evident that the only objective of the conventional oil extraction process is the optimization of the extraction of the oil exclusively and not the quality and fate of the rest of the ingredients.

To better use the full potential of this biomass, the conventional oil extraction needs to be replaced by milder processes during the application of which waste generation will be minimised and native functionality of all the ingredients will be preserved. A combination of cold-pressing and aqueous fractionation is suggested as a sustainable alternative for the processing of oilseeds that allows the utilization of both the oil and the rest of the ingredients (Campbell, et al., 2011). During these mild steps there is no use of excessive heating or solvents, which offers a dual advantage. The extracted oil has superior sensory properties, can be consumed after simple filtering (no further refining needed) (De Leonardis, Macciola, \& Di Rocco, 2003) and can be regarded as organic (Alimentarius, 1999). More importantly, the obtained residues have elevated physicochemical quality allowing the valorization of all the ingredients. Mildly produced oilseed cakes and meals consist of diverse ingredients (lipids, phenols, carbohydrates) in their native form and with their properties preserved (Lomascolo, et al., 2012).

\subsection{Sunflower seeds}

Sunflower (Helianthus annus L.) is the fourth most important oilseed crop after soybean, oil palm fruit, rapeseed (USDA, 2018). Compared to other oilseeds like soybean, rapeseed, sunflower seeds are advantageous since they contain low amounts of allergen factors, antinutritional and toxic compounds (e.g toxic cyanogens, saponins) (Martínez-Force, Dunford, \& Salas, 2015). At the same time, food industry is constantly searching for alternative food proteins to soy (Pickardt, et al., 2015). An additional advantage of sunflower seeds is related to their widespread availability where soy is not or only sparsely produced (González-Pérez, et al., 2007). The sunflower seed is a rich source for oil containing a high proportion of unsaturated fatty acids (about 90\% linoleic and oleic acid) and high levels of fat-soluble vitamins (Martínez-Force, et al., 2015). An average composition of a dehulled sunflower seed can be seen in Fig.1.2. Oil extraction from sunflower seeds resulted in the production of 19 million metric tons of sunflower cake in 2017 (USDA, 2018). These residue contains great amounts of proteins, $25-55 \% \mathrm{w} / \mathrm{w}$ (Pickardt, et al., 2015), and phenols that can reach up to 3\% w/w (Weisz, et al., 2009). 


\begin{tabular}{|l|c|}
\hline Component & Dehulled seed (\%) \\
\hline & \\
Proteins & $20.4-40$ \\
Carbohydrates & $4-6$ \\
Lipids & $47-65$ \\
Tocopherol & $0.07-0,08$ \\
Carotenoids & $0.01-0,02$ \\
Vitamin B1 & $0.002-0,001$ \\
Chlorogenic acid (CGA) & $0.5-2,4$ \\
Caffeic acid (CA) & $0.19-0,29$ \\
Quinic acid (QA) & $0.12-0,25$ \\
Minerals & $3-4$ \\
\hline
\end{tabular}

Figure 1.2 : Average composition of a dehulled sunflower seed as reported in literature (González-Pérez, et al., 2007; Martínez-Force, et al., 2015).

\subsubsection{Sunflower proteins}

Sunflower seeds and subsequently sunflower cake contain a large amount of proteins with good nutritional quality. The amino acid composition complies with FAO (Food and Agriculture Organization) pattern to a large extent (FAO, 2013). Seed proteins are normally mixtures of various protein groups and sunflower proteins are not an exception. The proteins present in sunflower seeds can be divided into two major classes that together represent about $95 \%$ of the total protein content of sunflower proteins (González-Pérez, van Konignsveld, et al., 2005). The first class is the $11 \mathrm{~S}$ globulins, the so-called helianthinin, consisting around $60-70 \%$ of the total proteins and the second class is $2 \mathrm{~S}$ albumins (sunflower albumins, SFAs) consisting around $20-30 \%$ of sunflower proteins (Žilić, et al., 2010). Sunflower $11 \mathrm{~S}$ globulins have a rather large molecular size (300-350 kDa) under non-denaturing conditions (Dalgalarrondo, Raymond, \& Azanza, 1985) and are similar to the homologous proteins in soy, so-called soy glycinin, both in structure and physicochemical properties (Lakemond, de Jongh, Hessing, Gruppen, \& Voragen, 2000). X-ray scattering studies revealed that these proteins have an almost spherical shape and that they consist of six spherical subunits arranged as a trigonal antiprism with a maximum dimension of $11 \mathrm{~nm}$ (Plietz, Damaschun, Muller, \& Schwenke, 1983). However, conformational changes of sunflower 11S globulin, both reversible and irreversible, are quite common depending on the $\mathrm{pH}$ and the ionic strength of the system (Fig.1.3) (González-Pérez, et al., 2007; Molina, Petruccelli, \& Añón, 2004). 


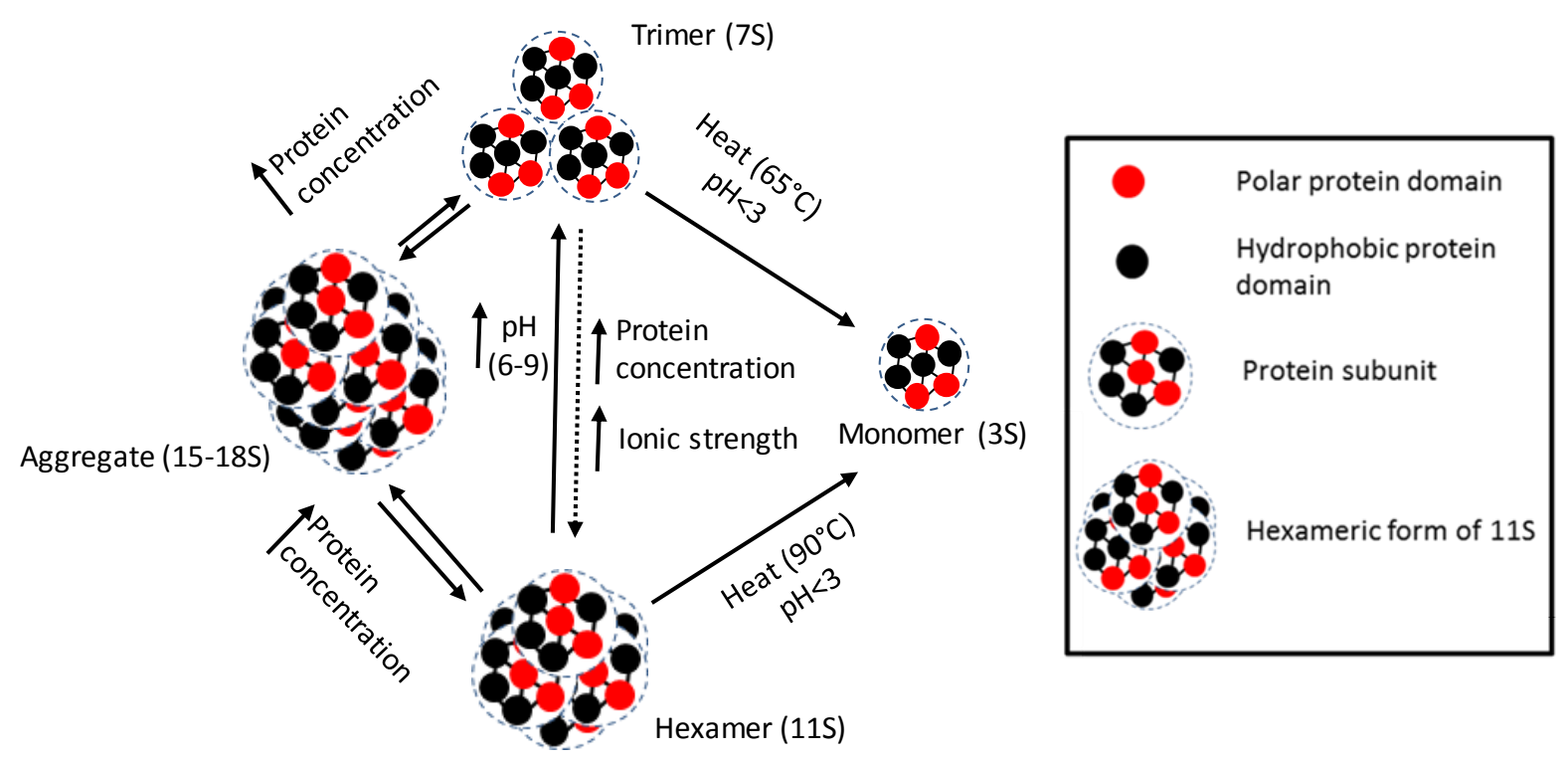

Figure 1.3 : Proposed shape and structure model of helianthinin inspired by Plietz et al. (Plietz, Damaschun, Muller, \& Schwenke, 1983) and schematic model for the quaternary structural changes of helianthinin at various conditions $(\uparrow=$ increase $)$ inspired by Gonzalez et al. (González-Pérez, et al., 2007).

On top of the conformation, also the solubility of $11 \mathrm{~S}$ proteins depends strongly on $\mathrm{pH}$ and ionic strength. At low ionic strength $(\mathrm{I}=30 \mathrm{mmolL}-1), 11 \mathrm{~S}$ proteins show a bell-shaped curve with a minimum solubility at $\mathrm{pH} 4-5.5$, which corresponds to their isoelectric $\mathrm{pH}$. At higher ionic strength $(\mathrm{I}=250 \mathrm{mmolL}-1)$, they are almost insoluble at $\mathrm{pH}<5.1$. The decreased solubility of these proteins at $\mathrm{pH} 3$ compared with that at $\mathrm{pH} 7$ or $8(\mathrm{I}=30$ mmolL-1) has been attributed to denaturation and dissociation of the protein hexamer (González-Pérez, van Konignsveld, et al., 2005; Molina, et al., 2004).

SFAs are a diverse group of random coil proteins, usually soluble in water, with a sedimentation coefficient of approximately 2S. SFAs are rich in cysteine (Kortt \& Caldwell, 1990). In contrast to $2 S$ seed albumins from other species that consist of two chains linked by disulfide bonds, SFAs consist of a single polypeptide chain (Anisimova, Fido, Tatham, \& Shewry, 1995). They have been reported to be proteins with high pI values (isoelectric point of approximately 8.8) and to have molecular weights ranging from about 10 to $18 \mathrm{kDa}$ (González-Pérez, Vereijken, Van Koningsveld, Gruppen, \& Voragen, 2005). SFAs have been found to remain soluble independently of $\mathrm{pH}$ and ionic strength (González-Pérez, Vereijken, et al., 2005).

Sunflower proteins are worthwhile ingredients from functionality point of view. Their capability to stabilize emulsions and foams has been well documented. However the gelforming properties of sunflower proteins have been found to be poor (González-Pérez, et al., 2007). 


\subsubsection{Sunflower phenols}

Phenolic compounds are plant metabolites that are often part of human and animal nutrition (Petti \& Scully, 2009). During the last years, several studies reported that phenols have several health benefits such as antioxidant, anti-inflamatory, antithrombotic properties and also prevention of cancer and cardiovascular disease (Balasundram, Sundram, \& Samman, 2006; Dos Santos, Almeida, Lopes, \& De Souza, 2006; Meng, Cao, Feng, Peng, \& Hu, 2013). Not only scientific but also industrial interest in phenols has been attracted for many years with the demand for functional foods being constantly growing due to an increasing consumer awareness and scientific evidence of the overall health benefits of these compounds (Jankowiak, Kantzas, Boom, \& van der Goot, 2014). Phenolic compounds comprise an aromatic ring, which bears one or more hydroxyl substituents. They can exist as simple phenolic molecules, polyaromatic molecules and highly polymerized compounds (Bravo, 1998). The main classes of dietary phenols are flavonoids, phenolic acids and tannins (Naczk \& Shahidi, 2006). Their antioxidant activity is reported to be dependent on molecule structure and especially the number and the position of the hydroxyl group, together with the nature of the aromatic rings (Crozier, Jaganath, \& Clifford, 2009).

In sunflower seeds, the major phenols are the chlorogenic acid (CGA), caffeic acid and quinic acid. The molecular structures of those components are presented in Fig.1.4. CGA comprises $80 \%$ of the total phenolic content of sunflower seed making it the major phenolic compound in sunflower (Wildermuth, et al., 2016). CGA is an ester of caffeic and quinic acid with molecular mass of $354 \mathrm{kDa}$. During oil extraction sunflower phenols are not transferred to the oil due to their polar nature, hence they end up in the solid residue, being the sunflower cake (Weisz, et al., 2009).

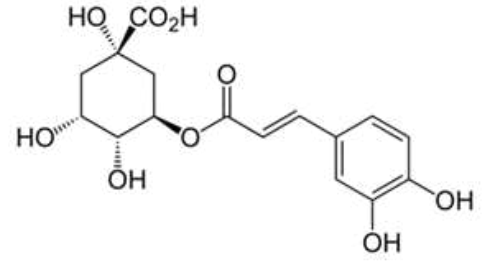

(a)<smiles>O=C(O)/C=C/c1ccc(O)c(O)c1</smiles>

(b)<smiles>O=C(O)C1(O)CC(O)C(O)C(O)C1</smiles>

(c)

Figure 1.4 : Molecular structures of a) CGA, b) Caffeic and c) quinic acid.

\subsubsection{Sunflower oil bodies and their membrane}

In oil seeds, oil is naturally present in oil bodies, which are oil droplets covered with a very stable membrane. (Nikiforidis, Kiosseoglou, \& Scholten, 2013). The primary function of oil bodies is to store the seed energy in the form of neutral lipids, during seed dormancy and to protect those lipids against environmental stresses (Bewley \& Black, 1994). This explains 
why oil bodies are equipped with a sophisticated membrane that covers the triglyceride core and grants them extreme physical and chemical stability (Tzen \& Huang, 1992). The membrane consists of complete monolayer of phospholipids to which a number of hydrophobic proteins are embedded (Fig.1.5). The main ones called oleosins, have hydrophobic domains that are anchored into the oil phase, while their amphiphilic termini rest on the hydrophilic oil body surface (Huang, 2018).

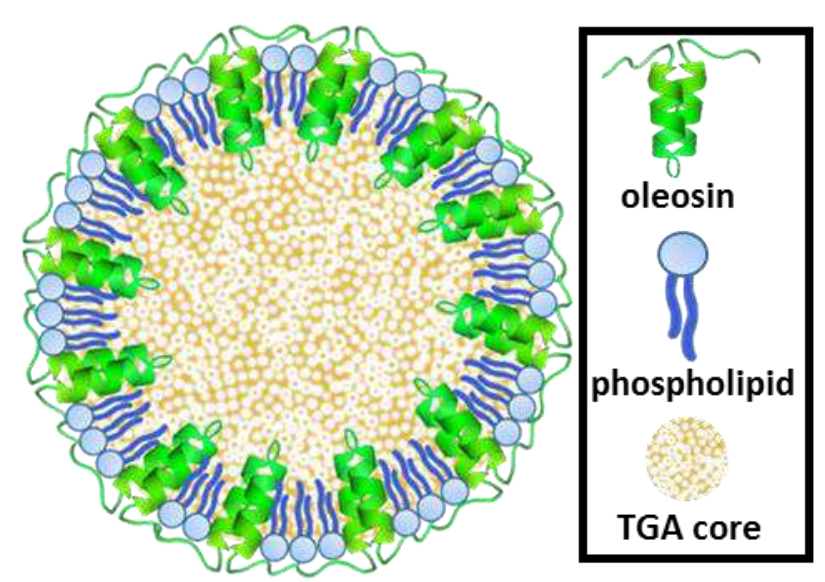

Figure 1.5 : 2D- model of an oil body with an emphasis on the configuration of the membrane, composed from a monolayer of phospholipids with the hydrophobic oleosin proteins anchored in the triglyceride (TGA) core.

Extracted oil bodies still possess the aforementioned noteworthy qualities of physical and chemical stability, which make them suitable to create a "natural" oil-in-water emulsions (Fisk, White, Lad, \& Gray, 2008; Iwanaga, et al., 2007). Besides stability, these biobased emulsions bear additional conveniences considering that neither emulsifiers nor the high energy consuming step of homogenization are required for their preparation (Karkani, Nenadis, Nikiforidis, \& Kiosseoglou, 2013). Therefore scientists are currently investigating the potential applications of these pre-emulsified systems in several fields like food, pharmaceuticals, and cosmetics (Chen, McClements, Gray, \& Decker, 2012; Chiang, Lin, Lu, \& Wang, 2011; Nikiforidis, Biliaderis, \& Kiosseoglou, 2012). It would be therefore highly beneficial if processing of oilseed plants would aim towards maintaining the residual oil in the form of intact oil bodies and take advantage of their properties. However, this is not the current case, since during the conventional sunflower oil extraction the majority of these organelles are destroyed. A combination of cold-pressing and aqueous fractionation for the processing of oilseeds might allow the survival of oil bodies so that the residual oil in the cake could be present in the form of oil bodies with their native properties preserved. 


\subsection{Mild fractionation and protein-phenol interactions}

There is not a unique methodology or protocol for extracting proteins from seeds or flours, leading to optimal products (Moure, et al., 2006). Current ingredient production focusses on high purity and standard quality, and much of the resources are spent on achieving this. More sustainable and efficient practices are needed during the application of which no excessive energy and minimum amount of chemicals will be used with the end result being much less waste streams full with ingredients of interest (van der Goot, et al., 2016). The design of less intensive processing of oilseeds with the consideration of the ingredients lying therein, eventually leads to the reassessment of the biorefinery philosophy. Milder conditions could be applied that may yield functional rather than pure ingredients. By using mild conditions and treatments, proteinaceous fractions are yielded, instead of protein isolates that still consist of diverse components (lipids, phenols, carbohydrates) with their native properties preserved (Pelgrom, Berghout, van der Goot, Boom, \& Schutyser, 2014). As it has been shown for multicomponent fractions from lupine and yellow peas (Geerts, Strijbos, van der Padt, \& van der Goot, 2017; Pelgrom, et al., 2015), the less enriched fractions exhibit functional properties comparable or even better than commercial preparations despite the relatively low purity. By applying the philosophy of mild processing novel solutions may emerge that can resolve the challenges associated with the use of sunflower proteins (covalent protein-phenol complexation). The interactions between proteins and phenols is one of the main long-lasting challenges behind the valorization of proteins from plants and agri-industrial by-products with high phenolic content (Balasundram, et al., 2006). The most representative example where these interactions give rise to considerable complications is the application of sunflower proteins as a food ingredient (González-Pérez, Vereijken, et al., 2005; Salgado, Ortiz, Petruccelli, \& Mauri, 2012).

Protein-phenolic interactions can be (1) physical or non-covalent (hydrogen bonding, ionic or/and hydrophobic interactions), which are reversible and (2) covalent via oxidation to quinones, which are irreversible in most cases (Prigent, 2005). A summary of the potential pathways of Chlorogenic acid after its oxidation and covalent conjugation with protein molecules is presented in Fig.1.6. (Prigent, 2005). The latter can affect sunflower proteins substantially either by diminishing their solubility and functionality, or by reducing protein digestibility and altering their organoleptic properties (dark-coloured products in Fig.1.6) (Wildermuth, Young, \& Were, 2016). Due to the aforementioned complications arising from their complexation with proteins, sunflower phenols are usually removed during the biorefinery efforts of sunflower press cake (Pickardt, et al., 2009). Many methods have been proposed for removing phenolic compounds from sunflower seeds and meals. The most promising ones with respect to the efficiency of chlorogenic acid extraction are those that extract phenolic compounds with mixtures of organic solvents (mainly ethanol and methanol) and water (González-Pérez, et al., 2002; Salgado, Drago, et al., 2012) and absorption technology (Kammerer, et al., 2014; Wijngaard, Hossain, Rai, \& Brunton, 2012). However, disadvantages of these methods are not only that organic solvent-water mixtures are known to decrease protein solubility and protein recovery, but also that they can alter the digestibility and availability of essential amino acids, involving higher processing costs for solvent 
management and safety precautions (Malik \& Saini, 2017; Suryaprakash, Kumar, \& Prakash, 2000).

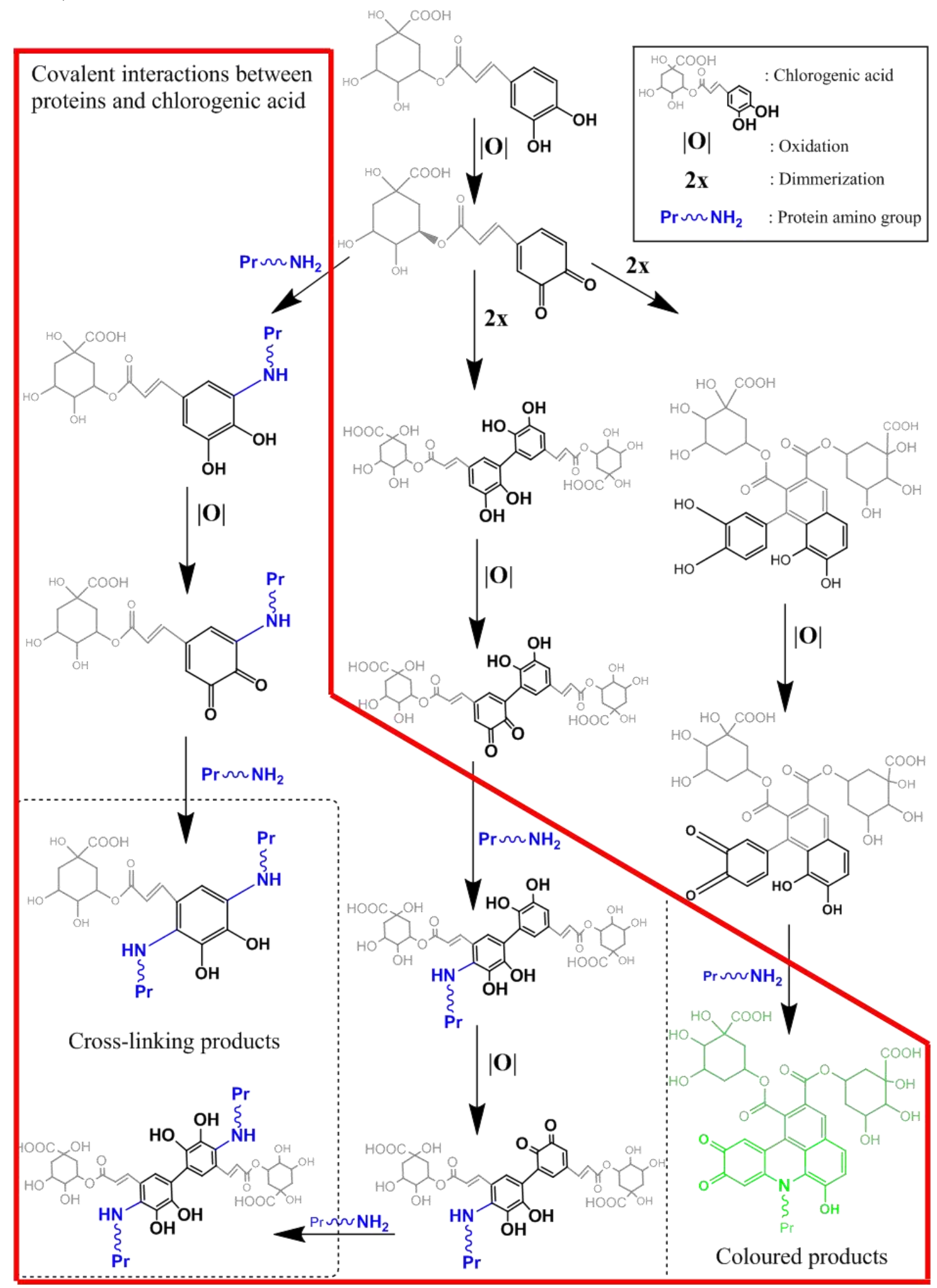

Figure 1.6 : A summary of the potential pathways of Chlorogenic acid after its oxidation and conjugation with protein molecules. 
At the same time, however, intriguing advantages have been reported when phenols are not removed throughout the extraction and use of oilseed proteins. For example, when sunflower phenols are added back in sunflower products, their antioxidant activity reinforces oxidative stability (De Leonardis, et al., 2003). A number of studies have shown that protein-phenol interactions can improve the stability of protein-based colloidal systems. For instance, the presence of phenols can improve the foam formation and stability in protein-surfactant systems by inducing cross-linking of proteins in the adsorbed layer (Sarker, Wilde, \& Clark, 1995). Further, strengthening of the mechanical properties of gelatin gels has been reported through covalently cross-linking of phenol dimers (cross-linking products in Fig.1.6) (Strauss $\&$ Gibson, 2004). In additions, it has been shown that phenol attachment induces changes on protein structure and even that complexation results in protein structural stabilization (Kanakis, et al., 2011). Therefore, industrial use of sunflower seeds and its residues though phenol removal not only has a considerable impact on protein properties but also disregards any positive cooperativity among the ingredients lying therein and the probability of their recombination in the final product.

\subsection{Aim and outline of this thesis}

The aim of this thesis is to create new scientific insights that will enable improved use of oilseed ingredients from underutilised sources, here the sunflower press cake, for food applications. The research can be divided into two objectives: Objective 1 focusses on understanding the interactions of ingredients present in sunflower seeds (proteins and phenols) being studied using pure components isolated from the seeds. These insights are used to reach objective 2 that analyses the interactions inside multicomponent fractions obtained after mild processing of seeds. Focus is on protein-rich fractions as well as on oil bodies. These topics are developed throughout the chapters.

Chapters 2 and 3 study model systems containing sunflower proteins and phenols. The study of protein-phenol mixtures were performed to stimulate the concept for more sustainable ingredient processing, which focusses on functionality rather than purity. In Chapter 2 the non-covalent interactions between the main phenolic compound in sunflower seeds, chlorogenic acid (CGA), and sunflower protein isolate (SFPI) are investigated. These insights can promote industrial use of sunflower cake. After extraction and characterization, pure and non-denatured sunflower proteins are mixed and complexed with increasing amounts of pure CGA. Then, the resulting complexes and their interplay at oil-water interfaces is studied, which sheds new light on the effect of their complexation on the functionality of proteins.

The formation of covalent protein-CGA complexes is unavoidable in the confined space of a sunflower seed cell during processing and storage. Given the importance of protein-phenol interactions, Chapter 3 covers the covalent protein-phenols interactions. The structural modifications induced by SFPI-CGA covalent interactions are monitored as a major step in elucidating the impact of phenol attachment on protein structure. Studies in the past only showed the effect on the antioxidant capacity of phenols, whilst they did not address the effect 
of complexation on the stability and conformation of proteins. To evaluate the covalent SFPICGA complex properties, their formation mechanism is monitored by calorimetric and electrophoretic techniques and the impact of complexation on protein structure is studied by spectroscopic techniques.

Chapter 4 describes the application of mild fractionation and the properties of the various fractions obtained using this method. Part of this novel approach is the investigation of the properties of sunflower proteins when natively embedded in complex molecular mixtures. The properties of course protein mixtures were compared with pure protein dispersion with respect to emulsifying properties. In addition, it links their properties with their molecular composition and opens a new path towards efficient exploitation of plant-derived ingredients. The temperate and more sustainable conditions used generate mixtures of storage proteins and oil, which is present in the form of oil bodies of which the impact on emulsification ability and stability is described.

Scientists are currently investigating the potential applications of the oil bodies as preemulsified systems in several fields like food, pharmaceuticals, and cosmetics. It would be therefore highly beneficial if processing of oilseed plants would aim towards maintaining of the residual oil in the form of intact oil bodies and take advantage of their extreme chemical and physical stability. For these reasons, sunflower oil bodies are mildly extracted from sunflower seeds and their behaviour on interfaces is shown in Chapter 5. Oil bodies are mildly extracted from sunflower seeds without focusing on absolute purification from storage proteins. To provide more information for potential applications the effect on oil body structure is shown at $\mathrm{O} / \mathrm{W}$ and $\mathrm{W} / \mathrm{O}$ interfaces. The findings clarify what happens to the structure of the oil bodies and how their membrane behaves once they reach the interface. In addition, they reveal if their hydrophobic core merges with the bulk oil and their membrane participates in the formation of the interface or if they remain intact acting as Pickering particles.

Novel approaches for the enhancement of the utilization potential of oilseed ingredients are reviewed in Chapter 6. Oilseeds and especially their underutilised by-products are promising sources of compounds with technological and nutritional interest. Characteristic examples are the functional and health promoting macromolecules and micronutrients like proteins and phenols found in by-products such as press cake from sunflower. Unlike soy proteins, which can be readily isolated and are utilised extensively, utilization of proteins from sunflower cake has yet to be realised. This review presents current barriers for the use of the materials and provides a summary of new approaches on how the availability and applicability of sunflower ingredients could be materialised. A key factor for potential success is an altered focus towards mild processing and the subsequent native multicomponent fractions rather than preparations consisting of pure components (e.g. proteins).

Chapter 7 reviews the main findings and conclusions of all the chapters. In addition, the main issues regarding the utilisation of sunflower ingredients are discussed together with the proposed solutions. The advantages and disadvantages associated with the removal of phenols are discussed. Since phenol oxidation and covalent complexation with proteins is the primary 
problem during protein extraction, phenols are often removed beforehand. Although there are many elaborate techniques for this purpose, none of them is trivial without drawbacks. To overcome this issue altogether, the retention of phenols is proposed. By avoiding higher than neutral $\mathrm{pH}$ values, non-covalent protein-phenol interactions are promoted, which enhance protein functionality. Therefore the removal of phenols is not a necessity and future efforts for the use of sunflower proteins should take into account the application of conditions that will promote multicomponent mixture productions. Similar conclusions were reached when the extraction of protein at neutral $\mathrm{pH}$ was discussed. It is shown that producing multicomponent mixtures is not compromising protein functionality. On the contrary, the properties of the less enriched mixtures are sometimes equal or even better than pure preparations. The last crucial aspect of this thesis that is discussed in Chapter 7, concerns the optimum equilibrium between the oil losses and the enhanced availability and functionality of the rest of the ingredients. It is shown that sacrificing a small part of the oil yield is insignificant in front of the potential advantages. Proteins and phenols can be used in functional mixtures and the mild conditions allow the presence of the residual oil in the form of intact oil bodies that bear intriguing properties. 


\section{References}

Aiking, H. (2011). Future protein supply. Trends in Food Science \& Technology, 22(2-3), 112-120.

Alimentarius, C. (1999). Codex standard for named vegetable oils. Codex Stan, 210, 1-13.

Anisimova, I. N., Fido, R. J., Tatham, A. S., \& Shewry, P. R. (1995). Genotypic variation and polymorphism of 2S albumins of sunflower. Euphytica, 83(1), 15-23.

Balan, V., Rogers, C. A., Chundawat, S. P., da Costa Sousa, L., Slininger, P. J., Gupta, R., \& Dale, B. E. (2009). Conversion of extracted oil cake fibers into bioethanol including DDGS, canola, sunflower, sesame, soy, and peanut for integrated biodiesel processing. Journal of the American Oil Chemists' Society, 86(2), 157-165.

Balasundram, N., Sundram, K., \& Samman, S. (2006). Phenolic compounds in plants and agri-industrial byproducts: Antioxidant activity, occurrence, and potential uses. Food Chemistry, 99(1), 191-203.

Bewley, J. D., \& Black, M. (1994). Seeds. In Seeds (pp. 1-33): Springer.

Boland, M. J., Rae, A. N., Vereijken, J. M., Meuwissen, M. P., Fischer, A. R., van Boekel, M. A., Rutherfurd, S. M., Gruppen, H., Moughan, P. J., \& Hendriks, W. H. (2013). The future supply of animal-derived protein for human consumption. Trends in Food Science \& Technology, 29(1), 62-73.

Boye, J. I., \& Arcand, Y. (2013). Current trends in green technologies in food production and processing. Food Engineering Reviews, 5(1), 1-17.

Bravo, L. (1998). Polyphenols: chemistry, dietary sources, metabolism, and nutritional significance. Nutrition reviews, 56(11), 317-333.

Campbell, K., Glatz, C., Johnson, L., Jung, S., De Moura, J., Kapchie, V., \& Murphy, P. (2011). Advances in aqueous extraction processing of soybeans. Journal of the American Oil Chemists' Society, 88(4), 449465.

Chen, B., McClements, D. J., Gray, D. A., \& Decker, E. A. (2012). Physical and oxidative stability of preemulsified oil bodies extracted from soybeans. Food Chemistry, 132(3), 1514-1520.

Chiang, C.-J., Lin, C.-C., Lu, T.-L., \& Wang, H.-F. (2011). Functionalized nanoscale oil bodies for targeted delivery of a hydrophobic drug. Nanotechnology, 22(41), 415102.

Crozier, A., Jaganath, I. B., \& Clifford, M. N. (2009). Dietary phenolics: chemistry, bioavailability and effects on health. Natural product reports, 26(8), 1001-1043.

Dalgalarrondo, M., Raymond, J., \& Azanza, J.-L. (1985). Sunflower seed protein: size and charge heterogeneity in subunits of the globulin fraction. Biochimie, 67(6), 629-632.

De Leonardis, A., Macciola, V., \& Di Rocco, A. (2003). Oxidative stabilization of cold-pressed sunflower oil using phenolic compounds of the same seeds. Journal of the Science of Food and Agriculture, 83(6), 523528.

Dos Santos, M. D., Almeida, M. C., Lopes, N. P., \& De Souza, G. E. P. (2006). Evaluation of the antiinflammatory, analgesic and antipyretic activities of the natural polyphenol chlorogenic acid. Biological and Pharmaceutical Bulletin, 29(11), 2236-2240.

Dunn, P. J., Wells, A., \& Williams, M. T. (2010). Green chemistry in the pharmaceutical industry: John Wiley \& Sons.

FAO, F. (2013). Food and Argricultural Organization of the United Nations.

Fisk, I. D., White, D. A., Lad, M., \& Gray, D. A. (2008). Oxidative stability of sunflower oil bodies. European journal of lipid science and technology, 110(10), 962-968.

Geerts, M. E., Strijbos, M., van der Padt, A., \& van der Goot, A. J. (2017). Understanding functional properties of mildly refined starch fractions of yellow pea. Journal of Cereal Science, 75, 116-123.

Geneau-Sbartaï, C., Leyris, J., Silvestre, F. O., \& Rigal, L. (2008). Sunflower cake as a natural composite: composition and plastic properties. Journal of Agricultural and Food Chemistry, 56(23), 11198-11208.

González-Pérez, S., Merck, K. B., Vereijken, J. M., van Koningsveld, G. A., Gruppen, H., \& Voragen, A. G. (2002). Isolation and characterization of undenatured chlorogenic acid free sunflower (Helianthus annuus) proteins. Journal of Agricultural and Food Chemistry, 50(6), 1713-1719.

González-Pérez, S., van Konignsveld, G. A., Vereijken, J. M., Merck, K. B., Gruppen, H., \& Voragen, A. G. (2005). Emulsion properties of sunflower (Helianthus annuus) proteins. Journal of Agricultural and Food Chemistry, 53(6), 2261-2267.

González-Pérez, S., Vereijken, J. M., Van Koningsveld, G. A., Gruppen, H., \& Voragen, A. G. (2005). Physicochemical properties of $2 \mathrm{~S}$ albumins and the corresponding protein isolate from sunflower (Helianthus annuus). Journal of food science, 70(1), C98-C103.

González-Pérez, S., \& Vereijken, J. M. (2007). Sunflower proteins: overview of their physicochemical, structural and functional properties. Journal of the Science of Food and Agriculture, 87(12), 2173-2191.

Huang, A. H. (2018). Plant lipid droplets and their associated proteins: potential for rapid advances. Plant physiology, 176(3), 1894-1918.

Iwanaga, D., Gray, D. A., Fisk, I. D., Decker, E. A., Weiss, J., \& McClements, D. J. (2007). Extraction and characterization of oil bodies from soy beans: a natural source of pre-emulsified soybean oil. Journal of Agricultural and Food Chemistry, 55(21), 8711-8716.

Jankowiak, L., Kantzas, N., Boom, R., \& van der Goot, A. J. (2014). Isoflavone extraction from okara using water as extractant. Food Chemistry, 160, 371-378.

Kammerer, D. R., Kammerer, J., Valet, R., \& Carle, R. (2014). Recovery of polyphenols from the by-products of plant food processing and application as valuable food ingredients. Food Research International, 65, 212.

Kanakis, C., Hasni, I., Bourassa, P., Tarantilis, P., Polissiou, M., \& Tajmir-Riahi, H.-A. (2011). Milk $\beta-$ lactoglobulin complexes with tea polyphenols. Food Chemistry, 127(3), 1046-1055. 
Karkani, O. A., Nenadis, N., Nikiforidis, C. V., \& Kiosseoglou, V. (2013). Effect of recovery methods on the oxidative and physical stability of oil body emulsions. Food Chemistry, 139(1-4), 640-648.

Kortt, A. A., \& Caldwell, J. B. (1990). Low molecular weight albumins from sunflower seed: identification of a methionine-rich albumin. Phytochemistry, 29(9), 2805-2810.

Lakemond, C. M., de Jongh, H. H., Hessing, M., Gruppen, H., \& Voragen, A. G. (2000). Soy glycinin: influence of $\mathrm{pH}$ and ionic strength on solubility and molecular structure at ambient temperatures. Journal of Agricultural and Food Chemistry, 48(6), 1985-1990.

Lomascolo, A., Uzan-Boukhris, E., Sigoillot, J.-C., \& Fine, F. (2012). Rapeseed and sunflower meal: a review on biotechnology status and challenges. Applied microbiology and biotechnology, 95(5), 1105-1114.

Malik, M. A., \& Saini, C. S. (2017). Polyphenol removal from sunflower seed and kernel: Effect on functional and rheological properties of protein isolates. Food Hydrocolloids, 63, 705-715.

Martínez-Force, E., Dunford, N. T., \& Salas, J. J. (2015). Sunflower: chemistry, production, processing, and utilization: Elsevier.

Matthäus, B. (2002). Antioxidant activity of extracts obtained from residues of different oilseeds. Journal of Agricultural and Food Chemistry, 50(12), 3444-3452.

Meng, S., Cao, J., Feng, Q., Peng, J., \& Hu, Y. (2013). Roles of chlorogenic acid on regulating glucose and lipids metabolism: a review. Evidence-Based Complementary and Alternative Medicine, 2013.

Meyer, E. W. (2016). Soya protein isolates for food. Proteins as human food, ed. by RA Lawrie, 346.

Molina, M. I., Petruccelli, S., \& Añón, M. C. (2004). Effect of pH and ionic strength modifications on thermal denaturation of the $11 \mathrm{~S}$ globulin of sunflower (Helianthus annuus). Journal of Agricultural and Food Chemistry, 52(19), 6023-6029.

Moure, A., Sineiro, J., Domínguez, H., \& Parajó, J. C. (2006). Functionality of oilseed protein products: A review. Food Research International, 39(9), 945-963.

Naczk, M., \& Shahidi, F. (2006). Phenolics in cereals, fruits and vegetables: occurrence, extraction and analysis. Journal of pharmaceutical and biomedical analysis, 41(5), 1523-1542.

Nikiforidis, C., Kiosseoglou, V., \& Scholten, E. (2013). Oil bodies: An insight on their microstructure-maize germ vs sunflower seed. Food Research International, 52(1), 136-141.

Nikiforidis, C. V., Biliaderis, C. G., \& Kiosseoglou, V. (2012). Rheological characteristics and physicochemical stability of dressing-type emulsions made of oil bodies-egg yolk blends. Food Chemistry, 134(1), 6473.

Pelgrom, P. J., Berghout, J. A., van der Goot, A. J., Boom, R. M., \& Schutyser, M. A. (2014). Preparation of functional lupine protein fractions by dry separation. LWT-Food Science and Technology, 59(2), 680688.

Pelgrom, P. J., Boom, R. M., \& Schutyser, M. A. (2015). Functional analysis of mildly refined fractions from yellow pea. Food Hydrocolloids, 44, 12-22.

Petti, S., \& Scully, C. (2009). Polyphenols, oral health and disease: A review. Journal of dentistry, 37(6), 413423.

Pickardt, C., Eisner, P., Kammerer, D. R., \& Carle, R. (2015). Pilot plant preparation of light-coloured protein isolates from de-oiled sunflower (Helianthus annuus L.) press cake by mild-acidic protein extraction and polyphenol adsorption. Food Hydrocolloids, 44, 208-219.

Pickardt, C., Neidhart, S., Griesbach, C., Dube, M., Knauf, U., Kammerer, D. R., \& Carle, R. (2009). Optimisation of mild-acidic protein extraction from defatted sunflower (Helianthus annuus L.) meal. Food Hydrocolloids, 23(7), 1966-1973.

Plietz, P., Damaschun, G., Muller, J. J., \& Schwenke, K. D. (1983). The Structure of 11-S Globulins from Sunflower and Rape Seed. European journal of biochemistry, 130(2), 315-320.

Prigent, S. (2005). Interactions of phenolic compounds with globular proteins and their effects on food-related functional properties.

Rodrigues, I. M., Coelho, J. F., \& Carvalho, M. G. V. (2012). Isolation and valorisation of vegetable proteins from oilseed plants: Methods, limitations and potential. Journal of Food Engineering, 109(3), 337-346.

Salgado, P. R., Drago, S. R., Ortiz, S. E. M., Petruccelli, S., Andrich, O., González, R. J., \& Mauri, A. N. (2012). Production and characterization of sunflower (Helianthus annuus L.) protein-enriched products obtained at pilot plant scale. LWT-Food Science and Technology, 45(1), 65-72.

Salgado, P. R., Ortiz, S. E. M., Petruccelli, S., \& Mauri, A. N. (2012). Functional food ingredients based on sunflower protein concentrates naturally enriched with antioxidant phenolic compounds. Journal of the American Oil Chemists' Society, 89(5), 825-836.

Salunkhe, D. K. (1992). World oilseeds: Springer Science \& Business Media.

Sarker, D. K., Wilde, P. J., \& Clark, D. C. (1995). Control of surfactant-induced destabilization of foams through polyphenol-mediated protein-protein interactions. Journal of Agricultural and Food Chemistry, 43(2), 295-300.

Sarkis, J. R., Côrrea, A. P. F., Michel, I., Brandeli, A., Tessaro, I. C., \& Marczak, L. D. (2014). Evaluation of the Phenolic Content and Antioxidant Activity of Different Seed and Nut Cakes from the Edible Oil Industry. Journal of the American Oil Chemists' Society, 91(10), 1773-1782.

Sharif, H. R., Williams, P. A., Sharif, M. K., Abbas, S., Majeed, H., Masamba, K. G., Safdar, W., \& Zhong, F. (2018). Current progress in the utilization of native and modified legume proteins as emulsifiers and encapsulants-A review. Food Hydrocolloids, 76, 2-16.

Strauss, G., \& Gibson, S. M. (2004). Plant phenolics as cross-linkers of gelatin gels and gelatin-based coacervates for use as food ingredients. Food Hydrocolloids, 18(1), 81-89.

Suryaprakash, P., Kumar, R. P., \& Prakash, V. (2000). Thermodynamics of interaction of caffeic acid and quinic acid with multisubunit proteins. International Journal of Biological Macromolecules, 27(3), 219-228.

Tzen, J., \& Huang, A. (1992). Surface structure and properties of plant seed oil bodies. The Journal of cell biology, 117(2), 327-335.

USDA. (2018). Oilseeds: World Markets and Trade. 
van der Goot, A. J., Pelgrom, P. J., Berghout, J. A., Geerts, M. E., Jankowiak, L., Hardt, N. A., Keijer, J., Schutyser, M. A., Nikiforidis, C. V., \& Boom, R. M. (2016). Concepts for further sustainable production of foods. Journal of Food Engineering, 168, 42-51.

Weisz, G. M., Kammerer, D. R., \& Carle, R. (2009). Identification and quantification of phenolic compounds from sunflower (Helianthus annuus L.) kernels and shells by HPLC-DAD/ESI-MS n. Food Chemistry, $115(2), 758-765$.

Weisz, G. M., Schneider, L., Schweiggert, U., Kammerer, D. R., \& Carle, R. (2010). Sustainable sunflower processing-I. Development of a process for the adsorptive decolorization of sunflower [Helianthus annuus L.] protein extracts. Innovative Food Science \& Emerging Technologies, 11(4), 733-741.

Wijngaard, H., Hossain, M. B., Rai, D. K., \& Brunton, N. (2012). Techniques to extract bioactive compounds from food by-products of plant origin. Food Research International, 46(2), 505-513.

Wildermuth, S. R., Young, E. E., \& Were, L. M. (2016). Chlorogenic Acid Oxidation and Its Reaction with Sunflower Proteins to Form Green-Colored Complexes. Comprehensive Reviews in Food Science and Food Safety.

Williams, M. A. (2005). Recovery of oils and fats from oilseeds and fatty materials. Bailey's industrial oil and fat products.

Žilić, S., Barać, M., Pešić, M., Crevar, M., Stanojević, S., Nišavić, A., Saratlić, G., \& Tolimir, M. (2010). Characterization of sunflower seed and kernel proteins. Helia, 33(52), 103-114. 


\section{Chapter 2}

\section{Physical bonding between sunflower proteins and phenols: Impact on interfacial properties}

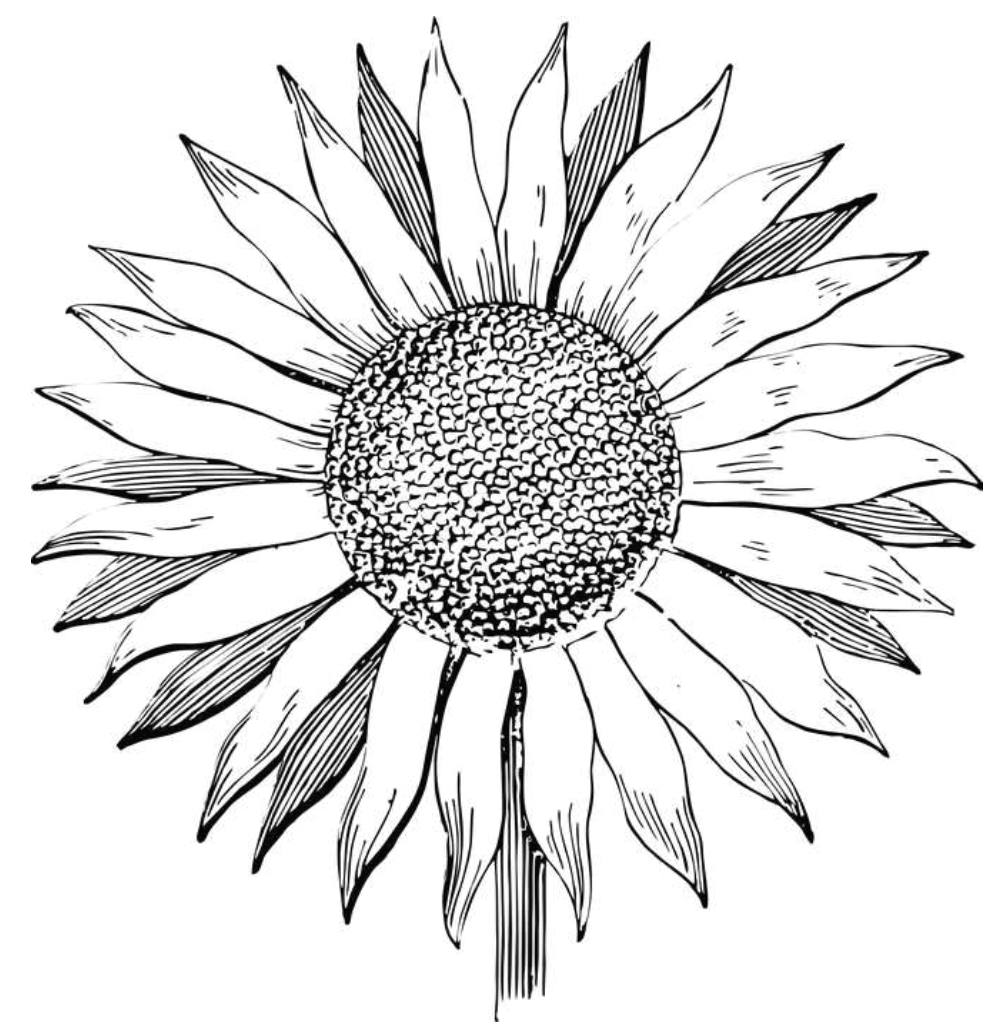

This chapter has been published as :

Karefyllakis, D., Altunkaya, S., Berton-Carabin, C. C., Van Der Goot, A. J., \& Nikiforidis, C. V. Physical bonding between sunflower proteins and phenols: Impact on interfacial properties. Food Hydrocolloids (2017). Vol 73, Pages 326-334. 


\section{A B S T R A C T}

The complexation of proteins with phenolic compounds has been recently considered a promising route to improve the oxidative stability of food dispersions, such as oil-in-water $(\mathrm{O} / \mathrm{W})$ emulsions. However, the effect of such a complexation on the functional properties of proteins, such as their emulsifying and interfacial properties, has not been deeply studied yet. To gain insight on this matter, non-covalently bonded protein-phenol complexes were formed in aqueous dispersions. Highly pure sunflower protein isolate (SFPI, $94 \mathrm{wt} \%$ ) and the polar phenolic compound chlorogenic acid (CGA) were mixed at neutral $\mathrm{pH}$ and the resulting complexes were characterised regarding their size and interfacial properties. Larger amounts of CGA led to more extensive complexation, therefore larger complexes, and reduction of free protein molecules. Hydrogen bonding was indicated as the main form of interaction between the elements. Sunflower proteins were able to adsorb at the oil-water interface and thereby to decrease the interfacial tension. The latter was further decreased when the complexes were used instead of the sole SFPI. Furthermore, O/W emulsion droplets stabilized by the complexes exhibited high stability against coalesence. These results indicate that the physical interactions between SFPI and CGA positively affected the interfacial and emulsifying properties of sunflower proteins. This is an intriguing bottom line regarding the challenges (e.g discoloration, loss of solubility and nutritional value) associated with full valorization of sunflower oil extraction residues and in general protein fractions rich in phenolic compounds. 


\subsection{Introduction}

The interactions between proteins and phenols have been a matter of continuous research. A number of studies have shown that such interactions can improve the stability of protein-based colloidal systems. For instance, the presence of phenols can improve the foam formation and stability in protein-surfactant systems by inducing cross-linking of proteins in the adsorbed layer (Sarker, Wilde, \& Clark, 1995) and also strengthen the mechanical properties of gelatin gels by covalently cross-linking of phenol dimers (Strauss \& Gibson, 2004). Besides such desirable effects, protein-phenol interactions can also have negative consequences. Proteinphenol interactions and formation of soluble or insoluble complexes is the main cause behind undesirable haze in beer, wine and clear fruit juices (Siebert, 1999). Astringency of various beverages has been also attributed to interactions between salivary proteins and phenols resulting in insoluble aggregates which interfere with the palate (Haslam, Lilley, \& Butler, 1988). Interfacial shear elasticity of salivary proteins on air-water interface can also be impaired by complexation with phenols (Rossetti, Yakubov, Stokes, Williamson, \& Fuller, 2008).

The interactions between proteins and phenols is also one of the main long-lasting challenges behind the valorization of proteins from plants and agri-industrial by-products(Balasundram, Sundram, \& Samman, 2006). A characteristic example where these interactions give rise to considerable complications is the application of sunflower proteins as a food ingredient (González-Pérez, van Konignsveld, et al., 2005; Salgado, et al., 2012). There are two possible ways that phenols can interact with sunflower proteins: (1) non-covalently (hydrogen bonding, ionic or/and hydrophobic interactions) and (2) covalently via oxidation to quinones (Sabir, Sosulski, \& Finlayson, 1974; Saeed \& Cheryan, 1989; Sastry \& Rao, 1990). The latter can affect sunflower proteins substantially either by diminishing their solubility and functionality, or by reducing protein digestibility and altering their organoleptic properties (Wildermuth, Young, \& Were, 2016).

When purified, sunflower proteins are worthwhile ingredients from functionality point of view. Their capability to stabilize emulsions and foams has been well documented (González-Pérez \& Vereijken, 2007; Ren, Sun, Lin, Zheng, \& Liu, 2012). Great amounts of sunflower proteins, $25-50 \% \mathrm{w} / \mathrm{w}$, can be found in residues obtained after sunflower oil extraction, the so-called sun flower cake. This by-product stream is currently underutilized as low-value animal feed, mainly due to protein-phenol interactions (Geneau-Sbartaï, Leyris, Silvestre, \& Rigal, 2008). The amounts of phenols present in sunflower cake can reach up to 3\% w/w (Weisz, Kammerer, $\&$ Carle, 2009). Due to the afforementioned complications arrising from their coexistance with proteins, phenols are usually removed during protein purification. Nevertheless, sunflower phenols may also play a beneficial role in food systems. Chlorogenic acid (CGA), the main phenolic compound in sunflower products (over $70 \%$ of sunflower phenols (Weisz, et al., 2009), exhibits many benefits, including antibacterial, anticarcinogenic and hypoglycemic activities, and is also a good antioxidant for food applications (De Leonardis, Macciola, \& Di 
Rocco, 2003; Dos Santos, Almeida, Lopes, \& De Souza, 2006; Meng, Cao, Feng, Peng, \& Hu, 2013; Sato, et al., 2011).

Due to all these intriguing qualities of sunflower proteins and phenols, it was decided to study in depth model systems where proteins and phenols coexist rather than focusing on their separation. In addition, studying protein-phenol mixtures is in line with the concepts for more sustainable ingredient processing which suggest that the focus should be on functionality rather than purity (van der Goot, et al., 2016). It is indicated that production of pure ingredients could be substituted by development of enriched fractions whith equivalent functionality. Taking into consideration the importance of protein-phenol interactions for the valorization of sunflower cake and the high potential of the ingredients contained therin, it was decided to investigate the physical interactions between chorogenic acid (CGA) and sunflower protein isolate (SFPI). Their interplay at oil-water interfaces and in model dispersion systems was studied, which sheds new light on the effect of their complexation not only on the functionality of proteins but also on non-purified fractions.

\subsection{Materials and methods}

\section{Materials}

Dehulled sunflower seeds of non-oilseed type (less oil and higher protein content) were bought from Notenstore (Bergschenhoek, The Netherlands). Sunflower oil was purchased from a local supermarket and was stripped by means of alumina to eliminate impurities, tocopherols and any polar compounds. Chlorogenic acid (CGA), petroleum ether, methanol, ethanol, bovine serum albumin, potassium monobasic dihydrate, potassium phosphate dibasic, tris base, tris hydrochloride, alumina, glycine, sodium dodecyl sulphate (SDS), glycerol, bromophenol blue, 2-mercaptoethanol, sodium hydroxide and hydrochloric acid were all purchased from Sigma Aldrich (Sigma, USA) and were of analytical grade. Syringe filters of $1 \mu \mathrm{m}$ pore size were purchased from Sartorius (Sartorius, Göttingen, Germany). For the protein extraction demiwater was used. For all other experiments Milli-Q purified water was used.

\section{Methods}

\subsubsection{Isolation of sunflower protein isolate}

Sunflower proteins were isolated following the procedure of González et al. (González-Pérez, et al., 2002), except that spray- instead of freeze-drying was used. Dehulled sunflower seeds were first milled with Pulverisette 14 (Fritch International, Germany), shieved with $2 \mathrm{~mm}$ shieve and defatted for at least $16 \mathrm{~h}$ using petroleum ether as solvent. The defatted seeds were left to dry overnight at room temperature. After drying, extensive dephenolization of the flour was performed. Defatted flour was washed eight times until no phenols were detected $(80 \% \mathrm{v} / \mathrm{v}$ methanol, $4{ }^{\circ} \mathrm{C}$ and 1:20 (w/v) flour to solvent ratio).. The defatted dephenolized sunflower flour was then left to dry overnight in a vacuum oven, at $30^{\circ} \mathrm{C}$. After drying, the protein content was determined with DUMAS (analysis not shown) and then the flour was mixed with demi- 
water and diluted until $1 \mathrm{wt} \%$ protein. The $\mathrm{pH}$ was adjusted to 9.0 with small amounts of $2 \mathrm{M}$ $\mathrm{NaOH}$ and was stirred for at least 30 minutes. The $\mathrm{pH}$ was continuously checked and re-adjusted when necessary. After protein solubilisation, the mixture was centrifuged (20 min, 10000 RPM, $20^{\circ} \mathrm{C}$ ) to remove the insoluble material. After centrifugation the protein solution was submitted to diafiltration with the crossflow concentrator Sartorious 200( Sartorius, Germany), using a 10 $\mathrm{kDa}$ membrane to increase solid content and remove the majority of low molecular compounds and salts present. When the desired solid content $(\approx 2 \mathrm{wt} \%)$ and neutral $\mathrm{pH}$ were reached, the solution was spray-dried (Mini Spray Dryer B-290, Büchi Labortechnik AG, Flawil, Switzerland). Protein content was measured with DUMAS method (FlashEA 1112 NC Analyzer, Thermo Fisher Scientific, Germany). A conversion factor of 6.25 was used for all samples (González-Pérez, et al., 2002).

\subsubsection{SDS-PAGE}

For protein characterization, sodium dodecyl sulphate polyacrylamide gel electrophoresis (SDS-PAGE) was performed with Mini-PROTEAN gels (any kDa and low range PROTEAN TGXTM. 10 well, $50 \mu$, Bio-rad, The Netherlands) and the samples were treated with Tris buffer containing $2 \% \mathrm{w} / \mathrm{v}$ SDS, $10 \% \mathrm{w} / \mathrm{v}$ glycerol, $0.5 \% \mathrm{w} / \mathrm{v}$ bromophenol blue and $5 \% \mathrm{~b}$ mercaptoethanol according to the manufacturer's instructions. After electrophoresis, the gels were stained for one hour using Bio-Safe Coomassie Blue (Bio-rad, Netherlands). For destaining, gels were washed overnight using ultrapure water.

\subsubsection{Protein solubility}

A solution containing $0.1 \mathrm{wt} \% \mathrm{SFPI}$ was made and $\mathrm{NaCl}$ was added until $\mathrm{I}=0.1 \mathrm{~mol} \cdot \mathrm{L}^{-1}$. The $\mathrm{pH}$ of the solution was adjusted to 9.0 using $1 \mathrm{M} \mathrm{NaOH}$ and in the end, the solution was equally divided in aliquots. The $\mathrm{pH}$ in each aliquot was adjusted with various amounts of $1 \mathrm{M} \mathrm{HCl}$ to obtain $\mathrm{pH}$ values in the range of 3.0 - 8.0. After stirring the samples for $2 \mathrm{~h}$ at room temperature, the solutions were centrifuged $\left(10000 \mathrm{~g}, 20 \mathrm{~min}, 20^{\circ} \mathrm{C}\right)$. The protein content of the supernatant was determined by the Biuret method (Smith, et al., 1985) using a BCA kit (Pierce BCA Protein Assay Kit, Thermo Scientific, Germany) according to the manufacturer's instructions. All experiments were performed in independent duplicates.

\subsubsection{Particle size and $\zeta$-potential measurements}

The particle size distribution in SFPI solutions, before or after complex formation with CGA, was measured using dynamic light scattering (DLS) (Zetasizer Nano ZS, Cell DTS1060, Malvern Instruments Ltd, UK). Solutions were diluted to the desired concentration with $0.1 \mathrm{M}$ phosphate buffer ( $\mathrm{pH} 7.0)$, and filtered with a $1-\mu \mathrm{m}$ filter. The $\zeta$-potential was measured (20 ${ }^{\circ} \mathrm{C}$ ) using the same equipment. For both type of measurements, the samples were diluted to a concentration of $0.01 \mathrm{wt} \%$. In order to measure the $\zeta$-potential as a function of $\mathrm{pH}$ the instrument 
was equipped with an autotitrator (MPT-2, Autotitrator, Malvern Intruments Ltd, UK). For the autotitration, $1 \mathrm{M} \mathrm{NaOH}, 0.1 \mathrm{M} \mathrm{NaOH}$ and $0.1 \mathrm{M} \mathrm{HCl}$ were used.

\subsubsection{Protein-phenol complexation}

Protein-phenol interactions were induced by mixing SFPI and chlorogenic acid (CGA) in a 0.1 $\mathrm{M}$ phosphate buffer ( $\mathrm{pH}$ 7.0) and were stirred mildly and left at ambient temperature overnight to assure complex formation. First CGA was mixed with the buffer and if necessary, the $\mathrm{pH}$ was setted back to 7.0 using $4 \mathrm{M} \mathrm{NaOH}$. $\mathrm{NaCl}$ was added to obtain the desired ionic strength $(0.1 \mathrm{M})$ and finally SFPI was added so that the spontenaous self-assembly could start. After the physical complexes were formed, the unbound phenols were removed from the solution by extensive dialysis (10 $\mathrm{kDa}$ membrane) in the same buffer at $4{ }^{\circ} \mathrm{C}$.

\subsubsection{Isothermal Titration Calorimetry (ITC) analysis}

ITC analysis were taken on MicroCal ITC200 (GE Lifesciences, USA). SFPI was prepared as $0.1 \mathrm{mM}$ solution in $0.1 \mathrm{M}$ phosphate, $\mathrm{pH}$ 7.0. The protein solution was placed in a $200 \mu \mathrm{L}$ calorimeter sample cell and CGA solution $(10 \mathrm{mM})$ was loaded into the injection syringe. Protein was titrated by CGA in a sequence of 20 injections of $5 \mu \mathrm{L}$ with time step of $200 \mathrm{~s}$ and under constant stirring $(100 \mathrm{rpm})$ and temperature $\left(20^{\circ} \mathrm{C}\right)$. As a control, the buffer was titrated by $10 \mathrm{mM}$ CGA. Corrected data refer to experimental data after subtraction of the CGA into buffer control data. ITC data were analyzed using the MicroCal ITC data analysis software.

\subsubsection{Interfacial properties}

Interfacial tension and dilatational rheology measurements at the oil-water interface were measured using an automated drop tensiometer (Tracker, Teclis-IT Concept, France). All aqueous solutions were used at a protein concentration of $0.1 \mathrm{wt} \%$. Prior to each measurement, the cuvette, syringe and needle were cleaned intensively. The initial droplet volume was set between 4 and $16 \mu \mathrm{L}$, with corresponding droplet area of $14 \mathrm{~mm}^{2}$ to $30 \mathrm{~mm}^{2}$. In all cases we made sure that the initial Bond number, which represents the balance between the gravity and interfacial tension forces, was $>0.1$, which is required for performing accurate measurements, as recommended by the manufacturer. The interfacial tension was first monitored for $3 \mathrm{~h}$ while keeping the droplet volume constant. After that, dilatational oscillations of the droplet area were performed with a constant amplitude (5\%) and a range of oscillation frequencies (periods of 10 , 20, 100 and $200 \mathrm{~s}$ ). The surface dilatational modulus $E$ depends on the frequency of surface deformation and can be presented as a complex number (Nikiforidis, et al., 2013) :

$E=E^{\prime}+i E^{\prime \prime}$

The real part $\mathrm{E}^{\prime}$ is the storage modulus representing the recoverable elastic energy stored in the surface (dilatational elasticity) whereas the imaginary part $\mathrm{E}^{\prime \prime}$ is the loss modulus reflecting the viscous dissipation of energy through any relaxation (time-dependent) processes at or near the 
surface (dilatational viscosity). Although such measurements can, in principle, be performed to characterize the instantaneous adsorbed surface layer even at times prior to equilibration, surface rheology properties at equilibrium are of primary concern.

\subsubsection{Emulsion preparation and characterisation}

Emulsions were prepared using SFPI and SFPI-CGA complexes in $0.1 \mathrm{M}$ phosphate buffer $\mathrm{pH}$ 7 and $\mathrm{I}=0.1 \mathrm{~mol} \cdot \mathrm{L}^{-1}$, as the continuous aqueous phase. The final emulsion composition was 10 $\mathrm{wt} \%$ sunflower oil and $0.5 \mathrm{wt} \%$ protein. SFPI was first solubilized in phosphate buffer under stirring for $30 \mathrm{~min}$. After dialysis for the removal of unbound CGA, protein concentration was checked and adjusted with buffer when neccesary. Mild centrifugation (5000 g, $20 \mathrm{~min}$, room temperature) was applied to the protein solutions to remove insoluble particles. After centrifugation, sunflower oil was added to the mixture and a coarse emulsion was made using a rotor-stator homogenizer (UltraTurrax, IKA, California, United states)9500 RPM 3 min). This first coarse emulsion was then passed through a lab homogenizer (labhoscope, Delta Instruments, The Netherlands) 2 times at 100 bar. Emulsions were optically analysed by light microscopy using an Axioscope device (Zeiss, Germany), after 100-fold dilution in buffer. The used magnification was 100x. To determine emulsion droplet size, a laser diffraction particle size analyser (Mastersizer 2000, Malvern Instruments Ltd, UK) was used, with a refractive index of 1.455 for the dispersed phase. Samples were first diluted and stirred to induce large aggregate break-up. All experiments were performed in duplicates.

\subsection{Results and discussion}

\section{Sunflower protein isolate characterization}

\subsubsection{Protein purity and profile analysis}

The produced sunflower protein isolate (SFPI) was highly pure (protein content $94 \% \mathrm{wt}$ ), nondenatured based on DSC analysis (data not shown) and with negligible amount of phenols. These findings are in accordance with the ones from González-Pérez et al. (González-Pérez, et al., 2002) where they found that proteins remained in their native configuration and were thus unaffected by the defatting and dephenolizing treatments. The different drying technique (freeze-drying in the reference study versus spray-drying in our study), was chosen due to convenience, small impact on protein state and due to better upscaling potential for future industrial applications (Walters, et al., 2014).

Seed proteins are normally mixtures of various protein groups, therefore qualitative analysis of their profile was necessary. Various protein molecules with molecular weights ranging from 9 $\mathrm{kDa}$ to $50 \mathrm{kDa}$ were present (Figure 2.1a). The smaller sized proteins of 9 to $17 \mathrm{kDa}$ can be associated with the $2 \mathrm{~S}$ albumins, which are random coil proteins with sizes between $10-18 \mathrm{kDa}$ (Kortt \& Caldwell, 1990). The protein cluster with sizes from 19 to $50 \mathrm{kDa}$ belongs to $11 \mathrm{~S}$ 
globulins, the so-called helianthinin, which has an hexameric configuration, globular shape and rather large size (300-350 kDa) under non-denaturing conditions (Dalgalarrondo, Raymond, \& Azanza, 1985). In sunflower proteins, the 11S fraction is the predominant one and deviates between $70-90 \%$ of total proteins with the $2 \mathrm{~S}$ fraction following with $10-30 \%$ (Žilić, et al., 2010). The reason behind low albumin levels is probably the $\mathrm{pH}$ used during extraction, which is very close to their isoelectric point ( $\mathrm{pH} \mathrm{9-10)} \mathrm{(Kortt,} \mathrm{et} \mathrm{al.,} \mathrm{1990)} \mathrm{resulting} \mathrm{in} \mathrm{significant}$ losses during the centrifugation step. González-Pérez et al. (González-Pérez, et al., 2002), whose isolation process was followed in this study, confirmed this by performing SDS-PAGE analysis on the pellet which showed that it was consisted mostly of $2 \mathrm{~S}$ albumins. To summarize, our final protein extract consists of two main protein fractions, $11 \mathrm{~S}$ globulins for the most part and $2 \mathrm{~S}$ albumins as a minor component.

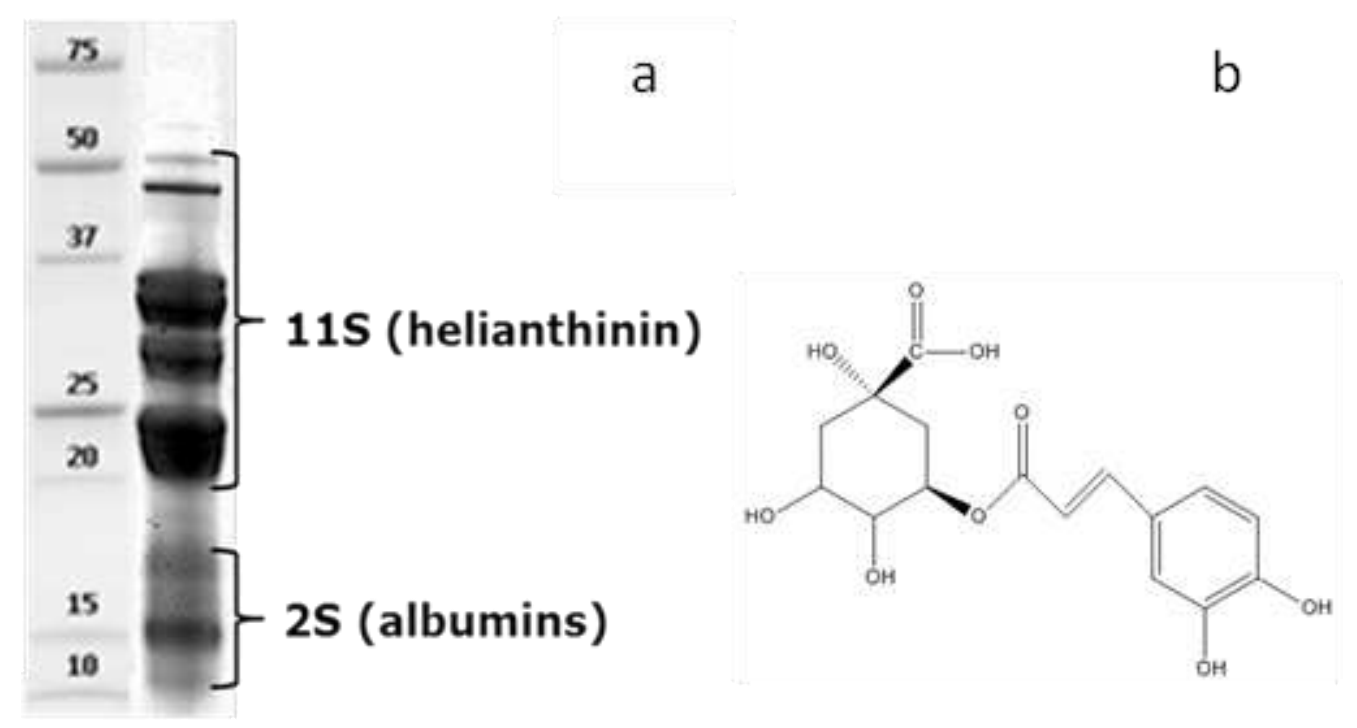

Figure 2.1 : (a) SDS-PAGE patterns of SFPI under reducing conditions. Molecular weight standard is shown in the first line $(\mathrm{kDa})$. (b) Chemical structure of Chlorogenic Acid (CGA).

\subsubsection{Solubility and charge}

Protein solubility in aqueous media is one of the most essential characteristics that a functional protein product should possess (Kinsella, 1979). The solubility profile of SFPI over a range of $\mathrm{pHs}$ is shown in Figure 2.2. There is a solubility minimum between $\mathrm{pH}$ 4-6 but below and above this region, the percentage of soluble fraction increases again. Especially at neutral to alkaline values, more than $80 \%$ of proteins were soluble. Comparable bell-shaped solubility curve was reported by González et al. (González-Pérez, Vereijken, Van Koningsveld, Gruppen, \& Voragen, 2005) for sunflower protein isolate produced following a similar procedure. In addition, they have shown that the outline of this curve resembles markedly to that of the $11 \mathrm{~S}$ protein (González-Pérez, et al., 2004). That is in line with the fact that this fraction is dominant in the produced SFPI, and $2 \mathrm{~S}$ albumin is soluble within all over the $\mathrm{pH}$ range (Kortt, et al., 1990). Conversely, Salgado et al.(Salgado, Ortiz, Petruccelli, \& Mauri, 2011) reported significant loss of solubility when sunflower proteins were extracted after dephenolizing with $80 \%(\mathrm{v} / \mathrm{v})$ aqueous methanol solutions which was not the case when water or $\mathrm{Na}_{2} \mathrm{SO}_{3}$ were used 
for the extraction. In that study, only 4 washing steps were performed thus phenols were still considerably present in the protein extracts, which, as mentioned above, can lead to phenol oxidation, covalent binding to proteins and decreased protein solubility. A similar explanation probably applies to the reported low protein solubility in another research, where no removal of phenols took place prior to alkaline extraction and protein isolation (Nesterenko, Alric, Violleau, Silvestre, \& Durrieu, 2013). Extensive removal of phenols seems therefore to be a key for obtaining highly soluble sunflower proteins and $80 \%(\mathrm{v} / \mathrm{v})$ aqueous methanol is a satisfactory media for this purpose.

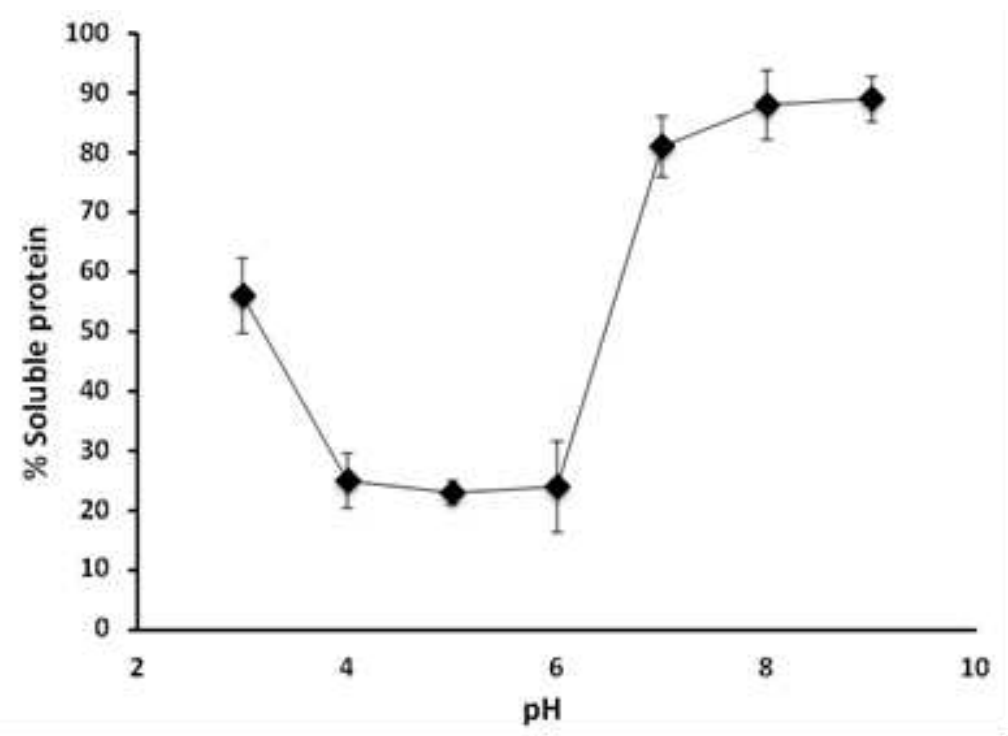

Figure 2.2 : Effect of $\mathrm{pH}$ on solubility profile of sunflower protein isolate (SFPI).

$\left(\mathrm{I}<0.1 \mathrm{~mol} \cdot \mathrm{L}^{-1}\right)$.

The $\mathrm{pH}$ of the solution affects the net charge of proteins thus modulating their interactions and functionality, therefore the charge of SFPI solutions was measured over a broad $\mathrm{pH}$ range and to our knowledge, this is the first time that it is documented. As we can see in Figure 2.3, the isoelectric point (IEP) of SFPI was found at around $\mathrm{pH} 5$ and increasingly strong positive (until $+30 \mathrm{mV}$ ) and negative (until $-30 \mathrm{mV}$ ) charges were measured at acidic and alkaline $\mathrm{pH}$ values, respectively. This property can be directly associated with the solubility results presented above. SFPI has a high charge density $(\approx-30 \mathrm{mV})$ at $\mathrm{pH} \geq 7$. This causes repulsion between the positively charged amino acid residues of proteins, accounting for high solubility $(\approx 85 \%)$. At the IEP, when the overall charge is zero, SFPI solubility reaches a minimum and rises again to lower $\mathrm{pH}$ values when negative charges start repelling each other (Walstra, 1996). The same charge density pattern and solubility/charge correlation was found for soy protein isolates (Malhotra \& Coupland, 2004). The $\zeta$-potential profile in soy protein preparations originates from the dominant protein of soy protein isolates, the 11S globulin (Liu, et al., 2011), which is structurally similar to sunflower $11 \mathrm{~S}$ globulin (González-Pérez, et al., 2007). The $\zeta$-potential 
profile of complexes and emulsions was measured over the same $\mathrm{pH}$ range but due to their clear similarities with the profile of SFPI, they are not presented here. CGA solution were also measured and almost zero charge was recorded all over the $\mathrm{pH}$ and this is probably the reason why SFPI governs completely the charge of all solutions.

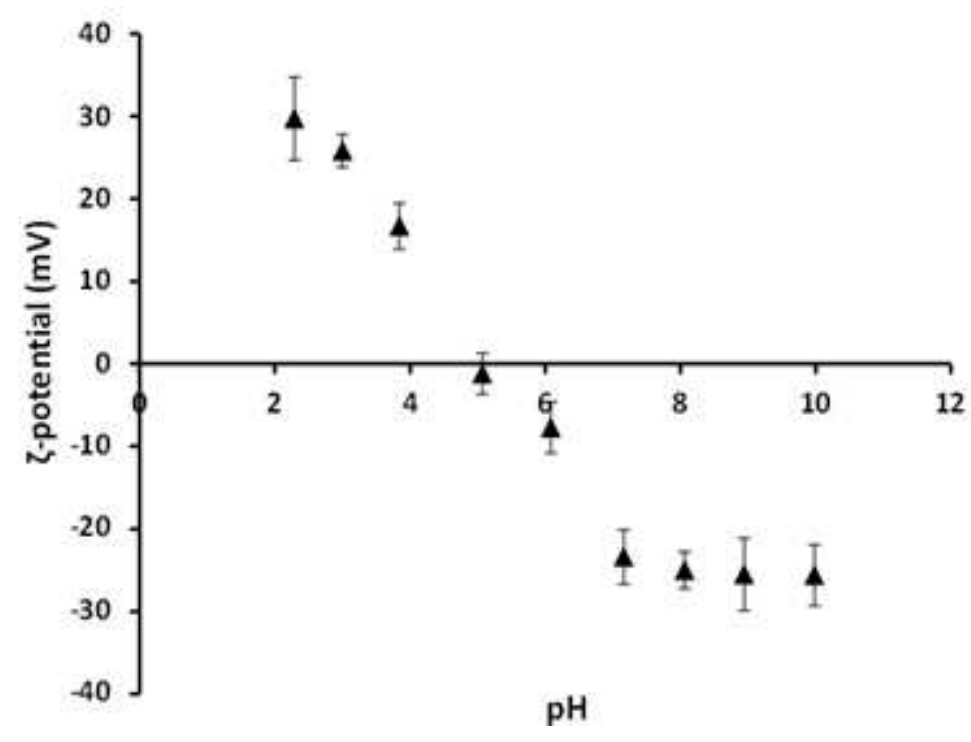

Figure 2.3 : $\zeta$-potential of sunflower protein isolate(SFPI) as a function of $\mathrm{pH}$. $\left(\mathrm{I}=0.1 \mathrm{~mol} \cdot \mathrm{L}^{-1}\right)$.

\section{Protein-phenol complexation}

\subsubsection{Size distribution of proteins}

Dynamic Light Scattering (DLS) was used to study protein-phenol interactions and the resulting complexes. As a first step, aqueous solutions of solely SFPI were investigated, in order to assess the size distribution of the protein molecules or structures when no CGA was present. The intensity size distribution of the SFPI solution is shown in Figure 2.4a. One single peak with sizes ranging from 6 to $28 \mathrm{~nm}$ appear with a maximum at $10.1 \mathrm{~nm}$ indicating that only monomers or small oligomers were present. When aqueous solutions of $11 \mathrm{~S}$ soy globulin were studied with DLS under the same conditions, comparable size distributions were observed with particle sizes 6-50nm and maximum peak of $11.7 \mathrm{~nm}$ (Ruiz-Henestrosa, Martinez, Sánchez, Patino, \& Pilosof, 2014). X-ray scattering studies have indicated that sunflower 11S proteins have an almost spherical shape and that they consist of six spherical subunits arranged as a trigonal antiprism with a maximum dimension of $11 \mathrm{~nm}$ (Plietz, Damaschun, Muller, \& Schwenke, 1983). We can therefore conclude that $11 \mathrm{~S}$ proteins belong among the population of this size distribution. However, conformational changes of $11 \mathrm{~S}$ globulin from sunflower are quite common depending on the $\mathrm{pH}$ and the ionic strength of the system (González-Pérez, et al., 2004; Molina, Petruccelli, \& Añón, 2004). At the chosen experimental conditions, neutral $\mathrm{pH}$ and $\mathrm{I}=0.1 \mathrm{~mol} \cdot \mathrm{L}^{-1}$, Molina et al. claimed that sunflower globulins retain their hexameric form, i.e. the $11 \mathrm{~S}$ fraction largely predominates. In a more detailed study of $11 \mathrm{~S}$ soy protein 
with DLS from Ruiz-Henestrosa and co-workers (Ruiz-Henestrosa, Martinez, Patino, \& Pilosof, 2012), three different conformational states of this protein were identified, the hexameric $11 \mathrm{~S}$, the trimeric $7 \mathrm{~S}$ and aggregated forms of $11 \mathrm{~S}$ such as $15 \mathrm{~S}$. The reported size of the protein particles was between 7 and $40 \mathrm{~nm}$ which differs from our value for the maximum particle size, $28 \mathrm{~nm}$. That could be an indication that in our case, aggregated forms of $11 \mathrm{~S}$ globulin, like $15 \mathrm{~S}$, were hardly present, and that the same holds for the trimeric $7 \mathrm{~S}$ form due to the specific conditions applied. The much smaller $2 \mathrm{~S}$ albumins could not be detected with DLS, probably due to their small numbers and because the signal of larger structures dominates the total signal thus masking any potential contribution of smaller particles.
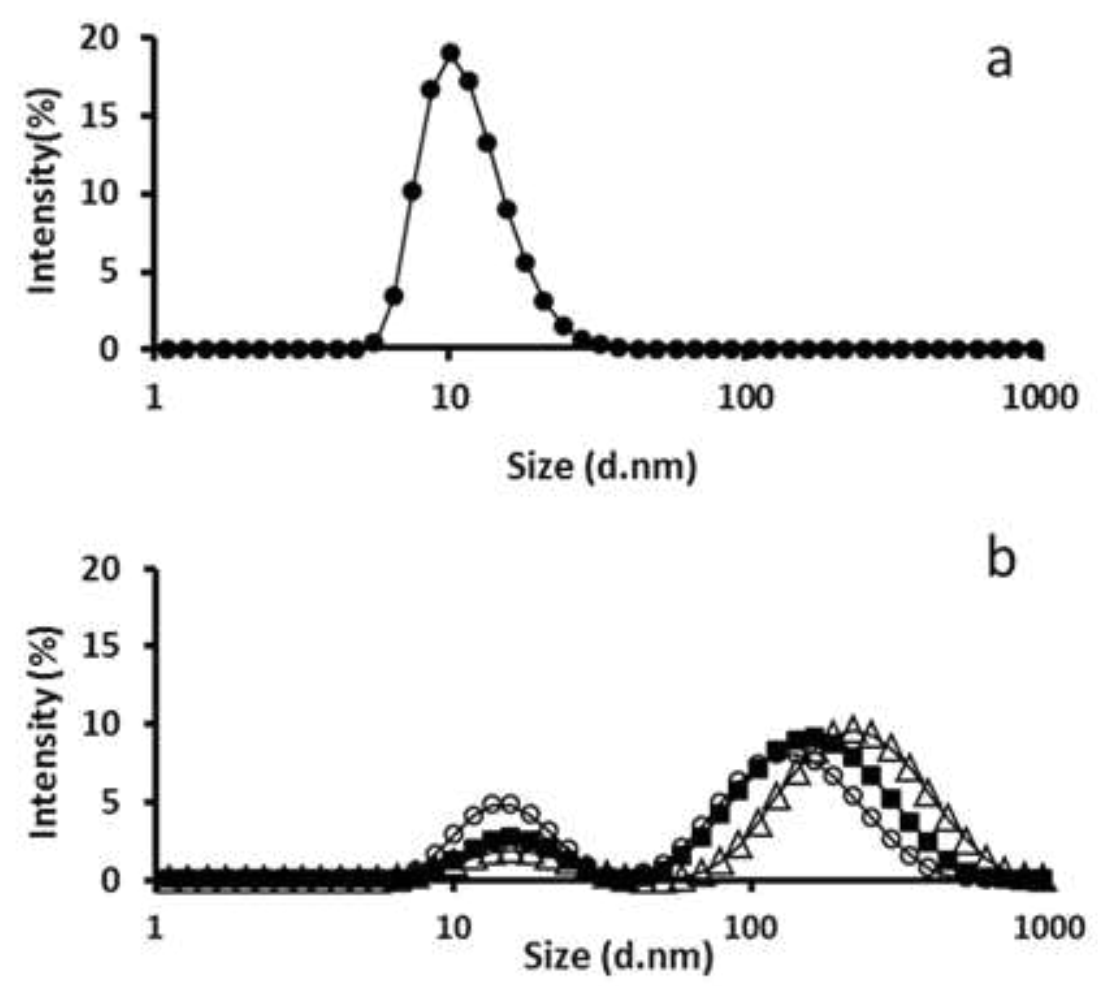

Figure 2.4 : (a) Intensity size distribution for sunflower protein isolate (SFPI) $(0.01 \% \mathrm{w} / \mathrm{w})$, I= $\left.0.1 \mathrm{~mol} \cdot \mathrm{L}^{-1}\right)$ and $\mathrm{pH}$ 7. (b) Intensity size distribution of SFPI: CGA 1:1 (o), 1:5 (•), and 1:10 $(\Delta)$ weight based ratios.

\subsubsection{Size distribution of protein-phenol complexes}

Regarding the protein-phenol complexes, the focus of the present work was only on noncovalent interactions between SFPI-CGA. Hence, all the experiments were performed at neutral $\mathrm{pH}$ to ensure that the complexes arising during the incubation were formed exclusively with physical interactions (Sastry, et al., 1990). Figure 2.4b depicts the intensity size distributions of SFPI-CGA dispersions in phosphate buffer containing constant SFPI concentration and different amounts of CGA (1:1, 1:5 and 1:10 weight based ratios) after $10 \mathrm{~min}$ of mixing. The amount of CGA bound on proteins was only determined indirectly by measuring the amount of CGA released during dialysis and it was found proportionate to the ratio used. Two distinctive 
peaks, one around $14 \mathrm{~nm}$ and another at sizes larger than $100 \mathrm{~nm}$, were detected for all samples tested. The intensity of the first peak decreased and the second peak shifted to larger sizes with increasing the amount of CGA. As we explained for Figure 2.4a the first peak can be attributed to the $11 \mathrm{~S}$ and $7 \mathrm{~S}$ forms of sunflower protein. The fact that the intensity of this peak decreases can be considered as a first indication of complex formation, meaning that $11 \mathrm{~S}$ and $7 \mathrm{~S}$ protein molecules act as the monomeric unit of larger particles and get depleted when more CGA is present . The presence of the second peak and its shift to larger sizes for higher SFPI:CGA ratios probably indicates complexation, since this peak was absent without CGA. Similar observations were reported for the complexation of protein and phenols such as in BSA-tannin solutions (Lin, Chen, Cheng, \& Chen, 2004), and whey protein and tea polyphenol mixtures, where the size of complexes was dependent on the amount of phenols (Rodríguez, von Staszewski, \& Pilosof, 2015).

The nature of the bonds developed between the 11S protein molecules and the polar CGA has been well documented by Sastry et al. (Sastry, et al., 1990) who reported that hydrogen bonding is the main underlying force. Likewise, non-covalent interactions between CGA and globular proteins seemed to be governed by the rapid development of hydrogen bonding which additionally seemed to induce no loss of solubility for globular proteins like BSA, $\alpha$ lactoglobulin and lysozyme (Prigent, et al., 2003). In general, when the phenol-protein ratio increases, phenols are able to act as multidentate ligands and bridge proteins or protein-phenol complexes. Protein dimers arise when two phenol-enriched proteins come closer (Le Bourvellec \& Renard, 2012). Since CGA is a phenol that contains an o-dihydroxyphenolic group (Figure 2.1b) capable of binding proteins via a bidentate hydrogen bond (McManus, Davis, Lilley, \& Haslam, 1981) it is logical to expect that higher phenol amounts lead to the development of more hydrogen cross-links. Therefore, by studying protein-phenol dispersions with DLS at neutral $\mathrm{pH}$ we were able to confirm not only the formation of SFPI-CGA complexes, selfassembled by multidendate hydrogen bonding, but also the fact that the complex size was proportional to the amount of CGA, for fixed protein concentration.

\subsubsection{Determination of binding of CGA to SFPI by isothermal titration calorimetry (ITC)}

The thermodynamic data of the binding reaction between CGA and SFPI was investigated based on the heat evolved during molecular association of increasing amounts of CGA. ITC biding isotherms were shown as a plot of heat flow against SFPI-CGA ratio (Figure 2.5). The complexation of SFPI-CGA was followed by a typical exothermic enthalpy change suggesting a strong binding of the elements. These findings are in agreement with literature data demonstrating that when globular proteins like BSA, lysozyme and $\alpha$-lactoglobulin interact with CGA, an exothermic enthalpy change is recorded (Prigent, et al., 2003). No clear value of the equilibrium binding constant and the stoichiometry could be extracted from this data as their estimation led to several outcomes with similar error. Both the entropic term and the enthalpy of the interaction were negative in all measurements (data not shown). SFPI-CGA interactions were thus enthalpy driven and the fact that the entropy was negative indicates an increase in molecular order. Similar behaviour has been also reported between BSA and epicatechin as 
well as between catechin and $\beta$-cyclodextrin when studied with ITC (Frazier, Papadopoulou, \& Green, 2006; Kríž, Koča, Imberty, Charlot, \& Auzély-Velty, 2003). In both of these cases, hydrogen bonding was indicated as the main form of interaction as it is expected also in this study where the polar CGA was used which contains an o-dihydroxyphenolic group (Figure 2.1b) capable of binding proteins via a bidentate hydrogen bond.

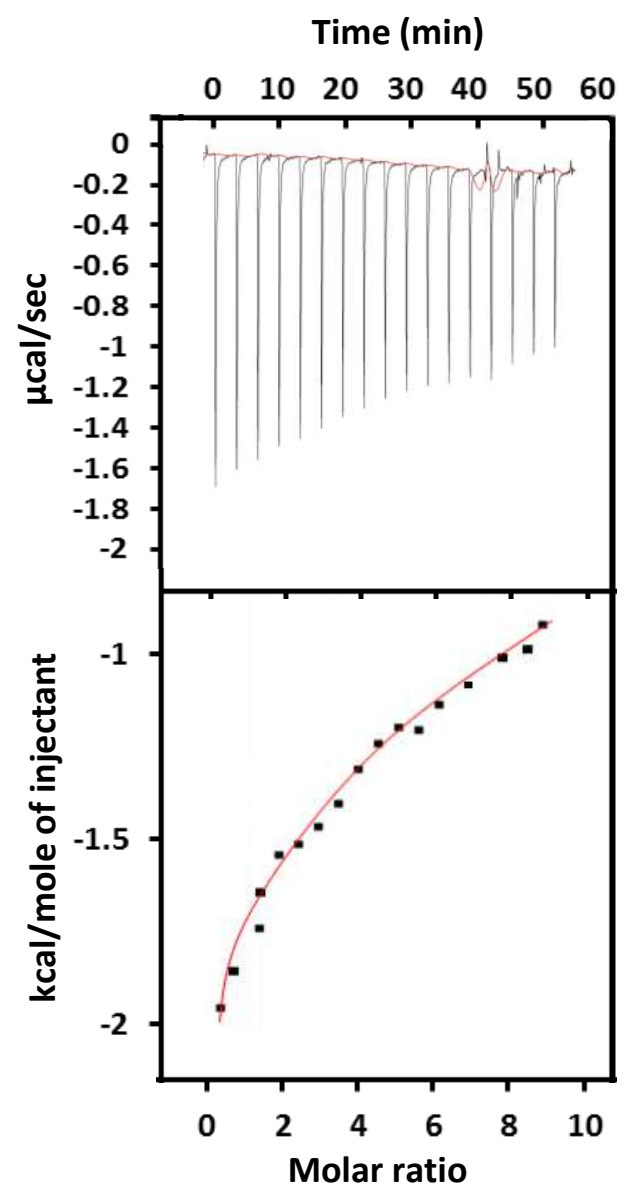

Figure 2.5 : Isothermal Titration Calorimetry data of SFPI $(0.1 \mathrm{mM})$ titrated by CGA $(10 \mathrm{mM})$; molar enthalpy $(\Delta \mathrm{H}, \mathrm{kcal} / \mathrm{mol})$ against the molar ratio of the total CGA to SFPI, after subtracting the control experiment.

\subsubsection{Interfacial behaviour of complexes}

An important functional property of globular proteins is their ability to adsorb at fluid interfaces and form interconnected, thick viscoelastic films, which in turn largely determines their emulsifying activity. However, so far only limited work has been conducted to study the effect of protein-phenol complexation on the protein interfacial properties. For this reason, the interfacial activity of SFPI, CGA and SFPI-CGA complexes in phosphate buffer at oil-water interface was studied (Figure 2.6). In pure CGA dispersions, a small interfacial tension decrease of only $5.5 \mathrm{mN} \cdot \mathrm{m}^{-1}$ was observed. The limited interfacial activity of CGA was expected since CGA is quite polar and therefore has a strong hydrophilic character and small tendency to 
adsorb at interfaces. In pure SFPI dispersions the interfacial tension drop was substantial (until $\left.\approx 7 \mathrm{mN} \cdot \mathrm{m}^{-1}\right)$. SFPI-CGA complexes $(1: 1$ and 1:5 weight based ratios) were capable of further decreasing the interfacial tension (down to $\approx 3.8 \mathrm{mN} \cdot \mathrm{m}^{-1}$ ) but between the two tested SFPI-CGA ratios no substantial differences were observed. There was no notable difference between the adsorption kinetics of SFPI and of the complexes (i.e., in the early stages of the measurements) although it was expected that diffusion rate would be proportionate to the size of the particles. This phenomena is probably related to the induction time of proteins, (Beverung, Radke, \& Blanch, 1999). since at early times and low protein concentrations, molecules are present at the interface, but do not appreciably reduce the interfacial tension. Interfacial measurements of soy $11 \mathrm{~S}$ globulin under similar conditions and concentration have shown that the adsorption of these molecules at the air-water interface does not start directly and that the diffusion of 11S was 100 s slower than the $7 \mathrm{~S}$ proteins (Martin, Bos, \& Van Vliet, 2002). A short lag time (10 s) before interfacial tension started to decrease was also observed for SFPI dispersions when the interfacial tension was plotted with time on a logarithmic scale.

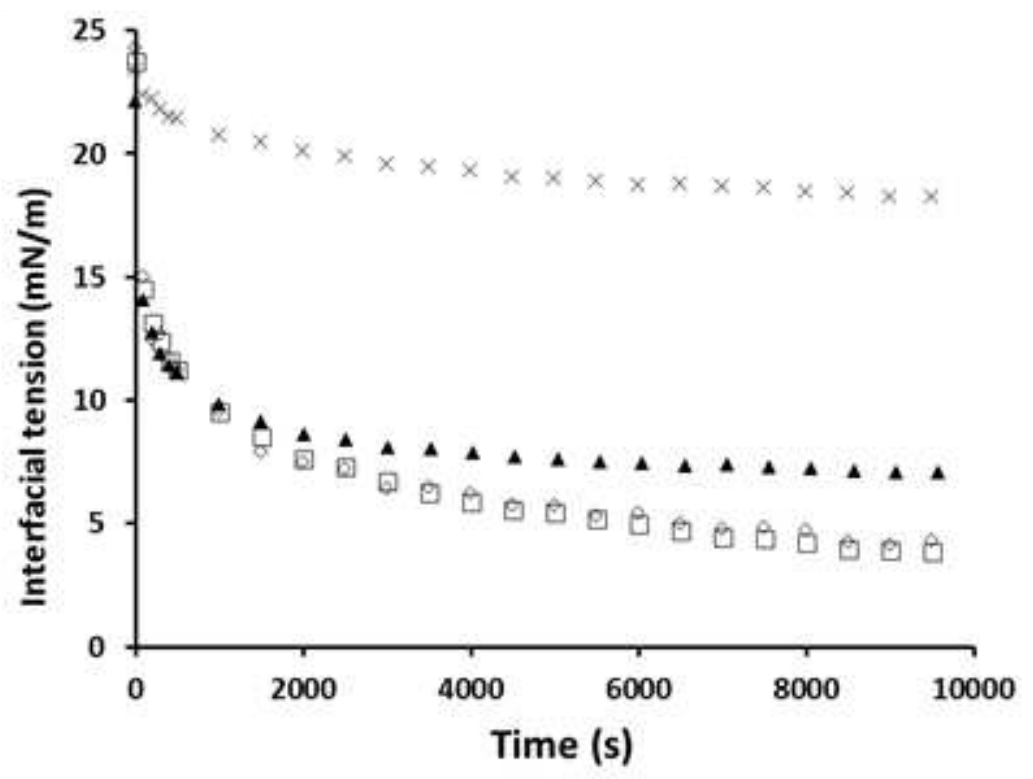

Figure 2.6 : Interfacial tension (oil-water interface) as a function of adsorption time in the

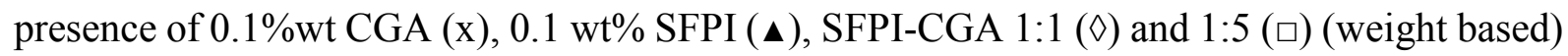
complexes in the aqueous phase, $\mathrm{pH} 7.0$ and $\mathrm{I}=0.1 \mathrm{~mol} \cdot \mathrm{L}^{-}{ }^{1}$.

After 2000 s differences in behaviour became more apparent since the interfacial tension in SFPI-CGA dispersions continued to decline. These observations were opposite to what was reported for complexes of $\beta$-lactoglobulin with green tea polyphenols on oil-water interface where the interfacial activity of the proteins was adversely affected by the presence of increasing phenol amounts (von Staszewski, Ruiz-Henestrosa, \& Pilosof, 2014). In this study the authors proposed that the non-polar tea phenols get stacked to hydrophobic groups on the interface in such a way that these hydrophobic domains could not be fully available to penetrate the interface. In addition to that, tea phenols seem to induce extra loss of protein hydrophobicity due to the introduction on the protein surface of many hydrophilic hydroxyl groups (Wei, Yang, Fan, Yuan, \& Gao, 2015). In our study, CGA was used which is a polar phenolic, involved in 
hydrogen bond formation, thus expected to be associated more with the hydrophilic groups on the protein surface and not to interfere with the hydrophobic domains which remain free to absorb on the interface.

Since the unbound CGA molecules were discarded during dialysis, the only qualitative difference between SFPI molecules and the complexes is the presence of physically bounded CGA. The fact that after extensive dialysis no free CGA was detected in the dialysis liquid shows that complexed molecules were strongly associated with proteins. This means that even if they are not irreversibly bound per se, CGA molecules are attached to proteins by sufficiently strong forces so they would not exist as independent molecules in the solution. Therefore, the additional interfacial tension decrease can be attributed to protein-phenol interactions. A synergistic mechanism could be suggested as a result of further cross-linking between phenols and the proteins of the adsorbed layer. Besides the partial unfoldment of proteins following adsorption (Figure 2.7a), it can be hypothesized that additional hydrogen bonds can be developed between the phenols bound on adjacent proteins and thus further unfolding is induced. This additional unfolding can lead to more efficient coverage of the interface and extra intermolecular interactions between the adsorbed proteins (Figure 2.7b). It has been shown that enhancement of protein-protein interactions in the adsorbed layer and increased resistance against their disruption was the reason behind the stabilization of $\beta$-lactoglobulin films by the formation of $(+)$-catechin bridges between the protein molecules (Sarker, et al., 1995).
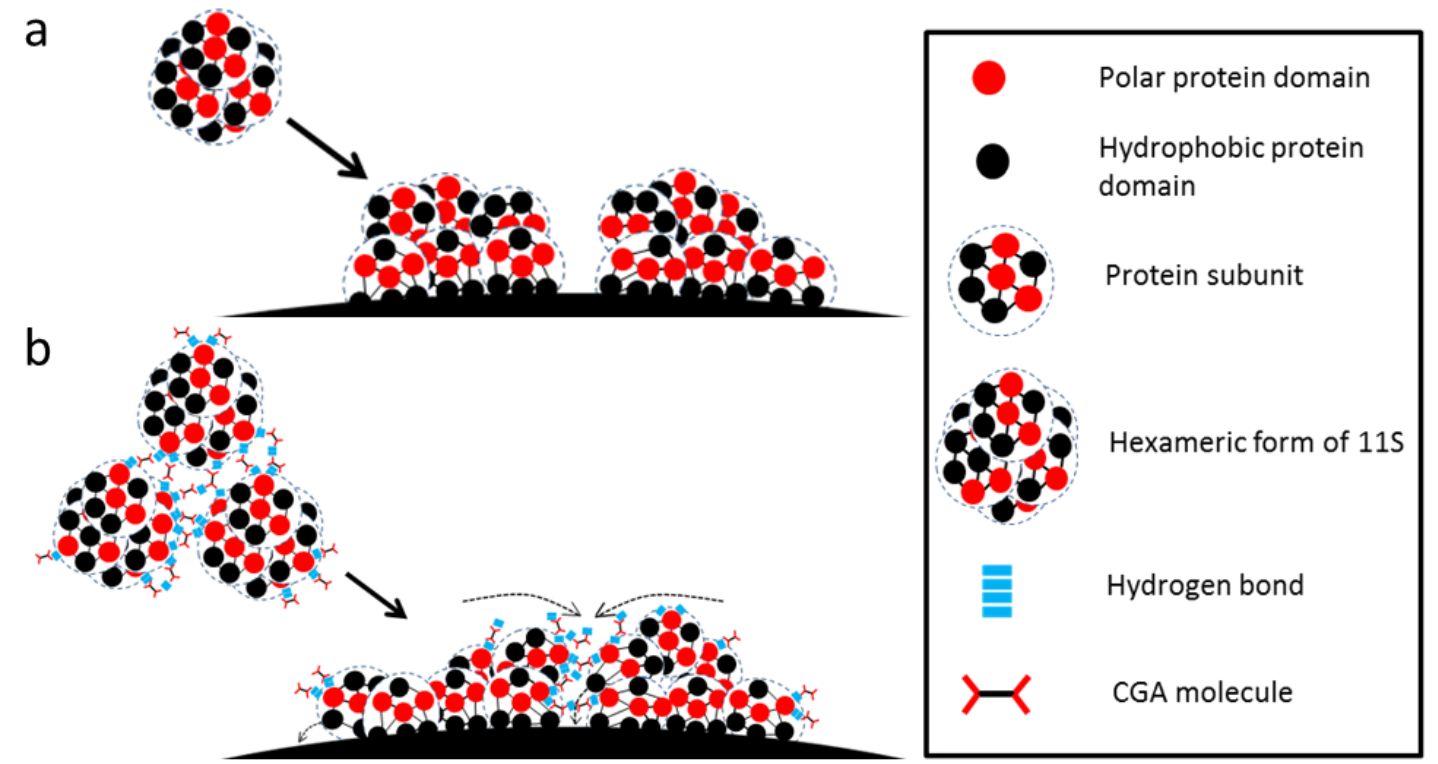

Figure 2.7 : (a) Illustration of the unfolding of the $11 \mathrm{~S}$ protein molecule on the $\mathrm{O} / \mathrm{W}$ interface and (b) of the protein-phenol complex on the $\mathrm{O} / \mathrm{W}$ interface.

The viscoelastic dilatational moduli of the formed interfacial films were measured using fixed oscillation amplitude of 5\% and frequency sweeps (periods of 10, 20, 100 and $200 \mathrm{~s}$ ). The oscillations were performed after $3 \mathrm{~h}$ when an equilibrium was reached at constant droplet area. The obtained storage or elastic modulus, $E^{\prime}$, and loss or viscous modulus, $E^{\prime \prime}$, for each sample 
are presented in Figure 2.8 where they are plotted against the applied frequency $\left(\mathrm{s}^{-1}\right)$. By being a polar molecule, CGA did not readily adsorb at the interface. However, since after 3 hours interfacial tension decreased slightly (Fig.2.7 x symbol), an oscillation experiment was performed but nothing of significance was observed (negative non-reproducible values of moduli) This means that no coherent layer of molecules was formed on the interface and that the interactions between phenols were rather weak. For both SFPI and the 1:5 complex, the storage moduli $\left(15-20 \mathrm{mN} \cdot \mathrm{m}^{-1}\right)$ were much higher than the loss moduli $(>2.5 \mathrm{mN} \cdot \mathrm{m}-1)$, indicating dominant elastic behaviour of the interface. For the interfaces made of the complexes, the elastic moduli were higher compared to that of the pure SFPI layer, which can indicate that the presence of CGA strengthened the connectivity of the interfacial protein network. This in not in line with previous results from Staszewski et al. (von Staszewski, et al., 2014), who reported a decrease in the dilatational elasticity of interfacial layers of $\beta$ lactoglobulin in the presence of tea phenols, at the oil-water interface. As mentioned above, in this study the forces governing the interactions were mainly hydrophobic in nature which led to a restriction of the intra and intermolecular hydrophobic interactions between proteins, needed to form an elastic film. In our case, where mainly hydrogen bonds were developed, after the adsorption of SFPI-CGA complexes and interfacial protein unfolding, development of additional interactions among the adjacent proteins of the complexes could still be possible. This fact can lead to strengthening of the protective film formed around the oil droplet. This film has an apparent elastic character which suggests that intermolecular protein interactions are efficiently strong and can maintain proteins to their original position and not allow them to be displaced by the oscillation. As a result, a densely packed film forms at the oil-water interface.

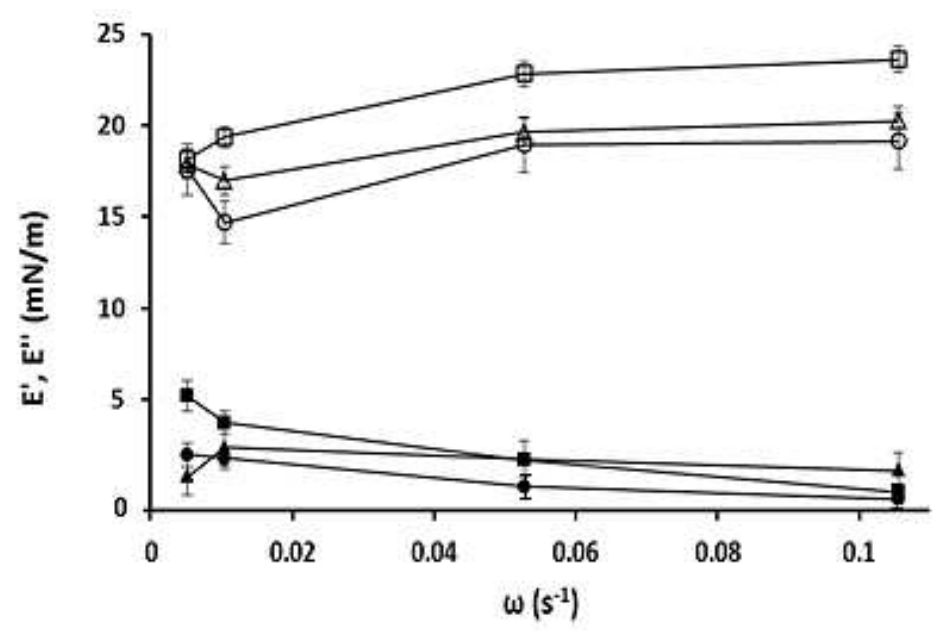

Figure 2.8 : Interfacial dilatational elastic/storage ( $E^{\prime}$ (hollow symbols)) and viscous/loss ( $E^{\prime \prime}($ bold symbols)) moduli as a function of oscillation frequency: SFPI (o), Complex 1:1 ( $\square$ ) and Complex 1:5 $(\Delta)$. Concentration: $0.1 \mathrm{wt} \%$. 


\subsubsection{Emulsification}

Droplet size and stability. Oil-in-water emulsions were made using SFPI, complex 1:1 or complex 1:5 as emulsifiers in phosphate buffer $(\mathrm{pH} \mathrm{7.0)}$ and the droplet size distributions obtained directly after production and after six days are depicted in Figure 2.9. The emulsion stabilized with SFPI had a broad droplet size distribution centred around $1 \mu \mathrm{m}$ while the droplet size distributions in emulsions stabilised by the complexes were more narrow with an average droplet size around $5 \mu \mathrm{m}$. To determine the stability of the emulsions against coalescence, the droplet size measurements were repeated after six days and as we see in the graph (Figure 2.9 hollow symbols) there was only a slight right-shift of the curves (towards larger sizes) over this period of time. In addition, the emulsion morphology was assessed by optical microscopy pictures (of 1:5 complex) as shown in Figure 2.9. The ability of SFPI to act as an efficient emulsifier has been previously showcased by González et al. (González-Pérez, van Konignsveld, et al., 2005) where similar results were obtained regarding the droplet size. Physical complexation with CGA clearly modified the adsorption behaviour of SFPI at the oilwater interface, as it can be judged from the alteration of droplet size, but had no negative repercussions to the emulsion physical stability since only a minor extent of coalescence took place over 6 days (for both SFPI-CGA ratios). Microscopy pictures confirm the negligible size increment for some emulsion droplets after the passage of 6 days (Figure 2.9a,b). Aggregation was absent in emulsions stabilized solely by SFPI (picture not shown) whereas it was rather apparent in the case of complexes both directly after emulsification (Figure 2.9a) as well as after 6 days (Figure 2.9b). This means that the actual size of the droplets stabilized by the complexes is not the one depicted in the graph at day 1 (Figure 2.9) but appears larger due to immediate aggregation that can only be mediated by CGA molecules.

As already shown by DLS and ITC results, CGA molecules readily bridge proteins by physical interactions resulting into the formation of complexes. In a similar fashion, bridging of droplets seems to be occurring after adsorption of complexes on the $\mathrm{O} / \mathrm{W}$ interface. CGA molecules which lie on the surface of the adsorbed complexes could be promoting interdroplet interactions of neighbouring droplets. Droplet size increment was also observed in cases of emulsions stabilized by physical complexes of curcumin with soy isolate (Chen, Zhang, \& Tang, 2016) when compared to the emulsions stabilized by the pure macromolecule. In the case of emulsions stabilized by curcumin-soy isolate complexes, firm resistance to coalescence for a week was observed, like in our case, despite the larger droplets and aggregates initially formed. Enhanced stability as a result of complexation was also reported in emulsions stabilized by green tea polyphenol- $\beta$-lactoglobulin complexes, compared to the ones solely stabilized by $\beta$ lactoglobulin, although in this study the presence of increasing amounts of phenols resulted in smaller emulsion droplets (von Staszewski, et al., 2014). From the moment that the SFPI-CGA complexes are placed at the oil-water interface, they seem to participate in the development of an effective interfacial film against coalescence, stable even after the course of six days. Development of additional protein-protein interactions seems to have a positive effect on the strength and the density of the interfacial layer and the overall stability and the size of the droplets. 


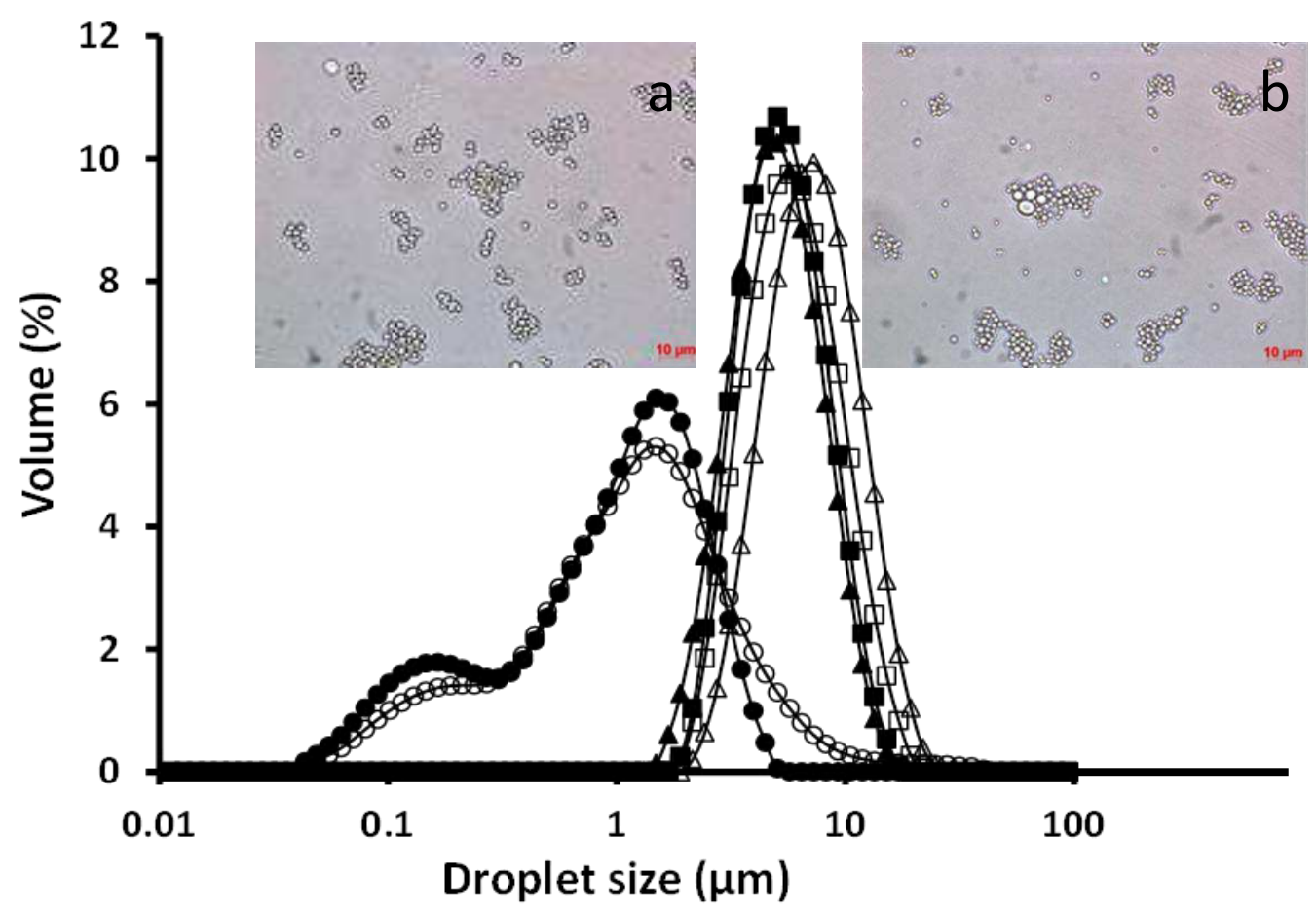

Figure 2.9 : Droplet size measurement emulsions day 1 (bold symbols) and 6 (hollow symbols) stabilized using sunflower protein isolate (SFPI) $(\bullet)$, SFPI-CGA 1:1 (•) and SFPI-CGA 1:5 (ム). The micrographs illustrate the emulsions with the SFPI-CGA complex 1:5 directly after preparation (a) and after 6 day storage (b) .

\subsection{Conclusions}

After extraction and characterisation, sunflower seed protein isolates (SFPI) were mixed and complexed with pure chlorogenic acid (CGA) at $\mathrm{pH} 7$,. The size of the complexes was directly dependent on the amount of CGA used thus giving the indication that CGA molecules were bridging the protein molecules and were holding them with physical bonds. The complexes readily adsorbed at the oil-water interface, and could further reduced the interfacial tension compared to SFPI alone. When they were used as $\mathrm{O} / \mathrm{W}$ emulsion stabilizers, emulsions with larger droplet size than SFPI-based ones were produced but with fairly high stability against coalesence. The findings could be considered as an extra step towards the unravelling of the way that protein-phenol interactions can modify protein properties and their potential applications into valorization of sunflower oil extraction residues and other protein fractions rich in phenolic compounds following concepts of sustaibable processing with less purification.

Intermolecular interaction between proteins might be essential for the physical stability of an emulsion but the contribution of CGA does not stop there. The fact that these phenols are positioned at the interface of the $\mathrm{O} / \mathrm{W}$ emulsion can also have advantageous implications for the chemical stability of the dispersed phase. It has been shown that the antioxidant capacity of 
phenols, like CGA, is enhanced by their accumulation at the oil-water interface (Waraho, McClements, \& Decker, 2011). It should be investigated in the future if besides retardation of lipid oxidation this complexes could be have any potential as delivery systems of antioxidants in the gastrointestinal track. Taking everything into account, the antioxidant potential of the physically complexed CGA at the oil-water interface should be considered an extra advantage for the applications of these complexes in food.

\section{Aknowledgments}

This work took place within the framework of the Institute for Sustainable Process technology (ISPT) 


\section{References}

Balasundram, N., Sundram, K., \& Samman, S. (2006). Phenolic compounds in plants and agri-industrial byproducts: Antioxidant activity, occurrence, and potential uses. Food Chemistry, 99(1), 191-203.

Beverung, C., Radke, C., \& Blanch, H. (1999). Protein adsorption at the oil/water interface: characterization of adsorption kinetics by dynamic interfacial tension measurements. Biophysical chemistry, 81(1), 59-80.

Chen, S., Zhang, N., \& Tang, C.-H. (2016). Influence of nanocomplexation with curcumin on emulsifying properties and emulsion oxidative stability of soy protein isolate at pH 3.0 and 7.0. Food Hydrocolloids, $61,102-112$

Dalgalarrondo, M., Raymond, J., \& Azanza, J.-L. (1985). Sunflower seed protein: size and charge heterogeneity in subunits of the globulin fraction. Biochimie, 67(6), 629-632.

De Leonardis, A., Macciola, V., \& Di Rocco, A. (2003). Oxidative stabilization of cold-pressed sunflower oil using phenolic compounds of the same seeds. Journal of the Science of Food and Agriculture, 83(6), 523-528.

Dos Santos, M. D., Almeida, M. C., Lopes, N. P., \& De Souza, G. E. P. (2006). Evaluation of the anti-inflammatory, analgesic and antipyretic activities of the natural polyphenol chlorogenic acid. Biological and Pharmaceutical Bulletin, 29(11), 2236-2240.

Frazier, R. A., Papadopoulou, A., \& Green, R. J. (2006). Isothermal titration calorimetry study of epicatechin binding to serum albumin. Journal of pharmaceutical and biomedical analysis, 41(5), 1602-1605.

Geneau-Sbartaï, C., Leyris, J., Silvestre, F. O., \& Rigal, L. (2008). Sunflower cake as a natural composite: composition and plastic properties. Journal of Agricultural and Food Chemistry, 56(23), 11198-11208.

González-Pérez, S., Merck, K. B., Vereijken, J. M., van Koningsveld, G. A., Gruppen, H., \& Voragen, A. G. (2002). Isolation and characterization of undenatured chlorogenic acid free sunflower (Helianthus annuus) proteins. Journal of Agricultural and Food Chemistry, 50(6), 1713-1719.

González-Pérez, S., van Konignsveld, G. A., Vereijken, J. M., Merck, K. B., Gruppen, H., \& Voragen, A. G. (2005). Emulsion properties of sunflower (Helianthus annuus) proteins. Journal of Agricultural and Food Chemistry, 53(6), 2261-2267.

González-Pérez, S., Vereijken, J. M., Merck, K. B., van Koningsveld, G. A., Gruppen, H., \& Voragen, A. G. (2004). Conformational states of sunflower (Helianthus annuus) helianthinin: effect of heat and $\mathrm{pH}$. Journal of Agricultural and Food Chemistry, 52(22), 6770-6778.

González-Pérez, S., Vereijken, J. M., Van Koningsveld, G. A., Gruppen, H., \& Voragen, A. G. (2005). Physicochemical properties of $2 \mathrm{~S}$ albumins and the corresponding protein isolate from sunflower (Helianthus annuus). Journal of food science, 70(1), C98-C103.

González-Pérez, S., \& Vereijken, J. M. (2007). Sunflower proteins: overview of their physicochemical, structural and functional properties. Journal of the Science of Food and Agriculture, 87(12), 2173-2191.

Haslam, E., Lilley, T. H., \& Butler, L. G. (1988). Natural astringency in foodstuffs-a molecular interpretation. Critical Reviews in Food Science \& Nutrition, 27(1), 1-40.

Kinsella, J. E. (1979). Functional properties of soy proteins. Journal of the American Oil Chemists' Society, 56(3), 242-258.

Kortt, A. A., \& Caldwell, J. B. (1990). Low molecular weight albumins from sunflower seed: identification of a methionine-rich albumin. Phytochemistry, 29(9), 2805-2810.

Kríž, Z., Koča, J., Imberty, A., Charlot, A., \& Auzély-Velty, R. (2003). Investigation of the complexation of (+)catechin by $\beta$-cyclodextrin by a combination of NMR, microcalorimetry and molecular modeling techniques. Organic \& biomolecular chemistry, 1(14), 2590-2595.

Le Bourvellec, C., \& Renard, C. (2012). Interactions between polyphenols and macromolecules: quantification methods and mechanisms. Critical reviews in food science and nutrition, 52(3), 213-248.

Lin, H.-C., Chen, P.-C., Cheng, T.-J., \& Chen, R. L. (2004). Formation of tannin-albumin nano-particles at neutral $\mathrm{pH}$ as measured by light scattering techniques. Analytical biochemistry, 325(1), 117-120.

Liu, C., Teng, Z., Lu, Q.-Y., Zhao, R.-Y., Yang, X.-Q., Tang, C.-H., \& Liao, J.-M. (2011). Aggregation kinetics and $\zeta$-potential of soy protein during fractionation. Food Research International, 44(5), 1392-1400.

Malhotra, A., \& Coupland, J. N. (2004). The effect of surfactants on the solubility, zeta potential, and viscosity of soy protein isolates. Food Hydrocolloids, 18(1), 101-108.

Martin, A., Bos, M., \& Van Vliet, T. (2002). Interfacial rheological properties and conformational aspects of soy glycinin at the air/water interface. Food Hydrocolloids, 16(1), 63-71.

McManus, J. P., Davis, K. G., Lilley, T. H., \& Haslam, E. (1981). The association of proteins with polyphenols. Journal of the Chemical Society, Chemical Communications(7), 309b-311.

Meng, S., Cao, J., Feng, Q., Peng, J., \& Hu, Y. (2013). Roles of chlorogenic acid on regulating glucose and lipids metabolism: a review. Evidence-Based Complementary and Alternative Medicine, 2013.

Molina, M. I., Petruccelli, S., \& Añón, M. C. (2004). Effect of pH and ionic strength modifications on thermal denaturation of the $11 \mathrm{~S}$ globulin of sunflower (Helianthus annuus). Journal of Agricultural and Food Chemistry, 52(19), 6023-6029.

Nesterenko, A., Alric, I., Violleau, F., Silvestre, F., \& Durrieu, V. (2013). A new way of valorizing biomaterials: The use of sunflower protein for a-tocopherol microencapsulation. Food Research International, 53(1), 115-124.

Nikiforidis, C. V., Ampatzidis, C., Lalou, S., Scholten, E., Karapantsios, T. D., \& Kiosseoglou, V. (2013). Purified oleosins at air-water interfaces. Soft Matter, 9(4), 1354-1363.

Plietz, P., Damaschun, G., Muller, J. J., \& Schwenke, K. D. (1983). The Structure of 11-S Globulins from Sunflower and Rape Seed. European journal of biochemistry, 130(2), 315-320.

Prigent, S. V., Gruppen, H., Visser, A. J., van Koningsveld, G. A., de Jong, G. A., \& Voragen, A. G. (2003). Effects of non-covalent interactions with 5-O-caffeoylquinic acid (chlorogenic acid) on the heat denaturation and solubility of globular proteins. Journal of Agricultural and Food Chemistry, 51(17), 5088-5095. 
Ren, J., Sun, X.-H., Lin, G.-P., Zheng, X.-Q., \& Liu, X.-L. (2012). Isolation and Characterization of Sunflower Protein Isolates and Sunflower Globulins. In Information Technology and Agricultural Engineering (pp. 441-449): Springer.

Rodríguez, S. D., von Staszewski, M., \& Pilosof, A. M. (2015). Green tea polyphenols-whey proteins nanoparticles: bulk, interfacial and foaming behavior. Food Hydrocolloids, 50, 108-115.

Rossetti, D., Yakubov, G., Stokes, J., Williamson, A.-M., \& Fuller, G. (2008). Interaction of human whole saliva and astringent dietary compounds investigated by interfacial shear rheology. Food Hydrocolloids, 22(6), 1068-1078.

Ruiz-Henestrosa, V. M. P., Martinez, M. J., Patino, J. M., \& Pilosof, A. M. (2012). A dynamic light scattering study on the complex assembly of glycinin soy globulin in aqueous solutions. Journal of the American Oil Chemists' Society, 89(7), 1183-1191.

Ruiz-Henestrosa, V. M. P., Martinez, M. J., Sánchez, C. C., Patino, J. M. R., \& Pilosof, A. M. (2014). Mixed soy globulins and $\beta$-lactoglobulin systems behaviour in aqueous solutions and at the air-water interface. Food Hydrocolloids, 35, 106-114.

Sabir, M. A., Sosulski, F. W., \& Finlayson, A. J. (1974). Chlorogenic acid-protein interactions in sunflower. Journal of Agricultural and Food Chemistry, 22(4), 575-578.

Saeed, M., \& Cheryan, M. (1989). Chlorogenic acid interactions with sunflower proteins. Journal of Agricultural and Food Chemistry, 37(5), 1270-1274.

Salgado, P. R., Drago, S. R., Ortiz, S. E. M., Petruccelli, S., Andrich, O., González, R. J., \& Mauri, A. N. (2012). Production and characterization of sunflower (Helianthus annuus L.) protein-enriched products obtained at pilot plant scale. LWT-Food Science and Technology, 45(1), 65-72.

Salgado, P. R., Ortiz, S. E. M., Petruccelli, S., \& Mauri, A. N. (2011). Sunflower protein concentrates and isolates prepared from oil cakes have high water solubility and antioxidant capacity. Journal of the American Oil Chemists' Society, 88(3), 351-360.

Sarker, D. K., Wilde, P. J., \& Clark, D. C. (1995). Control of surfactant-induced destabilization of foams through polyphenol-mediated protein-protein interactions. Journal of Agricultural and Food Chemistry, 43(2), 295-300.

Sastry, M. S., \& Rao, M. N. (1990). Binding of chlorogenic acid by the isolated polyphenol-free 11 S protein of sunflower (Helianthus annuus) seed. Journal of Agricultural and Food Chemistry, 38(12), 2103-2110.

Sato, Y., Itagaki, S., Kurokawa, T., Ogura, J., Kobayashi, M., Hirano, T., Sugawara, M., \& Iseki, K. (2011). In vitro and in vivo antioxidant properties of chlorogenic acid and caffeic acid. International Journal of Pharmaceutics, 403(1), 136-138.

Siebert, K. J. (1999). Effects of protein-polyphenol interactions on beverage haze, stabilization, and analysis. Journal of Agricultural and Food Chemistry, 47(2), 353-362.

Smith, P. K., Krohn, R. I., Hermanson, G., Mallia, A., Gartner, F., Provenzano, M., Fujimoto, E., Goeke, N., Olson, B., \& Klenk, D. (1985). Measurement of protein using bicinchoninic acid. Analytical biochemistry, 150(1), 76-85.

Strauss, G., \& Gibson, S. M. (2004). Plant phenolics as cross-linkers of gelatin gels and gelatin-based coacervates for use as food ingredients. Food Hydrocolloids, 18(1), 81-89.

van der Goot, A. J., Pelgrom, P. J., Berghout, J. A., Geerts, M. E., Jankowiak, L., Hardt, N. A., Keijer, J., Schutyser, M. A., Nikiforidis, C. V., \& Boom, R. M. (2016). Concepts for further sustainable production of foods. Journal of Food Engineering, 168, 42-51.

von Staszewski, M., Ruiz-Henestrosa, V. M. P., \& Pilosof, A. M. (2014). Green tea polyphenols- $\beta$-lactoglobulin nanocomplexes: Interfacial behavior, emulsification and oxidation stability of fish oil. Food Hydrocolloids, 35, 505-511.

Walstra, P. (1996). Dispersed systems: basic considerations. FOOD SCIENCE AND TECHNOLOGY-NEW YORKMARCEL DEKKER-, 95-156.

Walters, R. H., Bhatnagar, B., Tchessalov, S., Izutsu, K. I., Tsumoto, K., \& Ohtake, S. (2014). Next generation drying technologies for pharmaceutical applications. Journal of pharmaceutical sciences, 103(9), 26732695.

Waraho, T., McClements, D. J., \& Decker, E. A. (2011). Mechanisms of lipid oxidation in food dispersions. Trends in Food Science \& Technology, 22(1), 3-13.

Wei, Z., Yang, W., Fan, R., Yuan, F., \& Gao, Y. (2015). Evaluation of structural and functional properties of protein-EGCG complexes and their ability of stabilizing a model $\beta$-carotene emulsion. Food Hydrocolloids, 45, 337-350.

Weisz, G. M., Kammerer, D. R., \& Carle, R. (2009). Identification and quantification of phenolic compounds from sunflower (Helianthus annuus L.) kernels and shells by HPLC-DAD/ESI-MS n. Food Chemistry, 115(2), 758-765.

Wildermuth, S. R., Young, E. E., \& Were, L. M. (2016). Chlorogenic Acid Oxidation and Its Reaction with Sunflower Proteins to Form Green-Colored Complexes. Comprehensive Reviews in Food Science and Food Safety.

Žilić, S., Barać, M., Pešić, M., Crevar, M., Stanojević, S., Nišavić, A., Saratlić, G., \& Tolimir, M. (2010). Characterization of sunflower seed and kernel proteins. Helia, 33(52), 103-114. 
Chapter 2 


\section{Chapter 3}

\section{Covalent bonding of Chlorogenic Acid induces structural modifications on sunflower proteins}

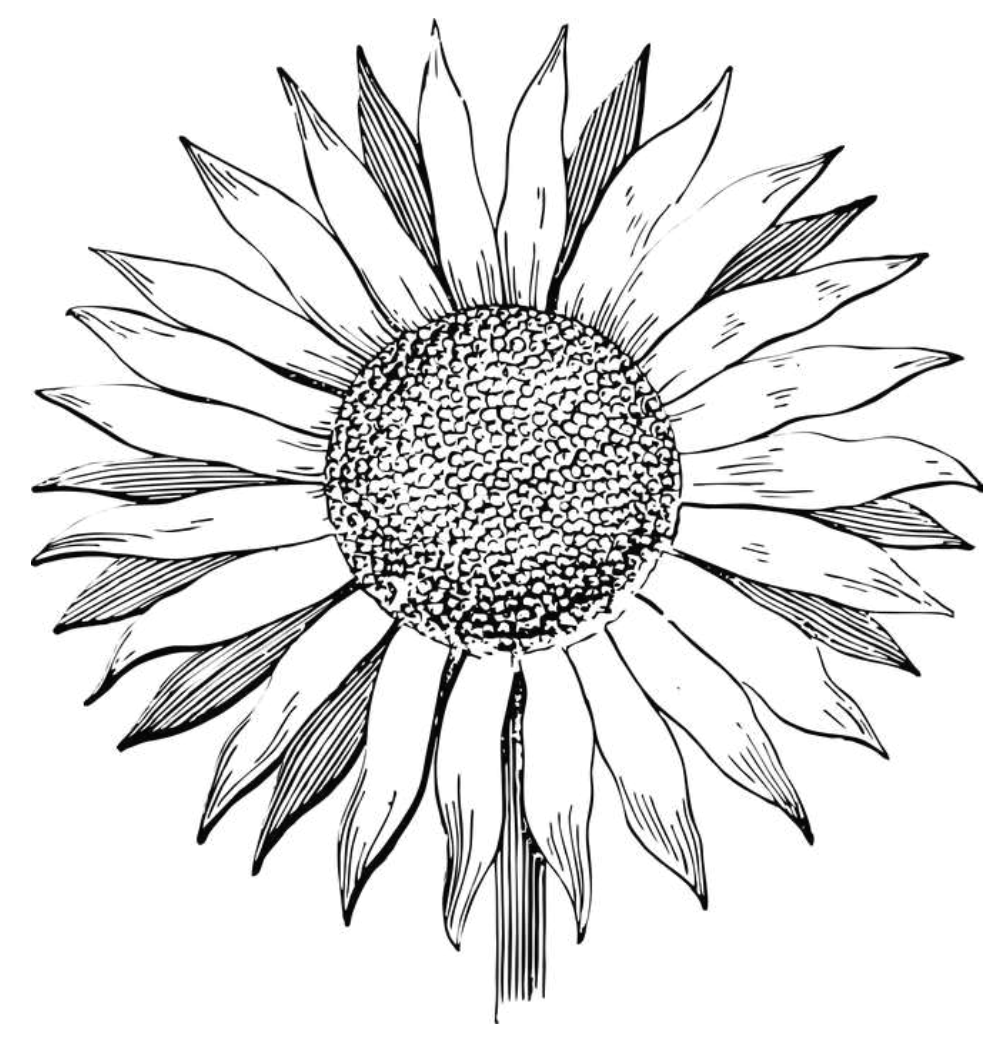

This chapter has been published as :

Karefyllakis, D., Salakou, S., Bitter, J. H., van der Goot, A. J., \& Nikiforidis, C. V. (2018). Covalent Bonding of Chlorogenic Acid Induces Structural Modifications on Sunflower Proteins. ChemPhysChem, 19(4), 459-468. 


\section{A B S T R A C T}

Proteins and phenols coexist in the confined space of plant cells leading to reactions between them which result in new covalently bonded complex molecules. This kind of reactions has been widely observed during storage and processing of plant materials. However, the nature of the new complex molecules and their physicochemical properties are largely unknown. Therefore we investigated the structural characteristics of covalently bonded complexes between sunflower protein isolate (SFPI,protein content $85 \mathrm{wt} \%$ ) and the dominant phenol in the confined space of a sunflower seed cell (chlorogenic acid, CGA). It was shown that the efficiency of bond formation goes through a maximum as a function of the SFPI/CGA ratio. Moreover, the bonding of CGA with proteins resulted in changes in the secondary and tertiary structure of the protein. It was also shown that the phenol bound strongly to the protein which resulted in new crosslinks between the polypeptide chains. As a result, secondary structures like $\alpha$-helices and $\beta$-sheets lessened which in turn resulted in more disordered domains and a subsequent modification of the tertiary structure of the proteins. These findings are relevant for establishing future protocols for extraction of high-quality proteins and phenols when utilizing plant material and offer insight into the impact of processing that these ingredients endure. 


\subsection{Introduction}

Plant cells are confined spaces where a number of reactions are taking place. A major reaction between plant cell compounds is the bonding of proteins with phenols, which exhibits critical impact on properties of both reactants(Liu, Ma, Gao, \& McClements, 2017). Therefore, understanding these potential reactions are of high importance when valorization of proteins and phenols from plant sources is strived for. In general, the bonding between proteins and phenols causes protein unfolding(Ozdal, Capanoglu, \& Altay, 2013), which can significantly influence the protein properties like solubility and interfacial activity(Salgado, Ortiz, Petruccelli, \& Mauri, 2011; van Koningsveld, et al., 2002). In the same way, complexation does not leave phenols unaffected since their potency to act as antioxidants is often negatively influenced by it(Bandyopadhyay, Ghosh, \& Ghosh, 2012).

Phenolic compounds comprise an aromatic ring which bears one or more hydroxyl substituents. They can exist as simple phenolic molecules, polyaromatic molecules and highly polymerized compounds(Bravo, 1998). During storage or processing of plant materials, phenols oxidize by enzymes, light, elevated temperatures and alkaline conditions(Oliver, Vittorio, Cirillo, \& Boyer, 2016). It has been suggested that the oxidized phenols (quinones) can react with protein molecules inside the confined environment of plant tissues leading to new covalently bonded complexes with various adducts being possible (Figure 3.1)(KROLL, RAWEL, \& ROHN, 2003). These reactions are irreversible and lead to the development of C-N or C-S bonds by an addition reaction of readily available protein nucleophiles on the phenolic ring(Alves \& Mano, 2008). Such nucleophiles include the terminal amino groups of polypeptide chains, the $\varepsilon$-amino group of lysine, the indole nitrogen of tryptophan and the sulfhydryl group of cysteine.

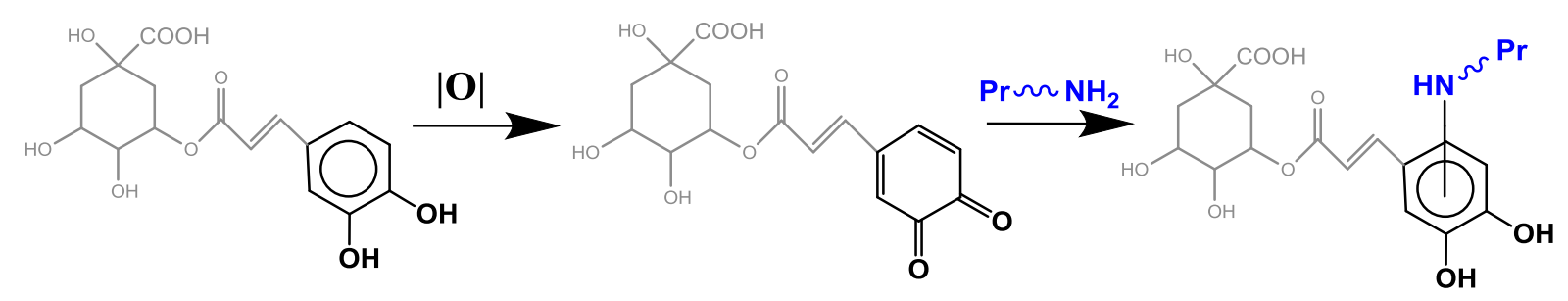

Figure 3.1 : Oxidation of phenols (here Chlorogenic Acid) and covalent bonding with proteins as it occurs inside the confined spaces of plant cells. For simplification, only C-N bonds are shown here.

A relevant example of a confined environment where a reaction between phenols and proteins is promoted, is the sunflower seed cell. Both compounds are present in high amounts and sunflower seed processing conditions $(\mathrm{pH}>8$ and elevated temperature during oil/protein extraction) catalyze their reaction(Moure, Sineiro, Domínguez, \& Parajó, 2006; Salunkhe, 1992). Sunflower proteins comprise up to $20-30 \mathrm{wt} \%$ of the seed, while phenols are up to $2 \%$ $\mathrm{wt} \%$, of which chlorogenic acid (CGA) is the major one(Weisz, Kammerer, \& Carle, 2009). It is important to mention that pure sunflower proteins exhibit valuable functional properties (solubility, interfacial activity)(González-Pérez, et al., 2005). However, when covalently complexed with CGA they become insoluble, indigestible and appear with a green color which 
hampers their potential applications as food or drug ingredient(Liang \& Were, 2018a, 2018b; Wildermuth, Young, \& Were, 2016). Nonetheless, CGA is also a biofunctional compound for food and drug applications(De Leonardis, Macciola, \& Di Rocco, 2003; Dos Santos, Almeida, Lopes, \& De Souza, 2006). Therefore current valorization procedures are often aimed at obtaining the proteins and/or CGA in a pure form which did not find industrial applications(Weisz, Schneider, Schweiggert, Kammerer, \& Carle, 2010), since, due to their high reactivity formation of complexes between the two is hardly avoidable.

Surprisingly the properties of protein-CGA complexes are unknown and therefore we will focus on them here. Since their formation is unavoidable in the confined space of a plant cell during processing and storage of plant material it is important to understand their properties in order to valorize them. To evaluate the protein-CGA complex properties we studied their formation mechanism by calorimetric and electrophoretic techniques and the impact of complexation on protein structure by spectroscopic techniques.

\subsection{Materials and methods}

\subsubsection{Materials}

Dehulled sunflower seeds were purchased from Notenstore (Bergschenhoek, The Netherlands). Chlorogenic acid (CGA), sodium dodecyl sulfate (SDS), Tris Base, Glycine, glycerol, bromophenol blue, 2-mercaptoethanol, 1-anilino-8-napthalensulfonate (ANS), sodium chloride, sodium hydroxide $(\mathrm{NaOH})$ were purchased from Sigma Aldrich (Sigma, USA). Dialysis cassettes (Slide-A-Lyzer ${ }^{\mathrm{TM}}$ Dialysis Cassette Kit, 10K MWCO, $12 \mathrm{~mL}$, ThermoFischer scientific, USA ) were used for equilibrium dialysis. In all the experiments MilliQ water was used.

\subsubsection{Methods}

Sunflower protein isolation. Sunflower protein isolate (SFPI) was obtained as described elsewhere(Karefyllakis, Altunkaya, Berton-Carabin, Van Der Goot, \& Nikiforidis, 2017). In short, sunflower seeds were milled and oil was extracted with hexane. Afterwards, phenols were removed by several washes with aqueous methanolic solutions $80 \% \mathrm{v} / \mathrm{v}$. After phenol removal, proteins were extracted at $\mathrm{pH} 9.0$ and dialyzed to increase their purity. Finally, the protein solution was spray-dried and SFPI ( $85 \mathrm{wt} \%)$ was obtained. Protein content was measured with DUMAS method (FlashEA 1112 NC Analyzer, Thermo Fisher Scientific, Germany). A conversion factor of 5.7 was used for all samples .

Covalent modification and sample preparation. $0.1 \mathrm{~g}$ of SFPI and different amounts (ranging from $0.005 \mathrm{~g}$ to $1 \mathrm{~g}$ ) of CGA were dissolved separately in $5 \mathrm{~mL}$ milliQ water and the $\mathrm{pH}$ was adjusted to $\mathrm{pH} 9.0$ with $1 \mathrm{M} \mathrm{NaOH}$ in both cases. The solutions were mixed $(10 \mathrm{~mL}$ final volume) and the $\mathrm{pH}$ was monitored and continuously readjusted to $\mathrm{pH} 9.0$ with $1 \mathrm{M} \mathrm{NaOH}$. The SFPI:CGA weight based ratios studied were 20:1, 10:1, 7:1, 5:1, 3:1, 2:1, 1:1, 1:5 and 1:10. The proteins and phenols were left to react for $24 \mathrm{~h}$ under continuous stirring at room 
temperature $\left(20^{\circ} \mathrm{C}\right)$, to induce oxidation. Dialysis was performed at room temperature using a membrane with a molecular cut-off of $10 \mathrm{kDa}$ to remove unbound phenols. Solutions were injected in dialysis cassettes and dialyzed against water for $24 \mathrm{~h}$ under continuous stirring with 6 renewals of dialysis liquid. For the reference proteins, the same procedures were applied however in the absence of CGA. Solutions with only CGA were dialyzed under the same conditions in order to allow for correction for the amount of phenol bound to the membrane.

Isothermal titration Calorimetry (ITC). Gibbs free energy changes, binding constants, and number of binding sites were established using ITC (MicroCal ITC200, GE Lifesciences, USA) at $20^{\circ} \mathrm{C}$. A SFPI solution of $0.1 \mathrm{mM}$ at $\mathrm{pH} 9.0$ was prepared and placed in a $200 \mu \mathrm{L}$ calorimeter sample cell. The reference cell contained only milliQ water. A CGA solution (10 mM, pH 9.0), was loaded into the injection syringe. Next, the protein solution was contacted with the CGA solution in 18 sequential injections of $1 \mu \mathrm{L}$ (time step of 180s) under constant stirring (100 rpm) and temperature $\left(20^{\circ} \mathrm{C}\right)$. As a control, milliQ water was titrated by $10 \mathrm{mM} \mathrm{CGA}$. For comparison (as discussed later) a similar set of experiments with the same concentrations and conditions, lysine was placed in the sample cell and was titrated by CGA at pH 7.0 and 9.0. Energy release presented in this paper refer to experimental measurements after subtraction of control CGA solution injected in milliQ water. ITC data were analyzed using the MicroCal ITC data analysis software and were presented as a plot of observed enthalpy change per mole of CGA $\left(\Delta \mathrm{H}_{\mathrm{obs}}, \mathrm{kcal} \mathrm{mol}^{-1}\right)$ against phenol-protein molar ratio. Equilibrium binding constants, heats of binding, and the stoichiometry of the complexation reaction were determined by nonlinear least-squares fitting for ITC data analysis.

Fluorescence spectroscopy. Fluorescence emission spectra were recorded from 300 to $540 \mathrm{~nm}$ (excited at $280 \mathrm{~nm}$ ) on a Fluorolog-3 spectrofluorometer (Horiba Scientific, USA) at $20^{\circ} \mathrm{C}$. The fluorescence emission spectrum of SFPI was also measured from 300 to $540 \mathrm{~nm}$ using excitation at $295 \mathrm{~nm}$ in order to identify and calculate the overlapping areas. Both the widths of the excitation and emission slit were set at $5 \mathrm{~nm}$. Each emission spectrum was the average of three runs.

Measurement of $U V$-vis absorbance. The UV-vis absorbance spectra of the protein-CGA complexes were recorded on a Cintra 4040 UV-vis spectrometer (GBC Scientific, Australia) from 200 to $500 \mathrm{~nm}$. Samples (SFPI:CGA 20:1, 10:1, 5:1, 2:1, 1:1, 1:2, 1:5, 1:10) were prepared as described above.

Circular Dichroism. The CD spectra were recorded using a CD spectropolarimeter J-715 (Jasco Inc., USA) under constant nitrogen flush. Far-UV (170-260nm) and near-UV (260-350nm) regions were studied. Path lengths were $0.1 \mathrm{~cm}$ for both far-UV and near UV-region. The ellipticity was recorded at a speed of $100 \mathrm{~nm} / \mathrm{min}, 0.2 \mathrm{~nm}$ resolution, 20 accumulations and 1 $\mathrm{nm}$ bandwidth. Protein concentration was kept constant $(0.1 \mathrm{mg} / \mathrm{mL})$, whilst varying phenol concentration (SFPI:CGA 20:1, 10:1, 5:1, 2:1, 1:1, 1:2, 1:5 for far-UV and 20:1, 10:1, 5:1 and $2: 1$ for near-UV). The protein secondary structure was calculated by an online CD structure prediction software (http://bestsel.elte.hu/). Samples were prepared as described above.

SDS-PAGE analysis. SFPI solutions of $5 \mathrm{mg} / \mathrm{mL}$ were prepared and mixed with reducing buffer at $\mathrm{pH} 6.8$ prepared with glycerol, Tris- $\mathrm{HCl} 0.5 \mathrm{M}, \mathrm{BPB} 0.5 \%(\mathrm{w} / \mathrm{v}), \mathrm{SDS} 10 \%(\mathrm{w} / \mathrm{v}), 2-$ 
Mercapethanol and deionized water. The samples were vortex mixed and then heated at $95^{\circ} \mathrm{C}$ for 10 minutes. After that, $8 \mu$ of SDS-PAGE marker were filled (broad range, Mw 202.2326.014 ) and 20-30 $\mu \mathrm{l}$ of sample was loaded to the gel pockets. The running buffer contained Tris Base, glycine, and SDS at pH 8.3. The electrophoresis was performed at $200 \mathrm{~V}$ for around 40 minutes in a Mini-Protean II electrophoresis cell (Bio-rad, Veenendaal, Netherlands) according to the manufacturer's instructions. After electrophoresis, the gels were stained for one hour using Bio-Safe Coomassie Blue (Bio-rad, Veenendaal, Netherlands). For de-staining, gels were washed overnight using Milli-Q water. All measurements were performed in triplicate.

High- performance liquid chromatography (HPLC). High-performance liquid chromatography was used for the quantification of CGA solutions obtained after dialysis. A Dionex Ultimate 3000 chromatograph (Thermo Scientific, USA) was used with a phenol column Phenomenex Gemini $3 \mathrm{u} \mathrm{C} 18$ at $30^{\circ} \mathrm{C}$. The column was eluted with $30 \%$ Acetonitrile in Milli-Q water and $0.1 \%$ Trifluoroacetic acid at a flow rate of $0.75 \mathrm{ml} / \mathrm{min}$. CGA was identified with corresponding standard compounds and was quantified on the basis of peak areas of the unknowns with those of pure standard (CGA). Detection and external calibration was conducted at $324 \mathrm{~nm}$.

Fourier transformed infrared spectroscopy (FTIR). The infrared spectra of samples were measured using a Tensor 27 Fourier transform spectrophotometer (Bruker, USA). Interferograms were accumulated over the spectral range $4000-500 \mathrm{~cm}^{-1}$, with a resolution of $4 \mathrm{~cm}^{-1}$. For each measurement, 11 scans were taken. The samples analyzed, which were freezedried prior to the measurement, were SFPI, and SFPI:CGA complexes 20:1, 1:1 and 1:10.

Surface hydrophobicity. A Fluorolog-3 spectrofluorometer (Horiba Scientific, USA) using excitation at $390 \mathrm{~nm}$ (slit of $5 \mathrm{~nm}$ ) and emission between 400 and $750 \mathrm{~nm}$ (slit of 5nm)was used to measure 1-anilino-8-napthalensulfonate (ANS), fluorescence intensity. The spectrum obtained was directly correlated with the surface hydrophobicity of SFPI before and after covalent attachment of chlorogenic acid since e.g. more hydrophobic sites result in increased binding of ANS thus higher intensity.

\subsection{Results and discussion}

\subsubsection{Physicochemical characterization of complexation}

Preparation of covalent SFPI-CGA complexes. To investigate the extent of complexation reaction between SFPI and CGA together with the influence of CGA concentration, SFPI was obtained and mixed at reactive conditions $(\mathrm{pH} 9)$ with different amounts of CGA. The SFPI:CGA ratios ranged from values relevant for the ones found in nature, e.g. sunflower seed cells, and above. As a first step of monitoring the attachment of CGA on protein molecules, the contents of free amino and thiol groups were determined. It is known that CGA oxidizes to reactive quinones which then react with nucleophilic groups such as amino and sulfhydryl groups forming covalent bonds. Both the contents of free amino and sulfhydryl groups decreased after complexation when compared with the initial amounts of these groups 
quantified for the unmodified protein. Since these methods provide only an indication about the occurrence of the reaction but do not estimate the overall number of phenols bound on protein, equilibrium dialysis was performed so that both bound and non-bound phenols would be measured. The SFPI:CGA weight ratios and pictures of their solutions are presented in Table 3.1. All samples changed color directly upon mixing. The color appeared as light green at 20:1 SFPI:CGA ratio and became darker upon increasing the amount of CGA. A solution containing only CGA became brown indicating interactions among phenols and formation of polymeric brown pigments(Namiki, Yabuta, Koizumi, \& YANo, 2001) since from the moment quinones interact with each other, brown polymerization complexes are formed but in the presence of proteins, quinones bind on them covalently giving rise to green derivatives (Bongartz, et al., 2016). Therefore green colouration serves an additional indication of covalent complexation.

Table 3.1 : Amount and percentage of bound CGA and color of solutions for different SFPI:CGA ratios.

\begin{tabular}{|c|c|}
\hline $\begin{array}{l}\text { SFPI:CGA } \\
\text { weight ratios }\end{array}$ & $\begin{array}{l}m g \text { of bound CGA/mg } \\
\text { of protein }\end{array}$ \\
\hline
\end{tabular}

\begin{tabular}{lll}
\hline $20: 1$ & 0.02 & \\
& & \\
\hline $1: 1$ & 0.40 & \\
& & \\
\hline $1: 10$ & 3.18 &
\end{tabular}

The data presented in Table 3.1 show the amount of CGA bound per protein, calculated after deduction of dialysed unbound CGA from the initial amount added. The amount of CGA bound per protein increased as more phenols were added to react with constant amount of proteins. This means that the bonding capacity is dependent on the concentration of CGA used. A similar concentration dependent complexation was reported for mixtures of CGA and soy glycinin(Ali, Homann, Khalil, Kruse, \& Rawel, 2013). To summarize, complexation results in coloured complexes and increasing amounts of phenol lead to more bonding.

Isothermal Titration Calorimetry (ITC). The nature of bonding between 2 molecules can be revealed by the amount of released or absorbed energy. Therefore, ITC analysis was applied to investigate the Gibbs free energy changes upon mixing of SFPI with CGA. At increased alkaline $\mathrm{pH}$, CGA oxidizes, which subsequently bind covalently to proteins, giving larger thermal effect(Prigent, Voragen, Visser, van Koningsveld, \& Gruppen, 2007). In contrast, at neutral $\mathrm{pH}$, the interactions that govern protein-CGA complexation are mainly noncovalent(Prigent, et al., 2003). The latter form of interactions holds less energy than covalent 
interactions (resulting in smaller thermal effects)(Sastry \& Rao, 1990). To investigate whether primarily covalent rather than non-covalent complexation occurs, the interactions among CGA and lysine (Lys) were studied since, as mentioned above, the $\varepsilon$-amino group of this amino acid is one of the preferred binding sites for covalent attachment of CGA in proteins(Sosulski, 1979). Figure 3.2 displays the measured heat flows for the reaction of Lys with CGA at neutral and alkaline $\mathrm{pH}$ values ( 7 and 9 respectively). And the top part of Figure 3.2 refers to the reaction between CGA and SFPI as function of CGA:SFPI ratio. In addition, the bottom part of the figure shows the heat of reaction (calculated from the heat flows) as function of CGA:SFPI ratio.

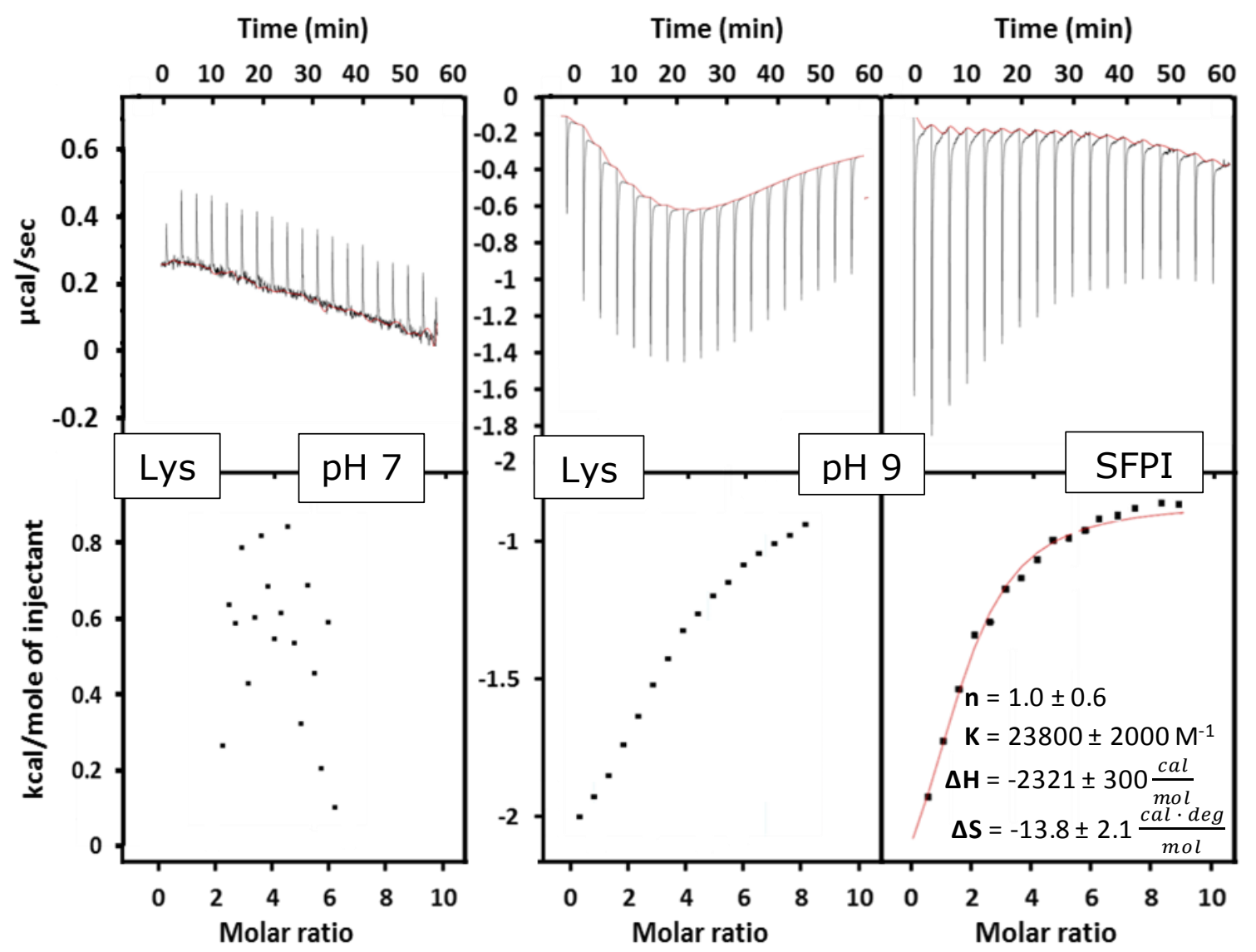

Figure 3.2 : Isothermal Titration Calorimetry data of lysine and SFPI $(0.1 \mathrm{mM})$ titrated by CGA $(10 \mathrm{mM})$; molar enthalpy $(\Delta \mathrm{H}, \mathrm{kcal} / \mathrm{mol})$ against the molar ratio of the total CGA to SFPI, after subtracting the control experiments. Above them, plots of observed enthalpy change in time.

The left side of Figure 3.2 shows that at $\mathrm{pH} 7.0$, the reaction between Lys and CGA is endothermic (positive observed enthalpy) with small amounts of energy absorbed (small peaks) and scattered reaction curve. When Lys and CGA reacted at $\mathrm{pH} 9.0$ the reaction is exothermic (negative observed enthalpy), more energy is released (bigger peaks) and there is a well-defined reaction curve, showing that there are pronounced differences among Lys-CGA complexation depending the $\mathrm{pH}$. When calculating the reaction enthalpy at $\mathrm{pH} 7.0$ low and scattered values were found. At pH 9.0 the reaction Lys-CGA was exothermic and the amounts of energy released were notably bigger. When CGA reacted with protein a similar profile was observed 
as that for Lys-CGA at $\mathrm{pH}$ 9. This clearly suggests Lys is reacting with CGA under alkaline conditions covalently and that the same holds for SFPI. In order to clarify this further, the thermodynamic parameters of SFPI-CGA binding were determined. From the heat flows of SFPI-CGA complexation the number of binding sites per protein molecule $(n)$, binding constant $(K)$, enthalpy change $(\Delta H)$ and entropy change $(\Delta S)$ were calculated (Figure 3.2, right low corner).

The complexation of SFPI-CGA was associated with a notable exothermic enthalpy change, suggesting a strong bonding of the compounds. The entropic term of the interaction was negative in all measurements, indicating an increase in molecular order, which was expected when two molecules react together to one. Approximately, one binding/reaction site per protein was calculated $(n=1.0 \pm 0.6)$ with a binding constant $K=23800 \pm 2000 \mathrm{M}^{-1}$. Negative enthalpic and entropic terms have also been reported after experiments with ITC between SFPI and CGA at $\mathrm{pH}$ 7, although of much smaller magnitude, which can be attributed to weaker complexation, hydrogen bonding in that case. (Karefyllakis, et al., 2017). Moreover, in this study no binding constants were published due to high standard deviations however all the estimated values were at least one order of magnitude smaller. These differences in the magnitude of released energy and binding constants demonstrate once more the covalent nature of SFPI-CGA bonding and how this differs in strength when compared with non-covalent complexation. The binding constants between $\beta$-lactoglobulin and tea polyphenols, where complexation is governed by non-covalent interactions, were reported to be also one order of magnitude smaller from the ones found here(Kanakis, et al., 2011).

Particle or Molecular size modifications. In order to monitor the complexation of molecules and changes in particle size distribution, Dynamic Light Scattering measurements (DLS) were performed. With the aid of DLS, the assembling of SFPI-CGA complexes can be identified only in the event of extensive development of linking of proteins, possibly via crosslinks of CGA, which results in larger sizes compared to the original protein. Despite the fact that in principle valuable information could be derived when studying the development of noncovalent sunflower protein-CGA complexes(Karefyllakis, et al., 2017), no clear information on the potential crosslinking and the complex size could be obtained for covalent SFPI-CGA complexation (data not shown). These measurements were performed directly after mixing SFPI-CGA and without the elimination of unbound CGA, which could participate in noncovalent complexation. Non-covalent bonds are weaker, less specific and easier to occur compared to covalent bonds that require a more specific stereochemistry(Desiraju \& Steiner, 2001). It was therefore hypothesized that those complexes based on non-covalent bonding would be created faster and would mask the presence of covalent complexes during DLS measurements. In addition, in the highly probable case of simple CGA attachment on the protein with negligible cross-link formation, no notable difference in size would be detected due to the small molecular size of CGA. In conclusion, masking of covalent complexes by the noncovalent ones and absence of widespread cross-linking could be the reasons that DLS measurements did not provide valuable findings. 
Since DLS measurements did not lead to clear conclusions on the size of the complexes, electrophoresis was used to determine those sizes. The electrophoretic analysis was performed under the presence of a detergent (SDS) which disrupts hydrogen bonds and reducing conditions ( $\beta$-mercaptoethanol) where disulfide bonds are expected to be cleaved but not the rest of the covalent bonds(Hames, 1998). In Figure 3.3, images of the electrophoresis gels of pure protein (P) and of SFPI:CGA ratios 20:1 (1), 10:1 (2) and 1:1 (3) are presented. The majority of the bands appear at sizes up to $50 \mathrm{KDa}$ and are similar to SDS-PAGE patterns usually observed in protein isolates from sunflower seeds(Dalgalarrondo, Raymond, \& Azanza, 1985), thus we concluded that they are related to the profile of sunflower proteins. Under conditions of alkaline complexation (lanes 2 and 3), there is an intriguing appearance of material with a high molecular weight $(>250 \mathrm{kDa})$ which are most likely polymers when higher concentrations of phenols were used. The high molecular weight complexes were not separated by the use of SDS or mercaptoethanol, suggesting that the bonds formed between the molecules are of covalent nature. This observation not only confirms complexation but also indicates protein crosslinking mediated by CGA molecules. Similar results were reported while monitoring cross-linking of soy protein with oxidized CGA under alkaline conditions(Insaward, Duangmal, \& Mahawanich, 2014) and when CGA was applied as a cross-linker for the production of myofibrillar protein polymers(Cao \& Xiong, 2015) testifying the tendency of this phenol to form crosslinks.

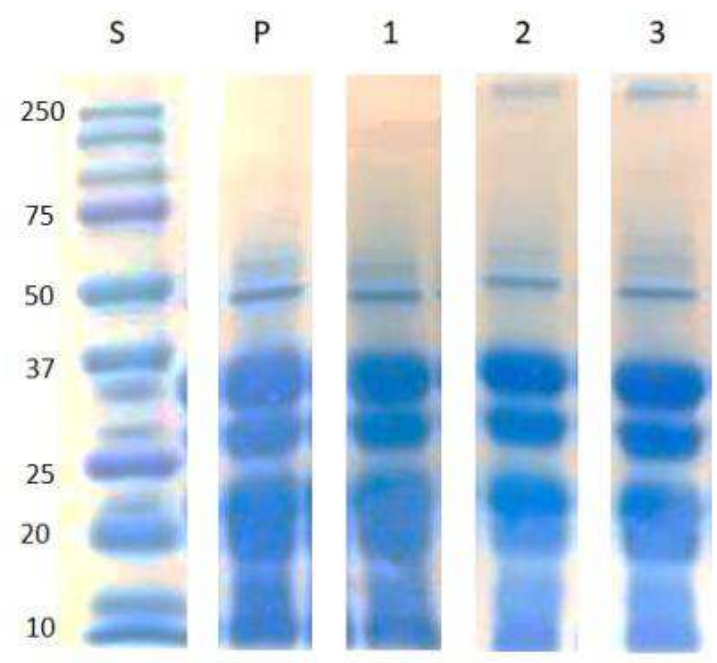

Figure 3.3 : The SDS-PAGE pattern of SFPI and SFPI-CGA derivatives. Molecular weight standard (S), SFPI (P), SFPI:CGA weight ratio 20:1 (1), 10:1 (2), 1:1 (3).

Changes in $U V$-vis absorbance. It is known that aromatic aminoacids absorb UV-vis light. Therefore UV-vis absorption spectroscopy was used to monitor changes in the amino acids during complexation with CGA. The absorbance over 200-500 nm is shown in Figure 3.4. The spectrum of control protein, represented by the dashed line shows that there is a broad maximum absorbance peak at $280 \mathrm{~nm}$, which can be attributed to tryptophan and tyrosine residues of protein. Pure CGA showed an absorbance peak at $324 \mathrm{~nm}$, represented by the dotted line, which is in agreement with what is known from literature(Narváez-Cuenca, Vincken, \& Gruppen, 2013). The continuous lines represent the SFPI-CGA complexes at different ratios starting from 
20:1 (lower continuous line) and increasing up to 1:10 (upper continuous line). As it is presented in Figure 3.4, the absorbance of the protein molecules was affected by the presence of CGA. The lowest concentration CGA did not give rise to absorbance increase, but when larger amounts of CGA have used the overall absorbance increases substantially and a very distinct shoulder appeared at $324 \mathrm{~nm}$ (following the direction of the blue arrow on the graph).

Covalent modification of lactoferrin with CGA at same $\mathrm{pH}(\mathrm{pH} 9)$ showed a similar increase in overall absorbance of protein, accompanied by the appearance of a shoulder at $324 \mathrm{~nm}$ (Liu, Sun, Wang, Yuan, \& Gao, 2015), thus it can be concluded that the increasing number of bound phenolic molecules lies behind this peak since the unbound phenols were removed by dialysis. To exclude the possibility of absorbance increase due to attached polymerization products of CGA oxidation, the UV-Vis spectra of CGA was recorded both at $\mathrm{pH} 7$ (where it is not oxidized) and $\mathrm{pH} 9$ (where oxidation is expected). However no notable differences were observed. Alternatively, the overall increase in absorbance could be attributed to rearrangements of peptide chains after extensive complexation. It is probable that covalent attachment of CGA on protein leads to the exposure of tryptophan and tyrosine molecules, previously buried within the structure indicating structural modifications. Although this extra exposure becomes apparent from the second lowest SFPI:CGA ratio (second continuous line from bellow in Figure 3.4), the CGA shoulder, which demonstrates complexation, only emerges afterward. Since complexation has been already showcased for the lowest concentration (first row of Table 3.1), it could be assumed that the first CGA molecules bind covalently in protein cavities that mask their absorbance. In summary, apart from the illustration of SFPI-CGA complexation through UV-vis results it became clear that rearrangements of polypeptide chains led to the exposure of previously buried tryptophan residues.

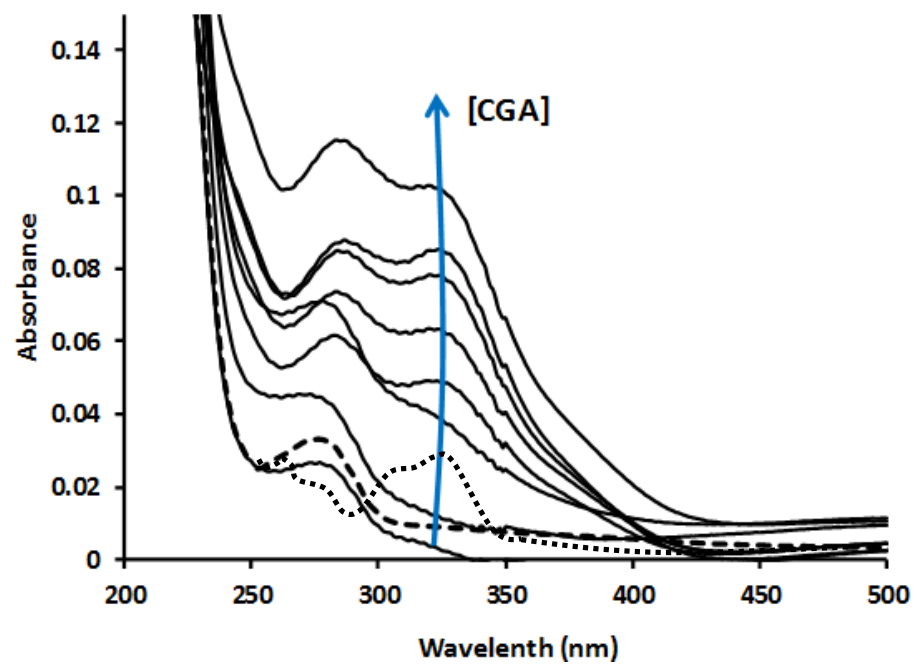

Figure 3.4 : UV-vis spectra of SFPI (dashed line), CGA (dotted line) and SFPI-CGA complexes of SFPI:CGA ratios 20:1, 10:1, 5:1, 2:1, 1:1, 1:2, 1:5 and 1:10 (continuous lines from bottom to top). 


\subsubsection{Structural characterization of complexes}

\section{Impact on secondary structure}

Far-UV CD spectra analysis. When protein-phenol complexes are formed, the intramolecular forces responsible for maintaining the secondary and tertiary structures can be altered, resulting in conformational changes in proteins. Circular dichroism (CD) spectroscopy is a valuable method to perceive structural changes after molecular complexation. The changes at near-UV and far-UV spectra were recorded for different CGA concentrations in order to reveal the changes in both secondary and in tertiary structure respectively. The spectra of the complexes were omitted since they were overlapping and it was preferred to show the impact on the specific secondary structural elements. After recording the far-UV spectrum from 190 to 260 $\mathrm{nm}$, the data obtained were analyzed(http://bestsel.elte.hu/) and the alterations in secondary structural elements are presented in Table 3.2. The percentages of structural elements ( $\alpha$-helices and $\beta$-sheets) are given in that table together with the unordered domains and turn in relation to SFPI:CGA ratio.

Table 3.2 : SFPI secondary structure composition for different SFPI:CGA ratios.

\begin{tabular}{ccccc}
\hline $\begin{array}{c}\text { Sample } \\
\text { SFPI:CGA }\end{array}$ & $\alpha$-helix & $\beta$-sheet & Turn & Unordered \\
\hline \hline $1: 0$ & 37.5 & 34.4 & 14.8 & 13 \\
$20: 1$ & 13.9 & 27 & 17.5 & 41.5 \\
$10: 1$ & 7.6 & 32.4 & 20.4 & 39.5 \\
$5: 1$ & 7.3 & 29.3 & 19.6 & 43.7 \\
$2: 1$ & 5.6 & 33.8 & 18.8 & 41.9 \\
$1: 1$ & 13.3 & 29 & 18 & 39.7 \\
$1: 2$ & 9 & 33.1 & 16.7 & 41.1 \\
$1: 5$ & 11.2 & 29.2 & 17.5 & 42.1 \\
\hline
\end{tabular}

The estimation of secondary structures showed that SFPI contained 37.5\% $\alpha$-helix, $34.4 \% \beta$ sheet, $14.4 \%$ turn, and $13.0 \%$ unordered components. The fact that sunflower proteins mainly consist of $\alpha$-helical structures has been previously reported although no $\beta$-sheets were detected in that case(González-Pérez, et al., 2004). Based on the data presented in Table 3.2, the protein conformational analysis suggests that protein complexation with CGA resulted in considerable changes in secondary structure, evidently destructuring the protein. Complexation is accompanied by a decrease in the percentage of $\alpha$-helices and $\beta$-sheets, with an increase in the number of unordered structures. The detected losses were more pronounced for $\alpha$-helices in all occasions. Unordered fractions increased irrespective of the CGA concentration compared to unmodified protein. After a significant increase for the smallest SFPI:CGA ratio there was no direct correlation between the percentage of unordered structure and the amounts of CGA bound at higher CGA concentrations. The destructuring effect of CGA on proteins has also been demonstrated after complexation with bovine serum albumin(Rawel, Rohn, Kruse, \& 
Kroll, 2002) where it resulted in a decrease in $\alpha$-helix with a parallel increase of unordered structures.

Fourier Transform Infra-Red (FTIR) analysis. FTIR spectroscopy is a sensitive technique to monitor environmental changes in several peptide chain bonds (e.g. $\mathrm{C}=\mathrm{O}, \mathrm{C}-\mathrm{N}, \mathrm{N}-\mathrm{H}$ ) which participate in the stabilization of protein secondary structure. Therefore any modifications of secondary structure after complexation with phenol are easily detectable with this technique. FTIR spectra of unmodified SFPI and SFPI:CGA 20:1 conjugate are presented in Figure 3.5 as curves of absorbance over wavenumber (the spectra of the other ratios were omitted since they were similar to that of SFPI:CGA 20:1 and the same was done for the CGA spectra for the reason that no notable peaks were detected since there no nitrogen present in CGA).

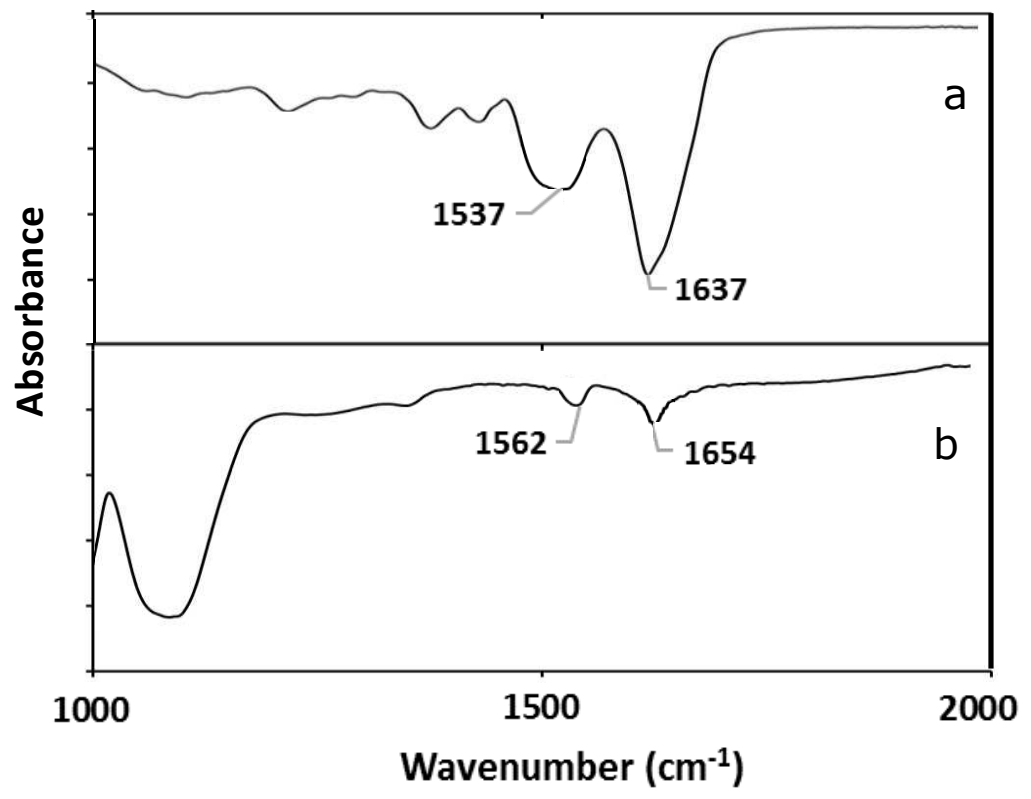

Figure 3.5 : Representative FTIR spectra of SFPI (a) and SFPI:CGA ratio 20:1 (b).

Figure 3.5a displays the IR spectrum of SFPI. Two important peaks are visible (and discussed before in literature, see below) i.e. at $1637 \mathrm{~cm}^{-1}$ and at $1537 \mathrm{~cm}^{-1}$. After alkaline derivatization with CGA (Figure 3.5b), the aforementioned peaks shifted to higher wavenumbers $\left(1654 \mathrm{~cm}^{-1}\right.$ and $1562 \mathrm{~cm}^{-1}$ ) and their intensity decreased substantially.

In general, infrared spectra of proteins feature various amide bands and each of them represents distinct vibrations of peptide moieties. Amide I band (1600-1700 $\mathrm{cm}^{-1}$, mainly $\mathrm{C}=\mathrm{O}$ stretch) and amide II band (1500-1600 $\mathrm{cm}^{-1}, \mathrm{C}-\mathrm{N}$ stretch coupled with $\mathrm{N}-\mathrm{H}$ bending mode) are among the amide bands mostly associated with the secondary structure of protein and the peaks represented by amide I and amide II are generally ascribed to $\alpha$-helices (Barth, 2007).

The intensity decrease in both amide I and II bands clearly demonstrate conformational changes in proteins, more specifically reduction of $\alpha$-helical structures(Beauchemin, et al., 2007). The disappearance of the peak representing amide III band can be assigned to a reduction in $\beta$-sheet percentages which is consistent with studies on human serum albumin and CGA(Kang, et al., 2004). A similar decrease in the intensity of amide I band accompanied by reduction of $\alpha$ - 
helices have also been reported for casein-EGCG complexes(Hasni, et al., 2011). In conclusion, FTIR results are in agreement with the results obtained from $\mathrm{CD}$, as they both conclude the alteration of the secondary structure with decrease of $\alpha$-helical structures as a consequence of covalent complexation of sunflower proteins with CGA.

\section{Impact on tertiary structure}

Fluorescence spectra of SFPI-CGA complexes. Intrinsic tryptophan fluorescence is highly sensitive to polarity variations of tryptophan microenvironment and is thus a suitable technique to evaluate conformational changes in the tertiary structure of proteins upon phenol association(Soares, Mateus, \& De Freitas, 2007). The fluorescence intensity in the range of $300-500 \mathrm{~nm}$ of SFPI (dashed line) and SFPI:CGA complexes is presented in Figure 3.6. The emission of all complexes was lower than the one of pure protein and the decrease was more significant with increasing amount of CGA added. This can be explained by a higher exposure of tryptophan residues, due to unfolding of the protein, with increasing CGA concentration. When proteins are in their native state, tryptophan residues are generally located within the hydrophobic protein core, bearing a high quantum yield and thus a high fluorescence intensity. In case of partial or total unfolding of proteins, tryptophans become exposed to the hydrophilic solvent giving a reduction of fluorescence intensity(Eftink, 2006). Besides the exposure of tryptophan, the presence of polar CGA around tryptophan residues would further decrease the hydrophobic environment, hence the fluorescence intensity. Similar conclusions were drawn for the lactoferrin-CGA complexes(Liu, Sun, Yang, Yuan, \& Gao, 2015).

The weakening of fluorescence intensity, called fluorescence quenching is usually classified as either dynamic or static. Static quenching is described as the decrease in intensity due to complex formation between the quencher and the fluorophore, while dynamic quenching occurs upon collision of the quencher and the fluorophore during the excitation process (Eftink, 2006). As in the case of SFPI-CGA reaction, a complex is formed, static quenching mechanism is assumed. Based on that assumption the number of binding sites per protein molecule $(n)$ and the binding constant $\left(K_{A}\right)$ can be obtained using the modified Stern-Volmer equation (Froehlich, Mandeville, Jennings, Sedaghat-Herati, \& Tajmir-Riahi, 2009):

$$
\log \left(\frac{F_{0}-F}{F}\right)=\log K_{A}+n \log [Q]
$$

(Equation 1)

where $F_{o}$ and $F$ stand for the fluorescence intensities of unmodified protein and the samples after CGA addition respectively and $[Q]$ is the concentration of quencher, in this case, CGA. Through the fitting model of the linear regression of this equation (Figure 3.6, inset), $\mathrm{K}_{\mathrm{A}}$ and $\mathrm{n}$ can be determined as the intercept and the slope respectively. Less than one binding site per protein molecule was calculated $(n=0.65 \pm 0.14)$ with a binding constant $\mathrm{K}_{\mathrm{A}}=24000 \pm 9000 \mathrm{M}^{-}$ 1. These values of $\mathrm{K}_{\mathrm{A}}$ and $\mathrm{n}$ are similar to the ones found with ITC and in line with those observed for complexes of human serum albumin with CGA (Kang, et al., 2004) showing that covalent complexation of CGA among different types of proteins occurs in a similar way. 


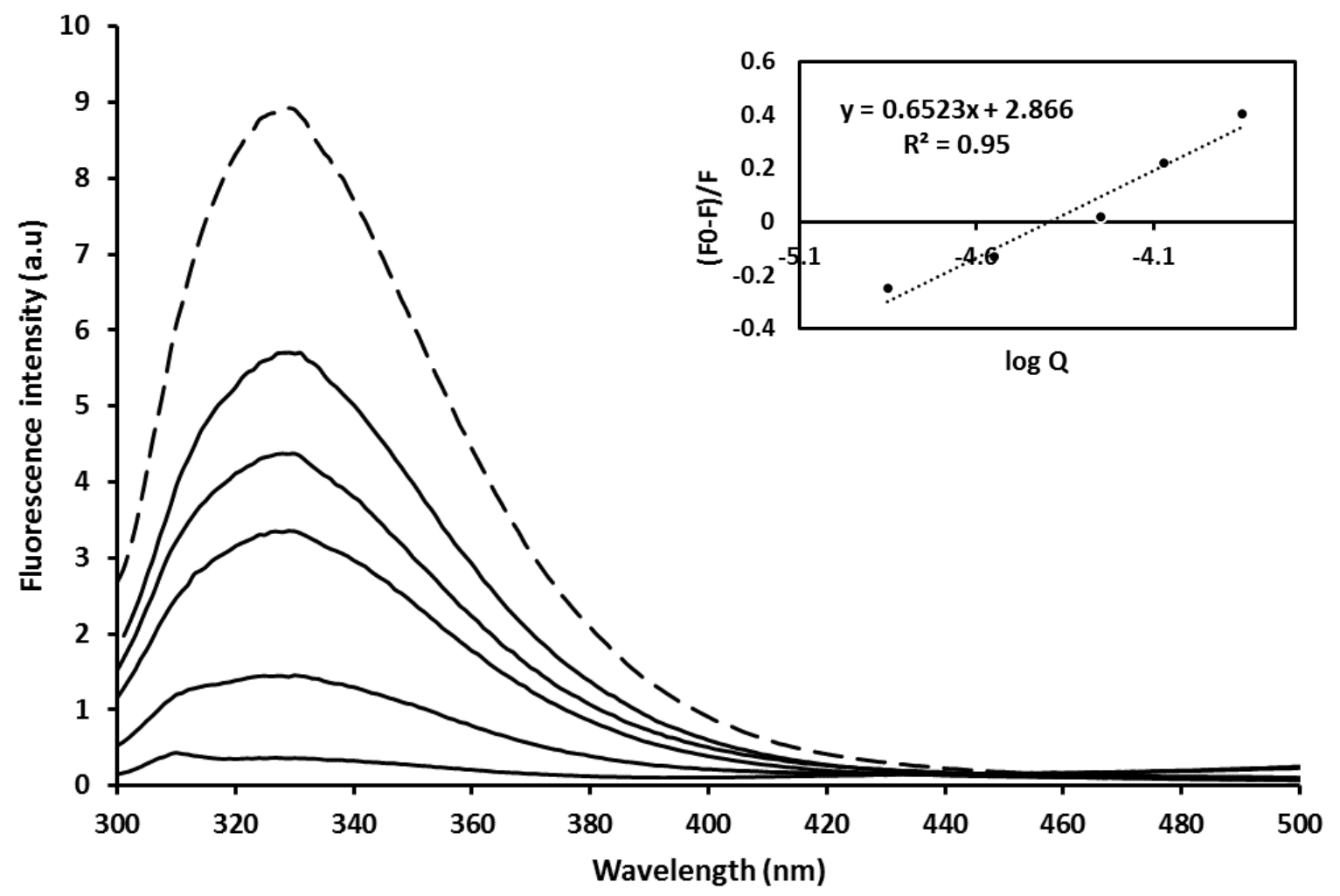

Figure 3.6 : Fluorescence emission spectra of SFPI (dashed line) and SFPI:CGA ratios 20:1, $10: 1,5: 1,2: 1$ and $1: 1$ (continuous lines from up to down). The inset shows the plot of modified Stern-Volmer equation.

Surface hydrophobicity. Changes in conformation and in the intra- and intermolecular interactions, particularly at the protein surface, can modify protein hydrophobicity which plays an important role in the solubility and interfacial properties of proteins(Feeney \& Whitaker, 1982). Additionally, protein conformational changes can lead to the exposure of hydrophobic domains(Gerbanowski, Malabat, Rabiller, \& Gueguen, 1999). By measuring the signal of a fluorescent compound, 1-anilino-8-naphthalensulfonate (ANS), that binds to the hydrophobic pockets the concentration of exposed hydrophobic pockets can be determined.

Figure 3.7 shows the ANS fluorescence emission spectra of the complexes as function of the wavelength in the range 400-700 $\mathrm{nm}$. Clearly, the intensity of the fluorescence signal increases when CGA was added to SFPI. This means adding CGA results in the exposure of more hydrophobic pockets. In another study with CGA, a partial destructuring of myofibrillar protein after complexation with CGA was also documented by applying hydrophobicity measurements(Cao, et al., 2015). Surprisingly, the highest fluorescence i.e. the highest hydrophobicity was observed at the lowest SFPI:CGA ratio (upper continuous line in figure 3.7). This is followed by a continuous decrease of the fluorescence signal with an increase in CGA concentration (blue arrow figure 3.7). Apparently, additional complexation of phenols results in partial restoration of hydrophilicity levels (blue arrow in graph). The fact that hydrophobicity decreases as more CGA binds on protein could be attributed to the polar nature 
of this phenolic compound bearing plenty hydroxyl groups on interfacial binding sites. After the completion of tertiary structure modifications, CGA bonding continues at the already available or at the newly exposed binding sites on protein surface which decreases the hydrophobicity again since a polar molecule is bound to the protein. A similar trend has been reported for the modification of proteins with increasing amounts of epigalo catechin galate (EGCG), a widely used polar phenol from green tea(Wei, Yang, Fan, Yuan, \& Gao, 2015).

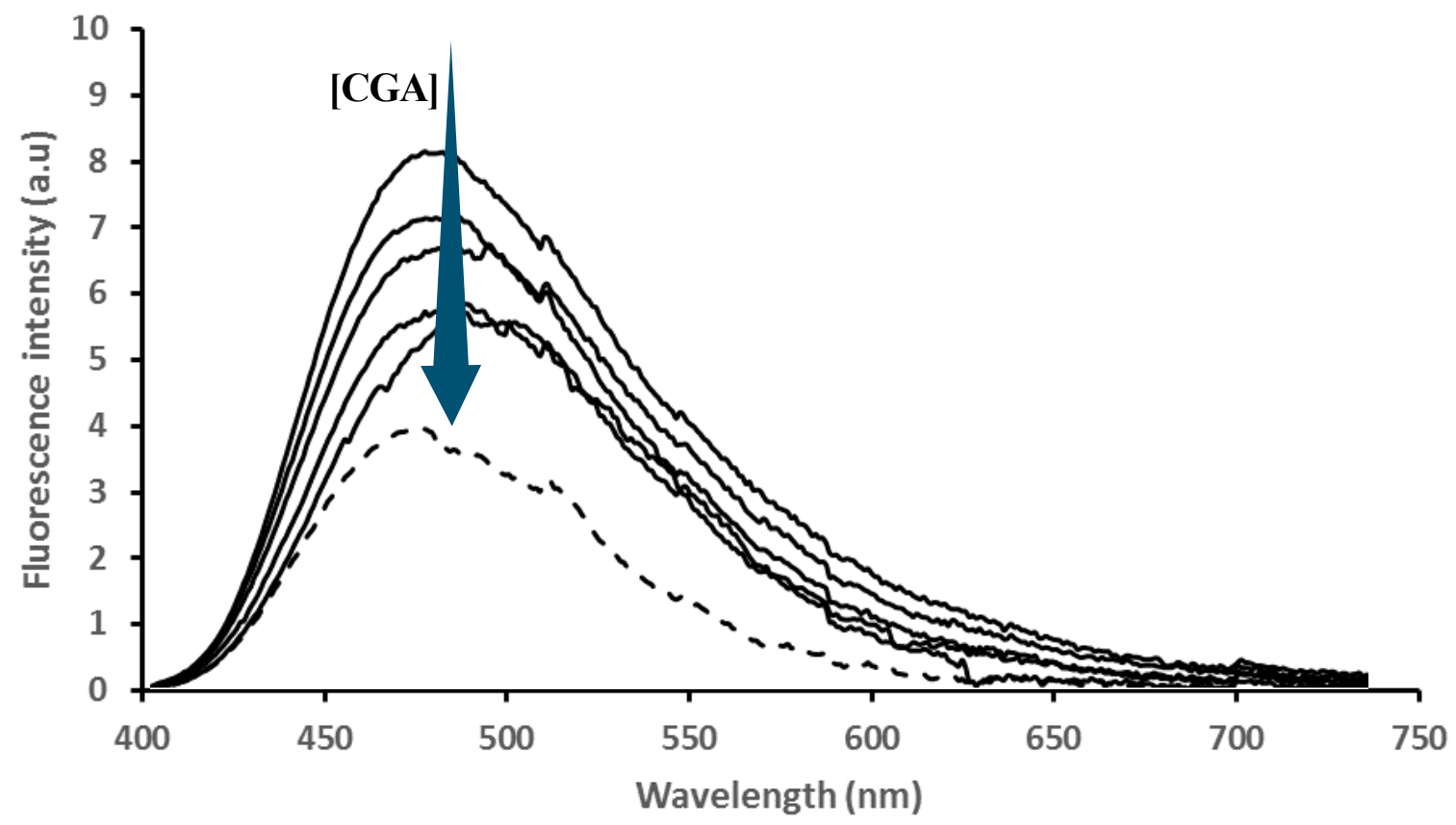

Figure 3.7 : ANS fluorescence of SFPI (dashed line) and SFPI:CGA ratios (from 20:1, 10:1, $5: 1,2: 1$ to $1: 1$ on the direction of the arrow).

Near-UV CD spectra analysis. Near-UV spectra were recorded to reveal the changes in tertiary structure of SFPI. The signals obtained from $260 \mathrm{~nm}$ to $310 \mathrm{~nm}$ are due to the absorption, dipole orientation and the nature of the surrounding environment of the phenylalanine, tyrosine, cysteine (or S-S disulfide bridges) and tryptophan amino acids. Signal alterations can be utilized to monitor microenvironmental and conformational changes of proteins. The molar ellipticity in the range of 260-310 nm is shown in Figure 3.8 for samples with different SFPI:CGA ratios. SFPI presents a maximum at $285 \mathrm{~nm}$ and a shoulder at $292 \mathrm{~nm}$ which are tyrosine and tryptophan contributions respectively(Kelly, Jess, \& Price, 2005). These spectra are in agreement with other near-UV spectra of sunflower proteins in literature(González-Pérez, et al., 2004).

When CGA is added in increasing amounts the molar ellipticity increased compared to that of the SFPI. This can be explained by rearrangements of the polypeptide chains. In analogy with the above-discussed changes in UV-spectra, it appears that amino acids like tyrosine and tryptophan become more exposed after complexation. Protein tertiary structure is modified and amino acids which were previously positioned away from protein surface get relocated in less hidden environment. This indicates that complexation resulted in substantial perturbation of the tertiary structure and to a certain extent unfolding of proteins. In a recent study, alkaline 
derivatization of $\beta$-lactoglobulin with CGA resulted in a pronounced increase of molar ellipticity which agrees with the findings here that complexation with CGA is accompanied by significant tertiary structure modifications in proteins. The near-CD findings presented here emphasize the alterations induced by CGA covalent complexation on tertiary structure and the corresponding rearrangement of the initial protein conformation and are in ample agreement with UV-vis, fluorescence spectroscopy, and hydrophobicity results. Complexation of CGA with SFPI at concentrations that exist in their native confined environment led to a remarkable unfolding of sunflower proteins, indicating a considerable impact on protein tertiary structure after covalent bonding between phenols and aminoacid moieties.

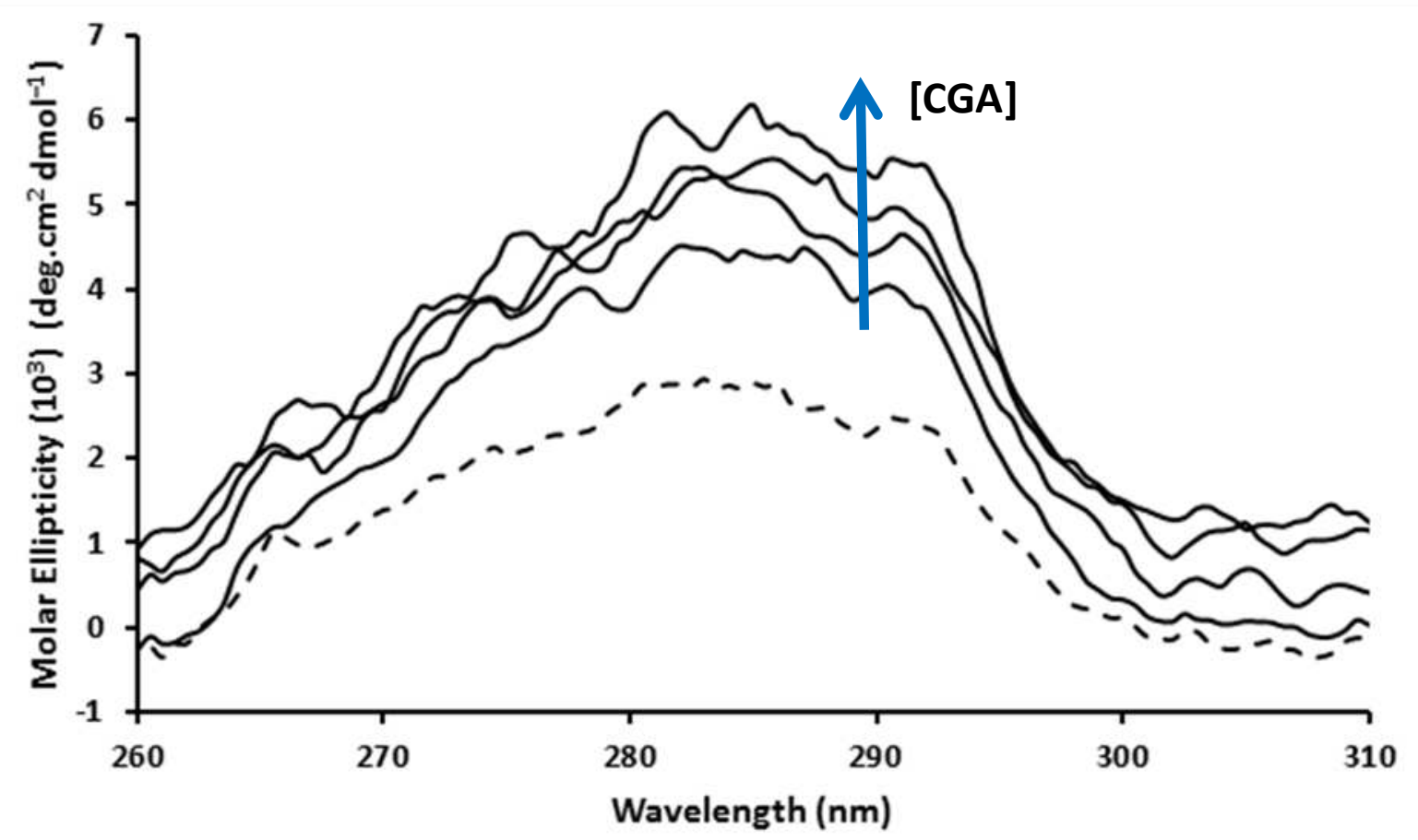

Figure 3.8 : Near UV CD spectra of SFPI (dashed line) and SFPI:CGA ratios 20:1, 10:1, 5:1 and 2:1 (continuous lines towards the direction of the arrow).

Combining complexation analyses. To summarize the overall findings, when SFPI and CGA are mixed at $\mathrm{pH} 9$ covalent complexation readily occurs. Both organoleptic and structural properties of the proteins are modified to a great extent. This already occurs at the low concentration of CGA which is similar to that occurring in the confined spaces of sunflower seed cells.

Especially during oil extraction, oil is driven out of the cell proteins and phenols are pressurized and get confined even more which brings them in closer contact facilitating complexation. In addition, the concentration of phenols is not constant inside the cell and local variations of CGA concentrations are possible. Thus the presence of phenols around proteins is expected to increase throughout processing. Therefore we, not only studied the natural SFPI:CGA ratios but also higher ratios. 
Complexation with CGA led to a remarkable unfolding of sunflower proteins with a significant loss of structural elements like $\alpha$-helices and $\beta$-sheets and had a considerable impact on protein tertiary structure. Since the structure of proteins and complexes differ significantly it can be assumed that several other protein functionalities might be modified as well. All in all, these findings are a bottom line for the utilization of proteins and phenols from plant tissues since complexes can easily develop leading to drastically different structures than the original protein. Since complex formation cannot be avoided, complexes could be potentially regarded as a separate class of ingredients.

\subsection{Conclusions}

Sunflower protein isolate (SFPI) was complexed with pure chlorogenic acid (CGA) at pH 9 with constant SFPI and increasing CGA concentration. Protein and phenols formed colored covalent complexes whose extend was dependent on the amount of CGA used. Complexation resulted in cross-link formation and had a notable impact on secondary and tertiary structure of proteins.

Protein structure modifications resulted in exposure of amino acids which were previously buried inside the protein structure but also in alterations of hydrophobicity profile of protein surface. These findings could be considered a step forward towards the deeper understanding of covalent protein-phenol complexation in confined environments like plant tissues. Since covalent complexation cannot be excluded in these environments, due to harsh processing or high phenol concentrations, the formation of complexes should be considered when utilization of proteins and phenols is attempted.

\section{Acknowledgments}

This work took place within the framework of the Institute for Sustainable Process technology (ISPT) 


\section{References}

Ali, M., Homann, T., Khalil, M., Kruse, H.-P., \& Rawel, H. (2013). Milk whey protein modification by coffee-specific phenolics: effect on structural and functional properties. Journal of Agricultural and Food Chemistry, 61(28), 6911-6920.

Alves, N., \& Mano, J. (2008). Chitosan derivatives obtained by chemical modifications for biomedical and environmental applications. International Journal of Biological Macromolecules, 43(5), 401-414.

Bandyopadhyay, P., Ghosh, A. K., \& Ghosh, C. (2012). Recent developments on polyphenol-protein interactions: effects on tea and coffee taste, antioxidant properties and the digestive system. Food \& function, 3(6), 592-605.

Barth, A. (2007). Infrared spectroscopy of proteins. Biochimica et Biophysica Acta (BBA)-Bioenergetics, 1767(9), 1073-1101.

Beauchemin, R., N'Soukpoe-Kossi, C., Thomas, T., Thomas, T., Carpentier, R., \& Tajmir-Riahi, H. (2007). Polyamine analogues bind human serum albumin. Biomacromolecules, 8(10), 3177-3183.

Bongartz, V., Brandt, L., Gehrmann, M. L., Zimmermann, B. F., Schulze-Kaysers, N., \& Schieber, A. (2016). Evidence for the formation of benzacridine derivatives in alkaline-treated sunflower meal and model solutions. Molecules, 21(1), 91.

Bravo, L. (1998). Polyphenols: chemistry, dietary sources, metabolism, and nutritional significance. Nutrition reviews, 56(11), 317-333.

Cao, Y., \& Xiong, Y. L. (2015). Chlorogenic acid-mediated gel formation of oxidatively stressed myofibrillar protein. Food Chemistry, 180, 235-243.

Dalgalarrondo, M., Raymond, J., \& Azanza, J.-L. (1985). Sunflower seed protein: size and charge heterogeneity in subunits of the globulin fraction. Biochimie, 67(6), 629-632.

De Leonardis, A., Macciola, V., \& Di Rocco, A. (2003). Oxidative stabilization of cold-pressed sunflower oil using phenolic compounds of the same seeds. Journal of the Science of Food and Agriculture, 83(6), 523-528.

Desiraju, G. R., \& Steiner, T. (2001). The weak hydrogen bond: in structural chemistry and biology (Vol. 9): International Union of Crystal.

Dos Santos, M. D., Almeida, M. C., Lopes, N. P., \& De Souza, G. E. P. (2006). Evaluation of the anti-inflammatory, analgesic and antipyretic activities of the natural polyphenol chlorogenic acid. Biological and Pharmaceutical Bulletin, 29(11), 2236-2240.

Eftink, M. R. (2006). Fluorescence techniques for studying protein structure. Methods of Biochemical Analysis: Protein Structure Determination, Volume 35, 127-205.

Feeney, R. E., \& Whitaker, J. R. (1982). Modification of proteins: food, nutritional, and pharmacological aspects: ACS Publications.

Froehlich, E., Mandeville, J., Jennings, C., Sedaghat-Herati, R., \& Tajmir-Riahi, H. (2009). Dendrimers bind human serum albumin. The Journal of Physical Chemistry B, 113(19), 6986-6993.

Gerbanowski, A., Malabat, C., Rabiller, C., \& Gueguen, J. (1999). Grafting of aliphatic and aromatic probes on rapeseed $2 S$ and $12 S$ proteins: influence on their structural and physicochemical properties. Journal of Agricultural and Food Chemistry, 47(12), 5218-5226.

González-Pérez, S., van Konignsveld, G. A., Vereijken, J. M., Merck, K. B., Gruppen, H., \& Voragen, A. G. (2005). Emulsion properties of sunflower (Helianthus annuus) proteins. Journal of Agricultural and Food Chemistry, 53(6), 2261-2267.

González-Pérez, S., Vereijken, J. M., Merck, K. B., van Koningsveld, G. A., Gruppen, H., \& Voragen, A. G. (2004). Conformational states of sunflower (Helianthus annuus) helianthinin: effect of heat and $\mathrm{pH}$. Journal of Agricultural and Food Chemistry, 52(22), 6770-6778.

Hames, B. D. (1998). Gel electrophoresis of proteins: a practical approach (Vol. 197): OUP Oxford.

Hasni, I., Bourassa, P., Hamdani, S., Samson, G., Carpentier, R., \& Tajmir-Riahi, H.-A. (2011). Interaction of milk a-and $\beta$-caseins with tea polyphenols. Food Chemistry, 126(2), 630-639.

http://bestsel.elte.hu/.

Insaward, A., Duangmal, K., \& Mahawanich, T. (2014). Mechanical, optical, and barrier properties of soy protein film as affected by phenolic acid addition. Journal of Agricultural and Food Chemistry, 63(43), 94219426.

Kanakis, C., Hasni, I., Bourassa, P., Tarantilis, P., Polissiou, M., \& Tajmir-Riahi, H.-A. (2011). Milk $\beta$-lactoglobulin complexes with tea polyphenols. Food Chemistry, 127(3), 1046-1055.

Kang, J., Liu, Y., Xie, M.-X., Li, S., Jiang, M., \& Wang, Y.-D. (2004). Interactions of human serum albumin with chlorogenic acid and ferulic acid. Biochimica et biophysica acta (BBA)-general subjects, 1674(2), 205214.

Karefyllakis, D., Altunkaya, S., Berton-Carabin, C. C., Van Der Goot, A. J., \& Nikiforidis, C. V. (2017). Physical bonding between sunflower proteins and phenols: Impact on interfacial properties. Food Hydrocolloids.

Kelly, S. M., Jess, T. J., \& Price, N. C. (2005). How to study proteins by circular dichroism. Biochimica et Biophysica Acta (BBA)-Proteins and Proteomics, 1751(2), 119-139.

KROLL, J., RAWEL, H. M., \& ROHN, S. (2003). Reactions of plant phenolics with food proteins and enzymes under special consideration of covalent bonds. Food science and technology research, 9(3), 205-218.

Liang, S., \& Were, L. M. (2018a). Chlorogenic acid induced colored reactions and their effect on carbonyls, phenolic content, and antioxidant capacity in sunflower butter cookies. LWT-Food Science and Technology, 87, 16-22.

Liang, S., \& Were, L. M. (2018b). Chlorogenic acid oxidation-induced greening of sunflower butter cookies as a function of different sweeteners and storage conditions. Food Chemistry, 241, 135-142. 
Liu, F., Ma, C., Gao, Y., \& McClements, D. J. (2017). Food-Grade Covalent Complexes and Their Application as Nutraceutical Delivery Systems: A Review. Comprehensive Reviews in Food Science and Food Safety, 16(1), 76-95.

Liu, F., Sun, C., Wang, D., Yuan, F., \& Gao, Y. (2015). Glycosylation improves the functional characteristics of chlorogenic acid-lactoferrin conjugate. RSC Advances, 5(95), 78215-78228.

Liu, F., Sun, C., Yang, W., Yuan, F., \& Gao, Y. (2015). Structural characterization and functional evaluation of lactoferrin-polyphenol conjugates formed by free-radical graft copolymerization. RSC Advances, 5(20), $15641-15651$.

Moure, A., Sineiro, J., Domínguez, H., \& Parajó, J. C. (2006). Functionality of oilseed protein products: a review. Food Research International, 39(9), 945-963.

Namiki, M., Yabuta, G., Koizumi, Y., \& YANo, M. (2001). Development of free radical products during the greening reaction of caffeic acid esters (or chlorogenic acid) and a primary amino compound. Bioscience, biotechnology, and biochemistry, 65(10), 2131-2136.

Narváez-Cuenca, C.-E., Vincken, J.-P., \& Gruppen, H. (2013). Quantitative fate of chlorogenic acid during enzymatic browning of potato juice. Journal of Agricultural and Food Chemistry, 61(7), 1563-1572.

Oliver, S., Vittorio, O., Cirillo, G., \& Boyer, C. (2016). Enhancing the therapeutic effects of polyphenols with macromolecules. Polymer Chemistry, 7(8), 1529-1544.

Ozdal, T., Capanoglu, E., \& Altay, F. (2013). A review on protein-phenolic interactions and associated changes. Food Research International, 51(2), 954-970.

Prigent, S. V., Gruppen, H., Visser, A. J., van Koningsveld, G. A., de Jong, G. A., \& Voragen, A. G. (2003). Effects of non-covalent interactions with 5-O-caffeoylquinic acid (chlorogenic acid) on the heat denaturation and solubility of globular proteins. Journal of Agricultural and Food Chemistry, 51(17), 5088-5095.

Prigent, S. V., Voragen, A. G., Visser, A. J., van Koningsveld, G. A., \& Gruppen, H. (2007). Covalent interactions between proteins and oxidation products of caffeoylquinic acid (chlorogenic acid). Journal of the Science of Food and Agriculture, 87(13), 2502-2510.

Rawel, H. M., Rohn, S., Kruse, H.-P., \& Kroll, J. (2002). Structural changes induced in bovine serum albumin by covalent attachment of chlorogenic acid. Food Chemistry, 78(4), 443-455.

Salgado, P. R., Ortiz, S. E. M., Petruccelli, S., \& Mauri, A. N. (2011). Sunflower protein concentrates and isolates prepared from oil cakes have high water solubility and antioxidant capacity. Journal of the American Oil Chemists' Society, 88(3), 351-360.

Salunkhe, D. K. (1992). World oilseeds: Springer Science \& Business Media.

Sastry, M. S., \& Rao, M. N. (1990). Binding of chlorogenic acid by the isolated polyphenol-free $11 \mathrm{~S}$ protein of sunflower (Helianthus annuus) seed. Journal of Agricultural and Food Chemistry, 38(12), 2103-2110.

Soares, S., Mateus, N., \& De Freitas, V. (2007). Interaction of different polyphenols with bovine serum albumin (BSA) and human salivary a-amylase (HSA) by fluorescence quenching. Journal of Agricultural and Food Chemistry, 55(16), 6726-6735.

Sosulski, F. (1979). Organoleptic and nutritional effects of phenolic compounds on oilseed protein products: a review. Journal of the American Oil Chemists' Society, 56(8), 711-715.

van Koningsveld, G. A., Gruppen, H., de Jongh, H. H. J., Wijngaards, G., van Boekel, M. A. J. S., Walstra, P., \& Voragen, A. G. J. (2002). The solubility of potato proteins from industrial potato fruit juice as influenced by $\mathrm{pH}$ and various additives. Journal of the Science of Food and Agriculture, 82(1), 134-142.

Wei, Z., Yang, W., Fan, R., Yuan, F., \& Gao, Y. (2015). Evaluation of structural and functional properties of protein-EGCG complexes and their ability of stabilizing a model $\beta$-carotene emulsion. Food Hydrocolloids, 45, 337-350.

Weisz, G. M., Kammerer, D. R., \& Carle, R. (2009). Identification and quantification of phenolic compounds from sunflower (Helianthus annuus L.) kernels and shells by HPLC-DAD/ESI-MS n. Food Chemistry, 115(2), 758-765.

Weisz, G. M., Schneider, L., Schweiggert, U., Kammerer, D. R., \& Carle, R. (2010). Sustainable sunflower processing-I. Development of a process for the adsorptive decolorization of sunflower [Helianthus annuus L.] protein extracts. Innovative Food Science \& Emerging Technologies, 11(4), 733-741.

Wildermuth, S. R., Young, E. E., \& Were, L. M. (2016). Chlorogenic Acid Oxidation and Its Reaction with Sunflower Proteins to Form Green-Colored Complexes. Comprehensive Reviews in Food Science and Food Safety. 


\section{Chapter 4}

\section{The emulsifying performance of mildly derived mixtures from sunflower seeds}

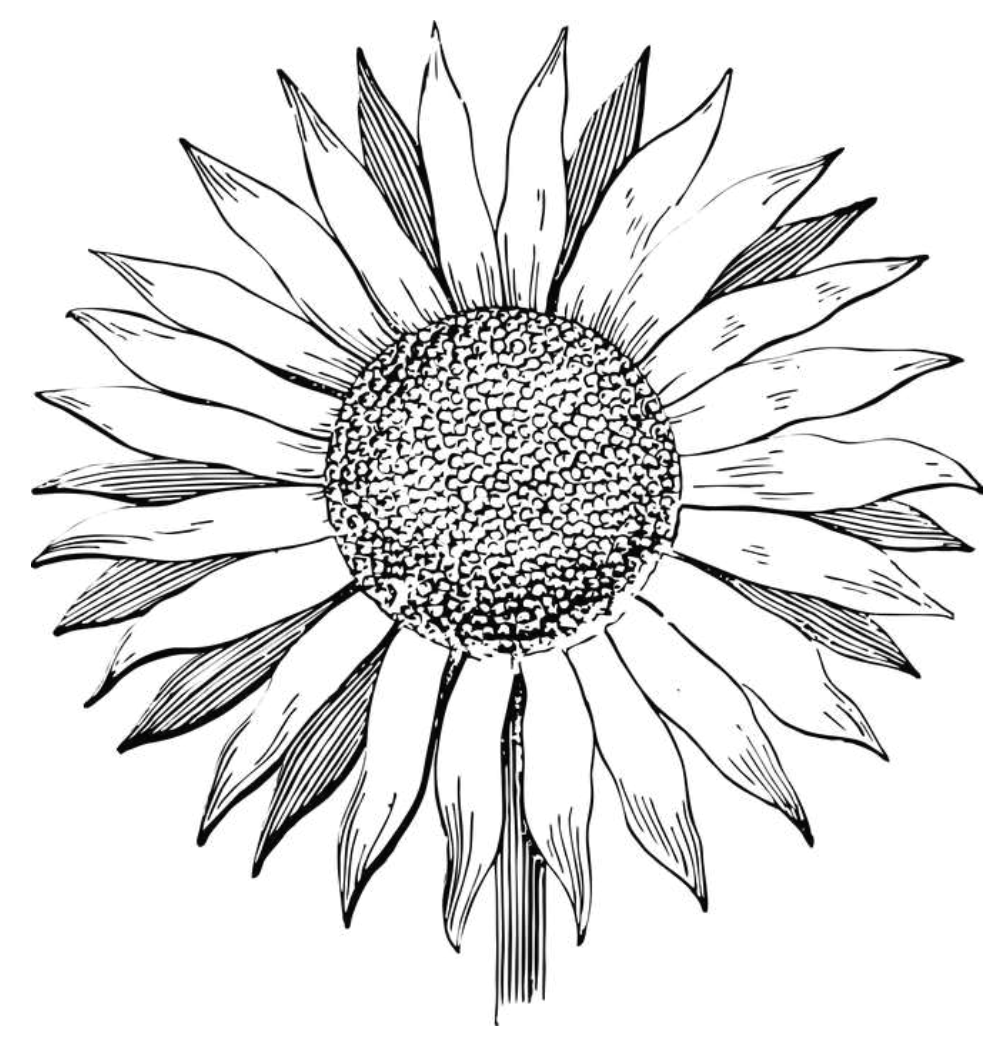

This chapter has been published as :

Karefyllakis, D., Octaviana, H., van der Goot, A. J., \& Nikiforidis, C. V. (2019). The emulsifying performance of mildly derived mixtures from sunflower seeds. Food Hydrocolloids, 88, 75-85. 


\section{A B S T R A C T}

Sustainability driven production of food ingredients is in the center of discussion the past years, with plants being a promising source, since they are widely available and have smaller environmental impact compared to animals. However, plant material consists of a sturdy configuration comprising many components, like proteins, which cannot be readily liberated. Thus, downstream processing of plants often involves intensive physicochemical and thermal processing, which might be accompanied by alteration of protein properties, like emulsification ability. Here, the aim was to investigate the emulsification ability of the native mixtures derived from sunflower seeds, obtained via simple separation steps and link their properties with their molecular composition. The investigated molecular mixtures were the cold-pressed sunflower cake, a protein-based and a fibre-based mixture. It was demonstrated that the residual oil in both the Sf cake and the protein-based mixture was present in the form of naturally emulsified oil droplets, so-called oil bodies. Oil bodies did not have a notable impact on the interfacial activity of the samples in contrast with the destabilization effect of polysaccharides. Despite their complex composition all mixtures could efficiently stabilize oil/water interfaces, showing similar properties compared to isolated proteins. This is an intriguing bottom line regarding the necessity for using pure emulsifiers. The findings prove that molecular mixtures which contain even minor amounts of proteins, can be used as ingredients for efficient emulsion stabilization. 


\subsection{Introduction}

Global demand for food escalates and the need for sustainability driven production of food ingredients intensifies. Various aspects of food production can be fine-tuned, from the selection of the raw material source and the holistic valorisation of the material (Boye \& Arcand, 2013). Animal sources of ingredients are extensively exploited, however they are considered less environmental friendly compared to ingredients derived from plants (Aiking, 2011). However, plant-based biomass requires different separation designs than those applied to produce animal ingredients, where for example, proteins from milk can be readily obtained in relative pure form (Mulvihill \& Ennis, 2003). Plant materials have significantly different biomass configuration which does not breakdown readily, due to the sturdy cell walls, perplexing the separation of ingredients within the matrix (Campbell, et al., 2011). In addition, the presence of a plethora of compounds, from polysaccharide to phenols, often results in complexation with proteins hindering their separation (Boland, et al., 2013). For these reasons downstream processing of plant proteins often involves intensive physicochemical and thermal steps which are often accompanied by alteration of their functional properties, i.e. emulsification ability (Moure, Sineiro, Domínguez, \& Parajó, 2006). Taking all these steps into account, separation processes of plant-based ingredients are not by default more sustainable than the production of animal ingredients (Apaiah, Linnemann, \& van der Kooi, 2006). The design of less intensive ingredient separation steps, eventually leads to the reconsideration of the biorefinery philosophy. There is a need for less intensive and efficient practices that use minimum amounts of energy and chemicals (van der Goot, et al., 2016).

As an example, by-products from sunflower oil industry (sunflower seed cake) constitute a worthwhile source of ingredients like proteins, fibres and phenols (Moure, et al., 2006). Sunflower press cake is ranking fourth with a worldwide production of about 19 million metric tons in 2017 (USDA, 2018). The protein content is 25-50 wt\% (Pickardt, Eisner, Kammerer, \& Carle, 2015), fibres are ranging between 29-52 wt\% and phenols reach up to $3 \mathrm{wt} \%$ (Weisz, Kammerer, \& Carle, 2009), with chlorogenic acid being the dominant phenol (2.8 wt\%). However, obtaining these components, is not trivial due to irreversible bonding with surrounding molecules (González-Pérez \& Vereijken, 2007).

A solution to that problem could be a shift from designs that do not aim towards pure components but to multicomponent mixtures (mixtures of oil, proteins and fibres) (Pelgrom, Berghout, van der Goot, Boom, \& Schutyser, 2014). As it has been shown in the case of emulsion stabilization, multicomponent fractions from yellow peas were capable to stabilize O/W emulsions (Geerts, Nikiforidis, van der Goot, \& van der Padt, 2017). This indicates that there is no need to separate pure proteins in order to use them as emulsifiers and that potentially coarse protein mixtures have good emulsifying properties.

Highly purified sunflower seed proteins are being reported as efficient emulsifiers (GonzálezPérez, et al., 2007). However, phenol oxidation occurs at protein extraction conditions ( $\mathrm{pH}>8$ ) and covalent bonds between proteins and phenols are triggered, which affect protein properties, like chemical stability and solubility (D. Karefyllakis, Salakou, Bitter, van der Goot, \& Nikiforidis, 2018; Sosulski, 1979). On the other hand, when mixtures of proteins and phenols 
are in native environment, only physical attractive forces between proteins and phenols occur, which has been proven to positively affect the protein interfacial and emulsifying properties (Dimitris Karefyllakis, Altunkaya, Berton-Carabin, Van Der Goot, \& Nikiforidis, 2017). Therefore, one realizes that full exploitation of all potentials of sunflower seeds and its byproducts might require a different approach. Part of this novel approach is the investigation of the properties of sunflower proteins when natively embedded in complex molecular mixtures.

For the above reasons, the aim of this work was to investigate the interfacial properties and emulsification ability of molecular complex mixtures derived at neutral $\mathrm{pH}$ from sunflower seeds and link their properties with their molecular composition. The obtained mixtures were the solid residue after cold pressing (cake), which was then aqueously divided to a protein and a fibre-based mixture. All fractions showed high interfacial activity and relativity good emulsification ability, opening a new path towards efficient exploitation of plant-derived ingredients.

\subsection{Materials and methods}

\section{Materials}

Whole sunflower seeds (SF seeds) were granted from Cargill B.V (Amsterdam, The Netherlands). Sunflower oil (SF oil) was purchased from the local market and was filtered with silica (MP Alumina N-Super I, MP Biomedicals, Germany) as described by Berton et al. (Berton, Genot, \& Ropers, 2011) to remove any polar compounds. Petroleum ether, ethanol, potassium monobasic dihydrate, potassium phosphate dibasic, sodium hydroxide and hydrochloric acid, Nile Blue were all purchased from Sigma Aldrich (Sigma, USA) and were of analytical grade. Qualitative filter paper Grade 595 1/2 was purchased by Whatman (GE Healthcare, USA). For all analyses ultrapure water was used.

\section{Methods}

\subsubsection{Preparation of samples}

Sunflower press cake (SF cake)

Cold-pressing. The diagram of the processing steps that were followed and the composition of the samples are presented in Fig. 4.1. Whole (with hulls) sunflower seeds were pressed using an oil press (KK20 F Universal, Kern Kraft, Germany) with a standard seed screw. Pressing temperature was kept below $45{ }^{\circ} \mathrm{C}$. The temperature was monitored with a thermometer and controlled with a water jacket. During the process, the oil and SF cake were collected in separate containers, as it is depicted in Fig.4.1.

Milling. The SF cake was milled using a rotor mill (Pulverisette 14, Fritsch, Germany) at 8000 rpm and simultaneously sieved with an integrated sieve with $1 \mathrm{~mm}$ pore size. 


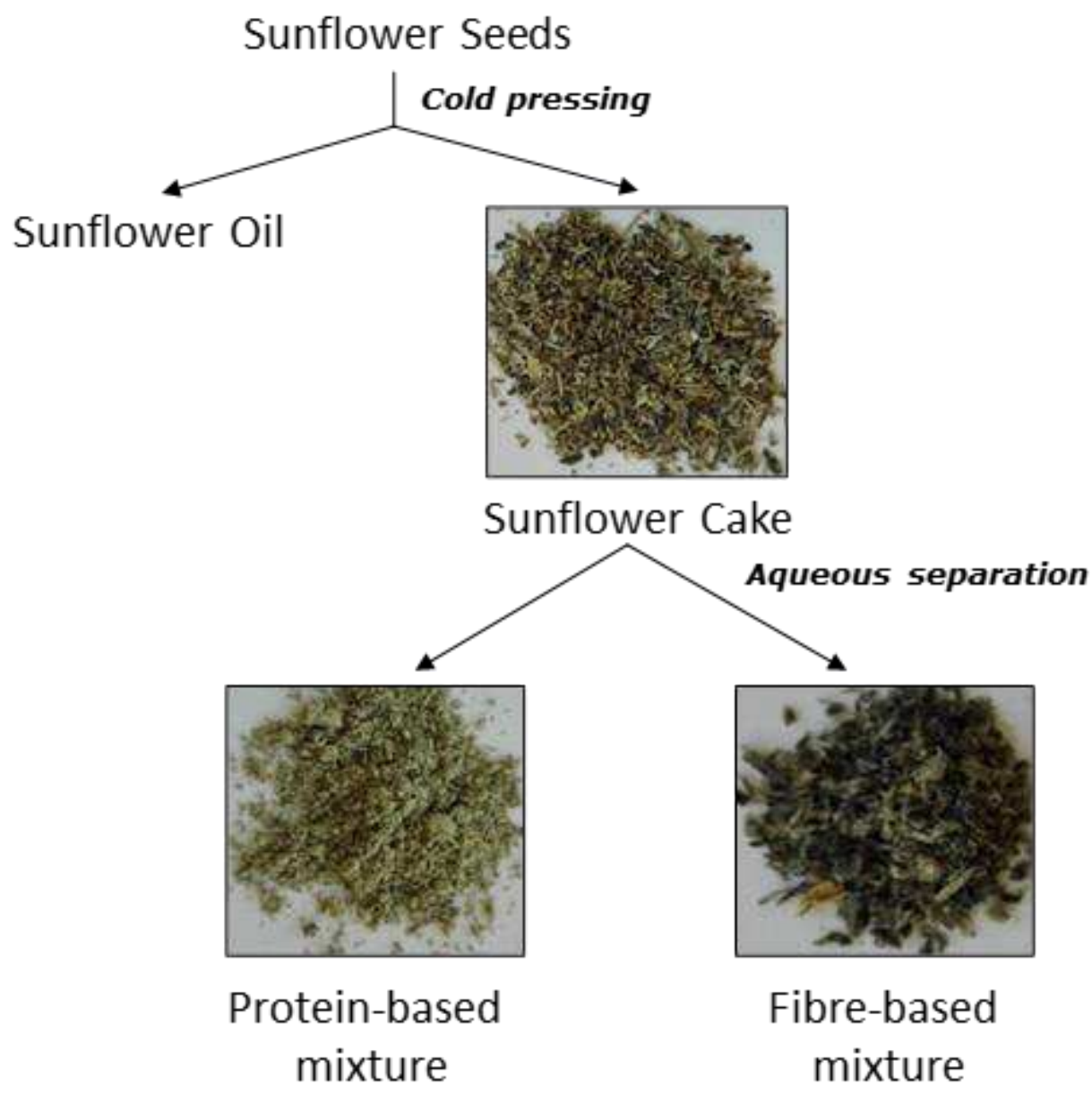

Figure 4.1 : Process scheme of the steps to derive the three different complex molecular mixtures and pictures of these mixtures in powdered form.

\section{Protein and fibre-based mixtures}

SF cake was dispersed in ultrapure water $(1: 20 \mathrm{w} / \mathrm{v}$ ratio) and the dispersion was stirred at 2000 rpm using an electric stirrer (IKA Eurostar digital Euro St-D, IKA, Germany) for $2 \mathrm{~h}$. During this step the $\mathrm{pH}$ was monitored and constantly adjusted to 7.0 with small additions of $\mathrm{NaOH}$ solution $(0.1 \mathrm{M})$. Afterwards, the dispersion was intensively mixed at $9500 \mathrm{rpm}$ using a rotorstator homogenizer (IKA T18 digital Ultra-Turrax, IKA, Germany) for $2 \mathrm{~min}$. The mixture was then centrifuged at $10.000 \mathrm{~g}$ for $30 \mathrm{~min}$ at $20{ }^{\circ} \mathrm{C}$ and the fibre-based mixture was collected from the pellet, while the supernatant contained the protein-based mixture (Fig.4.1). The supernatant was first filtered using a dense cheese cloth, then dialysed (10 kDa membrane, Snake Skin dialysis tubing, Thermo Scientific, USA) and spray dried (Buchi B290 mini spray dryer, Buchi Labortechnik AG, Switzerland). All samples, including the SF cake, were re-dispersed in ultrapure water $(1: 20 \mathrm{w} / \mathrm{v})$, then dialysed and spray-dried. This treatment was applied for the removal of the majority of the low molecular compounds in order to be able to focus on the interactions between the macromolecules in more detail. Subsequently, the composition of the samples was analysed. 


\subsubsection{Composition analysis}

The protein content was determined by Dumas analysis (Nitrogen analyzer FlashEA 1112 series, Thermo Scientific, The Netherlands). The protein factor used to calculate the percentage of protein was 5.8 (Martínez-Force, Dunford, \& Salas, 2015). The oil content was obtained using an automated Soxhlet device (Buchi B-811, Buchi Labortechnik AG, Flawil, Switzerland) for $12 \mathrm{~h}$ using petroleum ether. The amount of phenols present in every sample was quantified by chromatographic analysis (HPLC). A Dionex Ultimate 3000 chromatograph (Thermo Scientific, USA) was used with a phenol column Phenomenex Gemini $3 \mathrm{u} \mathrm{C} 18$ at $30^{\circ} \mathrm{C}$. The column was eluted with $30 \%$ Acetonitrile in ultrapure water and $0.1 \%$ Trifluoroacetic acid at a flow rate of $0.75 \mathrm{~mL} / \mathrm{min}$. Detection and external calibration was conducted at $324 \mathrm{~nm}$. Moisture and ash content were determined gravimetrically according to Method 44-15A (AACC, 1995) and Method 08-16 (AACC, 1995), respectively. All the analyses were performed in triplicates.

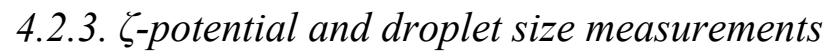

The $\zeta$-potential of diluted solutions $(0.01 \mathrm{wt} \%)$ was measured $\left(20^{\circ} \mathrm{C}\right)$ using a dynamic laser scattering device (Nano ZS, Malvern Instruments Ltd, Worchester, UK). The changes of $\zeta$ potential as a function of $\mathrm{pH}$ was measured with the aid of an autotitrator (MPT-2, Autotritator, Malvern Intruments Ltd, UK). For the autotitration, $\mathrm{NaOH}(0.1 \mathrm{M}) \mathrm{NaOH}$ and $\mathrm{HCl}(0.1 \mathrm{M})$ solutions were used. To determine the emulsion droplet size, a laser diffraction particle size analyser (Mastersizer 2000, Malvern Instruments Ltd, UK) was used, with a refractive index of 1.455 for the dispersed phase. Samples were diluted $(0.01 \mathrm{wt} \%)$ and mixed with SDS $(0.5 \mathrm{wt} \%)$ before analysis. To evaluate the stability of emulsions, the droplet size distributions of the emulsions at $\mathrm{t}=0$ and $\mathrm{t}=7$ days were measured. All experiments were performed in duplicates

\subsubsection{Dynamic interfacial properties}

Interfacial tension and dilatational rheology measurements at the oil-water interface were measured using an automated drop tensiometer (ADT) (Tracker, Teclis-IT Concept, France). All aqueous solutions were used at a constant protein concentration of $0.01 \mathrm{wt} \%$ and all samples were filtered prior to analysis with a filter paper with pore size $4-7 \mu \mathrm{m}$, Grade $5951 / 2$ (Whatman, GE Healthcare, USA). Stripped sunflower oil was used. The initial droplet volume was set to $16 \mu \mathrm{L}$, with corresponding droplet area of $30 \mathrm{~mm}^{2}$. In all analyses the initial Bond number which represents the balance between the gravity and interfacial tension forces, was $>0.1$, which is required for performing accurate measurements, as recommended by the manufacturer. The interfacial tension was first monitored for $3 \mathrm{~h}$ while keeping the droplet volume constant.

The interfacial tension data were analysed by fitting to a simple exponential decay model (Constantinos V Nikiforidis, et al., 2013):

$$
\gamma(t)=\gamma_{\infty}+\gamma_{1} e^{-\frac{t}{t_{1}}}+\gamma_{2} e^{-\frac{t}{t_{2}}}
$$


where $\gamma_{\infty}$ denotes the surface tension at equilibrium while the exponential terms represent two relaxation modes known for proteins and other macromolecules. The first exponential decay term may describe the adsorption, while the second exponential decay may be related to rearrangement of the components at the interface. Non-linear numerical fitting of Equation (1) to the experimental data was done with the curve fitting tool box in MATLAB (MathWorks, USA).

After the passage of $3 \mathrm{~h}$ and when the interface was at equilibrium, dilatational oscillations of the droplet area were performed with a constant amplitude (5\%) at the linear viscoelastic region and a range of oscillation frequencies (periods of 50, 100, 200 and 500 s). The surface dilatational modulus $E$ is presented as a complex number (Nikiforidis, et al., 2013) :

$E=E^{\prime}+i E^{\prime \prime}$

The real part $E^{\prime}$ is the storage modulus representing the recoverable elastic energy stored in the surface (dilatational elasticity) whereas the imaginary part $E^{\prime \prime}$ is the loss modulus reflecting the viscous dissipation of energy through any relaxation (time-dependent) processes at or near the surface (dilatational viscosity). All experiments were performed in duplicates.

\subsubsection{Emulsion preparation}

Emulsions were prepared using the SF cake and the protein and fibre-based mixtures that were firstly dispersed $(0.5 \mathrm{wt} \%$ in protein $)$ in aquatic $0.1 \mathrm{M}$ phosphate buffer $\mathrm{pH} 7$ and $\mathrm{I}=0.1 \mathrm{~mol} \cdot \mathrm{L}^{-}$ ${ }^{1}$ (the continuous phase) and stirred for $30 \mathrm{~min}$. Sunflower oil was then slowly added and a coarse emulsion (10 $\mathrm{wt} \%$ in sunflower oil) was made using a rotor-stator homogenizer (9500 rpm, 3 min) (UltraTurrax, IKA, California, United states). This coarse emulsion was then passed 2 times through a lab homogenizer (labhoscope, Delta Instruments, The Netherlands) at 100 bar. The emulsion was then recirculated through the lab homogenizer for $10 \mathrm{~min}$ at the same pressure and stored at $4{ }^{\circ} \mathrm{C}$ for $7 \mathrm{~d}$.

\subsubsection{Emulsion creaming index}

The emulsion stability during storage against creaming was examined by visual observation and calculation of the creaming index $(C I)$ from $t=0$ until $t=7$ days. The value of creaming index was calculated using the following equation:

$C I(\%)=\frac{H s}{H t} \times 100$

where $H t$ is the total height of the emulsion and $H s$ is the height of the serum layer (the sum of the transparent and/or the turbid layers at the bottom of container). All experiments were performed in duplicate.

\subsubsection{Optical microscopy.}

The microstructure of emulsions produced at $\mathrm{t}=0$ day and $\mathrm{t}=7$ days were optically analysed by light microscopy using an Axioscope device (Zeiss, Germany), after 100-fold dilution in buffer. The used magnification was 100x. 


\subsubsection{Confocal Laser Scanning Microscopy (CLSM).}

CLSM images were obtained at room temperature on a LEICA TCS SP5 Confocal Laser Scanning Microscope (Leica Microsystems GmbH., Mannheim, Germany) equipped with an inverted microscope (model Leica DMI6000), containing a set of four visible light lasers. The used objectives were HC PL APO $10 \times / 0.40 \mathrm{CS}$ and HC PL APO $20 \times / 0.70$ IMM/CORR CS. Digital image files were acquired in $1024 \times 1024$ pixel resolution. Samples were carefully placed on a microscope slide and stained with a droplet of aquatic Nile Blue $1 \% \mathrm{wt}$.

\subsection{Results and discussion}

\subsubsection{Composition analysis and microstructure of obtained molecular mixtures}

As presented at Table 4.1, the main components of the cold-pressed SF cake were fibres (52.0 $w t \%)$, proteins (19.7 wt \%) and residual oil (14.1 wt\%), while minor amounts of phenols and ash were present. The values are in line with those previously reported (Lomascolo, UzanBoukhris, Sigoillot, \& Fine, 2012; Salunkhe, 1992). It is important to note that the amount of residual oil in SF cake was considerably higher compared with industrially produced sunflower cake where oil content as low as $2 \mathrm{wt} \%$ can be achieved (Lomascolo, et al., 2012). This high yield in oil extraction is due to the combination of pressing with organic solvent extraction (Dunn, Wells, \& Williams, 2010). For this work cold-pressing was selected as an environmental and material friendly oil extraction method (Navarro \& Rodrigues, 2016).

Table 4.1. Composition of the resulting samples, SF cake and the derived protein and fibrebased mixtures.

\begin{tabular}{l|ccc}
\hline \multicolumn{1}{c|}{$\mathrm{wt} \%$} & SF cake & $\begin{array}{l}\text { Protein-based } \\
\text { mixture }\end{array}$ & $\begin{array}{c}\text { Fibre-based } \\
\text { mixture }\end{array}$ \\
\hline Protein & $19.7 \pm 0.4$ & $51.8 \pm 0.6$ & $16.7 \pm 0.3$ \\
Oil & $14.1 \pm 0.2$ & $27.9 \pm 0.3$ & $0.7 \pm 0.5$ \\
Fibres ${ }^{\mathrm{a}}$ & $52.0 \pm 0.6$ & $11.1 \pm 0.4$ & $73.0 \pm 0.8$ \\
Phenols & $1.9 \pm 0.1$ & $2.6 \pm 0.2$ & $0.5 \pm 0.1$ \\
Moisture & $7.0 \pm 0.2$ & $4.5 \pm 0.4$ & $6.3 \pm 0.2$ \\
Ash & $5.2 \pm 0.2$ & $2.1 \pm 0.2$ & $2.8 \pm 0.1$
\end{tabular}

The SF cake was suspended in water to divide it into a soluble protein-based mixture and an insoluble fibre-based mixture. The protein content of the protein-based mixture was considerably increased compared to SF cake ( 51.8 and $19.7 \mathrm{wt} \%$ respectively) indicating that aqueous extraction successfully enriched the protein content of the derived soluble mixture. 
Furthermore, as shown in Table 4.1, the soluble protein-based mixture consisted by $27.9 \mathrm{wt} \%$ oil. Despite the high oil content of that fraction, no free oil was observed on the surface. This was a first indication that triacylglyceride (plant oil) reservoirs in seeds, were still intact. In seeds, triacylglycerides are organized in distinct organelles, naturally protected by a sophisticated membrane consisting of highly hydrophobic proteins and phospholipids. This protected oil reservoir is called oil bodies or oleosomes (Karkani, Nenadis, Nikiforidis, \& Kiosseoglou, 2013). Due to the architecture of the membrane the inner side, facing the oil core is highly hydrophobic, while the outer part is hydrophilic, which facilitates their aqueous extraction, behaving similar to proteins. Aqueously extracted sunflower seed oil bodies have been reported to have a size distribution between 0.2 and $4 \mu \mathrm{m}$ (C. V. Nikiforidis, V. Kiosseoglou, \& E. Scholten, 2013). As it is presented in Fig.4.2a, the size distribution analysis of the obtained soluble protein-based fraction revealed that our oil bodies have a similar size range, which is another indication that the remaining oil after pressing was still in its native oil body structure. To further clarify the structure of the soluble fraction, confocal microscopy was employed. As it can be seen in Fig.4.2b spherical droplets with a hydrophobic core (red colour) were present with sub/microns sizes to a few $\mu \mathrm{m}$. It can also be seen that proteins (green colour) are surrounding the oil core, thereby acting as an additional external layer. The protein content of the soluble fraction is about double the amount of the oil, which also explains the extensive green coloured domains. This raises the possibility that a fraction of the observed spherical particles are not oil bodies but in fact re-emulsified lipids. The neighbouring proteins, which are in excess, could stabilise lipids, which have been released from disintegrated oil bodies, into emulsified droplets. These droplets might be hybrids with a mixed oil body/storage proteins membrane and due to the absence of a homogenization step, are expected to be larger than the native oil bodies (typical diameter $<3 \mu \mathrm{m}$ (C. Nikiforidis, V. Kiosseoglou, \& E. Scholten, 2013)). However, no sizeable population of oil droplets larger than $1 \mu \mathrm{m}$ was detected in Fig.4.2a indicating that the existence of the re-emulsified lipids was not dominant in the samples. For the above reasons it is assumed that the majority of the residual lipids is present in its native form, being oil bodies.

As expected, the fibre-based mixture mostly consisted of fibres $(73.0 \mathrm{wt} \%)$ and $16.7 \mathrm{wt} \%$ of proteins (Table 4.1). Sunflower seed proteins are consisted primarily of the water soluble globulins $(\sim 85 \%)$ and albumins $(\sim 15 \%)$ and minor quantities of insoluble and alkali soluble glutelins and prolamins (Žilić, et al., 2010). Glutelins and prolamins will be present in the SF Cake and the fibre-based mixture, and not in the soluble part. Due to their minor quantities, no significant impact on the sample properties is expected. It is also possible that a certain amount of the albumins might have co-precipitated with the fibres but that would not explain the high amounts of protein present in this mixture. At the separation conditions ( $\mathrm{pH} 7)$ about $20 \mathrm{wt} \%$ of sunflower globulins are insoluble (González-Pérez, et al., 2007), thus a significant amount of the globulins will end up in the fiber-based mixture. Taking this into account, all samples were regarded as mixtures of different protein fractions, comprising globulins for the most part and albumins as a minor component.

It has been previously showcased that mixtures of fibres with small amounts of proteins can exhibit considerable interfacial activity and emulsification stability (Tenorio, Gieteling, 
Nikiforidis, Boom, \& van der Goot, 2017). Therefore, since the fibre-based mixture had a considerable amount of proteins it was hypothesized that this mixture could also exhibit emulsifying ability. Following the same hypothesis, SF cake was also investigated for the same properties. Besides proteins and fibres the SF cake contained a significant amount of oil which was also expected to be in the form of oil bodies.

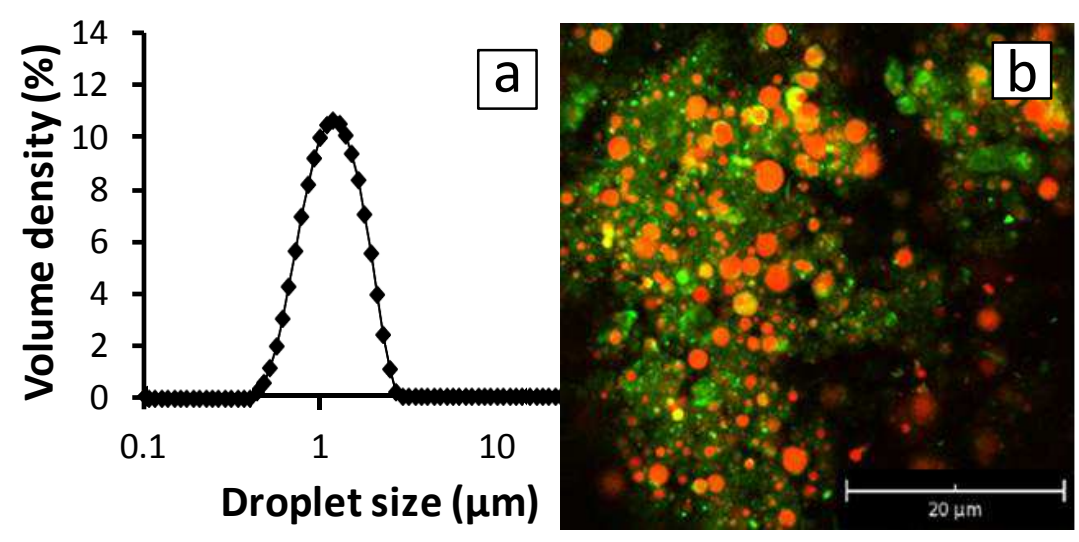

Figure 4.2 : Size distribution analysis of the obtained soluble protein-based mixture (a) and Confocal Laser Scanning Microscopy (CLSM) imaging of the same sample in ultrapure water (b). The CLSM sample was stained using Nile Blue

\subsection{2. ऊ-potential}

The $\zeta$-potential of the mixtures is an important indicator of the possible molecular interactions and subsequently the properties of the mixture. Therefore, as it is presented in Fig.4.3, the $\zeta$ potentials of all molecular mixtures were measured over a wide $\mathrm{pH}$ range. A first observation is that the charge density of all 3 samples reached a plateau at $\mathrm{pH}$ values higher than $7(-20$ $\mathrm{mV}$ ), which explains the fact that the protein and fiber-based mixtures could be separated at $\mathrm{pH}$ 7 during aqueous fractionation, since electrostatic repulsion between the molecules occurs at this environment. The $\zeta$-potential of a pure sunflower protein was previously measured (Dimitris Karefyllakis, et al., 2017) and showed the typical S shape curve that proteins exhibit and had a zero charge point at $\mathrm{pH}$ 5. As shown in Fig.4.3, when proteins were in mixture with oil bodies, the curve had the same shape, but there was a slight decrease of the zero charge point ( $\mathrm{pH} 4.0$ - 4.5). This zero charge point value is in agreement with previous studies, in which a protein/oil body mixture was aqueously derived from sunflower seeds (C. V. Nikiforidis, et al., 2013). The swift of the zero charge point is probably caused by negatively charged domains of oil body membrane proteins, the so-called oleosins, which are expected to interact through electrostatic or hydrophobic forces with the storage proteins as it has also been suggested for the zeta potential of oil body-protein mixtures from E.plantagineum (Payne, Lad, Foster, Khosla, \& Gray, 2014). When the protein:fibre ratio was at 2:5, as in the case of the SF cake (Table 4.1) the mixture had a zero charge point at $\mathrm{pH} 3.5-4.0$ and reached $-5 \mathrm{mV}$ at $\mathrm{pH} 3$. While, at even lower protein:fibre ratios $(2: 8)$, as is the case of the fibre-based mixture the $\zeta$ potential never reached the $\mathrm{x}$-axis, showing the dominant role of the fibres. Similar findings were reported in the case of the charge profile of sugar beet leaf cellulosic particles with minor 
amount of embedded proteins (Tenorio, et al., 2017). The negative charge of the fibre-based mixture is an interesting property that should be further investigated, since not many known emulsifiers have a negative charge at acidic $\mathrm{pH}$ values (McClements, 2015). For dispersions of soy proteins and soy polysaccharides, it was shown that the net charge of soy proteins particularly at $\mathrm{pH} 3$, became larger with higher fibre concentration suggesting electrostatic protein-polysaccharide complexation (Tran \& Rousseau, 2013).

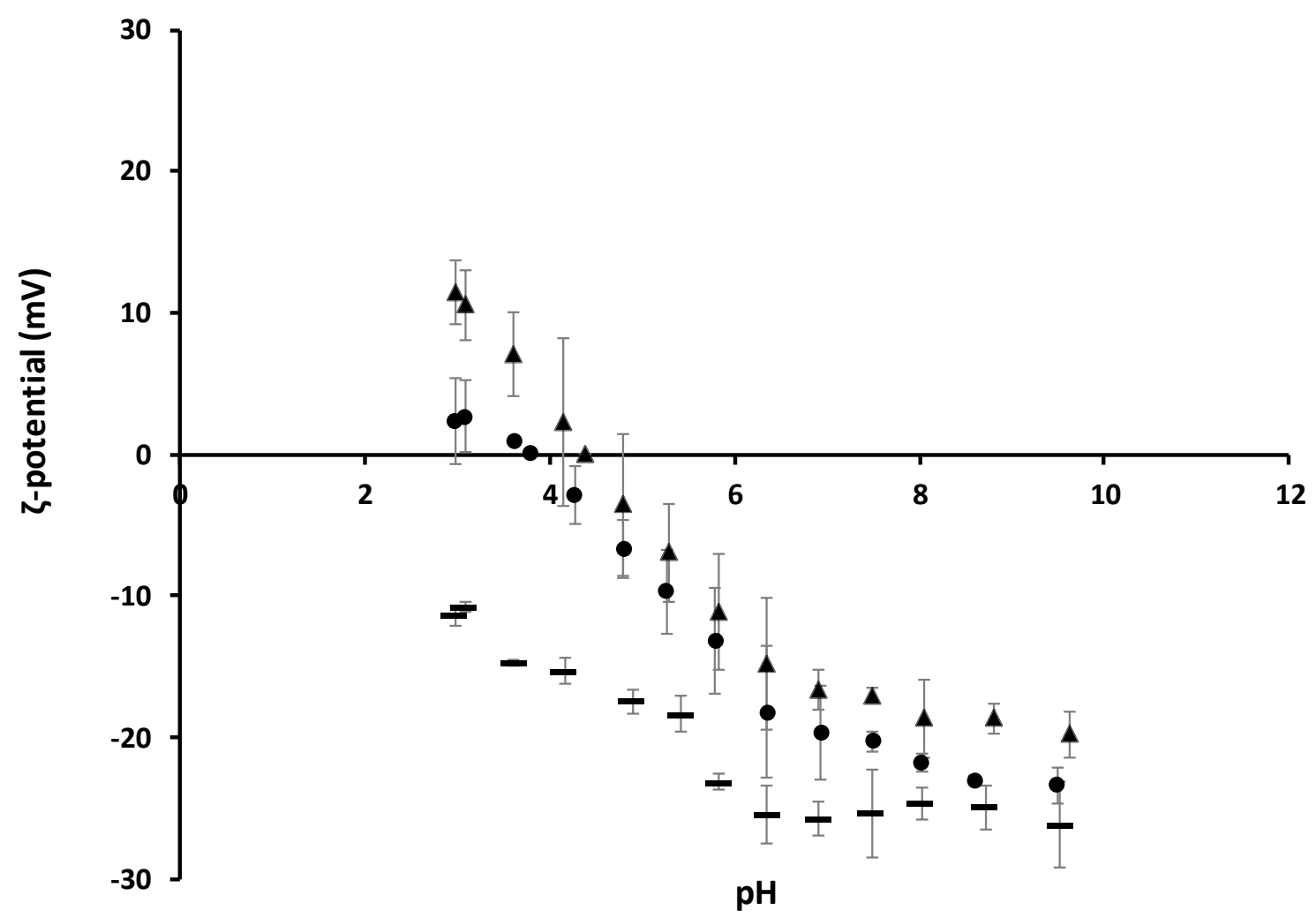

Figure 4.3 : $\zeta$-potential of SF cake $(\bullet)$, protein $(\boldsymbol{\Delta})$ and fibre-based mixtures $(-)$ as a function of $\mathrm{pH}$, at constant protein concentration $(0.01 \% \mathrm{w} / \mathrm{v})$.

\subsubsection{Interfacial behaviour of molecular mixtures}

Interfacial activity. Intermolecular interactions within molecular mixtures can potentially influence the interfacial activity. Therefore as it is presented in Fig.4.4, the decrease of the interfacial tension due to the absorption of the different molecules in the mixtures was investigated. The protein concentration was kept constant $(0.01 \% \mathrm{w} / \mathrm{v})$ so that any variations in the interfacial behaviour would only arise from the presence of the other two classes of macromolecules, fibres and oil bodies. At the first stage of the analysis, which is the diffusion stage of the molecules towards the interface, there was no notable difference between the behaviour of SF cake and the protein-based mixture. Apparently, the proteins, which are expected to be interfacially active molecules, dictate the molecular diffusion and are in sufficient amounts. To the contrary, at even lower protein:fibre ratios (fibre-based mixture) the kinetics of the diffusion is slower, showing the deceleration effect of the non-interfacially active 
fibres (inset Fig.4.4). The slow diffusion of the proteins towards the interface could be a result of the steric hindrance caused by the dispersed fibre or the protein-fibre physical interactions. Moreover, the insoluble polysaccharides could have participated in the development of hydrophobic interactions with the hydrophobic patches of sunflower proteins, rendering them unavailable for interfacial absorption on the oil/water interface. The fact that fibres diffuse slowly towards the interface has also been showcased for cellulosic particles from sugar beet leaves (Tenorio, et al., 2017). In this study, the slow diffusion was attributed to the large adsorption energy needed for the solid particles and the low interfacial tension decrease to the adsorption of polysaccharides assisted by a small amount of storage proteins $(\sim 5 \mathrm{wt} \%)$. In mixtures of $\beta$-lactoglobulin and non-absorbing polysaccharides in a 4:1 ratio, it has been shown that the interfacial behaviour of the mixed films was determined largely by the protein with the polysaccharides playing a secondary role (Baeza, Sanchez, Pilosof, \& Patino, 2005).

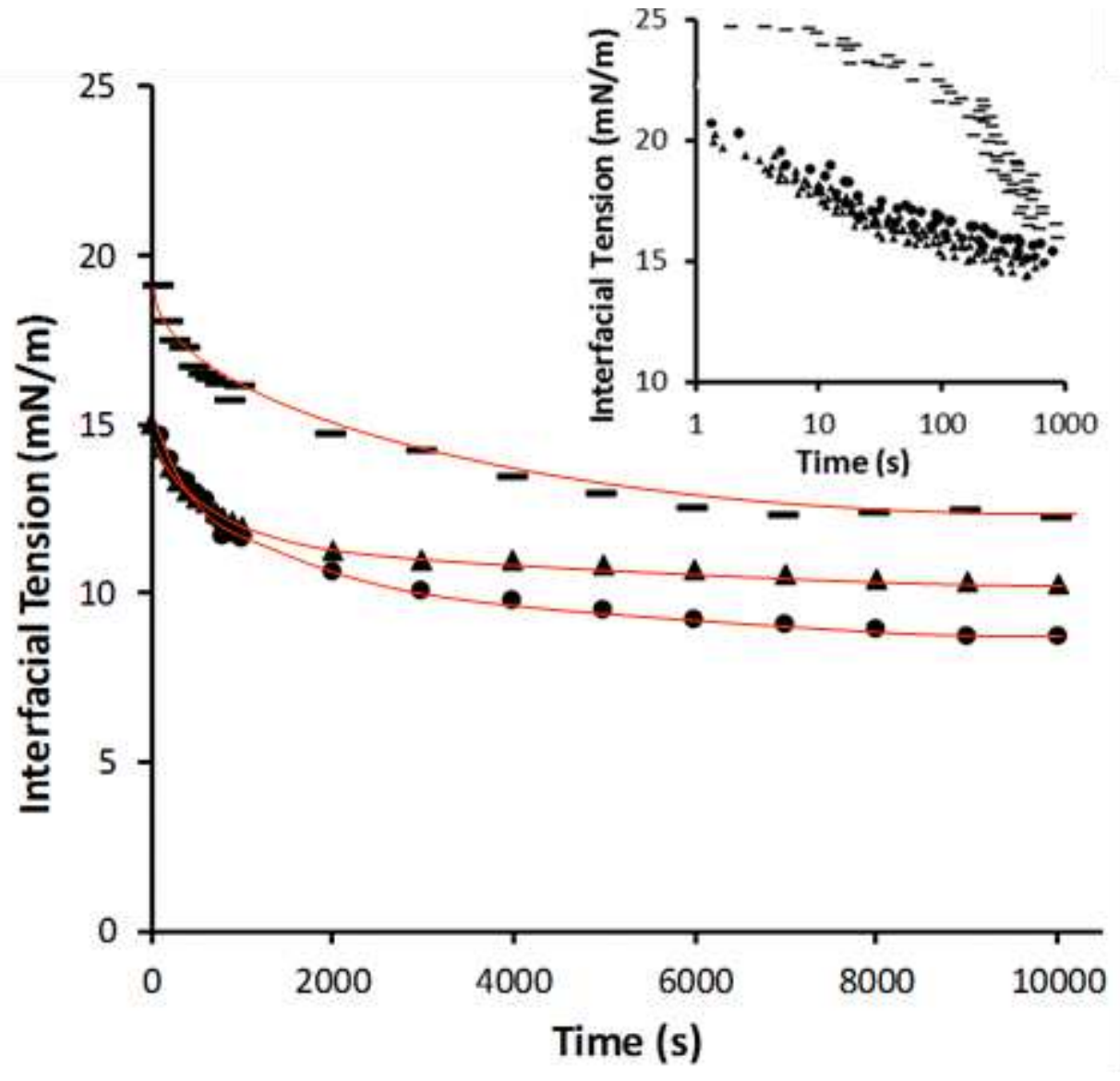

Figure 4.4 : Interfacial tension (oil-water interface) as a function of adsorption time in the presence of SF cake $(\bullet)$, protein $(\boldsymbol{\Delta})$ and fibre-based mixture (-) at constant protein concentration $(0.01 \% \mathrm{w} / \mathrm{v})$. In red: theoretical curves using Equation (1). In the inset, the first 1000 s of the same graph in logarithmic scale.

To gain further knowledge on the adsorption mechanism, the experimental data in Fig. 4.4 were fitted by Equation (1) as depicted by the red lines. The relaxation times $t_{1}$ for the fiber-based mixtures, the protein-based mixtures and the SF cake were 2535.6, 3751.8 and $1995.2 \mathrm{~s}$ respectively. The $t_{2}$ values were 154.2, 434.2 and $39.6 \mathrm{~s}$ respectively and the coefficient of determination $\left(\mathrm{r}^{2}\right)$ was 0.9948 . These parameters give an indication of the mechanism during 
the interfacial tension decay. At the concentration tested, $t_{1}$ were significantly larger than $t_{2}$, suggesting that adsorption of the particles was the rate limiting step in the dynamic interfacial tension compared with rearrangement of the particles. This means that the fibres showed slow diffusion and adsorption, which is typical for solid particles (Pickering stabilisers). The same behaviour was observed for the SF cake, which contained lower amounts of fibres, and more interestingly for the protein-based mixture where the major ingredients were proteins and oil bodies. At this case, the diffusion was expected to be faster due to the higher protein content. It is possible that protein molecules are associated with oil bodies and polysaccharides, forming a kind of large aggregates, which therefore, move slowly towards the interface but from the moment they reach it, quick rearrangements occur allowing proteins to reduce the interfacial tension. Unknown remains what happens to the structure of the oil bodies and how their membrane behaves once they reach the interface. Either their hydrophobic core merges with the pendant droplet and their membrane participates in the lowering of the interfacial tension or they remain intact acting as Pickering particles. In order to determine this, further investigation is required.

SF cake exhibited the strongest interfacial activity from the samples tested, decreasing the interfacial tension from the initial value $\left(27 \mathrm{mN} \cdot \mathrm{m}^{-1}\right)$ to an equilibrium value of $\sim 8.5 \mathrm{mN} \cdot \mathrm{m}^{-1}$. The first $2000 \mathrm{sec}$ of the measurement, the absorption pattern of SF cake and the protein-based mixture were similar but thereafter the interfacial tension decrease of the latter was moderated, reaching values around $10 \mathrm{mN} \cdot \mathrm{m}^{-1}$. An appreciable interfacial drop down until $\sim 12 \mathrm{mN} \cdot \mathrm{m}^{-1}$ was also recorded in the case of the fibre-based mixtures. The percentage of oil bodies in the proteinbased mixture (27.9 $\mathrm{wt} \%$ ) appears to have a considerable impact on the value of the interfacial tension at equilibrium, which is higher than the one of pure proteins $\left(10\right.$ and $7 \mathrm{mN} \cdot \mathrm{m}^{-1}$ respectively (Dimitris Karefyllakis, et al., 2017)). When the interfacial activity of soybean oil bodies at the same $\mathrm{pH}$ was examined, it was observed that the more proteins were present in the dispersion the lower was the observable interfacial tension drop (Ishii, et al., 2017). One possible explanation of this could be that oil body membrane proteins interact via hydrogen or electrostatic bonds with the storage proteins thus hindering their absorption and unfolding on the $\mathrm{O} / \mathrm{W}$ interface.

The use of pure sunflower protein preparations resulted in an interfacial equilibrium value of $\sim 7 \mathrm{mN} \cdot \mathrm{m}^{-1}$ (Dimitris Karefyllakis, et al., 2017), which means that the interfacial activity of our samples and especially of the SF cake is not drastically distinctive. Therefore, it appears that despite the presence of crude fibres and oil bodies in the surrounding environment of proteins, the overall performance of the multicomponent mixtures is comparable to dispersions with solely proteins. This finding is very important, since it opens a new route when designing the separation of plant derived interfacially active molecules, like proteins.

Interfacial elasticity. The viscoelastic dilatational moduli were measured when an equilibrium state on interface was reached. The obtained storage or elastic modulus, $E$ ', and loss or viscous modulus, $E$ ", for each sample are presented in Fig. 4.5 where they are plotted with frequency $\left(\mathrm{s}^{-1}\right)$. For all the samples the storage moduli $(15-20 \mathrm{mN} \cdot \mathrm{m}-1)$ are much higher than the loss 
moduli $(<5 \mathrm{mN} \cdot \mathrm{m}-1)$, indicating a more elastic behaviour. There is a clear dominance of the elastic character of the interface in all the samples tested but for the SF cake and the proteinbased mixture, this character was more definite compared with the fibre-based mixtures. Apparently oil bodies and fibres when are at this protein:fibre ratio (2:5) do not interfere with the contraction and expansion of the absorbed protein molecules thus do not decrease the elasticity. Even if oil bodies and fibres participate in the formation of the interfacial film, it seems that they do not limit the film deformability. Regarding the fibre-based mixtures, the less elastic interface can be explained by considering the high amount of fibres present in the mixture that apparently hinder the protein-protein interactions on the interface which are responsible for the elastic response against deformation. In addition, fibres are not expected to interact with proteins so instead of increasing the elasticity they seem to decrease the deformability of the interface.

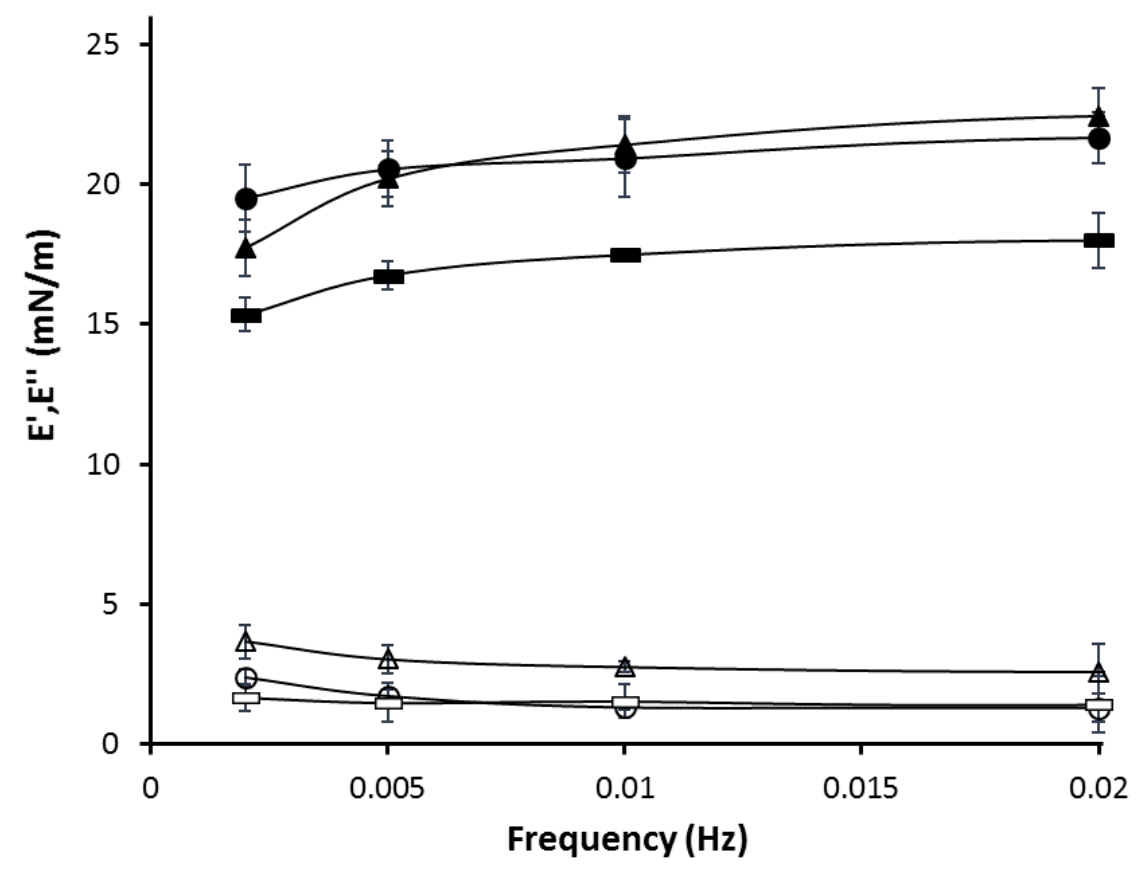

Figure 4.5 : Interfacial dilatational elastic/storage (E'(hollow symbols)) and viscous/loss (E' (bold symbols)) moduli as a function of oscillation frequency: SF cake $(\bullet)$, protein $(\boldsymbol{\Delta})$ and fibre-based mixtures(-).

\subsubsection{Emulsifying ability}

SF cake, the protein-based and the fibre-based mixtures were used to stabilise oil-in-water emulsions at $\mathrm{pH} 7$ with a constant oil and protein concentration (10 $\mathrm{wt} \%$ oil, $0.5 \mathrm{wt} \%$ protein). It is important to mention, that despite the brown colour of the derived mixtures (Fig.4.1), the emulsions formed had a white milky appearance (Fig.4.7a).

Droplet size distribution. The emulsion droplet size distributions were monitored over time as an assessment tool to investigate the emulsifying ability of the three multicomponent mixtures. The mean droplet size distributions values $\left(d_{4,3}\right)$ were recorded directly after preparation 
showcasing extensive aggregation in all the samples $\left(\mathrm{d}_{4,3} \sim 7,5 \mu \mathrm{m}\right)$. To determine the original droplet size of the emulsions and to distinguish the qualitative differences of the emulsification capacity of the mixtures, it was decided to use $0.5 \mathrm{wt} \%$ SDS for the breakage of the aggregates. SDS, as an anionic detergent, disrupts hydrogen bonds that develop among proteins and other dispersed molecules. In Fig.4.6, the droplet size distributions of fresh emulsions and after 7 days are depicted accompanied with optical microscopy images at the same time frames. The fresh oil droplets stabilized by the protein-based mixture showed a narrow size distribution from 0.3 to $1.7 \mu \mathrm{m}$ (Fig.4.6a) with average $d_{4.3}$ value at $1.27 \mu \mathrm{m}$. During storage for 7 days the droplet size remained almost stable, with a slight shift to the right and a small increase of the $d_{4.3}$ values to $1.78 \mu \mathrm{m}$. When a sunflower protein isolate was used at the same concentration to stabilize oil droplets, a similar size distribution was observed (Dimitris Karefyllakis, et al., 2017), suggesting that oil bodies did not affect the ability of proteins to stabilize the oil-water interface in 2:1 protein:oil body ratio. The droplet size distribution was also similar to the oil body size distribution (Fig.4.2a). Therefore, it was not possible to understand whether oil bodies remained stable or their membrane was ruptured to contribute to the newly formulated oil droplet membrane.

When fibres were also present, as is the case of the SF cake where proteins were in mixture with oil bodies and fibres, a clear bimodal size distribution was observed. Despite that the droplet size distribution started from the same range of $0.3 \mu \mathrm{m}$, a second major peak appeared at about $5 \mu \mathrm{m}$, resulting to $d_{4.3}$ values of $2.72 \mu \mathrm{m}$. Part of the proteins present can still independently move towards the surface and form submicron droplets, while proteins which have been associated with fibres might present decreased mobility and subsequent delayed absorption resulting in a fraction of droplets with bigger sizes $(1-10 \mu \mathrm{m})$. During storage, the population of the smaller droplets remained stable, as in the case of protein-based mixture emulsions, while a number of the bigger droplets coalesced, resulting in a shift of the second curve to the right and larger average $d_{4.3}$ values $(3.4 \mu \mathrm{m})$. The main mechanisms of emulsion destabilization are coalescence and disproportionation. Since the fraction of smaller droplets remained stable in time, it means that no significant amount of these droplets disappeared under the effect of disproportionation. At the same time, the sizes of the larger droplets, which are less stable, increased meaning that coalescence did happen for some of those droplets. It can be hypothesized that during storage, the presence of fibres in the bulk phase forced the bigger droplets to aggregate and coalesce, probably due to depletion flocculation phenomena. High concentration of non-absorbing polysaccharides have been shown to cause depletion flocculation and subsequent coalescence of the droplets, a phenomenon especially valid for larger fibres (Chanamai \& McClements, 2001).

When higher amount of fibres were present and oil bodies were absent (fibre-based mixtures) there was a profound shift to bigger droplet sizes. Apparently the enhanced presence of fibres results into the involvement of the majority of proteins into the formation of protein-fibre complexes and as a result there were not enough available protein molecules to form smaller droplets. Due to this, the depletion flocculation phenomena were more profound during storage. When the emulsification ability of cellulosic particles with $6 \mathrm{wt} \%$ protein content was examined, it was shown that the fine particles, below $1.0 \mu \mathrm{m}$ were good oil droplet stabilisers, 
as opposed to larger particles (Tenorio, et al., 2017). The presence of bigger particle sizes obtained with fibre-based mixture probably played a negative role and dictated the overall properties.

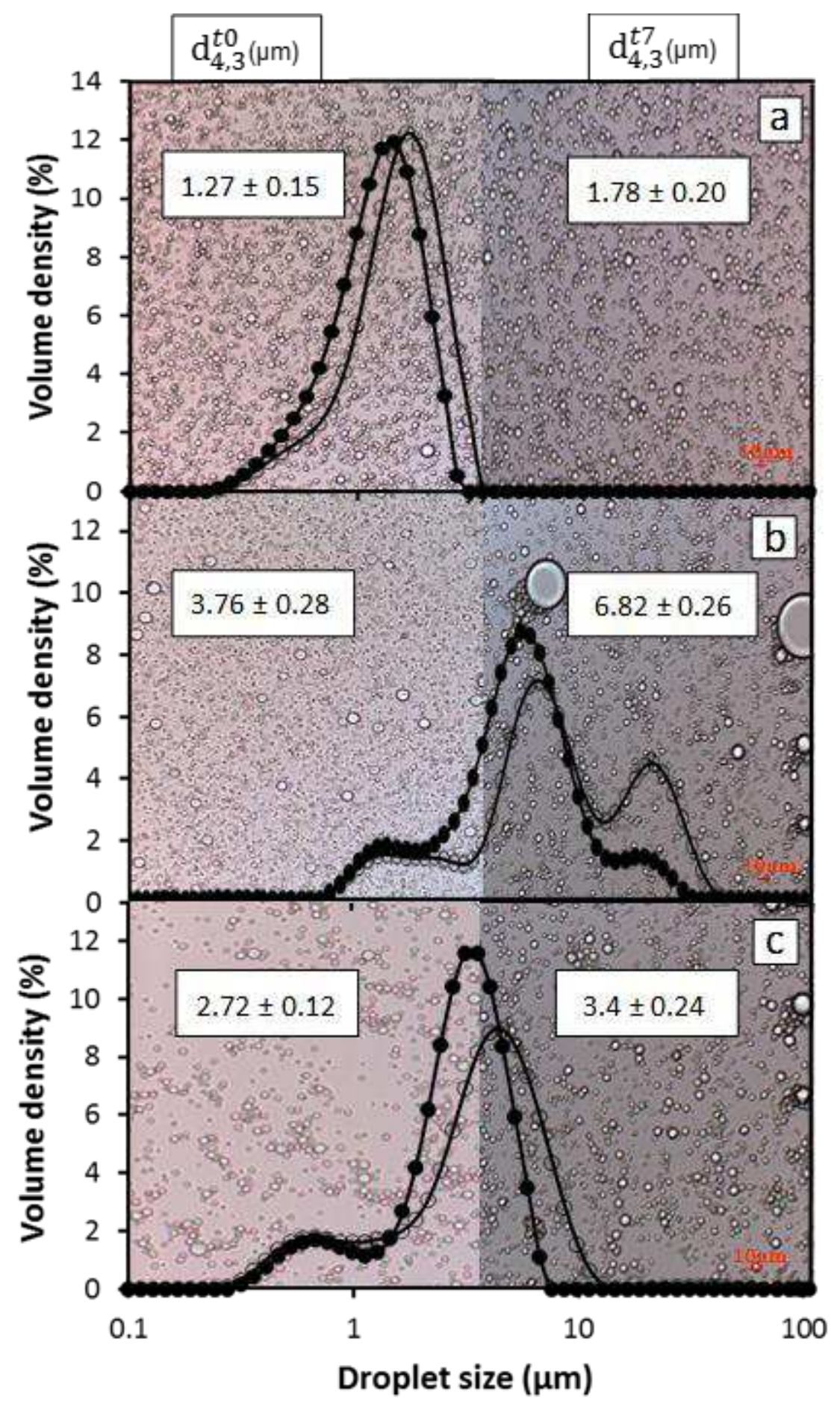

Figure 4.6 : Droplet size distributions of emulsions on day 1 (bold symbols) and 7 (hollow symbols) stabilized using a) protein and b) fibre-based mixtures and c) SF cake at $\mathrm{pH} 7$, with constant protein concentration $(0.5 \% \mathrm{w} / \mathrm{v})$ and $0.5 \mathrm{wt} \%$ SDS. Mean droplet size distributions $\mathrm{d}_{4,3}$ on day 1 and 7 are also presented in the text boxes. As background, optical microscopy images of the emulsion directly after preparation (left) and after seven days of storage (right) are illustrated. 
The $d_{4.3}$ values presented in Fig.4.6 do not differentiate greatly from the ones reported for emulsions stabilised with soy protein isolate at $\mathrm{pH} 7$ and the presence of SDS after 7 days (Chen, Zhang, \& Tang, 2016) showing that the functional properties of the much less refined fractions studied here are comparable to pure protein preparations. The performance of SF Cake as an emulsion stabiliser demonstrated high potential likewise other typical oilseed residues such as canola, soybean and flaxseed meals (Khattab \& Arntfield, 2009), although the aforementioned residues were almost completely defatted. Analogous fractions to the proteinbased mixture obtained after aqueous fractionation of yellow pea, exhibited similar stability over a period of 7 days (Geerts, et al., 2017). In overall, these results depict a notable performance of the protein-based mixture and the SF Cake at the oil-water interface against coalescence since minor changes in the droplet size were observed after the interval of 7 days proving the relevance of these ingredients as emulsifiers for food applications.

Creaming stability. The stability of the emulsions was monitored using the creaming index upon storage for 7 days. The results are depicted in Fig.4.7a; however, only the measurements until 30 hours are presented since the creaming reached a plateau by that point. Optical micrographs of the creamed emulsions at 30 hours revealed extensive aggregation of the droplets in all the samples (Fig.4.7c). All emulsions reached a similar creaming index after a period of $30 \mathrm{hrs}$, however the samples with SF cake and protein-based mixtures showed slower creaming. For comparison, $30 \%$ of creaming for emulsions stabilized by soy protein isolate at pH 7 was only reached after the passage of 120 hours (Chen, Zhang, \& Tang, 2016). The effect of fibres in the SF cake seems to be disrupting the network leading to faster creaming kinetics. The negative effect regarding the presence of fibres was as expected the highest in the fibrebased mixtures, where it is probable that extensive aggregation takes place due to depletion flocculation caused by the big amount of non-absorbing polysaccharides being present in this sample. It is possible that depletion flocculation might subsequently lead to bridging flocculation (Blijdenstein, Van Winden, Van Vliet, Van der Linden, \& Van Aken, 2004). However, no free oil separation was observed for any of the emulsions after 7 days of storage (Fig.4.7b). This indicates that no extensive coalescence occurred. Bridging flocculation can be caused by a polysaccharide molecule hydrophobically or electrically complexed with the interfacial proteins of two droplets which might be the main reason behind the rapid creaming of the fibre-based mixture emulsion. 


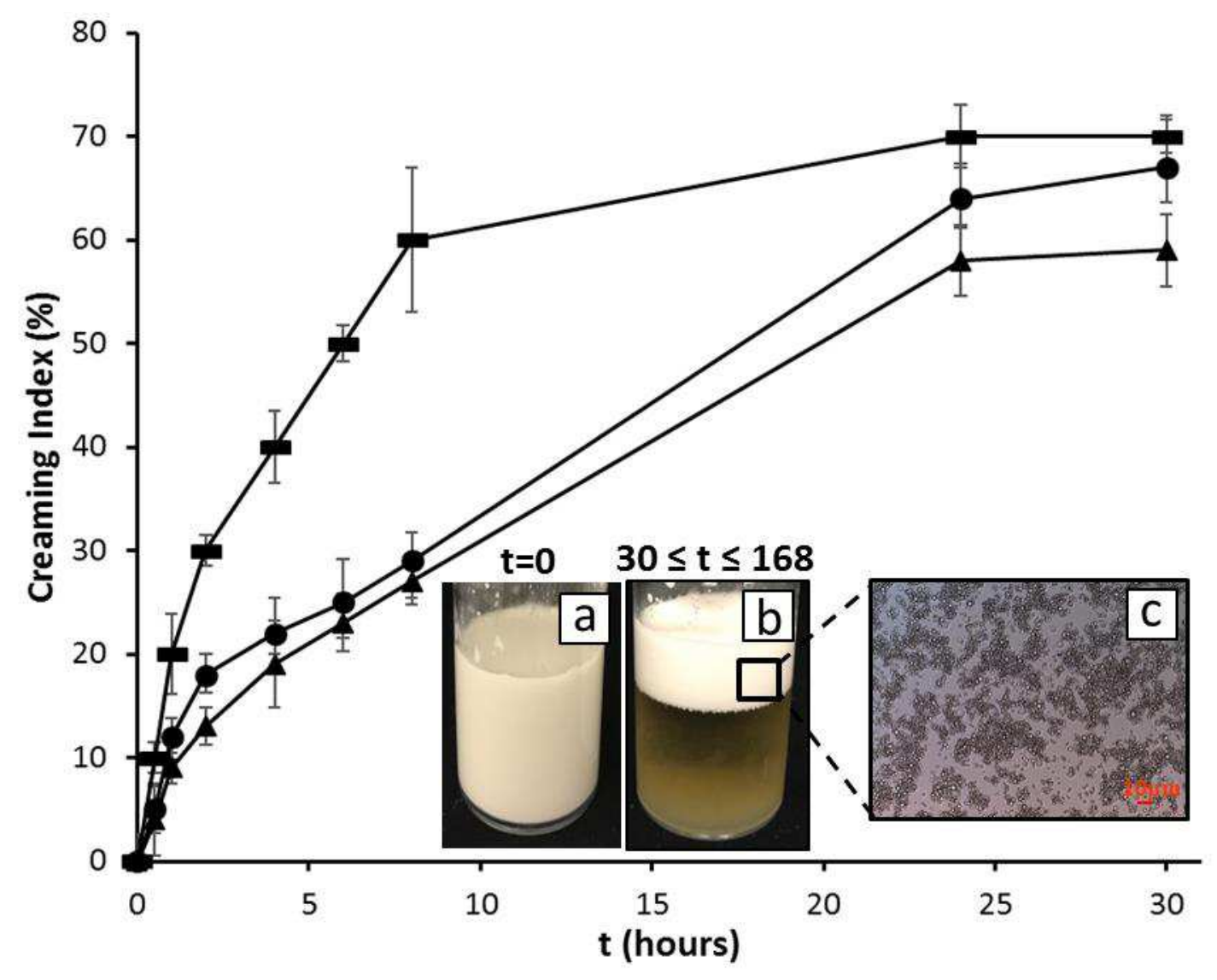

Figure 4.7 : Evolution of creaming index percentage for emulsions stabilized by SF cake $(\bullet)$, protein $(\boldsymbol{\Delta})$ and fibre-based mixtures $(-)$ at $\mathrm{pH} 7$ and with constant protein concentration $(0.5 \% \mathrm{w} / \mathrm{v})$. In the inset are a) a microscopic picture of an emulsion directly after preparation, b) a creamed emulsion where no oiling-off could be observed until 7 days of storage and c) a microscopy picture of the cream at $30 \mathrm{~h}$ where the extensive aggregation is evident.

\subsection{Conclusions}

The functionality of less refined fractions originating from sunflower seeds was investigated. The focus was the overall functionality of the multiple components rather than the performance of pure compounds. Sunflower seeds were cold-pressed resulting in the production of a sunflower press cake. The mild conditions applied during the subsequent aqueous fractionation of the SF cake resulted in protein and fibre-based mixtures. It was proven that the residual oil in the Sf cake and the protein-based mixtures was present in the form of naturally emulsified oil droplets, so-called oil bodies. Oil bodies and polysaccharides had a notable impact on the interfacial activity of the samples. Their presence delayed the diffusion of the protein molecules towards the interface and altered their rearrangement rate indicating the possibility that the multicomponent mixtures might act as Pickering stabilizers.

When the emulsification capacity of the samples was examined, it was shown that the complexity of the emulsifiers did not restrict their performance. Additionally, the oil bodies 
appeared to have little to no impact on the emulsification efficiency and stability. In addition, the fact that the SF cake exhibited a notable performance at the oil-water interface against coalescence, implies that SF Cake could find direct applications as an ingredient and that even simple processing steps, like centrifugation, applied for the isolation of more protein-rich fractions could be regarded unnecessary. Taking everything into account, the samples examined here were mixtures of high complexity containing three main classes of macromolecules, proteins polysaccharides and oil bodies, which nonetheless exhibited a satisfactory emulsification performance, even comparable to pure protein preparations, proving the relevance of these mixtures as ingredients for food applications.

\section{Acknowledgments}

This work took place within the framework of the Institute for Sustainable Process technology (ISPT) 


\section{References}

Aiking, H. (2011). Future protein supply. Trends in Food Science \& Technology, 22(2-3), 112-120.

Apaiah, R. K., Linnemann, A. R., \& van der Kooi, H. J. (2006). Exergy analysis: A tool to study the sustainability of food supply chains. Food Research International, 39(1), 1-11.

Baeza, R., Sanchez, C. C., Pilosof, A. M., \& Patino, J. M. R. (2005). Interactions of polysaccharides with $\beta-$ lactoglobulin adsorbed films at the air-water interface. Food Hydrocolloids, 19(2), 239-248.

Berton, C., Genot, C., \& Ropers, M.-H. (2011). Quantification of unadsorbed protein and surfactant emulsifiers in oil-in-water emulsions. Journal of colloid and interface science, 354(2), 739-748.

Boland, M. J., Rae, A. N., Vereijken, J. M., Meuwissen, M. P., Fischer, A. R., van Boekel, M. A., Rutherfurd, S. M., Gruppen, H., Moughan, P. J., \& Hendriks, W. H. (2013). The future supply of animal-derived protein for human consumption. Trends in Food Science \& Technology, 29(1), 62-73.

Boye, J. I., \& Arcand, Y. (2013). Current trends in green technologies in food production and processing. Food Engineering Reviews, 5(1), 1-17.

Campbell, K., Glatz, C., Johnson, L., Jung, S., De Moura, J., Kapchie, V., \& Murphy, P. (2011). Advances in aqueous extraction processing of soybeans. Journal of the American Oil Chemists' Society, 88(4)

Chanamai, R., \& McClements, D. (2001). Depletion flocculation of beverage emulsions by gum arabic and modified starch. Journal of food science, 66(3), 457-463.

Chen, S., Zhang, N., \& Tang, C.-H. (2016). Influence of nanocomplexation with curcumin on emulsifying properties and emulsion oxidative stability of soy protein isolate at $\mathrm{pH} 3.0$ and 7.0. Food Hydrocolloids, $61,102-112$.

Dunn, P. J., Wells, A., \& Williams, M. T. (2010). Green chemistry in the pharmaceutical industry: John Wiley

Geerts, M. E., Nikiforidis, C. V., van der Goot, A. J., \& van der Padt, A. (2017). Protein nativity explains emulsifying properties of aqueous extracted protein components from yellow pea. Food Structure, 14, 104-111.

González-Pérez, S., \& Vereijken, J. M. (2007). Sunflower proteins: overview of their physicochemical, structural and functional properties. Journal of the Science of Food and Agriculture, 87(12), 2173-2191.

Ishii, T., Matsumiya, K., Nambu, Y., Samoto, M., Yanagisawa, M., \& Matsumura, Y. (2017). Interfacial and emulsifying properties of crude and purified soybean oil bodies. Food Structure, 12, 64-72.

Karefyllakis, D., Altunkaya, S., Berton-Carabin, C. C., Van Der Goot, A. J., \& Nikiforidis, C. V. (2017). Physical bonding between sunflower proteins and phenols: Impact on interfacial properties. Food Hydrocolloids.

Karefyllakis, D., Salakou, S., Bitter, J. H., van der Goot, A. J., \& Nikiforidis, C. V. (2018). Covalent Bonding of Chlorogenic Acid Induces Structural Modifications on Sunflower Proteins. ChemPhysChem, 19(4), 459468.

Karkani, O. A., Nenadis, N., Nikiforidis, C. V., \& Kiosseoglou, V. (2013). Effect of recovery methods on the oxidative and physical stability of oil body emulsions. Food Chemistry, 139(1-4), 640-648.

Khattab, R., \& Arntfield, S. (2009). Functional properties of raw and processed canola meal. LWT-Food Science and Technology, 42(6), 1119-1124.

Lomascolo, A., Uzan-Boukhris, E., Sigoillot, J.-C., \& Fine, F. (2012). Rapeseed and sunflower meal: a review on biotechnology status and challenges. Applied microbiology and biotechnology, 95(5), 1105-1114.

Martínez-Force, E., Dunford, N. T., \& Salas, J. J. (2015). Sunflower: chemistry, production, processing, and utilization: Elsevier.

McClements, D. J. (2015). Food emulsions: principles, practices, and techniques: CRC press.

Moure, A., Sineiro, J., Domínguez, H., \& Parajó, J. C. (2006). Functionality of oilseed protein products: A review. Food Research International, 39(9), 945-963.

Mulvihill, D., \& Ennis, M. (2003). Functional milk proteins: production and utilization. In Advanced dairy chemistry-1 Proteins (pp. 1175-1228): Springer.

Navarro, S. L., \& Rodrigues, C. E. (2016). Macadamia oil extraction methods and uses for the defatted meal byproduct. Trends in Food Science \& Technology, 54, 148-154.

Nikiforidis, C., Kiosseoglou, V., \& Scholten, E. (2013). Oil bodies: An insight on their microstructure-maize germ vs sunflower seed. Food Research International, 52(1), 136-141.

Nikiforidis, C. V., Ampatzidis, C., Lalou, S., Scholten, E., Karapantsios, T. D., \& Kiosseoglou, V. (2013). Purified oleosins at air-water interfaces. Soft Matter, 9(4), 1354-1363.

Nikiforidis, C. V., Kiosseoglou, V., \& Scholten, E. (2013). Oil bodies: An insight on their microstructure - maize germ vs sunflower seed. Food Research International, 52(1), 136-141.

Payne, G., Lad, M., Foster, T., Khosla, A., \& Gray, D. (2014). Composition and properties of the surface of oil bodies recovered from Echium plantagineum. Colloids and Surfaces B: Biointerfaces, 116, 88-92.

Pelgrom, P. J., Berghout, J. A., van der Goot, A. J., Boom, R. M., \& Schutyser, M. A. (2014). Preparation of functional lupine protein fractions by dry separation. LWT-Food Science and Technology, 59(2), 680-688

Salunkhe, D. K. (1992). World oilseeds: Springer Science \& Business Media.

Sosulski, F. (1979). Organoleptic and nutritional effects of phenolic compounds on oilseed protein products: a review. Journal of the American Oil Chemists' Society, 56(8), 711-715.

Tenorio, A. T., Gieteling, J., Nikiforidis, C., Boom, R., \& van der Goot, A. (2017). Interfacial properties of green leaf cellulosic particles. Food Hydrocolloids, 71, 8-16.

Tran, T., \& Rousseau, D. (2013). Stabilization of acidic soy protein-based dispersions and emulsions by soy soluble polysaccharides. Food Hydrocolloids, 30(1), 382-392.

van der Goot, A. J., Pelgrom, P. J., Berghout, J. A., Geerts, M. E., Jankowiak, L., Hardt, N. A., Keijer, J., Schutyser, M. A., Nikiforidis, C. V., \& Boom, R. M. (2016). Concepts for further sustainable production of foods. Journal of Food Engineering, 168, 42-51.

Žilić, S., Barać, M., Pešić, M., Crevar, M., Stanojević, S., Nišavić, A., Saratlić, G., \& Tolimir, M. (2010). Characterization of sunflower seed and kernel proteins. Helia, 33(52), 103-114. 


\section{Chapter 5}

\section{The behaviour of sunflower oil bodies at the interfaces}

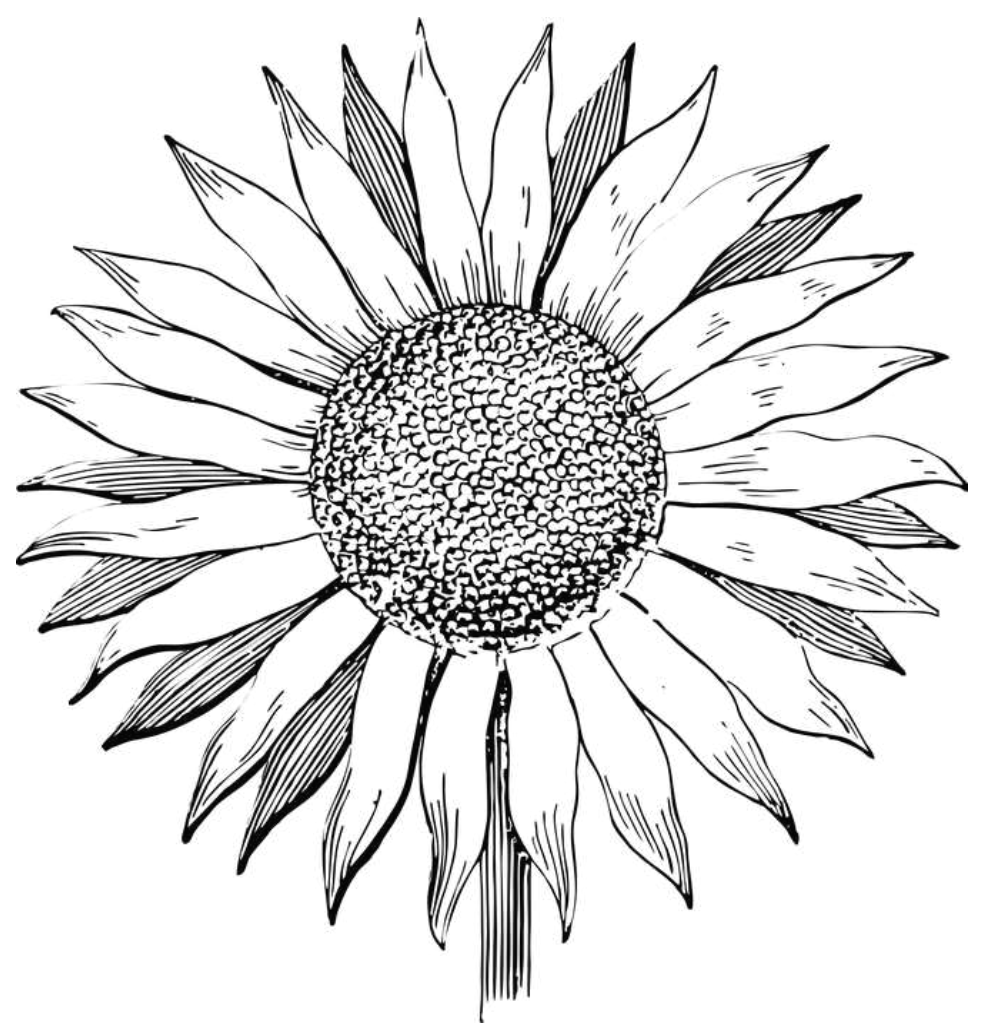

This chapter has been submitted as :

Karefyllakis, D., Van Der Goot, A. J., \& Nikiforidis, C. V. The behaviour of sunflower oil bodies at the interfaces. 


\section{A B S T R A C T}

The safe storage of oil and its arduous mixing with hydrophilic systems has been resolved by nature with organelles called oil bodies (or oleosomes). Oil bodies are particles equipped with a sophisticated membrane, comprising a continuous monolayer of phospholipids and hydrophobic proteins, which covers the triglyceride core and grants them extreme physical and chemical stability. The noteworthy qualities of oil bodies have attracted strong interest for their incorporation in emulsion formulations, however, little is known about their emulsifying properties and their behaviour on interfaces. For these reasons, oil bodies were isolated from sunflower seeds (96.2 wt $\%$ oil, $3.1 \mathrm{wt} \%$ protein) and used as an emulsifier for the stabilization of $\mathrm{O} / \mathrm{W}$ and $\mathrm{W} / \mathrm{O}$ interfaces. In both cases, oil bodies showed high interfacial and emulsifying activity. Individual oil body particles had a broad size distribution from 0.4 to $10.0 \mu \mathrm{m}$ and it was observed that the membrane of the larger oil bodies $(>1-5 \mu \mathrm{m})$ was disrupted and its fractions participated in the in newly formed interface. Oil bodies with a smaller diameter (< $1 \mu \mathrm{m}$ ) were resilient during the mild emulsification as a great number of them was present in the emulsions especially on the interface of the emulsion droplets. This phenomenon was more pronounced for the $\mathrm{W} / \mathrm{O}$ interface where oil bodies were absorbed intact in a manner similar to Pickering mechanism. However, when the triglycerides were removed from the core of oil bodies in order to focus more on the effect of the membrane, the remaining material formed sub-micron spherical particles, which clearly acted as Pickering stabilisers. These findings showcase the intriguing behaviour of oil bodies upon emulsification, especially the crucial role of their membrane. The study demonstrates relevance for future applications where immiscible liquid phases are present. 


\subsection{Introduction}

Nature has been always a great source of inspiration regarding innovations in science and technology. Emulating life's unique developments leads to the fabrication of bioinspired and bioderived materials with high functionality. Those biobased materials can offer evolvedthrough-the-millennia solutions to practical challenges humanity faces. A characteristic example of such a resourceful engineering can be found in plant seeds where the protection of oil (mostly triacylglycerides) against oxidation and its arduous mixing with hydrophilic systems has been resolved by nature with organelles called oil bodies (Tzen \& Huang, 1992).

The primary function of oil bodies is to store the seed energy source, during seed dormancy and protect them against environmental stresses (Bewley \& Black, 1994). To achieve this, oil bodies are equipped with a sophisticated membrane that covers the triacylglyceride core and grants them extreme physical and chemical stability (Karkani, Nenadis, Nikiforidis, \& Kiosseoglou, 2013; Tzen \& Huang, 1992). The membrane consists of a continuous monolayer of phospholipids to which a number of uniquely hydrophobic proteins (oleosins, caleosins and steroleosins) are embedded. Oleosins are the dominant ones and all three groups of proteins have long hydrophobic domains that are anchored into the oil phase, while their amphiphilic termini rest on the hydrophilic oil body surface (Huang, 2018).

When applying pressing or organic solvent extraction oil body membrane is disrupted and the oil core is extracted. However, in order to extract intact oil bodies an environmental friendly aqueous extraction process has to be followed. When intact oil bodies are extracted, the aforementioned noteworthy qualities of physical and chemical stability are conveyed to the resulting "natural" oil-in-water emulsions (Fisk, White, Lad, \& Gray, 2008; Iwanaga, et al., 2007). Besides stability, these biobased emulsions bear additional conveniences as a consequence of their pre-existence considering that neither emulsifiers nor the high energy consuming step of homogenization are required (Nikiforidis, Kiosseoglou, \& Scholten, 2013). Therefore, scientists from different disciplines are currently investigating their in situ properties and the potential applications of these pre-emulsified systems in several fields like foods and pharmaceuticals (Chen, McClements, Gray, \& Decker, 2012; Chiang, Lin, Lu, \& Wang, 2011; Nikiforidis, Biliaderis, \& Kiosseoglou, 2012).

Nonetheless, to deeply understand the molecular interactions in the oil body membrane and also explore new potential applications, it is important to investigate the properties of oil bodies when an extrinsic oil/water interface is present. Do actually the molecules of the oil body membrane rearrange and cover the new available interface or they remain intact? This was the aim of this work. Oil bodies were extracted from sunflower seeds and interfacial tensiometry combined with electron and confocal microscopy techniques were used to track the behaviour of the oil bodies on oil/water interfaces. Oil bodies from sunflower seeds were chosen due to their big size (Nikiforidis, et al., 2013) that could be more easily observed with the applied microscopy techniques. 


\subsection{Materials and methods}

\section{Materials}

Dehulled and not additionally treated sunflower seeds were ordered from Notenstore (Bergschenhoek, The Netherlands). Sunflower oil (SF oil) was purchased from the local market and was filtered with silica (MP Alumina N-Super I, MP Biomedicals, Germany) (Berton, Genot, \& Ropers, 2011) to remove any polar compounds. Sunflower protein isolate (SFPI) of high purity (96 wt $\%$ ) was isolated during a previous work (Karefyllakis, Altunkaya, BertonCarabin, Van Der Goot, \& Nikiforidis, 2017). Petroleum ether, ethanol, potassium monobasic dihydrate, potassium phosphate dibasic, sodium hydroxide and hydrochloric acid were all purchased from Sigma Aldrich (Sigma, USA) and were of analytical grade. For all analyses ultrapure water was used.

\section{Methods}

\subsubsection{Extraction of sunflower oil bodies (SFOB)}

SFOB were extracted from sunflower seeds using an aqueous method developed by Nikiforidis et al. (Nikiforidis \& Kiosseoglou, 2009) with slight modifications. First, seeds were soaked overnight in aqueous solution of $\mathrm{pH} 8$, adjusted with $4 \mathrm{M} \mathrm{NaOH}$, and stored at $4^{\circ} \mathrm{C}$. After overnight soaking (16 hours), the excess aqueous solution was drained off using a strainer. The seeds were then ground with demi water in the ratio 1:7 (w/v) for 90 seconds in a laboratory blender at maximum speed. The slurry was then passed through a commercial juicer in order to remove the solid left over. The crude extract obtained as filtrate was centrifuged at 10,000 $\mathrm{g}$ at $4^{0} \mathrm{C}$ for $30 \mathrm{~min}$. The cream layer was then carefully removed and subsequently re-suspended in aqueous solution $\mathrm{pH} 8$ at 1:4 ratio (w/v) and centrifuged at the same conditions. This washing circle was repeated once more.

\subsubsection{Protein and oil content}

The protein content was determined by Dumas analysis (Nitrogen analyzer FlashEA 1112 series, Thermo Scientific, The Netherlands). The protein factor used to calculate the percentage of protein was 5.8 (Martínez-Force, Dunford, \& Salas, 2015). The oil content was obtained using an automated Soxhlet device (Buchi B-811, Buchi Labortechnik AG, Flawil, Switzerland) for $12 \mathrm{~h}$ using petroleum ether. All the analyses were performed in triplicates.

\subsubsection{Defatting the $S F O B$ cream}

Part of the SFO cream was left to dry at $35^{\circ} \mathrm{C}$ over the course of 2 days. The dried cream was then subjected to oil extraction using an automated Soxhlet device using petroleum ether (Buchi B-811, Buchi Labortechnik AG, Flawil, Switzerland) for $12 \mathrm{~h}$. The resulting powder was left in open air until all the solvent was evaporated and was called defatted SFO.

\subsubsection{Emulsion preparation}

Emulsions were prepared by dispersing $0.5 \mathrm{wt} \%$ of the SFOB, SFPI and the defatted SFOB in aquatic $0.1 \mathrm{M}$ phosphate buffer $\mathrm{pH} 8$ and stirred for $30 \mathrm{~min}$. Sunflower oil was then slowly 
added and a coarse emulsion ( $10 \mathrm{wt} \%$ and $90 \mathrm{wt} \%$ in sunflower oil for $\mathrm{O} / \mathrm{W}$ and $\mathrm{W} / \mathrm{O}$ emulsions respectively) was made using a rotor-stator homogenizer (9500 rpm, $3 \mathrm{~min}$ ) (UltraTurrax, IKA, California, United states).

\subsubsection{Dynamic interfacial properties}

Interfacial tension measurements at the $\mathrm{O} / \mathrm{W}$ and $\mathrm{W} / \mathrm{O}$ interface were recorded using an automated drop tensiometer (ADT) (Tracker, Teclis-IT Concept, France). The protein concentration was equalised in both cases $(0.001 \%$ and $0.01 \% \mathrm{w} / \mathrm{v}$ for $\mathrm{O} / \mathrm{W}$ and $\mathrm{W} / \mathrm{O}$ respectively). Stripped sunflower oil was used and the emulsifiers were left to diffuse from the inside of the droplet towards the interface and from the cuvette towards the interface respectively. The initial droplet volume was set to $16 \mu \mathrm{L}$, with corresponding droplet area of $30 \mathrm{~mm}^{2}$. The interfacial tension was monitored for $3 \mathrm{~h}$ while keeping the droplet volume constant.

\subsubsection{Confocal Laser Scanning Microscopy (CLSM).}

CLSM images were obtained at room temperature on a LEICA TCS SP5 Confocal Laser Scanning Microscope (Leica Microsystems GmbH., Mannheim, Germany) equipped with an inverted microscope (model Leica DMI6000), containing a set of four visible light lasers. The used objectives were HC PL APO $10 \times / 0.40 \mathrm{CS}$ and HC PL APO $20 \times / 0.70 \mathrm{IMM} / \mathrm{CORR}$ CS. Digital image files were acquired in $1024 \times 1024$ pixel resolution and were analysed with the program Zeiss SLM image examiner (Zeiss group, Oberkochen, Germany). Samples were carefully placed on a microscope slide and stained with a droplet of aquatic Nile Blue $1.0 \mathrm{wt} . \%$.

\subsubsection{Cryo-Scanning Electron Microscope imaging (cryo-SEM).}

Dry SFOB cream was glued onto a brass sample holder by carbon glue (Leit-C, Neubauer Chemicalien,Germany) and subsequently frozen with the use of liquid nitrogen. The sample holder was fitted into the transfer cryogenic Leica holder. All manipulations were carried out under liquid nitrogen. The Leica sample holder was transferred in a non-dedicated cryopreparation system (MED 020/VCT 100, Leica, Vienna, Austria) onto a sample stage at $-93{ }^{\circ} \mathrm{C}$. In this cryo-preparation chamber, the samples were immediately fractured and freeze-dried for $23 \mathrm{~min}$ at $-93{ }^{\circ} \mathrm{C}$ at $1.3 \times 10^{-6} \mathrm{mbar}$ to remove contaminating water vapor. The samples were sputter-coated with a layer of $4 \mathrm{~nm}$ Tungsten at the same temperature and transferred cryoshielded into the field emission scanning microscope (Magellan 400, FEI, Eindhoven, the Netherlands) onto a sample stage equilibrated at $-122{ }^{\circ} \mathrm{C}$ at $4 \times 10^{-7} \mathrm{mBar}$. The analysis was performed with SE at $2 \mathrm{kV}, 13 \mathrm{pA}$. All images were recorded digitally. 


\subsection{Results and discussion}

\subsubsection{Membrane structure of oil bodies}

The detailed configuration of the oil body membrane has been investigated for long, however, even until today a general consensus has not been reached entirely (Huang, 2018). An illustration of the generally accepted oil body model can be seen in Fig.5.1 a and is valid for the majority of oilseeds, including sunflower. To investigate the structure of the extracted sunflower oil bodies, confocal microscopy was employed. As shown in Fig.5.1b, sunflower oil bodies were spherical droplets that appeared in various diameters from sub-micron sizes until a few $\mu \mathrm{m}$. The initial size of sunflower oil bodies is expected to be lower $(\sim 1 \mu \mathrm{m})$ (Nikiforidis, et al., 2013), therefore the presence of large oil bodies $(\sim 10 \mu \mathrm{m})$ could be attributed to partial coalescence during the extraction procedure. Despite that the tight packing and absence of bulk water inside the cells (Nikiforidis, et al., 2013) allow the survival of oil bodies, agitation and extensive hydrophobic forces between neighboured oil bodies is probably forcing them to aggregate and to certain extend coalesce. In addition, confocal microscopy revealed that besides the interfacial proteins, there is still the minor amount of extrinsic proteins present, which is shown in the CLSM image in red colour (Fig.5.1b). It has been reported that storage proteins are co-extracted with oil bodies from sunflower seeds and despite the applied washing steps they are not completely removed (Nikiforidis, et al., 2013). They interact through hydrophobic forces with the oil body interfacial proteins and can act as bridges between neighbouring oil bodies. Nevertheless, the protein content of the SFOB in dry basis was $3.1 \mathrm{wt} \%$, while the oil content was $96.2 \mathrm{wt} \%$. The oil/protein ratio in isolated oil bodies from different seeds is in this range (Tzen, Lie, \& Huang, 1992), therefore we presume that the amount of extrinsic proteins is minor.
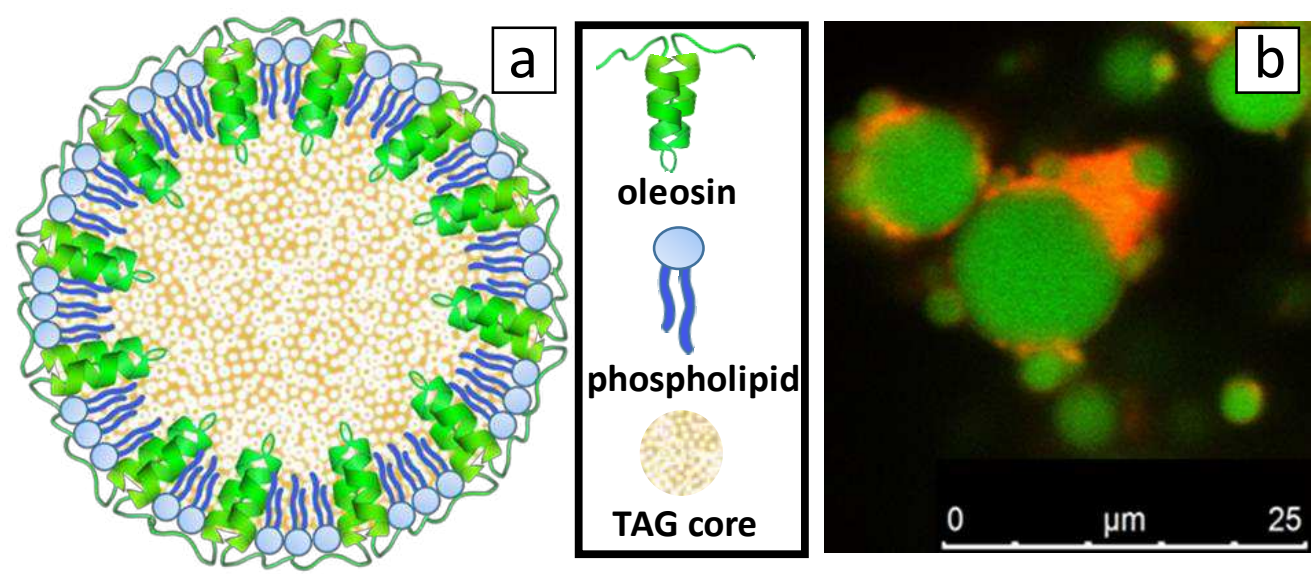

Figure 5.1 : a) 2D- model of an oil body with an emphasis on the configuration of the membrane, composed from a monolayer of phospholipids with the hydrophobic oleosin proteins anchored in the triacylglyceride (TAG) core (sizes not to scale), b) CLSM image of SFO stained by Nile Blue showing lipids in green and proteins in red. 


\subsubsection{Oil bodies at the $\mathrm{O} / W$ interface}

The behaviour of oil bodies on interfaces is still largely unknown as it is uncertain what happens to their membrane upon mixing with bulk oil, homogenization and absorption. It has been proven though that isolated oil bodies as well as their membrane components are highly interfacially active (Deleu, et al., 2010; Ishii, et al., 2017; Nikiforidis, et al., 2013). However, when mixed with high amounts of extraneous proteins (protein : oil body $3: 1$ ), oil bodies appeared to have little to no impact on the emulsification efficiency (Karefyllakis, Octaviana, van der Goot, \& Nikiforidis, 2019). This indicates that the presence of storage proteins should be taken into account when the interfacial behaviour of the oil bodies is examined as extraneous proteins might influence it severely when present in high concentration. This scenario is schematically illustrated in Fig.5.2a, where it is illustrated that storage proteins are hindering the absorption of oil bodies at the droplet interface by bridging them and by dominating the oil/water interface.

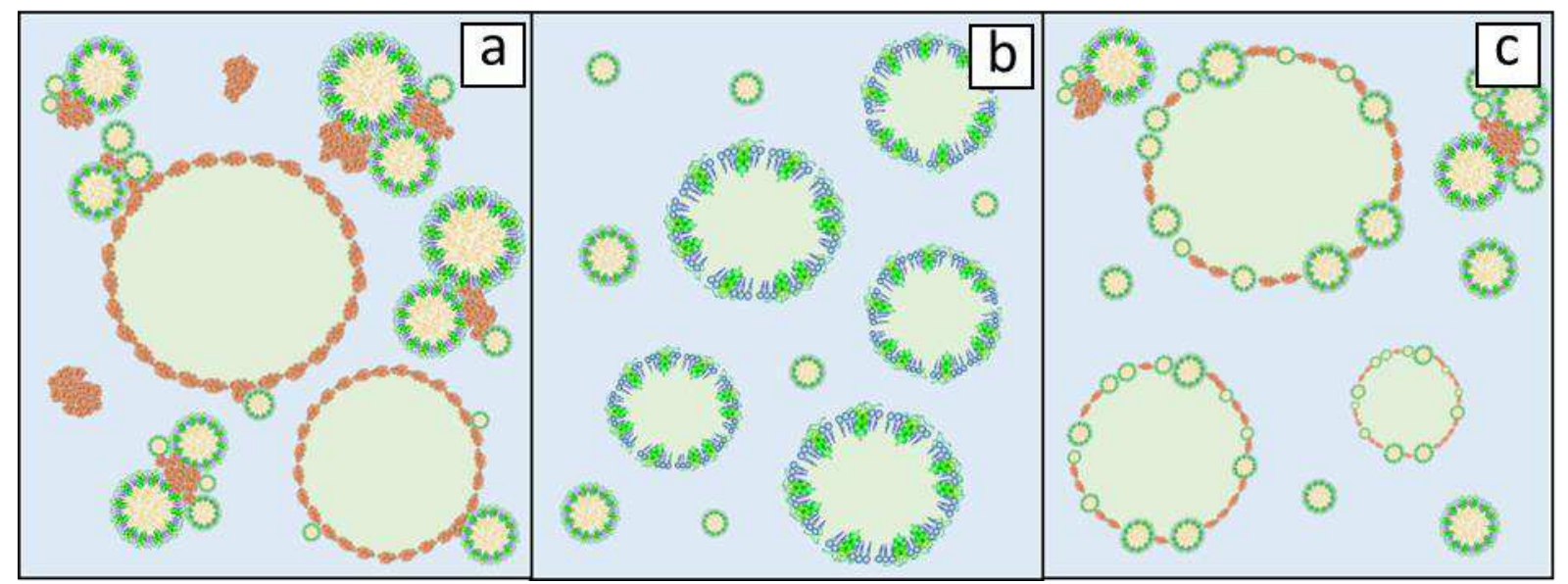

Figure 5.2 : Schematic representation of $\mathrm{O} / \mathrm{W}$ emulsion cases where a) oil bodies do not participate at the formation of the interface due to storage proteins (orange elements) and $b$ ) purified oil bodies stabilise the interface after disintegrating or c) oil bodies act as intact particles via Pickering mechanism together with absorbed proteins. The emulsified oil is depicted in light green and the continuous phase (water) in light blue.

The removal of storage proteins simplifies the picture and allows safer conclusions on the oil body behaviour. When the absorption of purified soybean oil bodies at the air-water interface was examined, it was showcased that rupture of these organelles presumably occurred and that fragments of their membrane (oleosin/phospholipid mixtures) participated in the stabilization of the interface (Waschatko, Schiedt, Vilgis, \& Junghans, 2012). Similar findings were reported for emulsions stabilised by purified soybean oil bodies where analysis of cryo-SEM images revealed an oil droplet interface free from intact oil bodies pointing also towards the potential rupture of these organelles upon absorption (Ishii, et al., 2017). A schematic representation of such an emulsion, stabilised by fragmented oil bodies, is shown in Fig.5.2b. One last scenario could be that oil bodies do not disintegrate upon absorption but they remain intact at the $\mathrm{O} / \mathrm{W}$ interface. Detailed surface pressure studies for soybean oil bodies and reconstituted oil bodies revealed that intact oil bodies can indeed stabilise the $\mathrm{O} / \mathrm{W}$ interface; however, after long time intervals, oil bodies seem to collapse followed by rearrangements of their components at the 
interface (Bettini, Santino, Giancane, \& Valli, 2014; Waschatko, Schiedt, et al., 2012). This could signify that oil bodies do not rupture but act as Pickering stabilizers on the $\mathrm{O} / \mathrm{W}$ interface. Pickering stabilisation is a mechanism of stabilisation of a membrane interface by solid particles that do not deform upon absorption like proteins do (Pickering, 1907). An illustration of such a scenario is represented in Fig.5.2c.

In order to clarify which scenario describes the behaviour of sunflower oil bodies more accurately, the isolated SFOB was used as an emulsifier for the stabilization of oil-in-water emulsions. CLSM analysis of an emulsion stabilized by SFOB is presented in Fig.5.3a. For comparison, CLSM images of an emulsion stabilised with sunflower protein isolate is shown in Fig.5.3b. As it is shown in Fig.3b, there were a few protein aggregates in the continuous phase (red colour), while absorbed proteins on the interface formed a very thin homogeneous film, since no red colour could be observed. On the other hand, when SFOB was used a different type of oil droplet interface was observed. At this case dense red coloured particles are observed on the interface. This indicates that a material that contains protein is absorbed, which should be the SFOB. The diameter of the formed oil droplets during homogenization had been deliberately chosen to be big $(>10 \mu \mathrm{m})$ in order to easily distinguish them from the SFOB $(\leq 10 \mu \mathrm{m})$. However, no droplets at the range of $1-10 \mu \mathrm{m}$ could be observed, an indication that the oil bodies that had this size (Fig.5.1a), probably merge with the newly formed oil droplets. At the same time, the smaller oil bodies $(<5 \mu \mathrm{m})$ seem to remain stable or absorb or participate on the oil/water interface.

Signal enhancement of the produced SFOB stabilised emulsions, shown in Fig.5.3c, lead to better visualisation of the elements present at the interface. It is important to state though that due to the signal enhancement the interface is probably not on scale. It became apparent that a material that contains protein (now with green) has been absorbed at the interface giving a strong signal. However, the most interesting observation is the red spherical particles that are uniformly arranged on the droplet interface. The colour difference indicates that a non-protein material is absorbed onto the interface. One can only assume that these small spheres are oil bodies that have been absorbed intact on the interface of new oil droplet. This could signify that the smaller oil bodies and apparently more stable than the bigger ones do not rupture but act as Pickering stabilizers on the $\mathrm{O} / \mathrm{W}$ interface. In addition, membrane material of the larger oil bodies that merged with the newly formed oil droplets could also participate to the interface. In detailed interfacial studies of purified soybean oil bodies on the air-water interface, it was suggested that rupture of all the oil bodies occurs and that their membrane fragments absorb on the interface (Waschatko, Junghans, \& Vilgis, 2012).In another research where the behaviour of pure soybean oil bodies was studied on the $\mathrm{O} / \mathrm{W}$ interface, same explanation was suggested for the stabilization of the interface (Ishii, et al., 2017). In both studies, it is supported that the oil bodies initially absorb intact on the interface and subsequently disintegrate in interfacially active membrane fragments. From our results, sunflower oil bodies seemed to either rupture (larger oil bodies) or act as Pickering stabilisers (smaller oil bodies) depending on their size. 


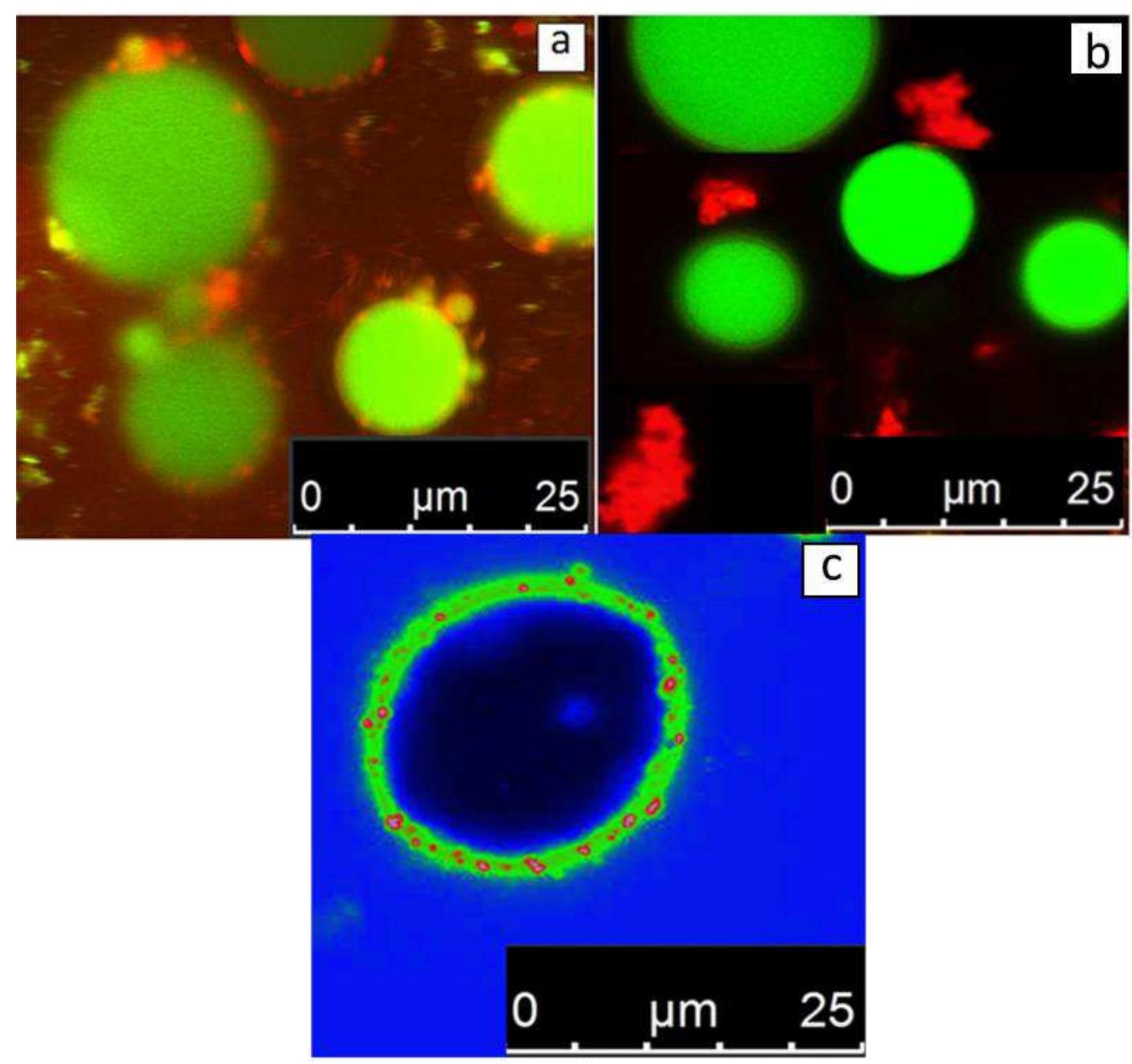

Figure 5.3 : CLSM-imaging of an O/W emulsion stabilised by a) SFOB and b) SFPI. In figure c)an $\mathrm{O} / \mathrm{W}$ emulsion stabilised by SFOB is shown with signal enhancement. Samples are stained by Nile Blue showing lipids in green and proteins in red. Due to signal enhancement, in Fig.5.3c proteins are shown green and red depending on their concentration. Water is shown in black and lipids are shown in blue.

\subsubsection{Oil bodies at the $W / O$ interface}

While some theories have been reported for the behaviour of oil bodies at the $\mathrm{O} / \mathrm{W}$ interface, nothing is known about how oil bodies behave at W/O interfaces. In this situation where oil bodies are exposed to a non-polar continuous phase, it is possible the impact would be different and even amplified. For these reasons W/O emulsions were prepared with the SFOB and their analysis with CLSM, are shown in Fig.5.4. Due to mild homogenization step, large water droplets with diameters ranging from 5 to $20 \mu \mathrm{m}$ where formed. No dispersed oil bodies observed in the oil continuous phase, showing that the bigger oil bodies ruptured and merged with the oil phase. It can also be seen at Fig.5.4 that the water droplets were stabilized by small spherical particles with a diameter up to $3 \mu \mathrm{m}$. It can be concluded that water droplets are stabilized through Pickering mechanism by the smaller oil bodies that initially occurred in SFOB and remain intact (Berton-Carabin \& Schroën, 2015; Feng \& Lee, 2016; Tan, et al., 2012; 
Ye, Zhu, \& Singh, 2013). Similar to the case of O/W emulsions (Fig.5.3), the water/oil interface can at the same time be stabilized by membrane material from the bigger ruptured oil bodies. Through this investigation, it can be hypothesized that sunflower oil bodies with a diameter below $5 \mu \mathrm{m}$ remain stable and possess the capacity to stabilize $\mathrm{O} / \mathrm{W}$ or $\mathrm{W} / \mathrm{O}$ interfaces through the Pickering mechanism. While larger oil bodies $(<5 \mu \mathrm{m})$ which are hybrids and thermodynamically unstable ruptured and merged with the oil phase.

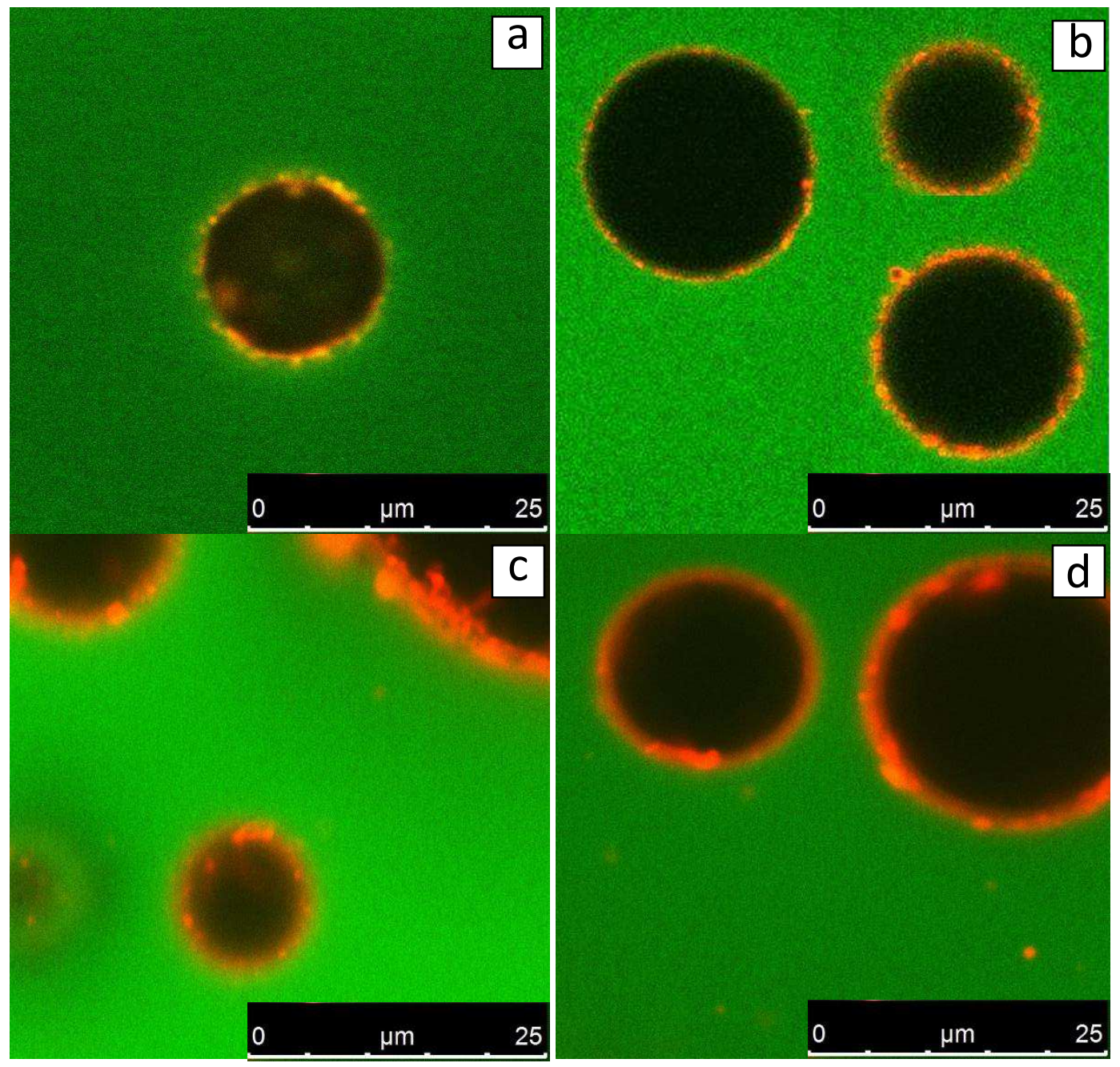

Figure 5.4 : CLSM-imaging of W/O emulsions stabilised by sunflower oil body. Samples are stained by Nile Blue showing lipids in green and proteins in red.

\subsubsection{Interfacial activity of oil bodies at the $\mathrm{O} / W$ and $W / O$ interfaces}

In order to investigate the interfacial activity of the sunflower oil bodies pendant droplet tensiometry analysis was performed. As it can be seen in Fig.5.5, the behaviour of SFOB on interfaces was directly compared with SFPI dispersions at both $\mathrm{O} / \mathrm{W}$ and $\mathrm{W} / \mathrm{O}$ interfaces. The protein concentration was equalised in both cases $(0.001 \%$ and $0.01 \% \mathrm{w} / \mathrm{v}$ for $\mathrm{O} / \mathrm{W}$ and $\mathrm{W} / \mathrm{O}$ interfaces respectively). 

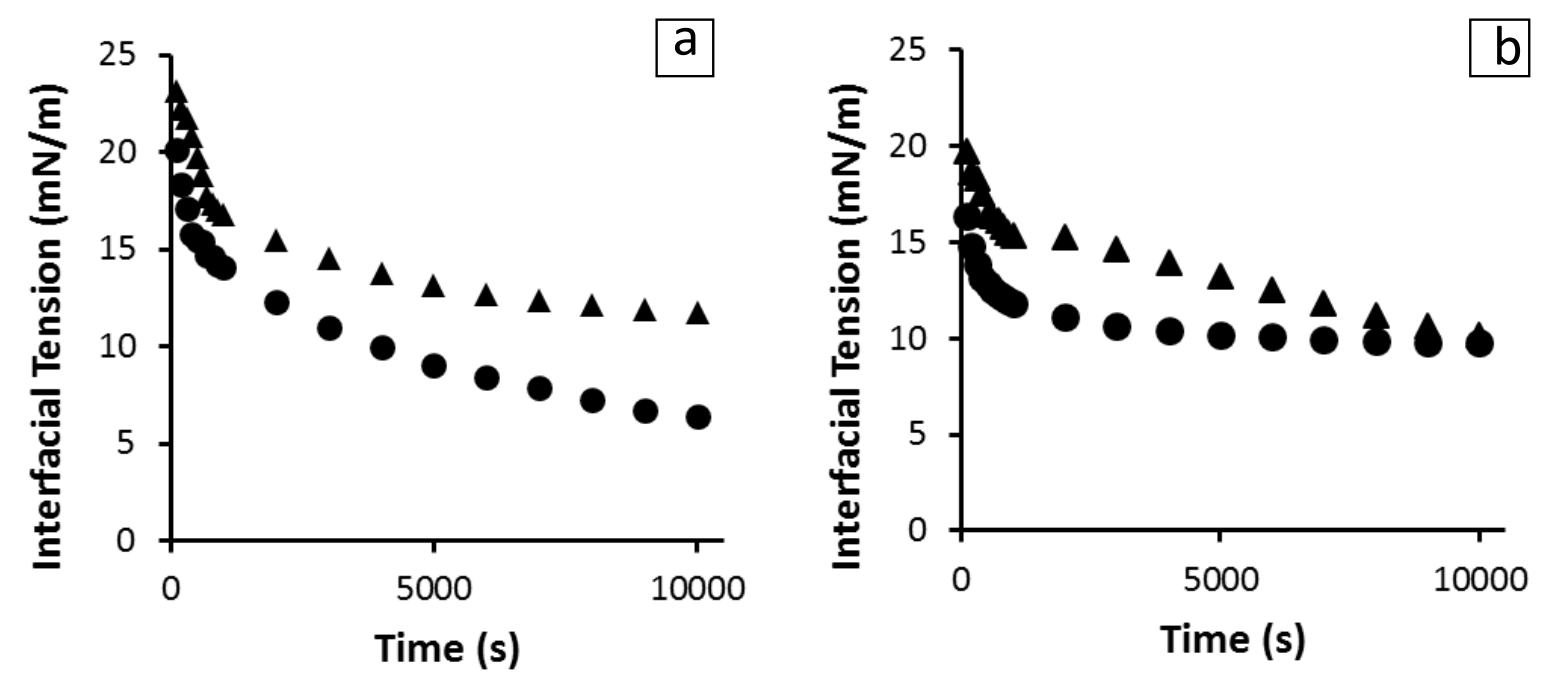

Figure 5.5 : Interfacial tension at the $\mathrm{O} / \mathrm{W}$ (a) and $\mathrm{W} / \mathrm{O}$ interface (b) as a function of adsorption time in the presence of SFOB $(\bullet)$ and SFPI $(\boldsymbol{\Delta})$ at constant protein concentration $(0.001 \%$ and $0.01 \% \mathrm{w} / \mathrm{v})$.

In both cases the dispersions showed significant interfacial activity. However, the SFOB seemed to absorb faster at the initial stages of both measurements and decreased the interfacial activity to a lower value at equilibrium state, $(\sim 6 \mathrm{mN} / \mathrm{m})$ compared to SFPI $(\sim 12 \mathrm{mN} / \mathrm{m})$. The differences between the absorption profiles of the two dispersions indicate that besides storage proteins that are present in minor amounts, oil bodies and also material from their membrane are absorbed at the interface. Therefore the scenario depicted in Fig.5.3a does not hold true when the concentration of storage proteins is that small but maybe only when proteins clearly dominate in a 3:1 protein:oil body ratio, as it has been previously published (Karefyllakis, et al., 2019). The interfacial activity of sunflower oil bodies was significantly lower than both crude and purified soybean oil bodies, which resulted to an $\mathrm{O} / \mathrm{W}$ interfacial tension of 12-15 $\mathrm{mN} / \mathrm{m}$ (Ishii, et al., 2017; Maurer, et al., 2013; Waschatko, Schiedt, et al., 2012). The lowest value of interfacial tension achieved by SFOB could maybe explained from the partial coalescence of SFOB during extraction that resulted to bigger and not rather unstable oil bodies. The membrane of those oil bodies can rupture at the presence of a non-polar phase, while its fragments, together with intact oil bodies, can absorb on the interface. The oil body membrane fragments, which comprised by oil body proteins and phospholipids is proven to be highly interfacially active (Roux, Baumberger, Axelos, \& Chardot, 2004). The fact that the absorption rate of SFOB is faster than the SFPI is surprising as the storage proteins are smaller molecules (average diameter $\sim 10 \mathrm{~nm}$ ) (Karefyllakis, et al., 2017)) and are expected to diffuse faster towards the interface compared to the sunflower oil bodies (average diameter $\sim 1 \mu \mathrm{m}$, (Karefyllakis, et al., 2019)). However, the concentration of oil bodies was significantly higher than the one of proteins which means that directly after the formation of the droplet a number of them could absorb readily on it, especially the smaller ones. After diffusion is completed, and oil bodies are absorbed on the interface, oil body membrane fragments can further decrease the interfacial tension. 


\subsubsection{Defatting Oil bodies and properties of their membrane}

In an effort to showcase the role of the oil body membrane to stabilise emulsions, it was decided to isolate the membrane without degrading it and subsequently study it with microscopy imaging. For this reason, SFOB cream was defatted. To visualise the morphology of the particles in greater detail, the SFOB was analysed with cryo-SEM before and after the defatting step. The obtained images are presented in Fig.5.6. Prior to lipid removal (Fig.5.6a), spherical particles with average diameter around $1 \mu \mathrm{m}$ were observed with relatively smooth surface that could be potentially identified as oil bodies. After the solvent extraction, particles of similar size were detected but with slightly distorted shape and severely punctured surface (Fig.5.6b). The observed holes are most likely caused during the penetration of the solvent inside the oil body and also during the exit of the triglycerides from the core. After the extraction is completed the remain material seem to be an empty spherical particle composed by the remaining membrane.

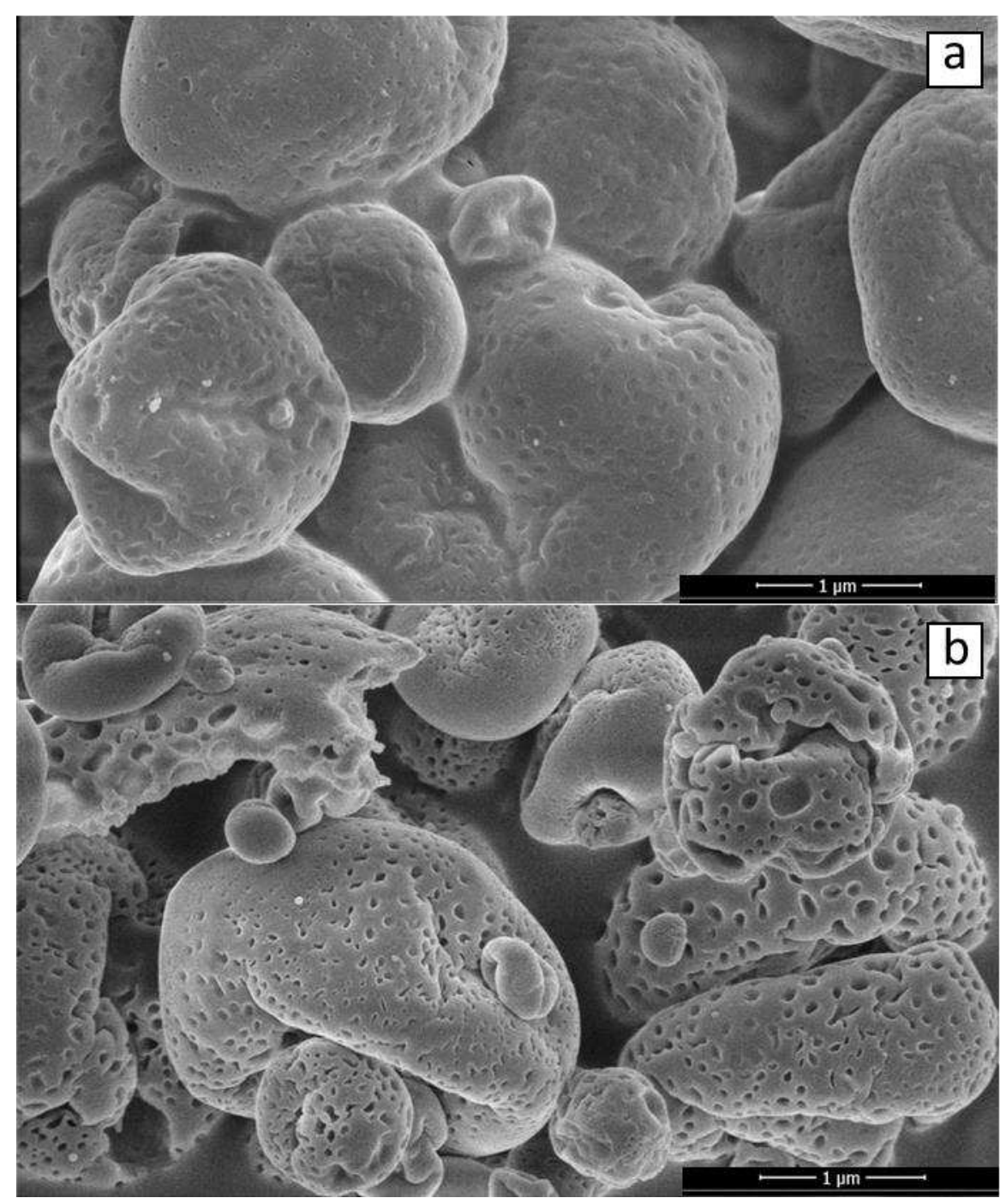

Figure 5.6 : Cryo-SEM imaging of a) SFOB material b) and of the same sample after removing the triglycerides with an organic solvent. 
As it can be observed in Fig.5.7, the defatted SFOB (Fig.5.7a) was then used to stabilize O/W emulsions (Fig.5.7b). From Fig.5.7a, and complementary to Fig.5.6b, it becomes obvious that oil was completely removed from oil bodies and only the survived membrane fractions are depicted with red, probably due to the present oil body proteins. When these particles were used as emulsifiers to stabilize an $\mathrm{O} / \mathrm{W}$ emulsion, a great number of them could be observed on the surface of the emulsion droplets (Fig.5.7b). Independently from the nature of these small spheres, they seem to widely absorb at $\mathrm{O} / \mathrm{W}$ interface without rupturing. These particles seem to be acting in a similar way as in Fig.5.3a,b and Fig.5.4 and as in those cases the Pickering mechanism can also be employed here for the explanation of the observed phenomena. These particles do not seem to rupture upon absorption but maintain their spherical shape and act as Pickering stabilisers. Excellent emulsion stabilization has been reported for soy protein/phospholipid nanoparticles although it was suggested that they disintegrate upon absorption (Gao, et al., 2013).
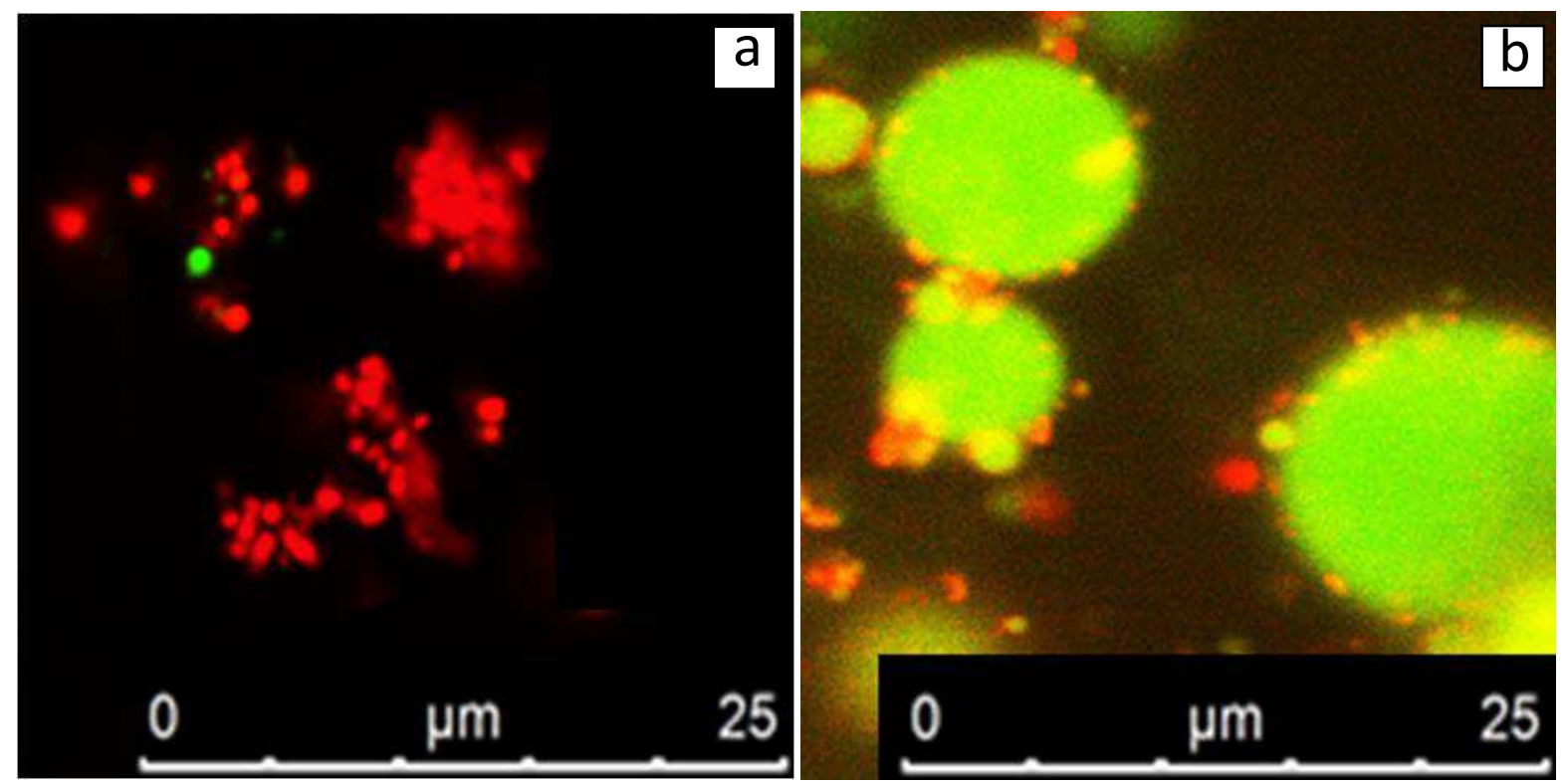

Figure 5.7 : CLSM-imaging of a) defatted SFO cream dispersion b) and of an O/W emulsion stabilised by it. Samples are stained by Nile Blue showing lipids in green and proteins in red.

An illustration of the possible oil body configurations after defatting is presented in Fig.5.8. Fig.5.8a shows an intact oil body membrane with an empty core, which as observed in Fig.5.6b, might be one of the configurations. Another configuration is Fig.5.8b, where phospholipids form a type of micelle and through hydrophobic interactions carry the oil body hydrophobic proteins. A similar model has been proposed for defatted soybean oleosin/phospholipid mixtures (Gao, et al., 2013).

All in all, the obtained spherical particles after the defatting of oil bodies are either composite protein/phospholipid particles or non-disintegrated oil body membrane shells. Both systems seem to survive the applied conditions and act as Pickering particles showcasing the important role of the oil body membrane when stabilizing an interface. 


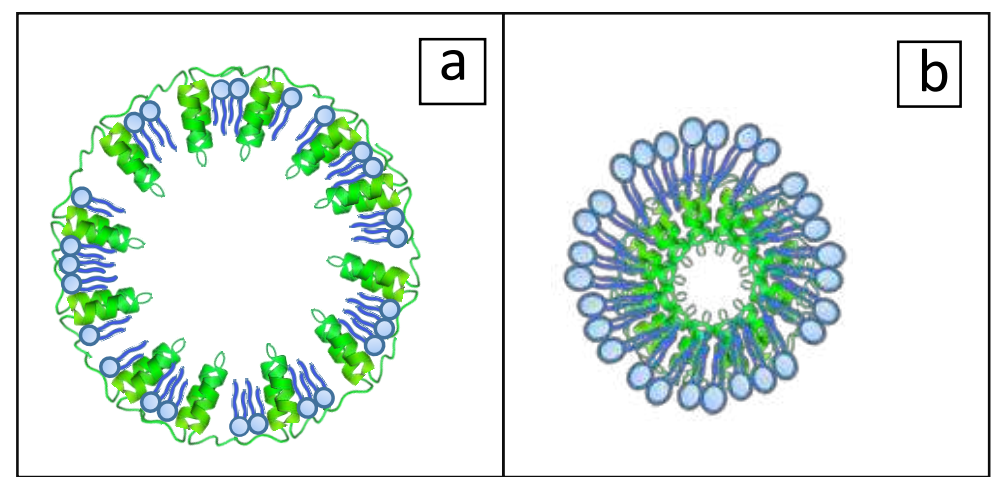

Figure 5.8 : Illustration of possible configurations that may be adapted by the oil bodies after the removal of lipids away from their core. a) Empty punctured oil body shell model. b) Coreshell model with oleosin molecules in the core and phospholipids on the outside layer inspired by Gao et al. (Gao, et al., 2013).

\subsection{Conclusions}

The noteworthy qualities of oil bodies have attracted strong interest for their incorporation in colloidal formulations where two immiscible phases are present. Especially, when external oil is added to an aqueous oil body dispersion, it is not certain what happens to the structure of the oil bodies and how their membrane behaves once they reach the interface. Through this work, it became clear that SFOB are capable to significantly decrease the interfacial activity of both $\mathrm{O} / \mathrm{W}$ and $\mathrm{W} / \mathrm{O}$ interfaces. Additionally, a clear difference in behaviour of oil bodies depending their size was observed upon emulsification. SFOB larger than $5 \mu \mathrm{m}$ were not detected when extrinsic oil was present and after applying a mild emulsification steps. These results indicate that oil bodies with big diameter are prone to rupture upon mixing with bulk oil, while the material from their membrane can absorb on the newly formed interface. Smaller oil bodies proved to be more resilient as a great number of them could act as Pickering stabilisers and absorb on the interface of the emulsion droplets. After the removal of the triglycerides from the core, intact but empty oil body shells or oil body membrane fractions were formed that could act as interfacial stabilisers. Therefore, it was showcased that the role of membrane and its elements was of paramount importance. These findings showcase the behaviour of sunflower oil bodies and the oil body membrane fractions upon emulsification and are of great relevance for future application where bulk oil or immiscible phases are present.

\section{Acknowledgments}

This work took place within the framework of the Institute for Sustainable Process technology (ISPT) 


\section{References}

Berton-Carabin, C. C., \& Schroën, K. (2015). Pickering emulsions for food applications: background, trends, and challenges. Annual review of food science and technology, 6, 263-297.

Berton, C., Genot, C., \& Ropers, M.-H. (2011). Quantification of unadsorbed protein and surfactant emulsifiers in oil-in-water emulsions. Journal of colloid and interface science, 354(2), 739-748.

Bettini, S., Santino, A., Giancane, G., \& Valli, L. (2014). Reconstituted oil bodies characterization at the air/water and at the air/oil/water interfaces. Colloids and Surfaces B: Biointerfaces, 122, 12-18.

Bewley, J. D., \& Black, M. (1994). Seeds. In Seeds (pp. 1-33): Springer.

Chen, B., McClements, D. J., Gray, D. A., \& Decker, E. A. (2012). Physical and oxidative stability of pre-emulsified oil bodies extracted from soybeans. Food Chemistry, 132(3), 1514-1520.

Chiang, C.-J., Lin, C.-C., Lu, T.-L., \& Wang, H.-F. (2011). Functionalized nanoscale oil bodies for targeted delivery of a hydrophobic drug. Nanotechnology, 22(41), 415102.

Deleu, M., Vaca-Medina, G., Fabre, J.-F., Roïz, J., Valentin, R., \& Mouloungui, Z. (2010). Interfacial properties of oleosins and phospholipids from rapeseed for the stability of oil bodies in aqueous medium. Colloids and Surfaces B: Biointerfaces, 80(2), 125-132.

Feng, Y., \& Lee, Y. (2016). Surface modification of zein colloidal particles with sodium caseinate to stabilize oilin-water pickering emulsion. Food Hydrocolloids, 56, 292-302.

Fisk, I. D., White, D. A., Lad, M., \& Gray, D. A. (2008). Oxidative stability of sunflower oil bodies. European journal of lipid science and technology, 110(10), 962-968.

Gao, Z.-M., Wang, J.-M., Wu, N.-N., Wan, Z.-I., Guo, J., Yang, X.-Q., \& Yin, S.-w. (2013). Formation of complex interface and stability of oil-in-water $(\mathrm{O} / \mathrm{W})$ emulsion prepared by soy lipophilic protein nanoparticles. Journal of Agricultural and Food Chemistry, 61(32), 7838-7847.

Huang, A. H. (2018). Plant lipid droplets and their associated proteins: potential for rapid advances. Plant physiology, 176(3), 1894-1918.

Ishii, T., Matsumiya, K., Nambu, Y., Samoto, M., Yanagisawa, M., \& Matsumura, Y. (2017). Interfacial and emulsifying properties of crude and purified soybean oil bodies. Food Structure, 12, 64-72.

Iwanaga, D., Gray, D. A., Fisk, I. D., Decker, E. A., Weiss, J., \& McClements, D. J. (2007). Extraction and characterization of oil bodies from soy beans: a natural source of pre-emulsified soybean oil. Journal of Agricultural and Food Chemistry, 55(21), 8711-8716.

Karefyllakis, Octaviana, H., van der Goot, A. J., \& Nikiforidis, C. V. (2019). The emulsifying performance of mildly derived mixtures from sunflower seeds. Food Hydrocolloids, 88, 75-85.

Karefyllakis, D., Altunkaya, S., Berton-Carabin, C. C., Van Der Goot, A. J., \& Nikiforidis, C. V. (2017). Physical bonding between sunflower proteins and phenols: Impact on interfacial properties. Food Hydrocolloids.

Karkani, O. A., Nenadis, N., Nikiforidis, C. V., \& Kiosseoglou, V. (2013). Effect of recovery methods on the oxidative and physical stability of oil body emulsions. Food Chemistry, 139(1-4), 640-648.

Martínez-Force, E., Dunford, N. T., \& Salas, J. J. (2015). Sunflower: chemistry, production, processing, and utilization: Elsevier.

Maurer, S., Waschatko, G., Schach, D., Zielbauer, B. I., Dahl, J., Weidner, T., Bonn, M., \& Vilgis, T. A. (2013). The role of intact oleosin for stabilization and function of oleosomes. The Journal of Physical Chemistry B, 117(44), 13872-13883.

Nikiforidis, C., Kiosseoglou, V., \& Scholten, E. (2013). Oil bodies: An insight on their microstructure-maize germ vs sunflower seed. Food Research International, 52(1), 136-141.

Nikiforidis, C. V., Ampatzidis, C., Lalou, S., Scholten, E., Karapantsios, T. D., \& Kiosseoglou, V. (2013). Purified oleosins at air-water interfaces. Soft Matter, 9(4), 1354-1363.

Nikiforidis, C. V., Biliaderis, C. G., \& Kiosseoglou, V. (2012). Rheological characteristics and physicochemical stability of dressing-type emulsions made of oil bodies-egg yolk blends. Food Chemistry, 134(1), 6473.

Nikiforidis, C. V., \& Kiosseoglou, V. (2009). Aqueous extraction of oil bodies from maize germ (Zea mays) and characterization of the resulting natural oil-in-water emulsion. Journal of Agricultural and Food Chemistry, 57(12), 5591-5596.

Pickering, S. U. (1907). Cxcvi.-emulsions. Journal of the Chemical Society, Transactions, 91, 2001-2021.

Roux, É., Baumberger, S., Axelos, M. A., \& Chardot, T. (2004). Oleosins of Arabidopsis thaliana: expression in Escherichia coli, purification, and functional properties. Journal of Agricultural and Food Chemistry, 52(16), 5245-5249.

Tan, Y., Xu, K., Liu, C., Li, Y., Lu, C., \& Wang, P. (2012). Fabrication of starch-based nanospheres to stabilize pickering emulsion. Carbohydrate Polymers, 88(4), 1358-1363.

Tzen, J., \& Huang, A. (1992). Surface structure and properties of plant seed oil bodies. The Journal of cell biology, $117(2), 327-335$.

Tzen, J., Lie, G., \& Huang, A. (1992). Characterization of the charged components and their topology on the surface of plant seed oil bodies. Journal of Biological Chemistry, 267(22), 15626-15634.

Vargo, K. B., Sood, N., Moeller, T. D., Heiney, P. A., \& Hammer, D. A. (2014). Spherical micelles assembled from variants of recombinant oleosin. Langmuir, 30(38), 11292-11300.

Waschatko, G., Junghans, A., \& Vilgis, T. A. (2012). Soy milk oleosome behaviour at the air-water interface. Faraday discussions, 158, 157-169.

Waschatko, G., Schiedt, B., Vilgis, T. A., \& Junghans, A. (2012). Soybean oleosomes behavior at the air-water interface. The Journal of Physical Chemistry B, 116(35), 10832-10841.

Ye, A., Zhu, X., \& Singh, H. (2013). Oil-in-water emulsion system stabilized by protein-coated nanoemulsion droplets. Langmuir, 29(47), 14403-14410. 


\section{Chapter 6}

\section{Enhancing the utilization potential of oilseed material : Multicomponent ingredients from sunflower seeds}

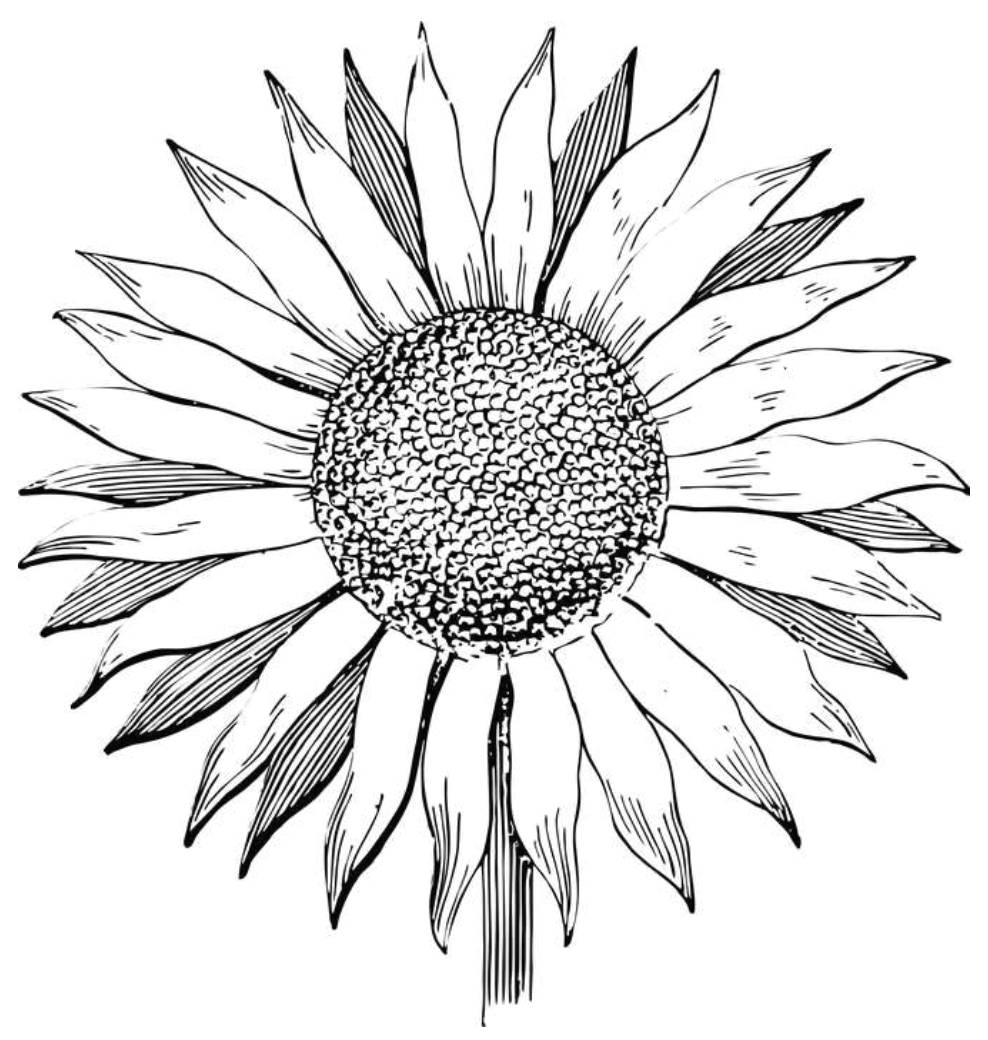

This chapter has been submitted as :

Karefyllakis, D., Van Der Goot, A. J., \& Nikiforidis, C. V. Enhancing the utilization potential of oilseed ingredients: Multicomponent emulsifiers from sunflower seeds. 


\section{ABSTRACT}

The increasing food demand of the fast-growing word population can be met by an improved utilization of plant ingredients to a certain extent. Abundant amounts of proteins are present in a number of biomass streams, but the current biorefinery strategies are not suitable to use their full potential amongst others due to the sturdy matrix and complex composition of the plant bio masses. Novel processes should be developed to avoid degradation of useful ingredients or hinder the utilisation of proteins altogether. This review presents new approaches on how the availability of oilseed ingredients could be materialised. A key factor is an altered focus towards mild processing and the subsequent native multicomponent emulsifiers rather than preparations consisting of pure components (e.g. proteins). 


\subsection{Introduction}

The increasing food demands throughout the globe bring about the need for a more resourceful and sustainable utilization of food material intensifies. Various aspects of food production can be improved, ranging from the raw material selection and the holistic valorisation of the material (Boye \& Arcand, 2013). A route towards a more sustainable use of food material is a switch from animal to plant-based derived products and ingredients (Aiking, 2011). However, ingredient production from plant-based biomass requires different processing conditions than those applied to produce animal ingredients (Mulvihill \& Ennis, 2003). Plant materials have different biomass configuration that does not breakdown effortlessly. For example, the sturdy cell walls of a number of plant materials may hinder the separation of ingredients within the matrix (Campbell, et al., 2011). In addition, the presence of a many compounds, from polysaccharides to phenols, often results in molecular complexation, which hinders separation (Boland, et al., 2013). For these reasons downstream processing of plant-based biomass streams often involves intensive physicochemical and thermal steps that are often accompanied by alteration of functional properties of the ingredients (Moure, Sineiro, Domínguez, \& Parajó, 2006). The challenges associated with the separation processes of plant-based ingredients explain why the availability and applicability of certain plant ingredients is still limited.

Oilseeds were always an important crop for humanity. These crops were used for their healthy vegetable oils primarily, while the remaining parts were applied as livestock feeds, pharmaceuticals, biofuels, and other oleochemical industrial uses (Farooq, et al., 2016). World oilseed production for 2018 amounted around 600 million metric tons (USDA, 2018), with its great majority used for oil extraction. Sunflower (Helianthus annus L.) is the third most important oilseed crop after soybean and rapeseed (USDA, 2018). Compared to these crops, sunflower seeds are advantageous since they contain low amounts of allergen factors, antinutritional and toxic compounds, such as toxic cyanogens and saponins (Friedman \& Brandon, 2001; Martínez-Force, Dunford, \& Salas, 2015). For these reasons, proteins from sunflower are regarded as potential substitute for soy (Pickardt, Eisner, Kammerer, \& Carle, 2015). In addition, sunflower seeds are appealing due to their widespread availability (González-Pérez \& Vereijken, 2007). The sunflower seed is a rich source for oil, containing a high proportion of unsaturated fatty acids (about 90\% linoleic and oleic acid) and high levels of fat-soluble vitamins (Martínez-Force, et al., 2015). Cakes (or meals) are by-products obtained after oil removal from different oilseeds used in the edible oil industry. These residues give a disposal problem for the industry and great amounts of them are currently underutilized as low-value animal feed (Geneau-Sbartaï, Leyris, Silvestre, \& Rigal, 2008), despite the fact that they are promising sources of compounds, e.g. proteins, with technological and nutritional relevance (Sarkis, et al., 2014). It explains why, the investigation of possible applications for these residues has been intensified over the last decades (Kammerer, Kammerer, Valet, \& Carle, 2014; Matthäus, 2002).

Currently, proteins are the primary ingredient of interest when the utilisation of these byproducts is pursued, as shown in Fig.6.1. As the extraction of proteins is usually prioritised over the rest of the ingredients, the chemicals and conditions applied during processing are 
meant to solubilise and extract the proteins exclusively (Sharif, et al., 2018). As a result, nonprotein ingredients are neglected and discarded. For example, the most extensively utilised oilseed proteins, soy proteins, are isolated after their solubilisation in alkaline solutions $(\mathrm{pH}$ 7.5-9) compounds (Meyer, 2016). Although soy proteins are industrially available, the same does not hold true for proteins from other sources. Extraction of proteins from other oilseed material, like sunflower cake, which contains great amounts of proteins, $25-55 \% \mathrm{w} / \mathrm{w}$ (Pickardt, et al., 2015), has yet to be realised. The reason for this is that the solubilisation of sunflower proteins at alkaline $\mathrm{pH}$ is accompanied by complications, mainly due to covalent protein-phenol complexation. This complexation yields dark-coloured products with decreased functionality (Fig.6.1) (González-Pérez, et al., 2007; Wildermuth, Young, \& Were, 2016). Similar effects occur in other by-products with high phenolic content such as rapeseed (Lomascolo, Uzan-Boukhris, Sigoillot, \& Fine, 2012).

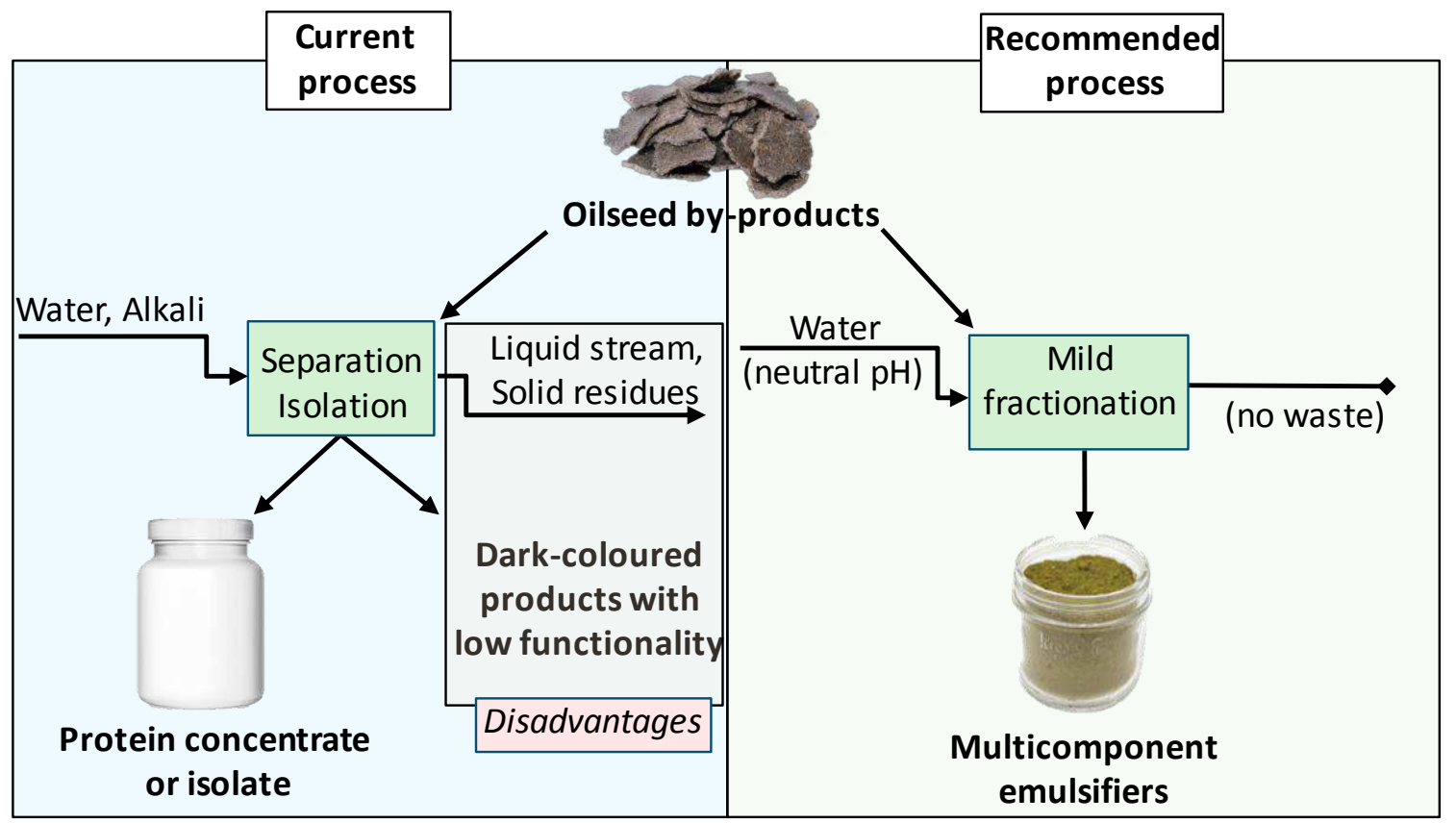

Figure 6.1: Conventional processing of oilseed by-products is meant to produce protein concentrates and isolates. However, in the case of oilseeds with high phenolic content (e.g. sunflower, rapeseed) the use of alkali induces undesirable changes while a big amount of ingredients is wasted throughout protein isolation. Isolating proteins is not always a necessity and should be replaced by more sustainable and mild practices regarding the processing of oilseed by-products.

Sunflower cake contains a large amount of phenolic compounds, up to 3\% w/w (Weisz, Kammerer, \& Carle, 2009). The phenolic compounds present in soybean, the so-called isoflavones, are neither highly reactive at alkaline conditions and are present in lower concentration (Jankowiak, Trifunovic, Boom, \& van der Goot, 2014). As a result they exert hardly any negative impact on protein extraction. The high concentration of reactive phenolic compounds, though, have hindered the industrial application of sunflower proteins (Weisz, Schneider, Schweiggert, Kammerer, \& Carle, 2010). It might therefore be possible that a different overall approach will enable potential applications for these ingredients in particular 
and for the whole material in general. Novel processing concepts should not use chemicals and conditions that either disregard useful ingredients or hinder the utilisation of proteins altogether. The focus should be the overall functionality of fractions containing multiple components rather than the performance of pure compounds, as shown in the right part of Fig.6.1.

\subsection{Oilseed processing and valuable ingredients}

Oil extraction from sunflower seeds resulted in the production of 19 million metric tons of sunflower cake in 2017 (USDA, 2018). Currently, the most commonly used method of processing in the industry of oilseeds, including sunflower seeds, is the pre-press solvent extraction (Le Clef \& Kemper, 2015). The first step in the process includes extraction of oil with a screw-press until the maximization of the oil recovery and subsequently the obtained residue is processed with organic solvents in order to achieve the removal of most of the remaining oil (Lomascolo, et al., 2012). The organic solvents that are usually used are toxic, flammable and harmful for the environment(the most prevalent being hexane), which is not appreciated by modern consumers (Dunn, Wells, \& Williams, 2010). Beyond that, desolventizing (the removal and recovery of solvent adhering to the residual solids) is an economic and environmental necessity for the application of these volatile organic solvents. However, the oil extraction process described above also leads to deterioration of ingredients functionality (Williams, 2005). Till now, the main focus of the conventional oil extraction process is on full extraction of the oil and not the quality and fate of the rest of the ingredients.

Sunflower proteins are valuable ingredients from functionality point of view. Their capability to stabilize emulsions and foams has been well documented (González-Pérez, et al., 2005). Besides proteins, several recent studies reported that sunflower phenols have several health benefit potentials such as antioxidant, anti-inflamatory, antithrombotic properties and also prevention of cancer and cardiovascular disease (Meng, Cao, Feng, Peng, \& Hu, 2013; Zhang $\&$ Tsao, 2016). During oil extraction the majority of sunflower phenols are not transferred to the oil due to their polar nature, hence they end up in the sunflower cake (Weisz, et al., 2009). In sunflower cake, chlorogenic acid (CGA) comprises $80 \%$ of the overall phenolic content, which makes it the major phenolic compound (Wildermuth, et al., 2016). All in all, the ingredients present in sunflower are interesting from a functionality and nutritional point of view and thus it is of paramount interest to achieve widespread applicability of these valuable ingredients.

In addition to proteins and phenols, also the oil has interesting properties, especially when it can be extracted in the form of native oil bodies. Inside the oilseed cells, oil is naturally emulsified by a very stable membrane in what are called oil bodies (Nikiforidis, Kiosseoglou, $\&$ Scholten, 2013). Oil bodies is the natural way that the neutral lipids are stored inside the oilseed cells (Bewley \& Black, 1994). They are surrounded by a complex membrane which protects them against physical and chemical stresses through its sophisticated structure (Tzen 
\& Huang, 1992). The membrane consists of continuous monolayer of phospholipids in which a number of hydrophobic proteins are embedded. The main ones called oleosins, have hydrophobic domains that are anchored into the oil phase, while their amphiphilic termini rest on the hydrophilic oil body surface (Huang, 2018). When oil bodies are extracted, the aforementioned noteworthy qualities of physical and chemical stability are conveyed to the resulting "natural" oil-in-water emulsions (Fisk, White, Lad, \& Gray, 2008; Iwanaga, et al., 2007). Besides stability, these natural emulsions bear additional conveniences including that no external emulsifiers are needed nor the high energy consuming step of homogenization is required (Karkani, Nenadis, Nikiforidis, \& Kiosseoglou, 2013). Due to the aforementioned advantages of oil bodies, scientists are currently investigating the potential applications of these pre-emulsified systems in several fields like food, pharmaceuticals, and cosmetics (Chen, McClements, Gray, \& Decker, 2012; Chiang, Lin, Lu, \& Wang, 2011; Nikiforidis, Biliaderis, \& Kiosseoglou, 2012). It would be therefore highly beneficial if processing of oilseed plants would aim towards maintaining of a certain amount of the residual oil in the form of intact oil bodies and take advantage of their properties.

\subsection{Removal vs retention of phenols}

Conventional alkaline extraction of sunflower proteins yields dark-coloured products with decreased functionality. A main reason for this darkening is the oxidation of phenols to highly reactive quinones, which subsequently form protein-phenol complexes (Weisz, et al., 2010). To avoid this complexation, fractionation attempts are focus towards the removal of sunflower phenols during the biorefinery of sunflower press cake (Pickardt, et al., 2009). Several methods have been developed to achieve this. Chlorogenic acid and other phenols can be efficiently removed through extraction using mixtures of organic solvents (mainly ethanol and methanol) and water (González-Pérez, et al., 2002; Salgado, et al., 2012). However, disadvantages of these methods are that organic solvent-water mixtures are known to decrease protein solubility and that they alter the digestibility and availability of essential amino acids, Besides, organic solvent extraction involve high processing costs for solvent management and safety precautions (Malik \& Saini, 2017; Suryaprakash, Kumar, \& Prakash, 2000). In addition, a disproportional relationship between protein purity and the percentage of protein recovery has been observed (Tenorio, et al., 2018). This indicates that every additional step like the removal of phenols will eventually lead to higher protein losses. One promising alternative seem to be the combination of acidic extraction with absorption technologies (Kammerer, et al., 2014; Weisz, et al., 2010) although it is characterised by the use of high amounts of salts and large water volumes.

Removing the phenols is a cumbersome process requiring the adjustment of several variables, considerable additional costs and effort (left side of Fig.6.2). In general, it is difficult to find the fine balance between the maximum phenol recovery and the minimum impact on the rest of the ingredients. Most of the techniques, including more elaborate ones like supercritical fluid and ultrasound extraction, have been developed for the extraction of high added value pharmaceuticals from plants (Ignat, Volf, \& Popa, 2011; Naczk \& Shahidi, 2006). The 
extraction of these ingredients may justify further investments but are not suitable for bulk ingredients of low value from oilseed by-products. In addition, the application of high temperature and pressure during some of these techniques can cause covalent complexation, which is the very same complication that was desired to be avoided in the first place. Instead of continuously exploring innovative methods that might work without disadvantages, we think that the challenges associated with the removal of phenols should inspire researchers to adapt a different overall approach. In this review, insights are provided regarding the retention of phenols inside the material (right side of Fig.6.2).

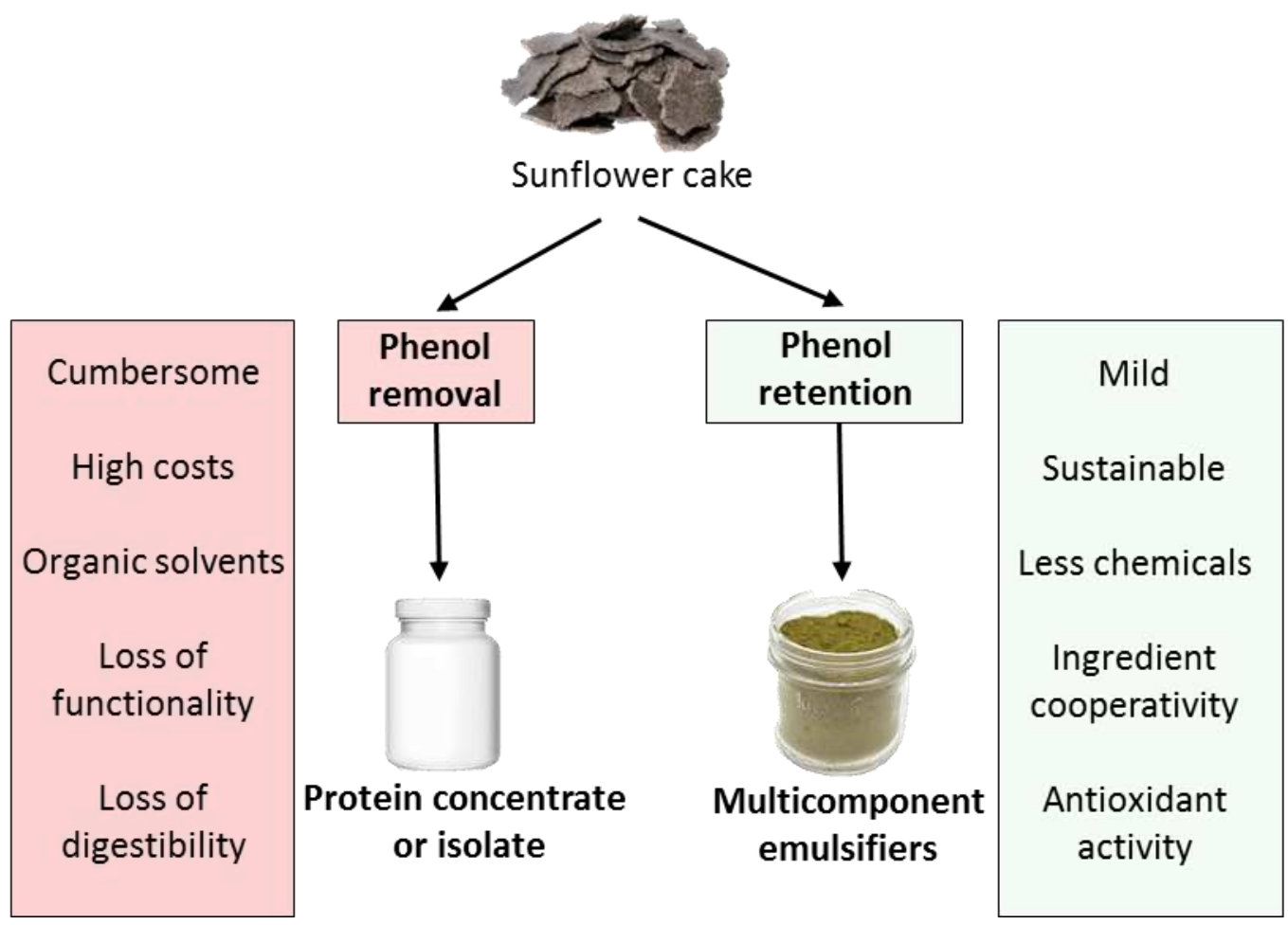

Figure 6.1: In order to obtain sunflower proteins, with a process devoid of negative complications, the precedent extraction of phenolic components is decisive. However, it is a complicated process characterised by many variables and a severe impact on the ingredients. Removing the phenols might not be a prerequisite for functional ingredients and should be investigated further as a more sustainable and mild practice.

Recent studies reveal intriguing advantages when phenols are retained in a proteinaceous fraction. Protein-phenol interactions can improve the stability of protein-based colloidal systems. One recent publication showcased that the presence of phenols affects the interfacial and emulsifying properties of sunflower proteins positively (Karefyllakis, Altunkaya, BertonCarabin, Van Der Goot, \& Nikiforidis, 2017). Alkaline conditions could be avoided, which promoted non-covalent interactions. These non-covalent interactions turned out to improve the functionality of proteins through the positive collaboration of phenols on the $\mathrm{O} / \mathrm{W}$ interface. As shown in Fig.6.3, the interfacial activity of sunflower proteins is enhanced under the presence of phenols and as a result a lower interfacial tension is achieved. Researches also reported that phenols can improve the foam formation and stability in protein-surfactant systems by inducing cross-linking of proteins in the adsorbed layer (Sarker, Wilde, \& Clark, 
1995) thereby enhancing the mechanical properties of gelatin gels by covalently cross-linking of phenol dimers (Strauss \& Gibson, 2004). Further, beneficial impact has been reported even when phenols were added back to sunflower products, e.g. sunflower oil, where their antioxidant activity reinforces oxidative stability (De Leonardis, Macciola, \& Di Rocco, 2003). Therefore, fractionation of sunflower cake that includes removal of phenols has a considerable impact (decreased protein solubility) on protein properties and disregards any positive cooperativity among the ingredients lying therein and the probability of their recombination in the final product. Clearly, removal of phenols seems essentially unnecessary essentially.

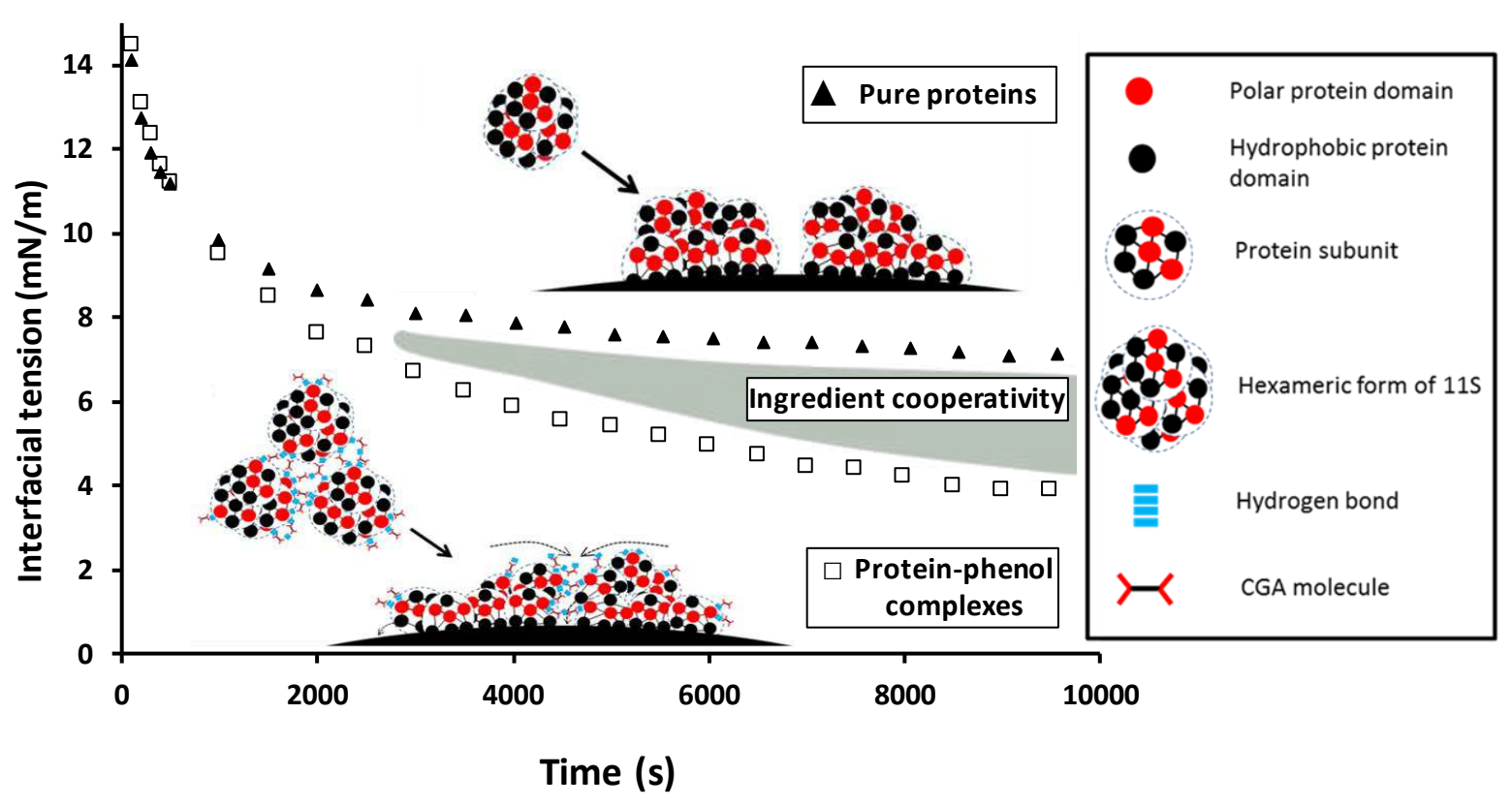

Figure 6.3 : Interfacial tension (oil-water interface) as a function of adsorption time in the presence of SFPI ( $\Delta)$ and SFPI-CGA physical complexes ( $\square$ ). The illustration of the unfolding of the major sunflower protein molecule and of the protein-phenol complex on the $\mathrm{O} / \mathrm{W}$ interface is shown. The interfacial properties were superior when phenols were present rather than removed indicating ingredient cooperativity.

Although attempting sunflower cake utilization without removing the phenols seems like a promising strategy, it does not come without challenges. The formation of covalent complexes should be deeply understood when fractionation of proteins and phenols under conditions of high temperature and alkaline $\mathrm{pH}$ is attempted. Especially, the role of the high phenol concentration should be taken into account (Prigent, Voragen, Visser, van Koningsveld, \& Gruppen, 2007), because this high concentration combined with phenol reactivity causes the occurrence of unpredictable covalent interactions during processing, storage, or ingestion of food product (Rohn, 2014). The fact that covalent protein-phenol complexation might be unavoidable during handling of sunflower products implies that it should be investigated how such complexes can find useful applications and possibly undesired effects can be mitigated. Covalent interactions between proteins and phenols are rather particular owing to the fact that they are irreversible and that they influence the 
properties of proteins significantly (Liu, Ma, Gao, \& McClements, 2017). Phenol attachment induces changes on protein structure. In some cases a notable impact on secondary and tertiary structure of proteins has been reported (Karefyllakis, Salakou, Bitter, van der Goot, \& Nikiforidis, 2018) while in others the complexation resulted in protein structural stabilization (Kanakis, et al., 2011). It is therefore clear that a fine balance exists between the potentially enhanced attributes of the resulting complexes and any undesirable consequences on the individual components.

\subsection{Focusing on mixtures of ingredients}

Current ingredient production focusses on high purity and standard quality, and much of the resources are spent on achieving this (Pelgrom, Boom, \& Schutyser, 2015). More sustainable and efficient practices are needed during the application of which no excessive energy and minimum amount of chemicals will be used with the end result being much less waste streams full with ingredients of interest (van der Goot, et al., 2016). The design of less intensive processing of oilseeds with the consideration of the ingredients lying therein, eventually leads to the reassessment of the biorefinery philosophy. One main aspect is that an overall efficient biorefinery chain does not automatically arise from a process in which all steps are optimised individually. This can be exemplified by using the conventional oil extraction as an example. Now, all oil is removed while fully neglecting consequences for extractability of other components from the remaining biomass. That is why we propose an alternative.

The conventional oil extraction needs to be replaced by milder processes during the application of which the least amount of material will be wasted and the preservation of the native functionality of all the ingredients will be of primary concern. A combination of coldpressing and aqueous fractionation is a sustainable alternative for the processing of oilseeds that allows the utilization of both the oil and the rest of the ingredients (Campbell, et al., 2011). Cold-pressing ensures low processing temperatures and aqueous fractionation includes simple mild steps like suspending the material in aqueous solutions at neutral $\mathrm{pH}$ with a subsequent centrifugation or decanting step to divide it into a soluble protein-rich mixture and an insoluble fibre-rich mixture. During these mild steps there is no use of excessive heating or solvents. Milder conditions could eventually lead to lower oil recovery. Although this may sound negative for the traditional oil industry, there are several advantages that accompany a decrease of the severity of processing conditions, which might compensate for the oil losses. The extracted oil with cold pressing has superior sensory properties, can be consumed after simple filtering (no further refining needed) (De Leonardis, et al., 2003). Further, it can be regarded as organic (Alimentarius, 1999). By using mild conditions and treatments, proteinaceous fractions are obtained that consist of diverse ingredients (lipids, phenols, carbohydrates) in their native form and with their properties preserved (Pelgrom, Berghout, van der Goot, Boom, \& Schutyser, 2014). As it has been shown for multicomponent fractions from sunflower seeds, lupine and yellow peas (Geerts, Strijbos, van der Padt, \& van der Goot, 2017; Karefyllakis, Octaviana, van der Goot, \& Nikiforidis, 2019; Pelgrom, et al., 2015), less enriched fractions exhibit functional properties comparable or even better than commercial preparations despite the lower purity. The fact that mild fractionation of these plant sources 
resulted in enhanced functionality despite the diversity of the compounds contained therein, showcases the high potential and widespread applicability of this processing philosophy. An optimum equilibrium can be found between the lower oil yield and the enhanced functionality potential of the multiple native ingredients.

\subsection{Multicomponent emulsifiers from sunflower seeds}

There is not a unique methodology or protocol for extracting protein from seeds or flours, leading to optimal products (Moure, et al., 2006). The philosophy of mild processing can enable novel solutions that can resolve the challenges associated with the use of sunflower proteins (covalent complexation). As it was showcased recently, mixtures of high complexity originating from mildly processed sunflower seeds, at neutral $\mathrm{pH}$, exhibited a satisfactory emulsification performance proving the relevance of these mixtures as ingredients for food applications (Karefyllakis, et al., 2019). Emulsion ability and stability were comparable when the performance of the multicomponent emulsifiers was compared with the one of pure proteins. In this research, the mild processing philosophy was manifested in a dual manner during the selection of processing conditions. First, the phenolic compounds were not removed during processing and second no alteration of $\mathrm{pH}$ was performed. This way the uncontrollable covalent protein-phenol complexation, which is inflicted during solubilisation of sunflower proteins under alkaline conditions, was avoided and the phenolic compounds were retained, together with all their advantageous properties. More importantly, as the $\mathrm{pH}$ of food products ranges from pH 3 to 7 (Ruiz-Henestrosa, Martinez, Patino, \& Pilosof, 2012) it was expected that the presence of phenols in the extracted ingredients would only result in antioxidant activity and positive cooperativity with the proteins rather than covalent complexation.

The combination of cold pressing and aqueous fractionation for the biorefinery of oilseeds, can also give rise to additional possibilities in addition to preserving the native functionality of proteins and promoting the positive cooperativity with the phenols. Residual oil obtained during mild fractionation of sunflower seeds (cold pressing and aqueous separation), was found to be present in the form of oil bodies with their native structure maintained, proving that mild conditions can potentially equip oilseed products with the additional benefits of the oil bodies (Karefyllakis, et al., 2019). In addition, the presence of oil bodies seemed to have little to no impact on the functional properties of sunflower proteins, indicating that complete deoiling of the multicomponent emulsifier is not a necessity. In a subsequent research, it was found that the role of the membrane and its elements was of paramount importance for the intact sunflower oil bodies and their ability to stabilise emulsions as Pickering stabilisers (Karefyllakis, van der Goot, Nikiforidis, 2019). These findings show the intriguing behaviour of oil bodies upon emulsification and are of great relevance for future application where bulk oil or different phases are present. 


\section{Summary}

Although ingredients originating from plant sources are regarded as more sustainable than the ones of animal origin, they have yet to be utilised extensively in food applications. Functional oilseed ingredients, like proteins and phenols, cannot be readily extracted from the sturdy matrix of the oilseeds and the press cakes, which explains why the by-products are still underutilized for direct human consumption. Moreover, purification of oilseed proteins often involves intensive physicochemical and thermal steps, which are often accompanied by alteration of functional properties of the components and lowering of the environmental friendliness of the product. For example, it is generally accepted that phenols have to be removed during the biorefinery of several press cakes. The approach of focussing on highly purified products from oilseed disregards any positive cooperativity among the ingredients. However, intriguing advantages have been reported when phenols are retained in the matrix as their presence enhances the emulsification performance of proteins on the $\mathrm{O} / \mathrm{W}$ interface. That is why we advocate novel practices that are needed to minimize excessive energy and chemicals use with the end result being much less waste streams full with ingredients of interest. By using mild conditions and treatments, proteinaceous fractions are yielded, instead of protein isolates, which consist of diverse ingredients (lipids, phenols, carbohydrates) in their native form and with their native properties preserved. Despite lower purity, the less enriched fractions exhibit functional properties comparable to or even better than pure protein preparations. In addition, the preservation of intact oil bodies can be achieved this way. The presence of oil bodies does not have a negative impact on the functionality of oilseed proteins in oil body-protein mixtures and can be considered as an additional component with interesting properties. All in all, it is hoped that with this review a clear insight is given regarding the possibilities to enhance the utilization potential of oilseed ingredients.

\section{Acknowledgments}

This work took place within the framework of the Institute for Sustainable Process Technology(ISPT). 


\section{References}

Aiking, H. (2011). Future protein supply. Trends in Food Science \& Technology, 22(2-3), 112-120.

Alimentarius, C. (1999). Codex standard for named vegetable oils. Codex Stan, 210, 1-13.

Bewley, J. D., \& Black, M. (1994). Seeds. In Seeds (pp. 1-33): Springer.

Boland, M. J., Rae, A. N., Vereijken, J. M., Meuwissen, M. P., Fischer, A. R., van Boekel, M. A., Rutherfurd, S. M., Gruppen, H., Moughan, P. J., \& Hendriks, W. H. (2013). The future supply of animal-derived protein for human consumption. Trends in Food Science \& Technology, 29(1), 62-73.

Boye, J. I., \& Arcand, Y. (2013). Current trends in green technologies in food production and processing. Food Engineering Reviews, 5(1), 1-17.

Campbell, K., Glatz, C., Johnson, L., Jung, S., De Moura, J., Kapchie, V., \& Murphy, P. (2011). Advances in aqueous extraction processing of soybeans. Journal of the American Oil Chemists' Society, 88(4), 449465.

Chen, B., McClements, D. J., Gray, D. A., \& Decker, E. A. (2012). Physical and oxidative stability of preemulsified oil bodies extracted from soybeans. Food Chemistry, 132(3), 1514-1520.

Chiang, C.-J., Lin, C.-C., Lu, T.-L., \& Wang, H.-F. (2011). Functionalized nanoscale oil bodies for targeted delivery of a hydrophobic drug. Nanotechnology, 22(41), 415102.

De Leonardis, A., Macciola, V., \& Di Rocco, A. (2003). Oxidative stabilization of cold-pressed sunflower oil using phenolic compounds of the same seeds. Journal of the Science of Food and Agriculture, 83(6), 523528.

Dunn, P. J., Wells, A., \& Williams, M. T. (2010). Green chemistry in the pharmaceutical industry: John Wiley \& Sons.

Farooq, M. A., Ali, B., Gill, R. A., Islam, F., Cui, P., \& Zhou, W. (2016). Breeding Oil Crops for Sustainable Production: Heavy Metal Tolerance. In Breeding Oilseed Crops for Sustainable Production (pp. 19-31): Elsevier.

Fisk, I. D., White, D. A., Lad, M., \& Gray, D. A. (2008). Oxidative stability of sunflower oil bodies. European journal of lipid science and technology, 110(10), 962-968.

Friedman, M., \& Brandon, D. L. (2001). Nutritional and health benefits of soy proteins. Journal of Agricultural and Food Chemistry, 49(3), 1069-1086.

Geerts, M. E., Strijbos, M., van der Padt, A., \& van der Goot, A. J. (2017). Understanding functional properties of mildly refined starch fractions of yellow pea. Journal of Cereal Science, 75, 116-123.

Geneau-Sbartaï, C., Leyris, J., Silvestre, F. O., \& Rigal, L. (2008). Sunflower cake as a natural composite: composition and plastic properties. Journal of Agricultural and Food Chemistry, 56(23), 11198-11208.

González-Pérez, S., Merck, K. B., Vereijken, J. M., van Koningsveld, G. A., Gruppen, H., \& Voragen, A. G. (2002). Isolation and characterization of undenatured chlorogenic acid free sunflower (Helianthus annuus) proteins. Journal of Agricultural and Food Chemistry, 50(6), 1713-1719.

González-Pérez, S., van Konignsveld, G. A., Vereijken, J. M., Merck, K. B., Gruppen, H., \& Voragen, A. G. (2005). Emulsion properties of sunflower (Helianthus annuus) proteins. Journal of Agricultural and Food Chemistry, 53(6), 2261-2267.

González-Pérez, S., \& Vereijken, J. M. (2007). Sunflower proteins: overview of their physicochemical, structural and functional properties. Journal of the Science of Food and Agriculture, 87(12), 2173-2191.

Huang, A. H. (2018). Plant lipid droplets and their associated proteins: potential for rapid advances. Plant physiology, 176(3), 1894-1918.

Ignat, I., Volf, I., \& Popa, V. I. (2011). A critical review of methods for characterisation of polyphenolic compounds in fruits and vegetables. Food Chemistry, 126(4), 1821-1835.

Iwanaga, D., Gray, D. A., Fisk, I. D., Decker, E. A., Weiss, J., \& McClements, D. J. (2007). Extraction and characterization of oil bodies from soy beans: a natural source of pre-emulsified soybean oil. Journal of Agricultural and Food Chemistry, 55(21), 8711-8716.

Jankowiak, L., Trifunovic, O., Boom, R. M., \& van der Goot, A. J. (2014). The potential of crude okara for isoflavone production. Journal of Food Engineering, 124, 166-172.

Kammerer, D. R., Kammerer, J., Valet, R., \& Carle, R. (2014). Recovery of polyphenols from the by-products of plant food processing and application as valuable food ingredients. Food Research International, 65, 212.

Kanakis, C., Hasni, I., Bourassa, P., Tarantilis, P., Polissiou, M., \& Tajmir-Riahi, H.-A. (2011). Milk $\beta-$ lactoglobulin complexes with tea polyphenols. Food Chemistry, 127(3), 1046-1055.

Karefyllakis, D., Altunkaya, S., Berton-Carabin, C. C., Van Der Goot, A. J., \& Nikiforidis, C. V. (2017). Physical bonding between sunflower proteins and phenols: Impact on interfacial properties. Food Hydrocolloids.

Karefyllakis, D., Octaviana, H., van der Goot, A. J., \& Nikiforidis, C. V. (2019). The emulsifying performance of mildly derived mixtures from sunflower seeds. Food Hydrocolloids, 88, 75-85.

Karefyllakis, D., Salakou, S., Bitter, J. H., van der Goot, A. J., \& Nikiforidis, C. V. (2018). Covalent Bonding of Chlorogenic Acid Induces Structural Modifications on Sunflower Proteins. ChemPhysChem, 19(4), 459468.

Karefyllakis, D., van der Goot, Nikiforidis. (2019). The behaviour of sunflower oil bodies at the interfaces. ela mou nte.

Karkani, O. A., Nenadis, N., Nikiforidis, C. V., \& Kiosseoglou, V. (2013). Effect of recovery methods on the oxidative and physical stability of oil body emulsions. Food Chemistry, 139(1-4), 640-648.

Le Clef, E., \& Kemper, T. (2015). Sunflower Seed Preparation and Oil Extraction. In Sunflower (pp. 187-226): Elsevier. 
Liu, F., Ma, C., Gao, Y., \& McClements, D. J. (2017). Food-Grade Covalent Complexes and Their Application as Nutraceutical Delivery Systems: A Review. Comprehensive Reviews in Food Science and Food Safety, 16(1), 76-95.

Lomascolo, A., Uzan-Boukhris, E., Sigoillot, J.-C., \& Fine, F. (2012). Rapeseed and sunflower meal: a review on biotechnology status and challenges. Applied microbiology and biotechnology, 95(5), 1105-1114.

Malik, M. A., \& Saini, C. S. (2017). Polyphenol removal from sunflower seed and kernel: Effect on functional and rheological properties of protein isolates. Food Hydrocolloids, 63, 705-715.

Martínez-Force, E., Dunford, N. T., \& Salas, J. J. (2015). Sunflower: chemistry, production, processing, and utilization: Elsevier.

Matthäus, B. (2002). Antioxidant activity of extracts obtained from residues of different oilseeds. Journal of Agricultural and Food Chemistry, 50(12), 3444-3452

Meng, S., Cao, J., Feng, Q., Peng, J., \& Hu, Y. (2013). Roles of chlorogenic acid on regulating glucose and lipids metabolism: a review. Evidence-Based Complementary and Alternative Medicine, 2013.

Meyer, E. W. (2016). Soya protein isolates for food. Proteins as human food, ed. by RA Lawrie, 346.

Moure, A., Sineiro, J., Domínguez, H., \& Parajó, J. C. (2006). Functionality of oilseed protein products: A review. Food Research International, 39(9), 945-963.

Mulvihill, D., \& Ennis, M. (2003). Functional milk proteins: production and utilization. In Advanced dairy chemistry -1 Proteins (pp. 1175-1228): Springer.

Naczk, M., \& Shahidi, F. (2006). Phenolics in cereals, fruits and vegetables: occurrence, extraction and analysis. Journal of pharmaceutical and biomedical analysis, 41(5), 1523-1542.

Nikiforidis, C., Kiosseoglou, V., \& Scholten, E. (2013). Oil bodies: An insight on their microstructure-maize germ vs sunflower seed. Food Research International, 52(1), 136-141.

Nikiforidis, C. V., Biliaderis, C. G., \& Kiosseoglou, V. (2012). Rheological characteristics and physicochemical stability of dressing-type emulsions made of oil bodies-egg yolk blends. Food Chemistry, 134(1), 6473.

Pelgrom, P. J., Berghout, J. A., van der Goot, A. J., Boom, R. M., \& Schutyser, M. A. (2014). Preparation of functional lupine protein fractions by dry separation. LWT-Food Science and Technology, 59(2), 680688.

Pelgrom, P. J., Boom, R. M., \& Schutyser, M. A. (2015). Functional analysis of mildly refined fractions from yellow pea. Food Hydrocolloids, 44, 12-22.

Pickardt, C., Eisner, P., Kammerer, D. R., \& Carle, R. (2015). Pilot plant preparation of light-coloured protein isolates from de-oiled sunflower (Helianthus annuus L.) press cake by mild-acidic protein extraction and polyphenol adsorption. Food Hydrocolloids, 44, 208-219.

Pickardt, C., Neidhart, S., Griesbach, C., Dube, M., Knauf, U., Kammerer, D. R., \& Carle, R. (2009). Optimisation of mild-acidic protein extraction from defatted sunflower (Helianthus annuus L.) meal. Food Hydrocolloids, 23(7), 1966-1973.

Prigent, S. V., Voragen, A. G., Visser, A. J., van Koningsveld, G. A., \& Gruppen, H. (2007). Covalent interactions between proteins and oxidation products of caffeoylquinic acid (chlorogenic acid). Journal of the Science of Food and Agriculture, 87(13), 2502-2510.

Rohn, S. (2014). Possibilities and limitations in the analysis of covalent interactions between phenolic compounds and proteins. Food Research International, 65, 13-19.

Ruiz-Henestrosa, V. M. P., Martinez, M. J., Patino, J. M., \& Pilosof, A. M. (2012). A dynamic light scattering study on the complex assembly of glycinin soy globulin in aqueous solutions. Journal of the American Oil Chemists' Society, 89(7), 1183-1191.

Salgado, P. R., Drago, S. R., Ortiz, S. E. M., Petruccelli, S., Andrich, O., González, R. J., \& Mauri, A. N. (2012). Production and characterization of sunflower (Helianthus annuus L.) protein-enriched products obtained at pilot plant scale. LWT-Food Science and Technology, 45(1), 65-72.

Sarker, D. K., Wilde, P. J., \& Clark, D. C. (1995). Control of surfactant-induced destabilization of foams through polyphenol-mediated protein-protein interactions. Journal of Agricultural and Food Chemistry, 43(2), 295-300.

Sarkis, J. R., Côrrea, A. P. F., Michel, I., Brandeli, A., Tessaro, I. C., \& Marczak, L. D. (2014). Evaluation of the Phenolic Content and Antioxidant Activity of Different Seed and Nut Cakes from the Edible Oil Industry. Journal of the American Oil Chemists' Society, 91(10), 1773-1782.

Sharif, H. R., Williams, P. A., Sharif, M. K., Abbas, S., Majeed, H., Masamba, K. G., Safdar, W., \& Zhong, F. (2018). Current progress in the utilization of native and modified legume proteins as emulsifiers and encapsulants-A review. Food Hydrocolloids, 76, 2-16.

Strauss, G., \& Gibson, S. M. (2004). Plant phenolics as cross-linkers of gelatin gels and gelatin-based coacervates for use as food ingredients. Food Hydrocolloids, 18(1), 81-89.

Suryaprakash, P., Kumar, R. P., \& Prakash, V. (2000). Thermodynamics of interaction of caffeic acid and quinic acid with multisubunit proteins. International Journal of Biological Macromolecules, 27(3), 219-228.

Tenorio, A. T., Kyriakopoulou, K. E., Suarez-Garcia, E., van den Berg, C., \& van der Goot, A. J. (2018). Understanding differences in protein fractionation from conventional crops, and herbaceous and aquatic biomass-Consequences for industrial use. Trends in Food Science \& Technology, 71, 235-245.

Tzen, J., \& Huang, A. (1992). Surface structure and properties of plant seed oil bodies. The Journal of cell biology, 117(2), 327-335.

USDA. (2018). Oilseeds: World Markets and Trade.

van der Goot, A. J., Pelgrom, P. J., Berghout, J. A., Geerts, M. E., Jankowiak, L., Hardt, N. A., Keijer, J., Schutyser, M. A., Nikiforidis, C. V., \& Boom, R. M. (2016). Concepts for further sustainable production of foods. Journal of Food Engineering, 168, 42-51.

Weisz, G. M., Kammerer, D. R., \& Carle, R. (2009). Identification and quantification of phenolic compounds from sunflower (Helianthus annuus L.) kernels and shells by HPLC-DAD/ESI-MS n. Food Chemistry, $115(2), 758-765$. 
Weisz, G. M., Schneider, L., Schweiggert, U., Kammerer, D. R., \& Carle, R. (2010). Sustainable sunflower processing-I. Development of a process for the adsorptive decolorization of sunflower [Helianthus annuus L.] protein extracts. Innovative Food Science \& Emerging Technologies, 11(4), 733-741.

Wildermuth, S. R., Young, E. E., \& Were, L. M. (2016). Chlorogenic Acid Oxidation and Its Reaction with Sunflower Proteins to Form Green-Colored Complexes. Comprehensive Reviews in Food Science and Food Safety.

Williams, M. A. (2005). Recovery of oils and fats from oilseeds and fatty materials. Bailey's industrial oil and fat products.

Zhang, H., \& Tsao, R. (2016). Dietary polyphenols, oxidative stress and antioxidant and anti-inflammatory effects. Current Opinion in Food Science, 8, 33-42. 


\section{Chapter 7}

\section{General discussion}

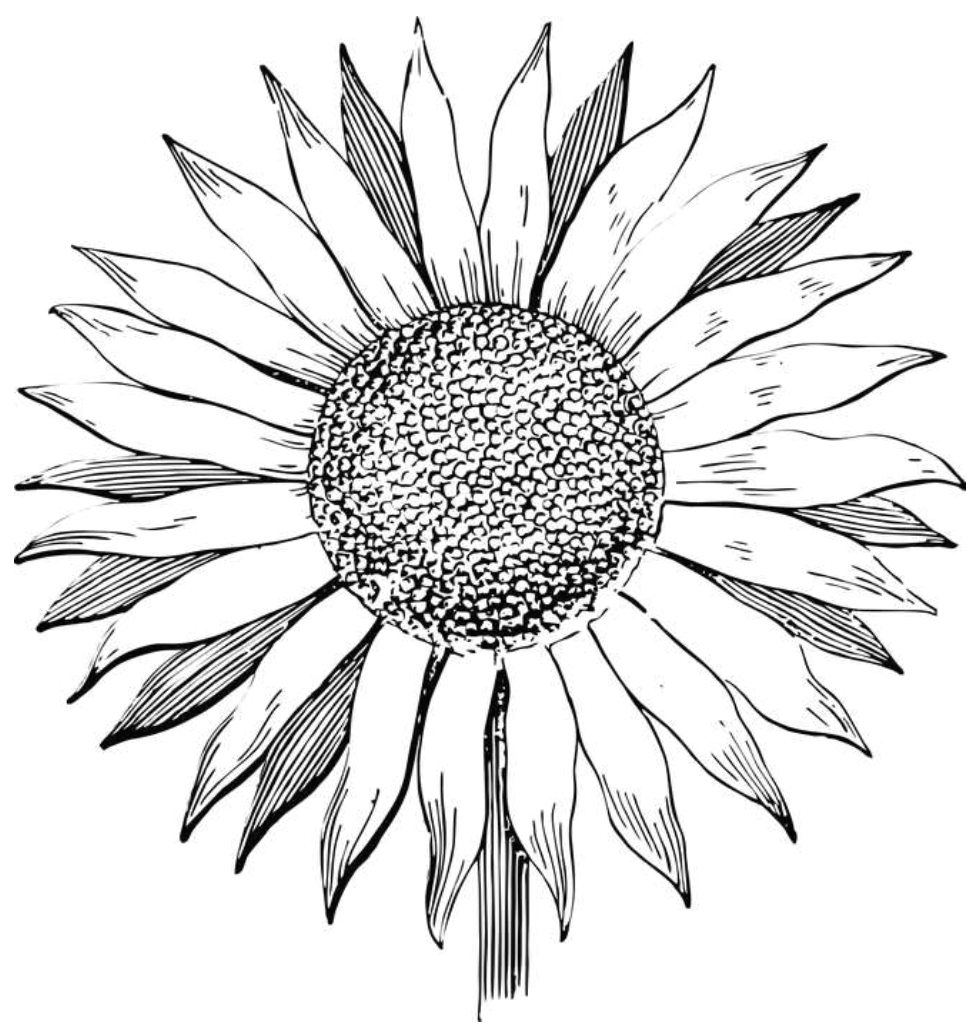




\section{Outline}

This thesis describes a scientific study on the potential of sunflower seeds as source for novel food ingredients, including proteins, phenols and oil bodies. Extraction of those components from sunflower seeds is complicated because of the high phenolic content and strong cell wall materials. The aim of the work in this thesis is to present new approaches on how the availability and applicability of ingredients from sunflower seeds could be materialised. A key factor for potential success is an altered focus towards mild processing and the subsequent native multicomponent ingredients rather than processing towards the production of pure components (e.g. proteins).

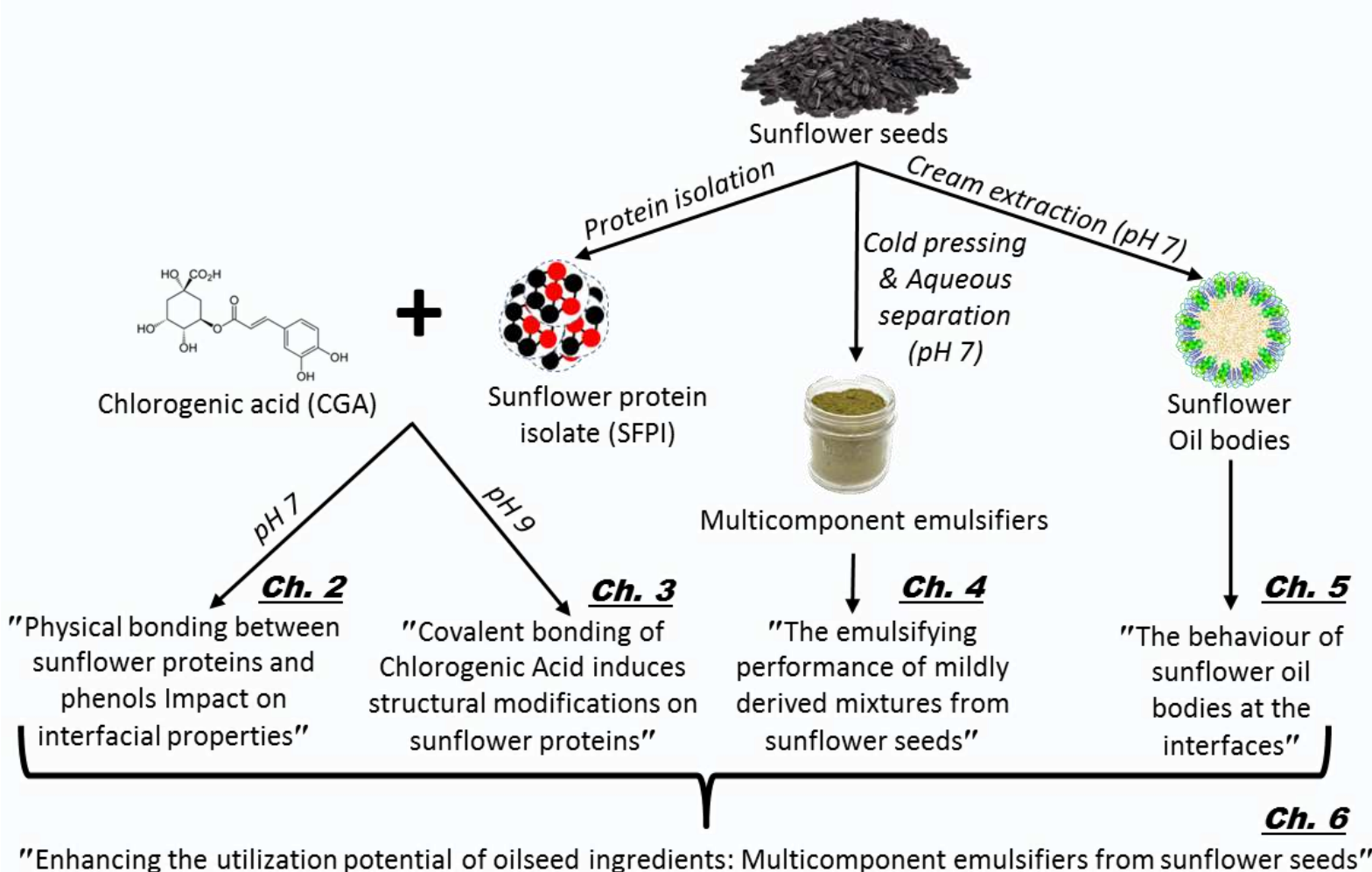

Figure 7.1: Outline of the main chapters of the thesis as a guideline for a better understanding of their origin and links. 


\section{Main findings and conclusions}

Conventional alkaline extraction of sunflower proteins yields dark-coloured products with low functionality due to oxidation of phenols to highly reactive quinones and the subsequent development of covalent protein-phenol complexes. Due to these complications, it is generally accepted that sunflower phenols have to be removed during the biorefinery of sunflower press cake. However, our research in Chapter 2 revealed intriguing advantages when phenols are retained in a proteinaceous fraction. Physical protein-phenol interactions can improve the stability of protein-based colloidal systems. We showcased that the presence of phenols affects the interfacial and emulsifying properties of sunflower proteins positively. In this study, it was shown that in case protein extraction was performed at neutral $\mathrm{pH}$ instead of alkaline $\mathrm{pH}$, the functionality of proteins was improved through the positive collaboration among proteins and phenols on the $\mathrm{O} / \mathrm{W}$ interface. After extraction and characterisation, sunflower seed protein isolates (SFPI) were mixed and complexed with pure chlorogenic acid (CGA) at pH 7. The size of the complexes was directly dependent on the amount of CGA used thus giving the indication that CGA molecules were bridging protein molecules with physical bonds. The complexes readily adsorbed at the oil-water interface, and could further reduce the interfacial tension compared to SFPI alone. When they were used as O/W emulsion stabilizers, emulsions with larger droplet size than SFPI-based ones were produced but with high stability against coalesence.

Separating phenols from sunflower proteins is a laborious and unsustainable solution to sunflower cake valorization issue and it disregards the potential positive cooperativity among proteins and phenols, as demonstrated in Chapter 2. Therefore we decided to direct our research towards not removing the phenols. However, retention of phenols is not a process without challenges. During storage or processing of sunflower cake, phenol oxidation can readily occur due to enzymes, light, elevated temperatures, atmospheric oxygen and alkaline conditions. Since it is difficult to avoid the formation of covalent complexes, we put our focus towards its understanding as described in chapter 3. Sunflower protein isolate (SFPI) was complexed with pure chlorogenic acid (CGA) at $\mathrm{pH} 9$ with constant SFPI and increasing CGA concentration. Protein and phenols formed colored covalent complexes. The amount of complexes formed depended on the concentration of CGA used. Complexation resulted in cross-link formation and had a notable impact on secondary and tertiary structure of proteins. Protein structure modifications resulted in exposure of amino acids that were previously buried inside the protein structure, leading to alterations of hydrophobicity profile of the protein surface. These findings can be considered a step forward towards the deeper understanding of covalent protein-phenol complexation during the storage or handling of sunflower protein preparations that are not purified from phenolic compounds.

After investigating the interactions between pure proteins and phenols, we decided to move away from model systems of high purity. In Chapter 4, the functionality of less refined fractions originating from sunflower seeds was investigated. Our focus was the overall functionality of the multicomponent ingredients rather than the performance of pure compounds. Sunflower seeds were cold-pressed resulting in the production of a sunflower 
press cake. The conditions applied during the subsequent aqueous fractionation of the sunflower cake resulted in protein and fibre-based mixtures. We proved that the residual oil in the sunflower cake and the protein-based mixtures was present in the form of naturally emulsified oil droplets, so-called oil bodies. When we examined the emulsification capacity of the samples, it was shown that the multicomponent nature of the emulsifiers did not restrict their performance. Additionally, the oil bodies appeared to have little to no impact on the emulsification efficiency and stability. In addition, the fact that the sunflower cake exhibited a notable performance at the oil-water interface against coalescence implies that SF cake could find direct applications as an ingredient. Even simple processing steps, like centrifugation, applied for the isolation of more protein-rich fractions could be regarded unnecessary. The samples we examined in Chapter 4 were mixtures of complex composition containing three main classes of macromolecules (proteins, polysaccharides and oil bodies) which nonetheless exhibited a good emulsification performance, even comparable to pure protein preparations, proving the relevance of these mixtures as ingredients for food applications.

During mild fractionation of sunflower seeds (cold pressing and aqueous separation) in Chapter 4, we showed that the residual oil was found to be present in the form of oil bodies with their native structure maintained. This suggests that mild conditions can potentially equip oilseed products with the additional benefits of the oil bodies. Not completely removing the oil from sunflower seeds thus does not mean loss of yield but the emergence of additional functional ingredients. In Chapter 5, we investigated whether the presence of intact sunflower oil bodies could have a positive impact on the functionality of a oil-water dispersion. We extracted oil body cream from sunflower seeds using aqueous fractionation and used the cream as an emulsifier for the stabilization of $\mathrm{O} / \mathrm{W}$ and $\mathrm{W} / \mathrm{O}$ interfaces. Especially in dispersions to which external oil is added, it is not certain what happens to the structure of the oil bodies and how their membrane behaves once they reach an interface. Although the presence of storage proteins was challenging for the accurate disambiguation of the results, it quickly became clear that sunflower oil bodies are capable to decrease the interfacial tension of both $\mathrm{O} / \mathrm{W}$ and $\mathrm{W} / \mathrm{O}$ interfaces and that a positive cooperativity with storage proteins was possible. Our findings showcase the intriguing behaviour of oil bodies upon emulsification and are of great relevance for future application where bulk oil or different phases are present.

From all the previous chapters, it became clear that sunflower seeds are full with valuable and functional ingredients. In Chapter 6, we decided to review all the reasons behind the lack of availability and applicability of these and similar type of ingredients. We proposed that future utilization attempts should refrain from using processing conditions that will cause covalent complexation. In addition, in this chapter, we suggested that the phenols should be maintained. Keeping the phenols results in mixtures of compounds and, as we showed in Chapter 6, induces cooperativity of ingredients. This can be achieved through the development of multicomponent ingredients, instead of full purification of ingredients. Further, it was demonstrated that those multicomponent ingredients have at least comparable 
functional properties to pure ingredients. We demonstrated that by applying the concepts of mild fractionation, the utilization potential of sunflower ingredients can be enhanced.

In conclusion, protein-phenol interactions is the biggest challenge regarding the utilisation of sunflower material but at the same time the presence of both components can be a source of potential cooperativity. An improved understanding of this rich behaviour of sunflower seeds extracts opens opportunities for better industrial use.

\section{Removing phenols: a cumbersome and unnecessary process}

As it has been shown until this point of the thesis, the amount and nature of the phenolic compounds contained in an oilseed directly defines the easiness of the utilization of the ingredients contained therein. A prominent example is the case of soybeans, where the phenolic compounds, the so-called isoflavones, are neither highly reactive at alkaline conditions (needed for the solubilisation of proteins) nor are present in rather high percentages (Jankowiak, Trifunovic, Boom, \& van der Goot, 2014). Similarly, the extraction of proteins from lupine seeds is much more straightforward since there are almost no reactive phenolic compounds hindering the separation (Kohajdova, Karovičová, \& Schmidt, 2011). On the other hand, oilseeds like sunflower and rapeseed, contain particularly high amounts of phenolic acids (Lomascolo, Uzan-Boukhris, Sigoillot, \& Fine, 2012) which are easily oxidised (especially under the desirable for protein solubilisation conditions) into highly reactive derivatives, which can cause polymerization or covalent association with proteins (see Fig.1.6 Chapter 1). Therefore it quickly became apparent to previous researchers that, the precedent extraction of phenolic components is decisive with respect to the possibility to obtain proteins from sunflower and rapeseed proteins,.

As phenolic compounds are health promoting and functional ingredients that can be found in various sources and by-products (Galanakis, 2012), a number of studies have described techniques to extract those components in high quantity. The existing classical techniques are Soxhlet extraction, maceration and hydrodistillation (Naczk \& Shahidi, 2004). The major challenges of conventional extraction are (1) longer extraction time, (2) requirement of costly and high purity solvent, (3) evaporation of the huge amount of solvent, (4) low extraction selectivity and (5) thermal decomposition of thermolabile compounds (De Castro \& GarciaAyuso, 1998). To overcome these limitations of conventional extraction methods, alternative and promising extraction techniques have been introduced. These techniques are referred as nonconventional extraction techniques. Some of these techniques are:

- Enzyme-assisted extraction. The enzyme-assisted extraction of phenols potentially provide a more reproducible extraction process at the commercial scale (Puri, Sharma, \& Barrow, 2012).

- Ultrasound assisted extraction. Ultrasonic cavitation creates shear forces that break cell walls and improve material transfer (Vinatoru, 2001). The application of 
ultrasound has been proven to be able to increase polyphenol extraction yields from several seed cakes (Teh \& Birch, 2014).

- Microwave-assisted extraction. Microwave heating due to its simplicity and rapidity, was proven to be more effective in releasing antioxidant compounds from agricultural by-products such as citrus peels (Hayat, et al., 2010).

- Supercritical fluid extraction. SFE methods are rapid, selective, avoid the use of large amounts of toxic solvents and are particularly recommended for the extraction of thermo-liable compounds (Ignat, Volf, \& Popa, 2011).

- Pressurized liquid extraction. Pressurised solvents use elevated pressures and sometimes temperatures that drastically improve the speed of the extraction process (Mustafa \& Turner, 2011). Subcritical water extraction (SWE) at $160^{\circ} \mathrm{C}$ produced the highest extract yields of phenols from rapeseed meal when compared with ethanol (Hassas-Roudsari, Chang, Pegg, \& Tyler, 2009). In a similar study, SWE was shown to efficiently recover phenolic acids (chlorogenic, caffeic, etc.) from potato peal (Singh \& Saldaña, 2011).

- Adsorptive extraction. Adsorption enables the separation of selected compounds from dilute solutions. Compared to alternative technologies, adsorption is attractive for its relative simplicity of design, operation and scale up, high capacity, favourable rate and low cost (Soto, Moure, Domínguez, \& Parajó, 2011).

- Pulsed electric field assisted extraction. In PEF, material located between two electrodes is exposed to a strong electrical field and subsequently pore formation occurs (Angersbach, Heinz, \& Knorr, 2000).

- Affinity separation assisted by molecularly imprinted polymers. Molecular imprinting technology can be used to generate specific artificial polymeric receptors like high affinity stationary phases (Brüggemann, Visnjevski, Burch, \& Patel, 2004). It was successfully applied to separate three phenolic acids, including caffeic acid, from a Salicornea herbacea extract(Park, Tian, \& Row, 2014).

The overview of all possibilities revealed that removing phenols is a cumbersome process requiring the adjustment of several variables, considerable additional costs and effort. Most of these techniques have been developed for the extraction of high added value pharmaceuticals from plants (Ignat, et al., 2011; Naczk \& Shahidi, 2006) that may justify further investments but are not suitable for bulk ingredient production of low value from oilseed by-products. In general, it is difficult to find the fine balance that exists in between the maximum phenol recovery and the minimum impact on the rest of the ingredients while maintaining low costs. For example, subcritical water extraction has proven to be an efficient recovery method of chlorogenic acid from potato peal (Singh, et al., 2011), a waste product, but this extraction method would have a considerable impact in case it is applied to chlorogenic acid from sunflower cake. Further, sunflower cake is an interesting by-product because of its richness in proteins. The application of high temperature and pressure during subcritical water extraction would cause covalent complexation of proteins and phenols, which is the very same complication that was desired to be avoided in the first place. Ultrasound, microwave and pulse electric filed assisted extractions can increase the recovery of chlorogenic acid but 
usually these techniques have to be combined with organic solvents for the complete removal of this compound (Rastogi, 2011). All in all, it does not come as a surprise that none of the aforementioned methods have found industrial application for the separation of sunflower proteins and phenols.

As the removal of phenols during sunflower protein extraction is so perplexed, we strongly believe that a biorefinery approach should be reconsidered. Instead of exploring continuously innovative methods that might work without disadvantages, we think that the challenges associated with the removal of phenols should inspire to adapt a different overall approach. In this thesis, we provided information regarding the retention of phenols inside the material. Since alkaline solubilisation of sunflower proteins exerts a negative impact on proteins and the removal of phenols is complicating the overall process, we decided to examine the potential of both keeping the phenols and extracting the proteins at neutral $\mathrm{pH}$. According to our opinion, this approach was not put into practice because unforeseen adverse effects on protein functionality were foreseen. However, we showed that the presence of phenols affects the interfacial and emulsifying properties of sunflower proteins positively (Karefyllakis, Altunkaya, Berton-Carabin, Van Der Goot, \& Nikiforidis, 2017). In conclusion, removing the phenols might not be a necessity. It should be investigated how inclusion of those components aligns with a more sustainable and mild practice regarding the processing of oilseed byproducts like sunflower cake.

\section{Focusing on functional rather than pure mixtures}

There is not a unique methodology or protocol for extracting protein from seeds or flours, leading to optimal products (Moure, Sineiro, Domínguez, \& Parajó, 2006). A lot of scientific research focusses on creation of protein products with high protein purity and standard quality (Pelgrom, Boom, \& Schutyser, 2015). More sustainable and efficient practices are needed during the application of which no excessive energy and minimum amount of chemicals will be used with the end result being much less waste streams full with ingredients of interest (van der Goot, et al., 2016). The design of less intensive processing of oilseeds eventually leads to the reassessment of the biorefinery philosophy. Our decision to retain phenols proved to be beneficial for the functionality of sunflower proteins. By using mild conditions and treatments, proteinaceous fractions are yielded, instead of protein isolates. Although this would be considered negative by the current standards of ingredient production, as it would result in less enriched protein fractions, we believe that the approach described above is not negative for the case for sunflower proteins.

As it has been shown for multicomponent fractions from other plant sources like lupine and yellow peas (Geerts, Strijbos, van der Padt, \& van der Goot, 2017; Pelgrom, et al., 2015), the less enriched fractions can exhibit functional properties comparable to or even better than commercial preparations despite the lower purity. As we have demonstrated, multicomponent mixtures originating from mildly processed sunflower seeds, exhibited a satisfactory emulsification performance proving the relevance of these mixtures as ingredients for food 
applications (Karefyllakis, Octaviana, van der Goot, \& Nikiforidis, 2019). More importantly, as the $\mathrm{pH}$ of food products ranges from $\mathrm{pH} 3$ to 7 (Ruiz-Henestrosa, Martinez, Patino, \& Pilosof, 2012) it is expected that the presence of phenols in the mildly extracted ingredients will only result in antioxidant activity and positive cooperativity with the proteins rather than covalent complexation. In this thesis, we recommend to avoid the removal of phenols and focus on properties of extracts containing both phenols and proteins. High purity of sunflower proteins is not a prerequisite for good functional properties meaning that utilisation of mixtures of ingredients, obtained at neutral $\mathrm{pH}$, is not only possible but also promising.

\section{Reconsidering sunflower oil extraction}

Oilseeds, as their name suggests, are primarily used as a source of vegetable oil. Currently, the most commonly used method of processing in the industry of oilseeds is the pre-press solvent extraction (Salunkhe, 1992). This method is developed in two steps, the first one being screw-pressing the seeds until a low oil content and the second being organic solvent extraction of the residual oil (Lomascolo, et al., 2012). What is problematic is the fact that the properties of the chosen organic solvents are undesirable. Flammable, toxic and harmful for the environment are used, e.g. hexane (Dunn, Wells, \& Williams, 2010). It should further be realised that the properties of the by-products and the utilisation potential of their ingredients are linked with the processing conditions during the industrial deoiling. In other words, there is a lot to be gained if there would be a change regarding the severity of the oil extraction conditions.

To use the full potential of oilseeds and their by-products, the conventional oil extraction needs to be replaced by milder processes, for example based on a combination of coldpressing and aqueous fractionation (Campbell, et al., 2011). As we saw in Chapter 4, cold pressing of sunflower seeds increases the amount of residual oil in the resulting cake. This is translated into losses and the only way to convince oil industry that a lower yield can be acceptable, is to showcase the intriguing advantages that mild conditions can offer.

We believe that the oil losses can be compensated by better utilisation of the other ingredients found in sunflower cake. The research in this thesis explored utilisation potential of proteins and phenols as emulsifying agents. However, the combination of cold pressing and aqueous fractionation for the biorefinery of oilseeds, can also give rise to additional possibilities due to the preserving the native functionality of proteins and promoting the positive cooperativity with the phenols. Additionally, we have shown that the residual oil was found to be present in the form of oil bodies with their native structure maintained (Karefyllakis, et al., 2019). Further, the presence of oil bodies seemed to have little to no impact on the functional properties of sunflower proteins, indicating that complete deoiling of the multicomponent emulsifier is not a necessity. In our subsequent research presented in Chapter 5, it was showcased that the role of the membrane and its elements was of paramount importance for 
the intact sunflower oil bodies and their ability to stabilise emulsions in a similar manner as Pickering stabilisers do (submitted research). In conclusion, we hope that with our investigation we have managed to prove that the mild fractionation concept can be beneficial in many obvious ways (lower energy, less chemical and waste) but also it might allow the emergence of new possibilities, e.g. the use of oil bodies. Purity achieved by means of severe processing should not persist as the mainstream approach regarding oilseed ingredient utilisation. . 


\section{References}

Angersbach, A., Heinz, V., \& Knorr, D. (2000). Effects of pulsed electric fields on cell membranes in real food systems. Innovative Food Science \& Emerging Technologies, 1(2), 135-149.

Brüggemann, O., Visnjevski, A., Burch, R., \& Patel, P. (2004). Selective extraction of antioxidants with molecularly imprinted polymers. Analytica Chimica Acta, 504(1), 81-88.

Campbell, K., Glatz, C., Johnson, L., Jung, S., De Moura, J., Kapchie, V., \& Murphy, P. (2011). Advances in aqueous extraction processing of soybeans. Journal of the American Oil Chemists' Society, 88(4), 449465.

De Castro, M. L., \& Garcia-Ayuso, L. (1998). Soxhlet extraction of solid materials: an outdated technique with a promising innovative future. Analytica chimica acta, 369(1), 1-10.

Dunn, P. J., Wells, A., \& Williams, M. T. (2010). Green chemistry in the pharmaceutical industry: John Wiley \& Sons.

Galanakis, C. M. (2012). Recovery of high added-value components from food wastes: conventional, emerging technologies and commercialized applications. Trends in Food Science \& Technology, 26(2), 68-87.

Geerts, M. E., Strijbos, M., van der Padt, A., \& van der Goot, A. J. (2017). Understanding functional properties of mildly refined starch fractions of yellow pea. Journal of Cereal Science, 75, 116-123.

Hassas-Roudsari, M., Chang, P. R., Pegg, R. B., \& Tyler, R. T. (2009). Antioxidant capacity of bioactives extracted from canola meal by subcritical water, ethanolic and hot water extraction. Food Chemistry, $114(2), 717-726$.

Hayat, K., Zhang, X., Chen, H., Xia, S., Jia, C., \& Zhong, F. (2010). Liberation and separation of phenolic compounds from citrus mandarin peels by microwave heating and its effect on antioxidant activity. Separation and Purification Technology, 73(3), 371-376.

Ignat, I., Volf, I., \& Popa, V. I. (2011). A critical review of methods for characterisation of polyphenolic compounds in fruits and vegetables. Food Chemistry, 126(4), 1821-1835.

Jankowiak, L., Trifunovic, O., Boom, R. M., \& van der Goot, A. J. (2014). The potential of crude okara for isoflavone production. Journal of Food Engineering, 124, 166-172.

Karefyllakis,D.,Octaviana, H., van der Goot, A. J., \& Nikiforidis, C. V. (2019). The emulsifying performance of mildly derived mixtures from sunflower seeds. Food Hydrocolloids, 88, 75-85.

Karefyllakis, D., Altunkaya, S., Berton-Carabin, C. C., Van Der Goot, A. J., \& Nikiforidis, C. V. (2017). Physical bonding between sunflower proteins and phenols: Impact on interfacial properties. Food Hydrocolloids.

Kohajdova, Z., Karovičová, J., \& Schmidt, Š. (2011). Lupin composition and possible use in bakery-a review. Czech J Food Sci, 29(3), 203-211.

Lomascolo, A., Uzan-Boukhris, E., Sigoillot, J.-C., \& Fine, F. (2012). Rapeseed and sunflower meal: a review on biotechnology status and challenges. Applied microbiology and biotechnology, 95(5), 1105-1114.

Moure, A., Sineiro, J., Domínguez, H., \& Parajó, J. C. (2006). Functionality of oilseed protein products: A review. Food Research International, 39(9), 945-963.

Mustafa, A., \& Turner, C. (2011). Pressurized liquid extraction as a green approach in food and herbal plants extraction: A review. Analytica chimica acta, 703(1), 8-18.

Naczk, M., \& Shahidi, F. (2004). Extraction and analysis of phenolics in food. Journal of Chromatography $A$, 1054(1), 95-111.

Naczk, M., \& Shahidi, F. (2006). Phenolics in cereals, fruits and vegetables: occurrence, extraction and analysis. Journal of pharmaceutical and biomedical analysis, 41(5), 1523-1542.

Park, H.-E., Tian, M., \& Row, K.-H. (2014). Molecularly Imprinted Polymer for Solid-Phase Extraction of Phenolic Acids from Salicornia herbacea L. Separation Science and Technology, 49(9), 1401-1406.

Pelgrom, P. J., Boom, R. M., \& Schutyser, M. A. (2015). Functional analysis of mildly refined fractions from yellow pea. Food Hydrocolloids, 44, 12-22.

Puri, M., Sharma, D., \& Barrow, C. J. (2012). Enzyme-assisted extraction of bioactives from plants. Trends in biotechnology, 30(1), 37-44.

Rastogi, N. K. (2011). Opportunities and challenges in application of ultrasound in food processing. Critical reviews in food science and nutrition, 51(8), 705-722.

Ruiz-Henestrosa, V. M. P., Martinez, M. J., Patino, J. M., \& Pilosof, A. M. (2012). A dynamic light scattering study on the complex assembly of glycinin soy globulin in aqueous solutions. Journal of the American Oil Chemists' Society, 89(7), 1183-1191.

Salunkhe, D. K. (1992). World oilseeds: Springer Science \& Business Media.

Singh, P. P., \& Saldaña, M. D. (2011). Subcritical water extraction of phenolic compounds from potato peel. Food Research International, 44(8), 2452-2458.

Soto, M. L., Moure, A., Domínguez, H., \& Parajó, J. C. (2011). Recovery, concentration and purification of phenolic compounds by adsorption: a review. Journal of Food Engineering, 105(1), 1-27.

Teh, S.-S., \& Birch, E. J. (2014). Effect of ultrasonic treatment on the polyphenol content and antioxidant capacity of extract from defatted hemp, flax and canola seed cakes. Ultrasonics sonochemistry, 21(1), 346-353.

van der Goot, A. J., Pelgrom, P. J., Berghout, J. A., Geerts, M. E., Jankowiak, L., Hardt, N. A., Keijer, J., Schutyser, M. A., Nikiforidis, C. V., \& Boom, R. M. (2016). Concepts for further sustainable production of foods. Journal of Food Engineering, 168, 42-51.

Vinatoru, M. (2001). An overview of the ultrasonically assisted extraction of bioactive principles from herbs. Ultrasonics sonochemistry, 8(3), 303-313. 


\section{Summary}

The overall aim of this thesis is to enhance the potential use of oilseed ingredients from underutilised sources, here the sunflower press cake, for food applications. The thesis emphasises on the interactions among the ingredients present in sunflower seeds and cake (proteins and phenols). Although these interactions are the main reason behind the underutilisation of sunflower cake, in this research we showcase their beneficial potential and argue against the removal of the phenols during protein extraction. The recommended processing concept directs the focus towards less enriched multicomponent mixtures. It concludes that high purity of sunflower proteins is not a prerequisite for good functional properties meaning that utilisation of mixtures of ingredients, obtained when using mild conditions, is not only possible but also promising.

In Chapter 1, the motivation behind this thesis is presented. It is shown that utilising of plant ingredients does not come without challenges. It explains the reasons behind the lack of industrially available sunflower ingredients for food products. Valuable ingredients found inside this material are researched for their chemical and functional properties. The importance of protein-phenol interactions is described.

Covalent protein-phenol complexation yields dark-coloured products with decreased functionality. Due to these complications, it is generally accepted that sunflower phenols have to be removed during the biorefinery of sunflower press cake. However, separating phenols from sunflower proteins is a laborious and unsustainable solution to the sunflower cake biorefinery issue. Therefore it was decided to direct the research towards maintaining of phenols. In Chapter 2, model mixtures are investigated that include the non-covalent interactions between the main phenolic compound in sunflower seeds, chlorogenic acid (CGA), and sunflower protein isolate (SFPI). The study of protein-phenol mixtures were performed to stimulate the concept for more sustainable ingredient processing, which focusses on functionality rather than purity. After extraction and characterization, pure and nondenatured sunflower proteins are mixed and complexed with increasing amounts of pure CGA. Then, the resulting complexes and their interplay at oil-water interfaces is studied, which sheds new light on the effect of their complexation on the functionality of proteins. Chapter 2 showcases that the presence of phenols affects the interfacial and emulsifying properties of sunflower proteins positively. This chapter concludes that the removal of phenols should not be regarded as a necessity when the utilisation of sunflower proteins is attempted.

Not removing the phenols during the handling of sunflower material does not come without challenges since it is difficult to avoid the formation of covalent complexes in the confined space of a sunflower seed cell during processing and storage. In Chapter 3 the focus is put towards understanding covalent protein-phenol complexation.. The structural modifications induced by SFPI-CGA covalent interactions are monitored as a major step in elucidating the impact of phenol attachment on protein structure. Sunflower protein isolate (SFPI) was complexed with pure chlorogenic acid (CGA) at $\mathrm{pH} 9$ with constant SFPI and increasing CGA concentration. Protein and phenols formed colored covalent complexes whose extend 
was dependent on the amount of CGA used. Complexation resulted in cross-link formation and had a notable impact on secondary and tertiary structure of proteins. Protein structure modifications resulted in exposure of amino acids, and alterations of the hydrophobicity profile of protein surface. These findings could be considered a step forward towards the deeper understanding of covalent protein-phenol complexation during the storage or handling of sunflower protein preparations that were not purified from phenolic compounds.

In Chapter 4 the focus was directed towards the overall functionality of the multicomponent ingredients. This chapter describes the application of the concept of mild fractionation and the properties of the various fractions obtained after simple separation steps. The mild conditions applied resulted in less enriched protein and fibre-based mixtures. In addition, Chapter 4 examines the emulsification capacity of the multicomponent ingredients and shows that the complexity of the emulsifiers did not restrict their performance. It also presents a comparison of the emulsifying properties of these multicomponent ingredients with ingredients comprising sunflower proteins mainly. Additionally, the consequences of the lower oil recovery are discussed. It is suggested that the residual oil in the sunflower cake was present in the form of naturally emulsified oil droplets, so-called oil bodies. The oil bodies appeared to have little to no impact on the emulsification efficiency and stability. Mild conditions can potentially equip oilseed products with the additional benefits of the oil bodies. Overall, it was concluded that mild fractionation of sunflower seeds can produce highly functional multicomponent emulsifiers despite their decreased purity.

Chapter 5 presents the properties of sunflower oil bodies at the interfaces. It is shown that intact oil bodies can be extracted by applying mild conditions. To provide more information for potential applications where bulk oil will be present, the effect on oil body structure is shown at $\mathrm{O} / \mathrm{W}$ and $\mathrm{W} / \mathrm{O}$ interfaces. It was shown that sunflower oil bodies are capable to significantly decrease the interfacial activity of both $\mathrm{O} / \mathrm{W}$ and $\mathrm{W} / \mathrm{O}$ interfaces and that a positive cooperativity with storage proteins is possible. Further, a clear difference exists in behaviour of oil bodies depending on their size upon emulsification. Larger oil bodies merge with the bulk oil, leaving fragments of the membranes, which can participate in the formation of the interface. In addition, the role of smaller oil bodies is discussed. It is concluded that the role of membrane and its elements was of paramount importance and are of great relevance for future application where bulk oil or different phases are present.

Novel approaches for the enhancement of the utilization potential of oilseed ingredients are reviewed in Chapter 6. Oilseeds and especially their underutilised by-products are promising sources of compounds with technological and nutritional interest. Characteristic examples are the functional and health promoting macromolecules and micronutrients like proteins and phenols found in for example sunflower by-products such as press cake. Unlike soy proteins, which can be readily isolated and are utilised extensively, utilization of proteins from sunflower cake has yet to be realised. This chapter presents current barriers for the use of the materials and provides a summary of new approaches on how the availability and applicability of sunflower ingredients could be materialised.. 
In Chapter 7, the main findings and conclusions of all the chapters are reviewed. In addition, the main issues regarding the utilisation of sunflower ingredients are discussed together with the proposed solutions. The advantages and disadvantages associated with the removal of phenols are discussed. Since phenol oxidation and covalent complexation with proteins are the primary problems during protein extraction, phenols are often removed beforehand. Although there are many elaborate techniques for this purpose, none of them is effortless and not accompanied by drawbacks. To overcome this issue altogether, the retention of phenols is proposed. By avoiding higher than neutral $\mathrm{pH}$ values, non-covalent protein-phenol interactions are promoted that enhance protein functionality. Therefore the removal of phenols is not a necessity and future efforts for the use of sunflower proteins should take into account the application of conditions which will promote multicomponent mixture productions. Same conclusions are reached when the extraction of protein at neutral $\mathrm{pH}$ is discussed. It is shown that producing multicomponent ingredients is not compromising protein functionality. On the contrary, the properties of the less enriched mixtures are sometimes equal or even better than pure preparations. The last crucial aspect of this thesis that is discussed in Chapter 7, concerns the optimum equilibrium between the oil losses and the enhanced availability and functionality of the rest of the ingredients. It is shown that sacrificing a small part of the oil yield is insignificant in front of the potential advantages. Proteins and phenols can be used in functional mixtures and the mild conditions allow the presence of the residual oil in the form of intact oil bodies which bear intriguing properties. 


\section{Acknowledgments}

The past four years were full of character building experiences of different kinds. It felt like o rollercoaster but thankfully the ups were more and longer than the downs. Doing a Ph.D. is not only a search of valid answers to a scientific hypothesis but also professional and social interaction with several unique individuals. To begin with I would like to thank my supervisors that helped me with the challenges I faced, both of managerial and scientific nature. Atze Jan (my promotor) thank you for always being there ready to discuss with me how to plan the strategy during all the steps of my project and provide answers regarding the management. Our collaboration was very friendly and I could always count on your support and understanding during unexpected events and difficult circumstances. Costas (my daily supervisor), you had the difficult task to keep me on track. Your excitement about science was keeping me motivated and our discussions were expanding my scientific imagination. Even though I was always complaining, I have to admit that your input was valuable and could guarantee a successful outcome when it comes to publishing. I hope I met, at least partially, your expectations. Thank you very much to my project partners from the Institute for Sustainable Process Technology (ISPT), Hilde Wijngaard, Ruud van Beckhoven, Albert van der Padt, and Peter de Jong for the insightful discussions and contributions to the development of this project. Special thanks to the Academy of Athens without the financial support of which this project would be impossible.

Besides the theoretical framework, many experiments had to be conducted and these experiments would be more tedious and less enjoyable without the help of Jarno (thanks for being so kind), Maurice (thanks for your humour and smile), Martin (always reminding me when I forgot something) and Jos (the father of the lab). Not to forget to mention the help and collaboration of all my MSc and BSc students without whom this project would never come to an end. I was learning alongside them. Besides the supervisors and the technicians, in the group of Food Process Engineering it was always possible to find a helping hand when in need for technical or psychological help. So many interesting individuals from several countries and backgrounds : Birgit (never forget the Munich experience), the real Victor, Pina, Ali, Anja, Anton, Steven, Jan, Jaap (yeap!), Nynke, Emma, Wanqing, Qinhui, Anna, Yu, Andrea, Zulhaj, Evelien, Jan-Eise, Sicong, Floor, Sirinan, Eline and the talented Lu. Jun, I am really sorry I could not be your paranymph. It was nice that we started and finished at the same time. Even though you are post-docs, Elvira and Kosntantina, you are the coolest in the group. Many thanks to all of you for the nice time in the group but also during borrels, Ph.D. trips, random trips, group days and housedinners.

Angelica, I will never forget the party you organised to re-welcome me in the group. I became red as a middle-aged friend of mine, you don't know her. You made me think that Copenhagen is not that bad after all. Just ring the bell, preciosa. Mauriciones, boludo, your inappropriate jokes and behaviour could always cheer me up. A genuine and funny drinking buddy, Europe 
is boring without you. Patchy, you are lucky I am writing the acknowledgments before I see the stukje. Thank you in advance for being a wonderful paranymph and remember my advice, relax and care less. Davide, please keep being one of the most social nerds I know. Fiona, next to you I always felt optimistic and safe. Special thanks to my officemates, Juliana, Alime and Victor, who had to bear me every day with good or not so good mood. Juliana you clumsiness was making my day. It was nice to have you as a scientific hermana. Alime, I will join you to Turkey for a ride with your bike. I promise. Victor thank you for all the valuable information about administration stuff.

Staying four more years in the little boring dark hole, a.k.a. Wageningen, would be unimaginable without the company of several nice friends. Without their presence I would never have returned and I seriously doubt if I would find the emotional strength to finish. It seems that when people do not have a wide variety of options when it comes to every day and night activities they tend to socialise in De Zaaier, cook delicious food at their places and build strong and meaningful relationships. So, thank you Wageningen, my cute little village!

Daje Bambino! Teasing you is the most enjoyable thing in the world, directly after defeating you in the soccer table. Imie and Bambi, you are an ultrasupernice couple. Lets eat in an Osteria (the one close to the Vatican) and shout Siempre Forza Roma! I will never also forget all the funny moments in waga with the crazy Marco Porco and Rafa. Vala, I hope you always feel fine with one " $i$ " and that you will stay an anarchic spirit! Once per month we should visit Paris to solve all of our issues. I am really proud of your strength when it comes to multitasking, not so proud for your music taste though. A re Giorgi, even though you live in the capital you will always be a true villager. Thank you for your filoxenia, I might give it back to you with sharing a cabin. I hope you did not bet that I will not finish, although I don't blame you. Christo, if the last four years were a movie you would be definitely playing the soundtrack. Thanks for all the

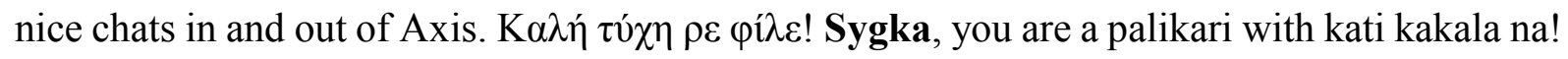
A true and valuable member of the crew, I was always hoping that you will come back. But I am ok if you are happy wherever you are. No I am kidding, come back! Sine and Tibo thank you for the countless times we met and had fun. Tibo thanks for your help with the car and for keeping us clean. Many thanks to Evita, Gianki, Simha and Elena as well!

Simon, you not so graceful piece of not so useful thing, $20 \%$ was more than enough after all. Who knew? I am glad we were going through this process simultaneously and that we finish the same month. One of the highlights in the past years of my life was a civil something something on a lighthouse. Monse and you make me happy. Joao, maybe during my defence I should do to the microphone what I did not during yours. Welcome back to the village and lets keep our weekly routine. Stefano and Lavinia, thank you for the nice BBQs at your place. Stefano, I never understood why you were continuously supplying me with free spirits but then again...cheers! One of the few who appreciated my fashion taste. You should be cloned and replace the rest of us. Meto, every day should be a Meto-Day. You are a true fellow 
countryman. Long live the Balkans! Gautham, thank you for searching with me the meaning in all this. Even though we failed to find any, at least we managed to have fun and become wiser in the process. You will always be my one and only individual with restricted freedom who deserves tones of raki.

For the whole duration of the Ph.D. I stayed in Droef 101 and I could never imagine a better environment and a place that would truly feel like home. Many wonderful housemates to thank for the friendly and always easy-going atmosphere. Countless dinners, movies, discussions, games and morning and night interactions. Omer you are above everything a friend but also a housemate and a paranymph. A dangerous combination if you consider the amount of material and information you have on your possession. Amsterdam ha? We will continue to be family wherever we go. Thanks for everything friend. We did it together. Previous housemates like Joris (who's gonna own this day?), Taco (bohemian free spiriti), Monse, Simon, and Matthew (you crazy crazy manny, never forget the Eindoven airport experience!) but also current ones like Jone (the most mature person among us), Jorge (tzeeees! And I thought I was relaxed), Claudia (and her roommate Veronica), and Leo (good luck with the proposal, baking and mixing).

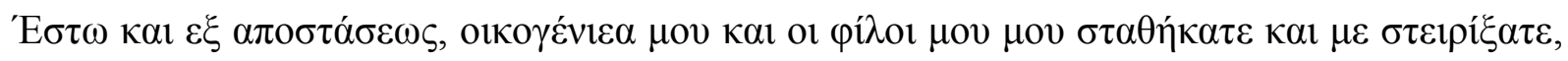

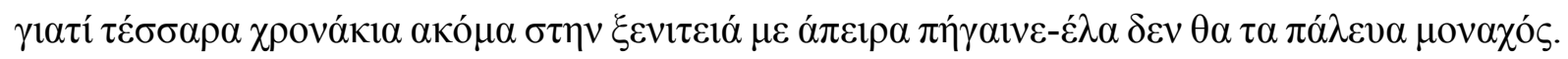

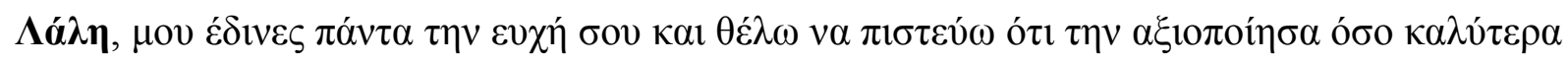

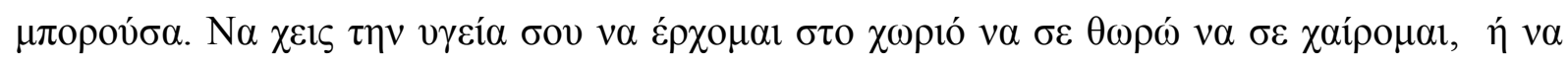

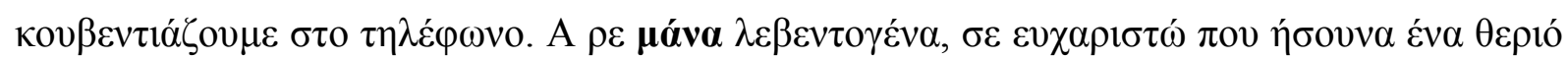

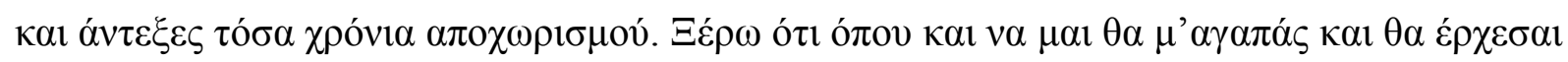

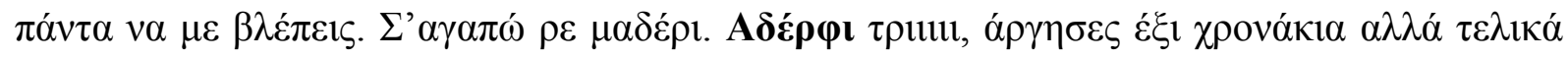

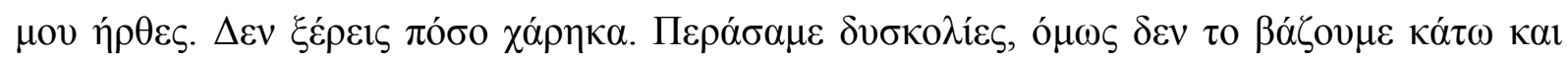

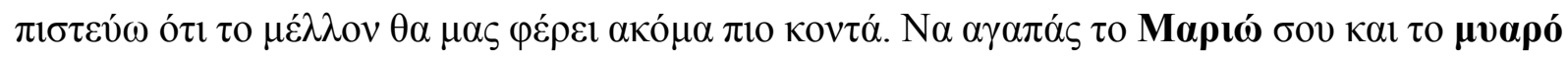

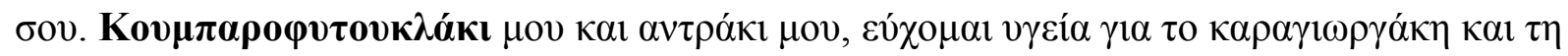

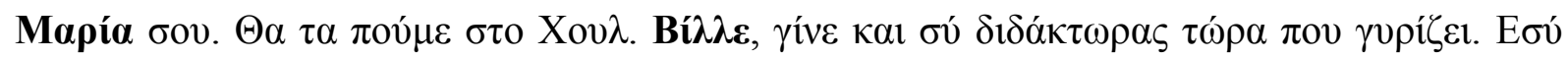

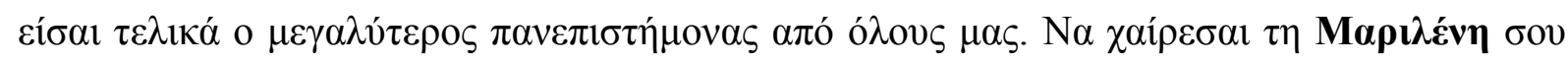

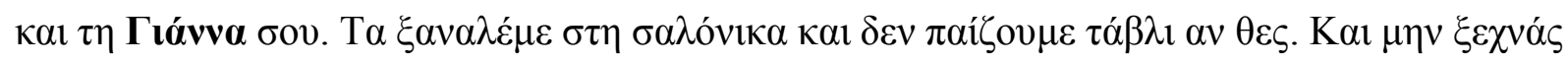

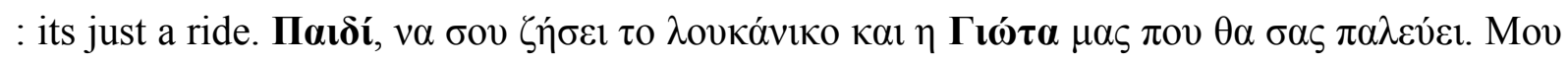

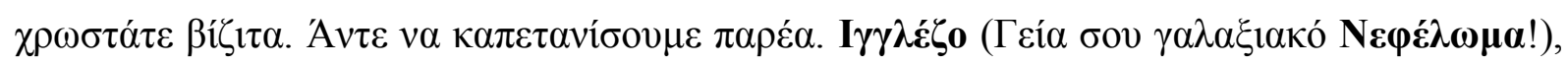

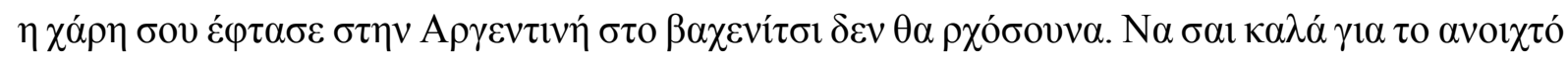

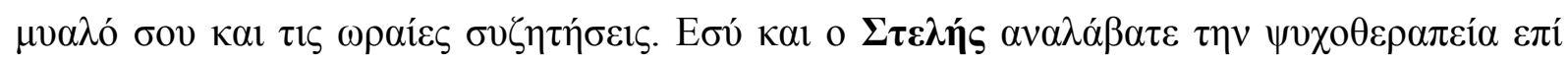

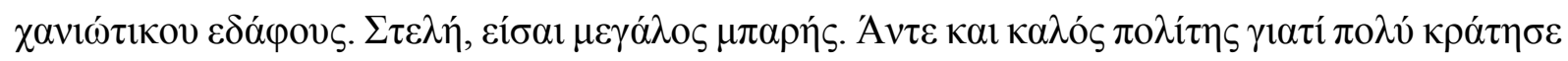

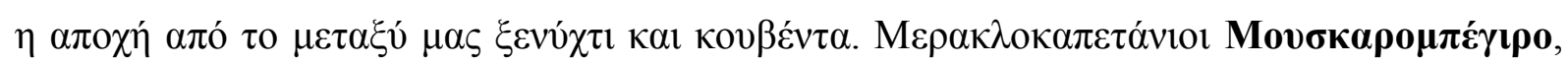

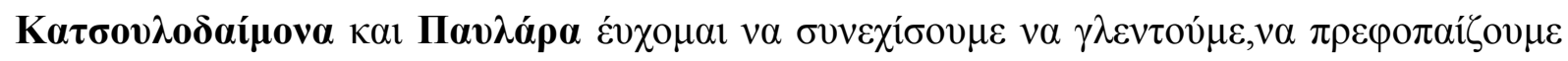

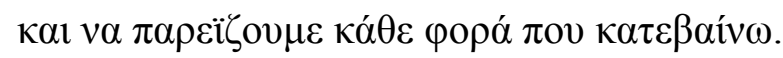

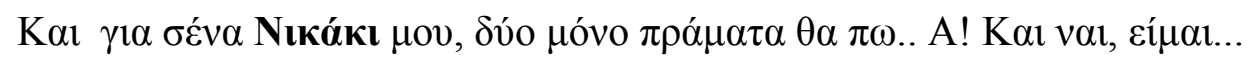




\section{About the author}

Dimitris Karefyllakis was born in Chania, Greece, on October $26^{\text {th }} 1988$. He went to the Aristotle University of Thessaloniki where he obtained his bachelor degree in Chemistry, in 2011.

In 2012, he was granted with a scholarship from the "Academy of Athens", an independent nongovernment educational organization, in order to perform his master studies abroad. During the same year, he started the Food Technology Master Degree, with the specialization of Ingredient Functionality, at Wageningen University. He conducted his master thesis at the group of Physics and Physical Chemistry of Foods with the tittle "Potentials of Chitin Nanocrystals to stabilize foams under various

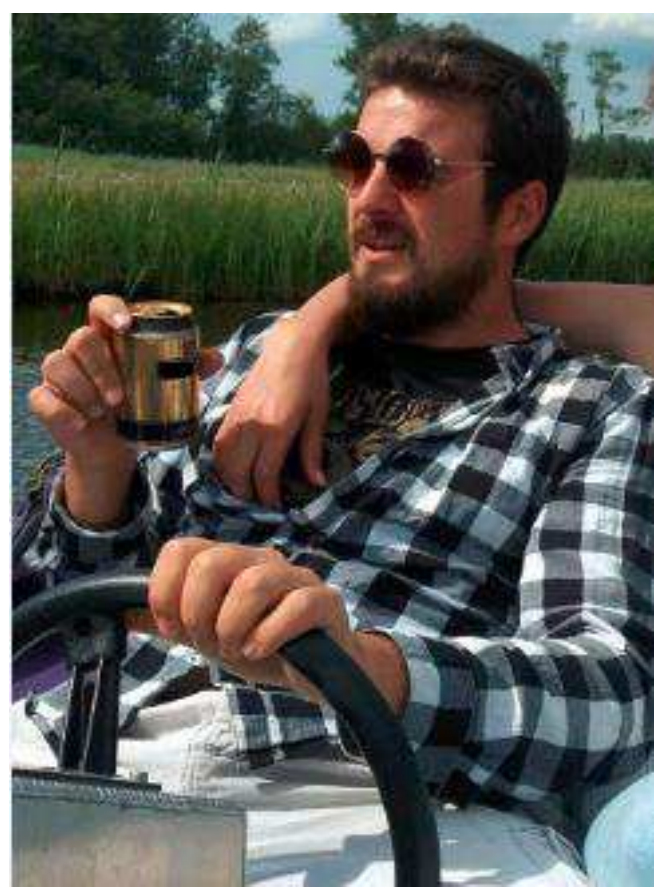
conditions". He conducted his master internship at the University of Buenos Aires, Department of Industry, Faculty of Exact and Natural sciences. His internship project was entitled "Caseinomacropeptide as carrier of iron". After completing his MSc studies, his was granted an extension of his scholarship for two more years in order to continue for a doctorate. In 2015, he joined the Food Process Engineering Group at Wageningen University, working as a $\mathrm{PhD}$ on the Mild Separation project and the utilization of oilseed proteins. The results of his $\mathrm{PhD}$ research are presented in this thesis.

Dimitri can be contacted at : $\underline{\text { dkaref@gmail.com }}$ 


\section{List of publications}

This thesis

Karefyllakis, D., Altunkaya, S., Berton-Carabin, C. C., Van Der Goot, A. J., \& Nikiforidis, C. V. (2017). Physical bonding between sunflower proteins and phenols: Impact on interfacial properties. Food Hydrocolloids

Karefyllakis, D., Salakou, S., Bitter, J. H., van der Goot, A. J., \& Nikiforidis, C. V. (2018). Covalent Bonding of Chlorogenic Acid Induces Structural Modifications on Sunflower Proteins. ChemPhysChem, 19(4), 459-468.

Karefyllakis, D., Octaviana, H., van der Goot, A. J., \& Nikiforidis, C. V. (2019). The emulsifying performance of mildly derived mixtures from sunflower seeds. Food Hydrocolloids, 88, 75-85.

Karefyllakis, D., Van Der Goot, A. J., \& Nikiforidis, C. V. (2019) The behaviour of sunflower oil bodies at the interfaces. Submitted

Karefyllakis, D., Van Der Goot, A. J., \& Nikiforidis, C. V. (2019) Enhancing the utilization potential of oilseed ingredients: Multicomponent emulsifiers from sunflower seeds. Submitted

\section{Others}

Tzoumaki, M. V., Karefyllakis, D., Moschakis, T., Biliaderis, C. G., \& Scholten, E. (2015). Aqueous foams stabilized by chitin nanocrystals. Soft Matter, 11(31), 6245-6253. 


\section{Overview of completed training activities}

\section{Discipline specific activities}

\section{Conferences and meetings}

Food Colloids Conference ${ }^{\mathrm{P}}$, Wageningen (NL), 2016

Innovations in Food Science \& Technology conference ${ }^{O}$, Freising (GE), 2017

EFFoST International Conference ${ }^{\mathrm{O}}$, Nantes (FR), 2018

International Conference on Oil Bodies ${ }^{\mathrm{O}}$, Wageningen (NL), 2018

\section{Courses}

Biorefinery for Biomolecules (Vlag), Wageningen (NL), 2015

Molecular Affinity Separations (ISPT), Amersfoort (NL), 2016

Food Proteins (University of Copenhagen), Copenhagen (DE), 2016

\section{General Courses}

Ph.D introduction week (VLAG), Baarlo (NL), 2015

Project and time management (WGS), Wageningen (NL), 2015

Efficient writing strategies (WGS), Wageningen (NL), 2015

Data Management Planning (WGS), Wageningen (NL), 2016

Career Assessment (WGS), Wageningen (NL), 2019

Microscopy and Spectroscopy in Food and Plant Sciences (Vlag), Wageningen (NL), 2019

\section{Optional}

Preparation of research proposal, Wageningen (NL), 2015

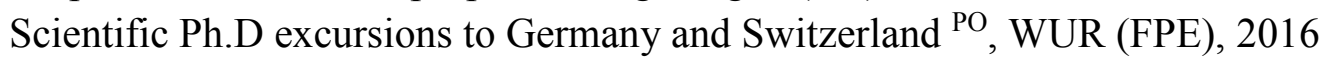

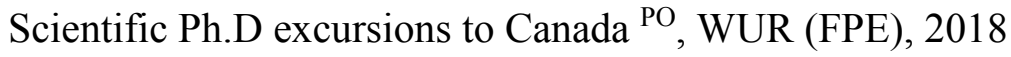

Weekly scientific meetings (FPE), Wageningen (NL), 2015-2018

Food Structuring group meetings (FPE), Wageningen (NL), 2015-2018

Ph.D meeting group (FPE), Wageningen (NL), 2015-2018

\section{Used abbreviations}

VLAG : Graduate School for Nutrition, Food Technology, Agrobiotechnology and Health Science

WGS : Wageningen Graduate School

WUR : Wageningen University

FPE : Laboratory of Food Process Engineering 
The work described in this thesis was performed at the Laboratory of Food Process Engineering of Wageningen University \& Research, the Netherlands. This project was sponsored by Institute of Sustainable Process Technology (ISPT) under the project "CM-2004: Bio-refinery of solid raw materials for food purpose and by a scholarship from the Academy of Athens.

Financial support from Wageningen University and the Graduate School VLAG for printing this thesis is gratefully acknowledged.

This thesis was printed by ProefschriftMaken, Digiforce

Covered design by Dimitris Karefyllakis

Edition :150 copies

Dimitris Karefyllakis, May, 2019 